\title{
Renal cell cancer : a molecular-epidemiological approach to unravel new pathways underlying disease etiology and prognosis
}

Citation for published version (APA):

Deckers, I. A. G. (2015). Renal cell cancer : a molecular-epidemiological approach to unravel new pathways underlying disease etiology and prognosis. [Doctoral Thesis, Maastricht University]. Maastricht University. https://doi.org/10.26481/dis.20150629id

Document status and date:

Published: 01/01/2015

DOI:

10.26481/dis.20150629id

Document Version:

Publisher's PDF, also known as Version of record

Please check the document version of this publication:

- A submitted manuscript is the version of the article upon submission and before peer-review. There can be important differences between the submitted version and the official published version of record.

People interested in the research are advised to contact the author for the final version of the publication, or visit the DOI to the publisher's website.

- The final author version and the galley proof are versions of the publication after peer review.

- The final published version features the final layout of the paper including the volume, issue and page numbers.

Link to publication

\footnotetext{
General rights rights.

- You may freely distribute the URL identifying the publication in the public portal. please follow below link for the End User Agreement:

www.umlib.nl/taverne-license

Take down policy

If you believe that this document breaches copyright please contact us at:

repository@maastrichtuniversity.nl

providing details and we will investigate your claim.
}

Copyright and moral rights for the publications made accessible in the public portal are retained by the authors and/or other copyright owners and it is a condition of accessing publications that users recognise and abide by the legal requirements associated with these

- Users may download and print one copy of any publication from the public portal for the purpose of private study or research.

- You may not further distribute the material or use it for any profit-making activity or commercial gain

If the publication is distributed under the terms of Article $25 \mathrm{fa}$ of the Dutch Copyright Act, indicated by the "Taverne" license above, 


\title{
Renal Cell Cancer
}

\author{
A molecular-epidemiological \\ approach to unravel new pathways \\ underlying disease etiology and \\ prognosis
}


Renal Cell Cancer. A molecular-epidemiological approach to unravel new pathways underlying disease etiology and prognosis.

ISBN: 978-94-6259-723-5

Layout: Tiny Wouters, Maastricht

Cover: Jeanine Kierkels, Roermond

Production: Ipskamp Drukkers, Enschede

Copyright Ivette A.G Deckers, Maastricht 2015

No part of this book may be reproduced or transmitted in any form or by any means, without prior permission in writing by the author, or when appropriate, by the publishers of the publications.

The research presented in this thesis was performed within GROW, School for Oncology and Developmental Biology at Maastricht University and supported by the Dutch Cancer Society (KWF).

Financial support by the Dutch Kidney Foundation and Agena Bioscience for the publication of this thesis is gratefully acknowledged. 


\title{
Renal Cell Cancer
}

\section{A molecular-epidemiological approach to unravel new pathways underlying disease etiology and prognosis}

\author{
PROEFSCHRIFT \\ ter verkrijging van de graad van Doctor aan de Universiteit Maastricht, \\ op gezag van de Rector Magnificus, \\ Prof. dr. L.L.G. Soete \\ volgens het besluit van het College van Decanen, \\ in het openbaar te verdedigen \\ op maandag 29 juni 2015 om 16:00 uur
}

door

Ivette Antoinette Gerarda Deckers

Geboren op 22 januari 1987 te Nijmegen 


\section{Promotores:}

Prof. dr. P.A. van den Brandt

Prof. dr. M. van Engeland

\section{Copromotor:}

Dr. L.J. Schouten

\section{Beoordelingscommissie:}

Prof. dr. M.P.A. Zeegers, voorzitter

Dr. J.M. Geleijnse (Wageningen UR)

Dr. C.A. Hulsbergen-van de Kaa (Radboud UMC)

Prof. dr. J.P. Kooman

Prof. dr. P.M. Steijlen 



\section{CONTENTS}

$\begin{array}{lll}\text { Chapter } 1 \quad \text { General introduction } & 9\end{array}$

$\begin{array}{lll}\text { Part I Dietary intakes } & 27\end{array}$

Chapter 2: $\quad$ Long-term dietary sodium, potassium and fluid intake; exploring $\quad 29$ potential novel risk factors for renal cell cancer in the Netherlands Cohort Study on diet and cancer.

Part II Gene-environment interactions

Chapter 3: Polymorphisms in genes of the renin-angiotensin-aldosterone system and renal cell cancer risk: interplay with hypertension and dietary intakes of sodium, potassium and fluid.

Chapter 4: Gene-diet interactions in ion transport mechanisms in relation to renal cell cancer risk.

Part III Tumor heterogeneity

Chapter 5: Promoter $\mathrm{CpG}$ island methylation in ion transport mechanisms and associated dietary intake jointly influence the risk of clear-cell renal cell cancer.

Chapter 6: Alcohol and dietary folate intake and gene promoter methylation in clear-cell renal cell cancer.

Chapter 7: Promoter methylation of $C D O 1$ identifies clear-cell renal cell cancer patients with poor survival outcome.

Chapter 8: General discussion

Summary

Samenvatting

Valorisation addendum

Dankwoord

About the author

List of publications 

CHAPTER 1

General introduction 
Cancer of the kidney is the $7^{\text {th }}$ most common cancer in the more developed regions of the world [1]. Globally, kidney cancer accounted for 337.860 new cases in 2012, which was $2-3 \%$ of the total human cancer burden [1]. Renal cell cancer (RCC) is the most common type of kidney cancer (90\%) [2,3]. In the Netherlands, the age-standardized incidence (per 100,000 per year) of RCC has been increasing from 8.85 in 1989 to 10.76 in 2007, but stabilized over the last five years (10.33 in 2012) [4]. The incidence of RCC has been reported to be twice as high among men as women and increases with advancing age [5].

In addition to sex and age, several risk factors have been established to increase the risk of RCC, including hypertension, cigarette smoking, obesity and familial cancer syndromes [6]. For several other factors, including diabetes, end-stage renal disease, low parity in women, low physical activity, trichloroethylene exposure and genetic predisposition, positive associations with RCC risk are suggested, but conflicting results have been observed among different studies [6]. In addition, epidemiological evidence suggests that moderate alcohol consumption and diets rich in fruits and vegetables might be associated with a lower RCC risk [6]. However, the effects that these factors have on RCC risk are rather modest and, in general, the etiology of RCC is still poorly understood.

Remarkably, despite that dietary intakes affect the homeostasis of sodium, potassium and water in the human body, and that the regulation of this homeostatic balance is one of the main aspects in renal physiology, the number of epidemiological studies investigating dietary intakes of sodium, potassium [7] and fluid [8-10] in relation to RCC risk is limited. In order to advance in the field of RCC research and gain insight into its etiology and prognosis, it is important to search beyond current perspectives and generate new hypotheses for future research. Therefore, this thesis describes the endeavor to unravel the associations between dietary sodium, potassium and fluid intake as potential novel risk factors for RCC and to discover novel disease pathways that may link renal (patho)physiology to RCC etiology and prognosis using molecular epidemiology.

\section{RENAL PHYSIOLOGY: THE ESSENTIALS}

In humans, the kidneys are located in the abdominal cavity behind the peritoneum, one on each side of the spine. The renal parenchyma is the functional tissue of the kidney and is divided into two major structures: the outer renal cortex and the inner renal medulla (Figure 1.1). A healthy parenchyma contains more than 1 million nephrons. The nephron is the main working unit of the kidney and is involved in the production of urine. A nephron consists of a glomerulus, a tuft of capillaries in between the afferent and the efferent arterioles, and a series of renal tubules, which 
are divided into four histo-physiological segments: the proximal tubule, the loop of Henle, the distal tubule and the collecting tubule.

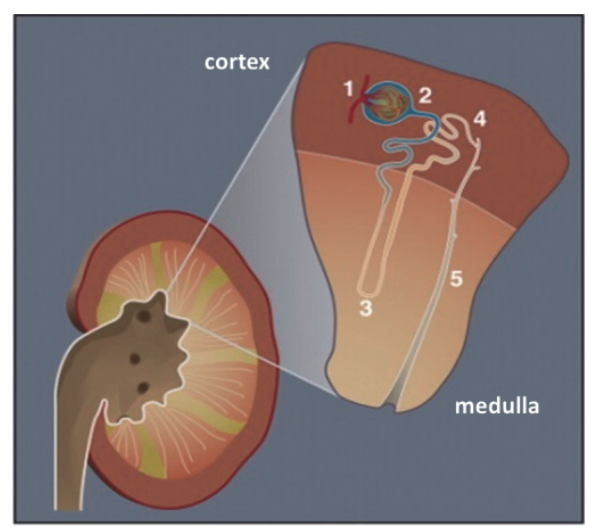

Figure 1.1 The kidney. The renal parenchyma includes an outer cortex and an inner medulla. The nephron consists of the glomerulus (1) and a series of renal tubules, which are divided into four histo-physiological segments: proximal tubule (2), loop of Henle (3), distal tubule (4) and collecting tubule (5). Adapted from: Baldewijns et al., 2008. [11]

Each part of the nephron has different permeability and transport characteristics and, therefore, performs a distinct function. The glomerulus forms the pre-urinary filtrate from blood plasma. The proximal tubule and loop of Henle reabsorb large amounts of water and important nutrients into the systemic circulation to prevent essential losses. The remaining part of the renal tubular system is involved in the final composition of the urine. Many of the kidney's functions are accomplished by the processes of filtration, reabsorption, secretion and excretion of water, electrolytes and waste products, which all take place in the nephron. The kidney is involved in a wide scala of physiologic processes, including the removal of waste products of metabolism, acid-base balance, electrolyte balance, osmoregulation, volume regulation and blood pressure regulation. Volume regulation and osmoregulation are two functions of the kidney that are of particular interest when investigating dietary intakes of sodium, potassium and water.

The process of volume regulation keeps the effective circulating volume (ECV), which is the volume in the arterial system effectively perfusing human tissues, at adequate levels [12]. Volume regulation is a vital and acute process in the human body. There are several types of conditions that may cause an inappropriate decrease the ECV. In order to restore the ECV, sodium is reabsorbed from the renal tubules into the blood vessels. Via the principle of osmosis, water will naturally follow. Sodium is thus the main determinant of volume regulation. 
If the aforementioned ECV is maintained at adequate levels, day-to-day fluctuations in dietary sodium and water intakes are handled by osmoregulation [12]. The adult human body contains $65 \%$ water [13]. This water is distributed over two major body fluid compartments (the intracellular fluid volume and the extracellular fluid volume, including the interstitial fluid volume and the plasma volume). Water and the bodily solute content within these compartments is maintained within narrow limits, which is essential for adequate cell functioning. Sodium is the primary determinant of the extracellular fluid volume, whereas potassium is the primary determinant of the intracellular fluid volume. Changes in water content across these compartments are facilitated by changes in sodium. In order to maintain an electroneutral balance in the cells after a shift of sodium across the compartments, sodium is exchanged for potassium. This exchange is primarily governed by the sodium-potassium-ATPase pump in the cell membrane, which is therefore an important mechanism in ion transport.

\section{THE ROLE OF DIETARY INTAKES IN VOLUME- AND OSMOREGULATION}

The kidney is programmed to reabsorb large amounts of sodium from the diet [14,15], because sodium is evolutionary important to our body, given its vital role in volume regulation. However, the sodium content in our diet is nowadays much higher than what we would physically need. This chronic excess of sodium intake in populations to date results in a chronic volume overload [13]. Therefore, excess of sodium has been associated with multiple diseases, such as a high blood pressure and the development of hypertension across many populations [15].

The role of dietary sodium intake in osmoregulation may best be explained using the example of consuming a high sodium product such as chips, an isotonic drink (in which the sodium concentration is equal to that of the extracellular volume) and plain water. In healthy humans, consuming chips will raise the plasma sodium concentration. This will result in a movement of water out of the cells into the extracellular space. The net effect is an increase of osmolality of both the intra- and extracellular volume. Since there is no change in total body volume, urinary sodium excretion is low. However, the decrease in intracellular volume influences the hormonal mechanism that induces thirst and the secretion of antidiuretic hormone (ADH) in the hypothalamus. As a result, also the water excretion by the kidney is low. When consuming an isotonic drink, the plasma sodium concentration does not change, while the consumed volume will result in an increase of extracellular volume and a subsequent raise in blood pressure. Even though consuming an isotonic drink will not change the plasma sodium concentration, the raise in blood pressure will result in excretion of excess sodium and water. Finally, the consumption of plain water decreases the plasma sodium 
concentration and will subsequently result in a movement of water out of the extracellular space into the cells. The net effect is a decrease of osmolality of both the intra- and extracellular volume, with an overall volume expansion, which will increase the urinary sodium excretion. ADH is inhibited due to the increase in intracellular volume. Without $A D H$, water excretion by the kidney is high.

Dietary intakes may also affect potassium homeostasis (i.e. the distribution of potassium between intracellular and extracellular fluids) [12]. When drinking a potassium-rich drink, such as orange juice, plasma potassium concentration increases and, because such increases could be lethal, potassium immediately enters the cell. Excess of potassium is excreted within 6 to 8 hours. In addition to variations in dietary intakes, the distribution of potassium between intracellular and extracellular fluids is also influenced, among many others, by any condition that changes the rates of cell breakdown and cell production, such as cancer $[12,16]$. Cell breakdown results in release of potassium. The subsequent change in plasma potassium concentration depends on the degree of cellular potassium uptake by other cells and the ability of the kidney to excrete potassium.

Taken together, sodium is a key determinant in two major aspects of renal physiology, including volume regulation and osmoregulation. In these processes, water and sodium balance is directly related to each other, yet independently regulated, and sodium and potassium are exchanged. Therefore, we hypothesized that dietary sodium, potassium and fluid intake may be novel risk factors for RCC and that their potential effects may be influenced by each other.

\section{HYPERTENSION AND OTHER POTENTIAL BIOLOGIC MECHANISMS IN RENAL CELL CANCER}

In order to better understand the role of dietary intakes in RCC etiology, it is important to investigate these associations in more detail. This thesis particularly focuses on the role of hypertension as intermediate, because high sodium intake is an important determinant of hypertension, while hypertension is an established risk factor for RCC [6]. Therefore, we hypothesized that dietary sodium intake may influence RCC risk, through hypertension. Hypertension is a major chronic disease, which affected approximately 40\% of the world's population in 2008 [17]. Uncontrolled hypertension can lead to chronic kidney disease, worsening renal function, and enhancing progression to end-stage renal disease, conditions that may predispose to the development of RCC [6].

Furthermore, two potentially cancer-causing, biologic mechanisms in renal physiology, i.e. ion transport mechanisms (ITMs) and the renin-angiotensin-aldosterone-system 
(RAAS), will be investigated in this thesis to further explore the association between sodium, potassium and fluid intake and RCC risk.

\section{Ion transport mechanisms}

In the nephron, ion channels, transporters, exchanger pumps and associated enzymes, collectively referred to as ion transport mechanisms (ITMs), facilitate tubular reabsorption and secretion, because the lipid layers of the cell membranes hinder free diffusion of ions [12]. Tubular reabsorption consists of two steps; from the tubular lumen, through the luminal membrane, into the cell and from the cell across the basolateral membrane, into the interstitium, which is connected to the systemic circulation (Figure 1.2).

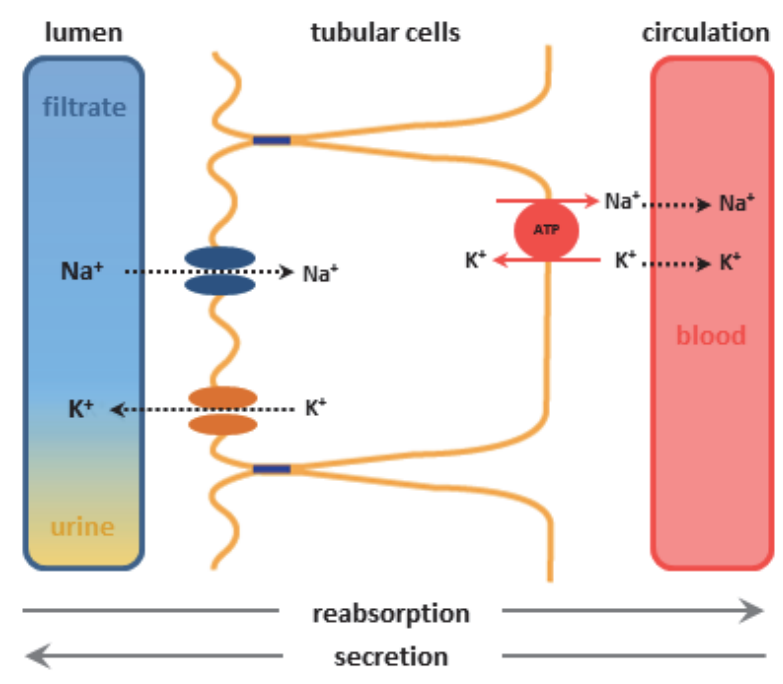

Figure 1.2 Schematic presentation of renal reabsorption and secretion of sodium and potassium. Sodium $\left(\mathrm{Na}^{+}\right)$is reabsorbed actively, in exchange for potassium $\left(\mathrm{K}^{+}\right)$, from the tubular cell into the circulation and passively from to luminal pre-urinary filtrate into the tubular cell. The excess of potassium is secreted out of the tubular cell into the luminal pre-urinary filtrate, which will eventually be excreted as urine.

Firstly, sodium is, in exchange for potassium, actively transported from the tubular cell into the circulation using the aforementioned sodium-potassium-ATPase pump. Sodium-potassium-ATPase is an abundantly expressed protein in all epithelial cells, not only in the kidney, and maintains trans-membrane sodium and potassium electrochemical gradients, which are essential for other ITMs to function properly [18]. After the cellular sodium concentration is decreased, sodium is reabsorbed 
passively from the luminal pre-urinary filtrate into the tubular cell via ITMs. Since different functions are performed throughout the tubular system of the nephron, ITMs are site-specific. In the proximal tubule, the sodium/hydrogen exchanger type 3 (NHE3 also SLC9A3) is for example the principle mediator of the proximal reabsorption of $70-80 \%$ of the sodium filtered at the glomerulus $[19,20]$. In the distal nephron, epithelial sodium channels $(\mathrm{ENaC})$ facilitate the process of sodium transport from the lumen into the cell in order to maintain electrolyte and water homeostasis [21]. ITMs have recently emerged as novel mechanisms that drive carcinogenesis throughout the multi-stage process [16].

\section{Renin-angiotensin-aldosterone system}

The renin-angiotensin-aldosterone system (RAAS) is a peptide-based system that has been recognized for decades as a principal determinant of arterial blood pressure, but is also involved in fluid and electrolyte balance [22]. Basically, the RAAS focuses on the processing of the precursor angiotensinogen to the active peptide angiotensin II and the interactions with its receptors [22]. Renin is activated in response to low stretch of the afferent arteriole resulting from hypotension or volume depletion. Subsequently, renin induces the generation of angiotensin, which will be converted into angiotensin II by the angiotensin II conversing enzyme (ACE). To restore blood pressure, angiotensin II induces sodium reabsorption and thereby extracellular volume expansion, through increasing the secretion of aldosterone and, simultaneously, higher systemic blood pressure and cardiac output by arterial vasoconstriction. The kidney influences the RAAS and blood pressure by secreting the hormones such as renin and angiotensin II [12]. It has been established that the RAAS does not only play a role in normal renal physiology, but also has important implications in the pathogenesis and treatment of disease. Mostly, the RAAS has been investigated in relation to cardiovascular diseases. For example, up-regulated RAAS is known to be involved in the development of hypertension and several forms of antihypertensive therapy intervene on various aspects of the RAAS [22,23]. Recent developments indicate that aberrant regulation of the RAAS may also contribute to carcinogenesis through stimulation of angiogenesis, invasion, cell survival and proliferation [22].

Taken together, ITMs and the RAAS are two potentially cancer-causing, biologic mechanisms involved in both renal (patho)physiology and carcinogenesis. Therefore, we hypothesize that these mechanisms may be underlying disease pathways in the association between sodium, potassium and fluid intake and RCC risk. 


\section{MOLECULAR (PATHOLOGICAL) EPIDEMIOLOGY}

In an attempt to investigate the role of ITMs and the RAAS in the associations under study, the present thesis uses a molecular-epidemiological approach. Molecular epidemiology evaluates the relationship between a biomarker on the one hand and exposures, susceptibility and disease on the other hand, in order to understand the mechanisms through which environmental exposures (e.g. nutrients) interact with host susceptibility factors (e.g. genetic variation) and influence disease risk (e.g. RCC risk) by combining laboratory and population research [24]. In this thesis, we use molecular data, in addition to dietary exposure data, to investigate gene-environment interactions and tumor heterogeneity.

\section{Gene-environment interactions}

A gene-environment interaction may be defined as: "a joint effect of one or more genes with one or more environmental factors that cannot readily be explained by their separate marginal effects" [25]. Although gene-environment interactions are worth studying for many reasons [25], in this thesis we used them mainly to investigate RAAS and ITMs as underlying, potentially cancer-causing biological pathways that may link dietary intakes of sodium, potassium and fluid to RCC risk. However, in complex diseases, such as RCC, it has emerged that part of the interindividual differences in disease risk may be explained by gene-environment interactions [25]. To address this issue, we will additionally try to identify and specify subpopulations that are particularly at risk for RCC.

Approximately $1 \%$ of the DNA differs between individuals. The most common type of genetic variation is the single nucleotide polymorphism (SNP). SNPs in RAAS and ITM genes have mainly been investigated in relation to cardiovascular disease risk [26-30]. Few SNPs were, in this context, associated with response to sodium, for example SNPs in adducin1 (ADD1) and angiotensinogen (AGT) [31]. Only one study previously investigated SNPs in RAAS genes in relation to RCC risk [32]. This study showed that several SNPs in AGT increased RCC risk, particularly among the subpopulations with hypertension or obesity [32]. In this thesis, we seek to replicate this finding and additionally investigate SNPs in other candidate genes encoding for major RAAS factors that cover the essential part of the system. SNPs in ITM genes have not yet been investigated in relation to RCC risk.

\section{Tumor heterogeneity}

It is increasingly recognized that RCC is not a single disease. RCC is usually classified based upon extensive evaluation of both histological and molecular features of the tumor [2]. The World Health Organization (WHO) distinguishes three major subtypes 
of malignant renal tumors. The most common subtype is clear-cell RCC (80-90\%), which is characterized by cells containing clear cytoplasm and which shows often a specific deletion of chromosome $3 p$ and mutations in the Von Hippel-Lindau (VHL) gene [2,33]. Two other common subtypes are papillary RCC (10-15\%) and chromophobe RCC (4-5\%) [2]. Besides heterogeneity with respect to histological features, resulting in the traditional histological subtypes of RCC, it has been acknowledged that substantial, molecular heterogeneity exists within subtype-specific tumors. Molecular heterogeneity may reflect the unique carcinogenic route along which a tumor has been developing and may progress. Therefore, molecular subgroups may be associated with different risk factors and a different clinical behavior. The emerging field of molecular pathological epidemiology (MPE) integrates molecular subgroups into traditional epidemiological research [34]. MPE aims to increase our knowledge on the underlying biologic pathways that are responsible for these differences and to explain observed differences in risk factors across populations and studies [34]. MPE is, however, not (yet) commonly used in relation to RCC [35].

In addition to gene-environment interactions with germline genetic variations (i.e. SNPs), we focus in this thesis also on the molecular characterization of clear-cell RCC in terms of acquired epigenetic abnormalities. Epigenetic mechanisms regulate gene expression on multiple levels without changing the sequence of the genome [11]. DNA methylation is one such process, in which a methyl group $\left(\mathrm{CH}_{3}\right)$ binds to a cytosine at a CpG dinucleotide where a cytosine precedes a guanine [36]. CpG-rich areas, in for example the promoter region of a gene, are so-called 'CpG islands'. Most promoter $\mathrm{CpG}$ islands are normally unmethylated. Promoter CpG island hypermethylation has been associated with gene silencing [37]. Gene silencing and subsequent inappropriate loss of function of tumor suppressor genes (TSGs) has been associated with carcinogenesis [38]. The degree to which promoter methylation is present can be used to classify tumors [39]. Promoter hypermethylation of TSGs is thought to occur early and frequently in carcinogenesis and, therefore, may contribute to both cancer development and progression [38,40-42]. Therefore, we hypothesized that promoter methylation status may be used to classify the RCC tumor in terms of molecular heterogeneity and that promoter methylation may play a role in the etiology and prognosis of RCC. In this thesis, we use three approaches to study promoter methylation. Firstly, we will study the interplay between promoter methylation of ITM genes and dietary intakes related to ITMs (i.e. sodium, potassium and fluid intakes) in relation to RCC risk. Secondly, we will investigate whether promoter methylation in RCC is associated with dietary alcohol and folate intakes. Finally, we will use promoter methylation to distinguish RCC subtypes with a different survival. 


\section{Promoter CpG island hypermethylation and ITMs}

In addition to the aforementioned gene-environment interactions with SNPs, the role of ITMs in the associations between sodium, potassium and fluid intake and RCC risk is also investigated using promoter $\mathrm{CpG}$ island hypermethylation. This multidimensional approach highlights two distinct mechanisms by which the genes involved in ITMs may be aberrantly regulated or silenced, including genetics (SNPs) and epigenetics (promoter methylation) and, therefore, this multidimensional approach provides a broader view of the role of ITMs in RCC carcinogenesis.

\section{Promoter CpG island hypermethylation and dietary intakes}

Several factors have been hypothesized to mediate the general process of methylation, i.e. methyl metabolism, including dietary intakes. An adequate folate metabolism is essential to properly regulate the methylation of DNA. Folate, as 5-methyltetrahydrofolate, has a central role in methyl metabolism, because it supplies a methyl group to convert homocysteine to methionine, which is then converted to S-adenosylmethionine, the universal methyl donor [43]. Folate deficiency is reported to be associated with global hypomethylation [44] and might therefore also affect hypermethylation. However, the relation between hypo- and hyper-methylation remains inconclusive $[45,46]$. The methyl metabolism may indirectly also be influenced by the intake of alcohol [47]. High alcohol intake decreases the absorption of folate from the intestinal lumen $[48,49]$. Moreover, folate is degraded by acetaldehyde, which is a metabolite of alcohol.

\section{Promoter CpG island hypermethylation and prognosis of clear-cell renal cell cancer}

Currently, the prognosis of patient outcome in a clinical setting is predicted using several prognostic parameters, including cancer stage, for which the tumor-nodemetastasis (TNM) staging system is commonly used [50], and Fuhrman nuclear grading, in which nuclear grades between 1 and 4 were defined by means of increasing nuclear size, irregularity and nucleolar prominence [51]. However, in this era of molecular diagnostics, tumor behavior in response to molecular therapies can no longer accurately be predicted without considering the molecular heterogeneity of the tumor. In addition, molecular heterogeneity for example with respect to promoter methylation may also be used to classify the tumor to improve early detection and to determine prognosis [52]. Promoter methylation of cysteine dioxygenase type 1 (CDO1) has been identified as marker of poor breast cancer survival. CDO1 may be related to general carcinogenic processes, such as oxidative stress responses $[42,53,54]$, but is also indirectly involved in renal physiology through the taurine pathway $[55,56]$. Therefore, we investigated promoter methylation of CDO1 in relation to RCC survival. 


\section{AIM OF THE THESIS}

The overall aim of this thesis is to unravel novel disease pathways implicated in renal (patho)physiology in the etiology and prognosis of RCC. In the first part of this thesis, we evaluated dietary intakes of sodium, potassium and fluid as potential novel risk factors for RCC. In the second part of this thesis, we studied gene-environment interactions with genetic variation in the RAAS and ITMs to elucidate these renal (patho)physiological pathways as novel disease pathways that may link dietary intakes of sodium, potassium and fluid intake to RCC risk. In the third part of the thesis, we use promoter methylation status to classify the RCC tumor in terms of molecular heterogeneity and aim to clarify its role in disease pathways in the etiology and prognosis of RCC.

\section{STUDY DESIGN AND STUDY POPULATION}

All studies in this thesis were conducted within the framework of the Netherlands Cohort Study on diet and cancer (NLCS). The NLCS is a prospective cohort study that was initiated in 1986 and included 120,852 participants aged 55-69 years at baseline [57]. All participants returned a mailed, self-administered, baseline questionnaire on diet and other potential risk factors for cancer, such as smoking habits and hypertension. This baseline questionnaire included a 150 -item, semi-quantitative food frequency questionnaire (FFQ), which was used for the assessment of dietary habits. In addition to the baseline questionnaire, approximately 90,000 participants provided toenail clippings, which showed to be a valid source of DNA for the genotyping of a limited set of SNPs when using the Agena Bioscience (formerly Sequenom Bioscience) MassARRAY ${ }^{\circledR}$ platform using the iPLEX TM assay $[58,59]$. The NLCS was designed as case-cohort study for efficiency in questionnaire processing and follow-up. Cases were derived from the entire cohort, whereas a subcohort of 5,000 subjects was randomly sampled at baseline to estimate person years at risk for the entire cohort [60]. Subcohort members were regularly followed up for vital status information. All cohort members were followed up for cancer occurrence using record linkage with the Netherlands cancer registry and with the Dutch pathology registry (PALGA) [61].

A large and unique population-based collection of tumor DNA of incident RCC cases is nested within the NLCS. Formalin-fixed paraffin-embedded (FFPE) tumor tissues from $\sim 50$ pathology laboratories throughout the Netherlands were collected. Clinical information and tumor characteristics, such as age at diagnosis and tumor size, were available from the pathological reports and Netherlands cancer registry. Information on the survival time was accomplished by record linkage to the municipal population registries and the causes of death registry from Statistics Netherlands. 
In this thesis, the overall associations between dietary exposure data and RCC risk were studied using follow-up data between 1986 and 2003. An overview of the study designs including two types of molecular data is shown in Figure 1.3. All analyses with molecular data included cases from the maximum follow-up period until 2006. During this period of 20.3 years, 608 RCC cases were identified.

1. the NLCS cohort study design for gene-environment interactions

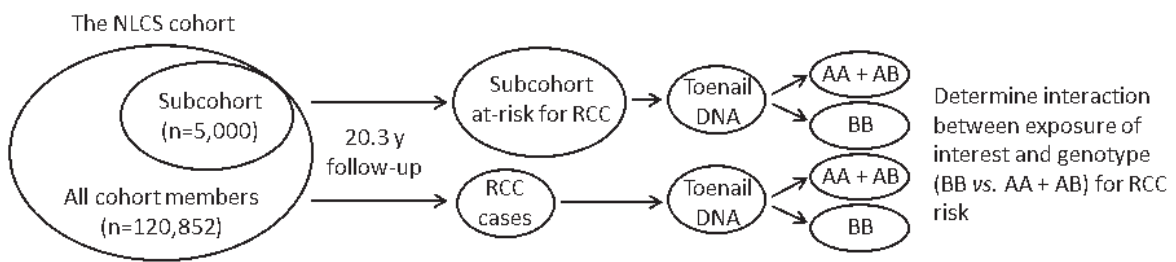

2. the NLCS cohort study design for molecular pathological epidemiology

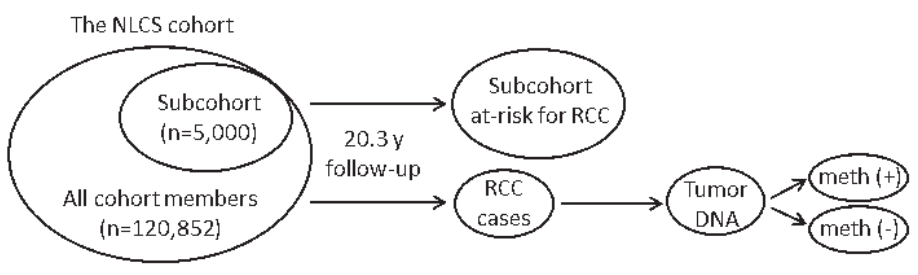

\author{
Compare RCC risk for \\ exposure of interest \\ Between meth $(+\}$ and \\ meth (-)
}

Figure 1.3 Overview of study designs for molecular analyses in the Netherlands Cohort Study (NLCS). Molecular analyses regarding gene-environment interactions (design 1) are used to determine the interactions between the exposures of interest (e.g. sodium intake) established at baseline and a particular genotype based on SNP genotyping of toenail DNA in relation to RCC risk. Molecular (pathological) analyses (design 2) are used to compare the effect of the exposure of interest (e.g. sodium intake) established at baseline on RCC risk for different subtypes of the tumor (methylated vs. unmethylated) determined using tumor DNA. Abbreviations: RCC, renal cell cancer; $A A$, homozygote common genotype; $A B$, heterozygote genotype; $\mathrm{BB}$, homozygote rare genotype; meth $(+)$, tumors with promoter $\mathrm{CpG}$ island hypermethylation; meth (-), tumors without promoter $\mathrm{CpG}$ island hypermethylation. 


\section{OUTLINE OF THE THESIS}

Part one (chapter 2) of this thesis describes the overall associations between dietary intakes of sodium, potassium and fluid and, the risk of RCC from the traditional epidemiological perspective. In part two, gene-environment interactions are used to highlight the interplay between SNPs in candidate genes involved in the RAAS (chapter 3) and candidate genes involved in ITMs (chapter 4) and the dietary intakes of sodium, potassium and fluid in relation to RCC risk. Finally, in part three, the clearcell RCC tumor is classified according to promoter methylation status of a subset of genes to study molecular subtype-specific etiology (chapters 5 and 6) or prognosis (chapter 7) using the approach of MPE. Finally, in chapter 8 we summarize, discus and interpret our main findings and conclude with some final remarks on our vision on future directions in RCC research. 


\section{REFERENCES}

1. International Agency for Research on Cancer (IARC). GLOCOBAN 2012. 2012 July 8, 2014; Available from: http://globocan.iarc.fr/Pages/fact_sheets_population.aspx.

2. Eble J, et al., World Health Organization Classification of Tumours. Pathology and Genetics. Tumours of the Urinary System and Male Genital Organs. 2004, Lyon: IARC Press.

3. Ljungberg B, Cowan NC, Hanbury DC, Hora M, Kuczyk MA, Merseburger AS, Patard JJ, Mulders PF, Sinescu IC; European Association of Urology Guideline Group. EAU guidelines on renal cell carcinoma: the 2010 update. Eur Urol 2010;58:398-406.

4. Dutch Cancer Registry, Cijfers over kanker. 2014, Integraal Kankercentrum Nederland (IKNL).

5. Chow WH, Devesa SS. Contemporary epidemiology of renal cell cancer. Cancer J 2008;14:288-301.

6. Chow WH, Dong LM, Devesa SS. Epidemiology and risk factors for kidney cancer. Nat Rev Urol 2010;7:245-57.

7. Mellemgaard A, McLaughlin JK, Overvad K, Olsen JH. Dietary risk factors for renal cell carcinoma in Denmark. Eur J Cancer 1996; 32a:673-82.

8. Allen NE, Balkwill A, Beral V, Green J, Reeves G; Million Women Study Collaborators. Fluid intake and incidence of renal cell carcinoma in UK women. Br J Cancer 2011; 104:1487-92.

9. Lee JE, Giovannucci E, Smith-Warner SA, Spiegelman D, Willett WC, Curhan GC. Total fluid intake and use of individual beverages and risk of renal cell cancer in two large cohorts. Cancer Epidemiol Biomarkers Prev 2006;15:1204-11.

10. Hu J, Mao Y, DesMeules M, Csizmadi I, Friedenreich C, Mery L; Canadian Cancer Registries Epidemiology Research Group. Total fluid and specific beverage intake and risk of renal cell carcinoma in Canada. Cancer Epidemiol 2009;33:355-62.

11. Baldewijns MM, van Vlodrop IJ, Schouten LJ, Soetekouw PM, de Bruïne AP, van Engeland M. Genetics and epigenetics of renal cell cancer. Biochim Biophys Acta 2008; 1785:133-55.

12. Rose BD, Post TW. Clinical Physiology of acid-base and electrolyte disorders. 5th edition ed. 2001, New York: McGraw-Hill, Medical Publishing Division.

13. Guyton AC, Hall JE. Textbook of medical physiology. 10th ed. 2000, Philadelphia, Pennsylvavia: W.B. Saunders Company.

14. Cordain L, Eaton SB, Sebastian A, Mann N, Lindeberg S, Watkins BA, O'Keefe JH, Brand-Miller J. Origins and evolution of the Western diet: health implications for the 21st century. Am J Clin Nutr 2005;81:341-54.

15. De Wardener HE, MacGregor GA. Sodium and blood pressure. Curr Opin Cardiol 2002;17:360-7.

16. Djamgoz MB, Coombes RC, Schwab A. Ion transport and cancer: from initiation to metastasis. Philos Trans R Soc Lond B Biol Sci 2014;369:20130092.

17. World Health Organization (WHO), A global brief on hypertension; Silent killer, global public health crisis. 2013, WHO Press: Geneva, Switzerland.

18. Selvakumar P, Owens TA1, David JM2, Petrelli NJ3, Christensen BC4, Lakshmikuttyamma A5, Rajasekaran AK1. Epigenetic silencing of Na,K-ATPase beta subunit gene by methylation in clear cell renal cell carcinoma. Epigenetics 2014;9:579-86.

19. Orlowski J, Grinstein S. Na+/H+ exchangers of mammalian cells. J Biol Chem 1997;272:22373-6.

20. Biemesderfer D, Pizzonia J, Abu-Alfa A, Exner M, Reilly R, Igarashi P, Aronson PS. NHE3: a $\mathrm{Na}+/ \mathrm{H}+$ exchanger isoform of renal brush border. Am J Physiol 1993; 265:F736-42.

21. Garty H, Palmer LG. Epithelial sodium channels: function, structure, and regulation. Physiol Rev 1997; 77:359-96.

22. George AJ, Thomas WG, Hannan RD. The renin-angiotensin system and cancer: old dog, new tricks. Nat Rev Cancer 2010;10:745-59.

23. Dupont AG; The place of diuretics in the treatment of hypertension: a historical review of classical experience over 30 years. Cardiovasc Drugs Ther 1993;7 Suppl 1:55-62.

24. Rothman, N., et al., Molecular epidemiology: principles and practices. 2011, Lyon, France: IARC Scientific Publications, No. 163.

25. Thomas D. Gene--environment-wide association studies: emerging approaches. Nat Rev. Genet 2010; 11:259-72.

26. Jeunemaitre X. Genetics of the human renin angiotensin system. J Mol Med 2008;86:637-41. 
27. Niu WQ, Qi Y. Association of alpha-Adducin and G-Protein beta 3 Genetic Polymorphisms with Hypertension: A Meta-Analysis of Chinese Populations. PloS one 2011;6:e17052..

28. Xi B, Shen Y, Zhao X, Chandak GR, Cheng H, Hou D, Li Y, Ott J, Zhang Y, Wang X, Mi J. Association of common variants in/near six genes (ATP2B1, CSK, MTHFR, CYP17A1, STK39 and FGF5) with blood pressure/hypertension risk in Chinese children. J Hum Hypertens 2014;28:32-6.

29. Zhao Q, Gu D, Hixson JE, Liu DP, Rao DC, Jaquish CE, Kelly TN, Lu F, Ma J, Mu J, Shimmin LC, Chen J, Mei H, Hamm LL, He J; Genetic Epidemiology Network of Salt Sensitivity Collaborative Research Group. Common variants in epithelial sodium channel genes contribute to salt sensitivity of blood pressure: The GenSalt study. Circ Cardiovasc Genet 2011;4:375-80.

30. Ehret GB, Caulfield MJ. Genes for blood pressure: an opportunity to understand hypertension. Eur Heart J 2013;34:951-61.

31. Beeks E, Kessels AG, Kroon AA, van der Klauw MM, de Leeuw PW Genetic predisposition to saltsensitivity: a systematic review. J Hypertens 2004;22:1243-9.

32. Andreotti G, Boffetta P, Rosenberg PS, Berndt SI, Karami S, Menashe I, Yeager M, Chanock SJ, Zaridze D, Matteev V, Janout V, Kollarova H, Bencko V, Navratilova M, Szeszenia-Dabrowska N, Mates D, Rothman N, Brennan P, Chow WH, Moore LE. Variants in blood pressure genes and the risk of renal cell carcinoma. Carcinogenesis 2010;31:614-20.

33. Kovacs G, Akhtar M, Beckwith BJ, Bugert P, Cooper CS, Delahunt B, Eble JN, Fleming S, Ljungberg B, Medeiros L, Moch H, Reuter VE, Ritz E, Roos G, Schmidt D, Srigley JR, Störkel S, van den Berg E, Zbar B. The Heidelberg classification of renal cell tumours. J Pathol 1997;183:131-3.

34. Ogino S, Stampfer M. Lifestyle factors and microsatellite instability in colorectal cancer: the evolving field of molecular pathological epidemiology. J Natl Cancer Inst 2010;102:365-7.

35. Hakimi AA, Furberg H, Zabor EC, Jacobsen A, Schultz N, Ciriello G, Mikklineni N, Fiegoli B, Kim PH, Voss $\mathrm{MH}$, Shen H, Laird PW, Sander C, Reuter VE, Motzer RJ, Hsieh JJ, Russo P. An epidemiologic and genomic investigation into the obesity paradox in renal cell carcinoma. I Natl Cancer Inst 2013;105:1862-70.

36. Bird A. DNA methylation patterns and epigenetic memory. Genes Dev 2002;16:6-21.

37. van Engeland M, Derks S, Smits KM, Meijer GA, Herman JG. Colorectal cancer epigenetics: complex simplicity. J Clin Oncol 2011;29:1382-91.

38. Jones PA, Baylin SB. The fundamental role of epigenetic events in cancer. Nat Rev Genet 2002;3: 415-28.

39. Issa JP. CpG island methylator phenotype in cancer. Nat Rev Cancer 2004;4:988-93.

40. Wolffe AP, MatzkeMA. Epigenetics: regulation through repression. Science 1999;286:481-6.

41. Fukushige $S$, Horii A. DNA methylation in cancer: a gene silencing mechanism and the clinical potential of its biomarkers. Tohoku J Exp Med 2013;229:173-85.

42. Das PM, Singal R. DNA methylation and cancer. J Clin Oncol 2004;22:4632-42.

43. van Engeland $M$, Weijenberg MP, Roemen GM, Brink $M$, de Bruïne AP, Goldbohm RA, van den Brandt PA, Baylin SB, de Goeij AF, Herman JG. Effects of dietary folate and alcohol intake on promoter methylation in sporadic colorectal cancer: the Netherlands cohort study on diet and cancer. Cancer Res 2003;63:3133-7.

44. Duthie SJ, Narayanan S, Blum S, Pirie L, Brand GM. Folate deficiency in vitro induces uracil misincorporation and DNA hypomethylation and inhibits DNA excision repair in immortalized normal human colon epithelial cells. Nutr Cancer 2000;37:245-51.

45. Warnecke PM, Bestor TH. Cytosine methylation and human cancer. Curr Opin Oncol 2000;12:68-73.

46. Bariol C, Suter C, Cheong K, Ku SL, Meagher A, Hawkins N, Ward R. The relationship between hypomethylation and CpG island methylation in colorectal neoplasia. Am J Pathol 2003;162:1361-71.

47. Homann N, Tillonen J, Salaspuro M. Microbially produced acetaldehyde from ethanol may increase the risk of colon cancer via folate deficiency. Int J Cancer 2000;86:169-73.

48. Mason JB, Choi SW. Effects of alcohol on folate metabolism: implications for carcinogenesis. Alcohol 2005;35:235-41.

49. McKay JA, Mathers JC. Diet induced epigenetic changes and their implications for health. Acta Physiol (Oxf) 2011;202:103-18.

50. Greene FL, Sobin LH. A worldwide approach to the TNM staging system: collaborative efforts of the AJCC and UICC. J Surg Oncol 2009;99:269-72. 
51. Fuhrman SA, Lasky LC, Limas C. Prognostic significance of morphologic parameters in renal cell carcinoma. Am J Surg Pathol 1982;6:655-63.

52. Ogino S, Fuchs CS, Giovannucci E. How many molecular subtypes? Implications of the unique tumor principle in personalized medicine. Expert Rev Mol Diagn 2012;12:621-8.

53. Jeschke J, O'Hagan HM, Zhang W, Vatapalli R, Calmon MF, Danilova L, Nelkenbrecher C, Van Neste L, Bijsmans IT, Van Engeland M, Gabrielson E, Schuebel KE, Winterpacht A, Baylin SB, Herman JG, Ahuja $\mathrm{N}$. Frequent inactivation of cysteine dioxygenase type 1 contributes to survival of breast cancer cells and resistance to anthracyclines. Clin Cancer Res 2013;19:3201-11.

54. Stipanuk MH, Ueki I, Dominy JE Jr, Simmons CR, Hirschberger LL. Cysteine dioxygenase: a robust system for regulation of cellular cysteine levels. Amino Acids 2009;37:55-63.

55. Satsu H, Terasawa E, Hosokawa Y, Shimizu M. Functional characterization and regulation of the taurine transporter and cysteine dioxygenase in human hepatoblastoma HepG2 cells. Biochem J 2003;375:441-7.

56. Chesney RW, Han X, Patters AB. Taurine and the renal system. J Biomed Sci 2010;17 Suppl 1:S4.

57. van den Brandt PA, Goldbohm RA, van 't Veer P, Volovics A, Hermus RJ, Sturmans F. A large-scale prospective cohort study on diet and cancer in The Netherlands. J Clin Epidemiol 1990;43:285-295.

58. Oeth P. iPLEX TM Assay: Increased Plexing Efficiency and Flexibility for MassARRAY ${ }^{\circledR}$ System Through Single Base Primer Extension with Mass-Modified Terminators.

59. van Breda SG, Hogervorst JG, Schouten LJ, Knaapen AM, van Delft JH, Goldbohm RA, van Schooten FJ, van den Brandt PA. Toenails: an easily accessible and long-term stable source of DNA for genetic analyses in large-scale epidemiological studies. Clin Chem 2007;53:1168-70.

60. Prentice RL. On the design of synthetic case-control studies. Biometrics 1986;42:301-10.

61. Van den Brandt PA, Schouten LJ, Goldbohm RA, Dorant E, Hunen PM. Development of a record linkage protocol for use in the Dutch Cancer Registry for Epidemiological Research. Int J Epidemiol 1990;19:553-558. 
PART I

\section{Dietary intakes}




\section{CHAPTER 2}

Long-term dietary sodium, potassium and fluid intake; exploring potential novel risk factors for renal cell cancer in the Netherlands Cohort Study on diet and cancer 


\section{ABSTRACT}

\section{Introduction}

As sodium, potassium and fluid intake are related to hypertension, an established risk factor for renal cell cancer (RCC), they may be independent risk factors for RCC.

\section{Methods}

The NLCS with case-cohort design includes 120,852 participants aged 55-69 years. At baseline, diet and lifestyle were assessed with questionnaires. After 17.3 years follow-up, 485 RCC cases and 4,438 subcohort members were available for analyses.

\section{Results}

Sodium intake increased RCC risk ( $P$-trend $=0.03$ ), whereas fluid and potassium intake did not. For high sodium and low fluid intake RCC risk additionally increased ( $P$-interaction $=0.02$ ).

\section{Conclusion}

Sodium intake is a potential risk factor for RCC, particularly if fluid consumption is low. 


\section{INTRODUCTION}

The suggested risk factor pattern for renal cell cancer (RCC), including an increased risk with hypertension, smoking and obesity and a decreased risk with moderate alcohol consumption [1] also determines cardiovascular disease risk. In addition, evidence clearly suggests that high sodium intake may cause a rise in blood pressure, the development of hypertension [2] and affects renal function [3-5]. Furthermore, prolonged sodium excess may contribute directly to kidney damage [6]. Therefore, high sodium intake may be a risk factor for RCC, potentially through hypertension.

The effect of sodium on blood pressure may, however, be modified by potassium intake or fluid intake, given their influence on blood pressure regulation and sodium homeostasis, which are both key functions of the kidney [7,8]. That considered, potassium intake and fluid intake may individually influence RCC risk, or modify potential effects of sodium intake on RCC risk. Until now, only few studies investigated the potential association between RCC risk and sodium intake, potassium intake [9] or fluid intake [10-12]. In these studies, no attention has been given to their joint effects on renal function or on the potential influence of hypertension. In this study, we investigate whether sodium, potassium and fluid intake and their potential interactions are associated with RCC risk in a prospective study.

\section{METHODS}

\section{Study design, study population and follow-up}

The Netherlands Cohort Study is a prospective cohort study initiated to investigate the association between diet and the development of cancer [13-15]. The cohort included 58,279 men and 62,573 women between the ages of 55-69 years at baseline (1986). The case-cohort design [16] was used for data processing and analysis. Cases were derived from the entire cohort, whereas a subcohort of 5,000 subjects was randomly sampled at baseline to estimate person years at risk for the entire cohort. Participants with prevalent cancer (excluding skin cancer) at baseline were excluded. All cohort members were followed-up for cancer occurrence through computerized record linkage with the Netherlands cancer registry and the Dutch pathology registry [17]. The completeness of cancer follow-up is over 96\% [18]. After 17.3 years of follow-up, 514 histological confirmed, epithelial RCC cases were identified [International Classification of Diseases for Oncology 3 (ICD-O-3): C64]. 


\section{Assessment of dietary intakes}

At baseline, all participants returned a mailed, self-administered questionnaire on diet and other risk factors for cancer, including smoking habits and hypertension. Participants with incomplete or inconsistent questionnaires were excluded [13]. A 150-item, semi-quantitative food frequency questionnaire (FFQ) represented the dietary part of the questionnaire, which particularly focused on habitual consumption of food and beverages during the preceding year $[13,14]$. The daily intakes were defined as the intakes through both foods and beverages, including amounts naturally present in foods and beverages plus amounts added during food processing by food manufacturers. Intakes were calculated using the computerized Dutch food composition table [19]. Sodium, potassium and fluid intake were validated against nine-day dietary records ( $r=0.64,0.67$ and 0.74 , respectively) and tested for reproducibility $[13,14,20]$.

The daily sodium intake did not include sodium from salt added during homepreparation, yet the baseline questionnaire included specific questions on salt added during home-preparation or before consumption [20]. Together, the questions on cooking salt intake (no/yes, number of teaspoons per person) and table salt intake (ranging from "never" to "very often") represent discretionary salt intake. We considered the actual intake of discretionary salt through consumption of a cooked meal to be two third of the amount of salt added to the meal during cooking [21], as the rest may be discarded in cooking fluid or left in pans or on the plate. The use of table salt was converted into frequencies and quantified by multiplying this frequency by a standard serving size of $0.88 \mathrm{~g}$ [22]. As salt preference may be related to (sodium) salt intake, participants were asked to indicate the saltiness of restaurant food and soups from package or can (ranging from "not salty enough" to "much too salty").

Both sodium and potassium intake were adjusted for total energy intake by using the residual method [23] and modelled as sex-specific quintile distribution and as continuous variable (i.e. per increment of $1 \mathrm{~g} / \mathrm{d}$ ). Similarly, fluid intake was modelled as sex-specific quintile distribution and per increment of $1 \mathrm{l} / \mathrm{d}$, whereas discretionary salt intake was modelled using a categorical variable (i.e. non-consumers plus quartiles of consumers) and per increment of $1 \mathrm{~g} / \mathrm{d}$. For discretionary salt intake and perceived saltiness, the second category was used as reference, as this category seemed most normal in our population.

\section{Statistical analyses}

In total, 485 RCC cases and 4,438 subcohort members with complete dietary information were included in Cox proportional hazards analyses for the case-cohort design [24], which was used to obtain hazard ratios (HR) and 95\% confidence intervals (CI). Associations between sodium, potassium and fluid intake and RCC risk were 
analysed in the total population, by hypertension status and when participants with a low-salt diet were excluded, as these subpopulations may differ in dietary behaviours, so influencing the associations under study. Confounders were selected a priori. Analyses were adjusted for sex (men/women), age at baseline (y), smoking status (never or ex/current), smoking duration (y), smoking intensity (cigarettes/d), body mass index (BMI, $\mathrm{kg} / \mathrm{m}^{2}$ ), alcohol intake ( $\mathrm{g}$ ethanol/d), total energy intake $(\mathrm{kcal} / \mathrm{d})$, a diagnosis of hypertension (no/yes) and use of diuretic medication (no/yes). Age at baseline, smoking intensity and use of diuretic medication were modelled as timedependent variables, due to violation of the proportional hazards assumption, tested using scaled Schoenfeld residuals. Robustness of data was investigated by excluding the first two years of follow-up and by reanalysing data separately for the first and second half of follow-up. Interactions with sodium and discretionary salt intake were investigated for potassium and fluid intake and for suggested RCC risk factors using the Wald $\chi^{2}$ test. A $P$-value $<0.05$ was considered significant. Data were analysed with STATA (version 12).

\section{RESULTS}

Energy-adjusted sodium intake was lower in subcohort members than in RCC cases (Table 2.1). Discretionary salt intake, perceived saltiness, potassium intake and fluid intake were similar among RCC cases, subcohort members and quintiles of sodium intake. Sodium intake was associated with an increased RCC risk (Table 2.2). In multivariable adjusted analyses, we observed a significantly increasing trend across quintiles ( $P$-trend $=0.03$ ) to a maximum in the highest quintile $[\mathrm{HR}(95 \% \mathrm{Cl})$ : 1.40(0.99-1.97)] and a significant increase in RCC risk per increment of $1 \mathrm{~g} / \mathrm{d}$ [HR(95\%Cl): 1.07(1.00-1.15)]. For discretionary salt intake, the RCC risk was u-shaped, with a significantly increased HR for non-users and a non-significantly increased HR for the fourth quartile of users compared to first quartile of users $[\mathrm{HR}(95 \% \mathrm{Cl})$ : 2.36(1.56-3.56) and 1.16(0.85-1.58), respectively]. Only after excluding non-users, there was a significant increase in RCC risk per increment of $1 \mathrm{~g} / \mathrm{d}[\mathrm{HR}(95 \% \mathrm{Cl})$ : 1.04(1.00-1.08)]. Furthermore, participants who indicated soups and restaurant food as 'much too salty' (versus 'good') had the highest RCC risk [HR( $95 \% \mathrm{Cl})$ : 1.70(1.24-2.33)]. Fluid and potassium intake were not associated with RCC risk. We observed no difference between multivariable adjusted models with and without hypertension as confounder, indicating that mediation was not present (data not shown). In addition, no significant interactions between hypertension and any of the exposures under study regarding RCC risk were observed (Suppl Table S2.1). 


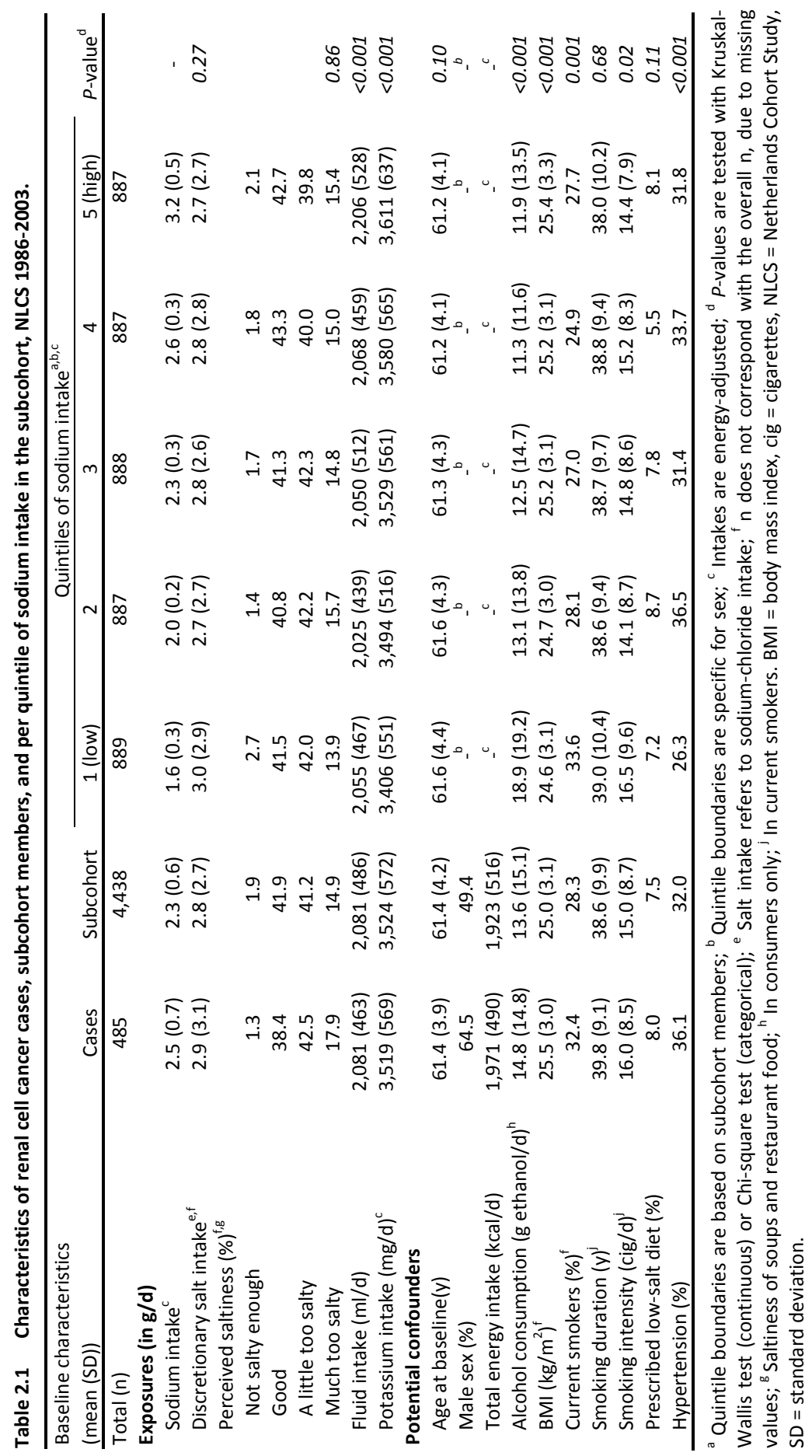


Table 2.2 Renal cell cancer risk according to indicators of sodium intake, fluid intake and potassium intake, NLCS 1986-2003.

\begin{tabular}{|c|c|c|c|c|c|c|}
\hline \multirow{2}{*}{$\begin{array}{l}\text { Exposures in } \mathrm{g} / \mathrm{d} \\
\text { (median in subcohort (men/women)) }\end{array}$} & \multirow[b]{2}{*}{ Cases } & \multirow{2}{*}{$\begin{array}{l}\text { Person } \\
\text { years }\end{array}$} & \multicolumn{2}{|c|}{$\begin{array}{c}\text { Age- and sex-adjusted } \\
\text { model }^{\mathrm{a}} \\
\end{array}$} & \multicolumn{2}{|c|}{$\begin{array}{c}\text { Multivariable } \\
\text { adjusted model }^{\mathrm{b}}\end{array}$} \\
\hline & & & $\mathrm{HR}$ & $95 \% \mathrm{Cl}$ & HR & $95 \% \mathrm{Cl}$ \\
\hline \multicolumn{7}{|l|}{ Sodium intake } \\
\hline Quintile 1 (1.9/1.5) & 70 & 11842 & 1.00 & (ref) & 1.00 & (ref) \\
\hline Quintile $2(2.2 / 1.8)$ & 76 & 11,803 & 1.10 & $(0.78-1.55)$ & 1.07 & $(0.75-1.52)$ \\
\hline Quintile $3(2.5 / 2.0)$ & 81 & 11,833 & 1.17 & $(0.83-1.63)$ & 1.11 & $(0.78-1.57)$ \\
\hline Quintile $4(2.8 / 2.3)$ & 89 & 11,553 & 1.35 & $(0.97-1.88)$ & 1.28 & (0.91-1.79) \\
\hline Quintile $5(3.4 / 2.8)$ & 93 & 11,370 & 1.41 & $(1.01-1.95)$ & 1.40 & (0.99-1.97) \\
\hline$P$-trend & & & & 0.02 & & 0.03 \\
\hline Increment per $1 \mathrm{~g} / \mathrm{d}$ & & & 1.07 & $(1.00-1.14)$ & 1.07 & $(1.00-1.15)$ \\
\hline \multicolumn{7}{|l|}{ Discretionary salt intake ${ }^{c}$} \\
\hline No salt & 45 & 3,033 & 2.51 & $(1.69-3.74)$ & 2.36 & $(1.56-3.56)$ \\
\hline Quartile $1(0.7 / 0.7)$ & 91 & 14,392 & 1.00 & (ref) & 1.00 & (ref) \\
\hline Quartile 2 (2.0/1.7) & 79 & 13,981 & 0.89 & $(0.65-1.23)$ & 0.92 & $(0.66-1.26)$ \\
\hline Quartile 3 (3.4/2.9) & 100 & 13,985 & 1.12 & $(0.83-1.51)$ & 1.14 & $(0.84-1.55)$ \\
\hline Quartile 4 (5.5./5.1) & 94 & 13,009 & 1.16 & $(0.85-1.57)$ & 1.16 & $(0.85-1.58)$ \\
\hline$P$-trend & & & & 0.27 & & 0.39 \\
\hline Increment per $1 \mathrm{~g} / \mathrm{d}$ & & & 1.01 & $(0.97-1.06)$ & 1.02 & $(0.98-1.06)$ \\
\hline \multicolumn{7}{|l|}{ Perceived saltiness $^{d}$} \\
\hline Not salty enough & 4 & 1,084 & 0.52 & $(0.19-1.45)$ & 0.48 & $(0.17-1.35)$ \\
\hline Good & 148 & 22,589 & 1.00 & (ref) & 1.00 & (ref) \\
\hline A little too salty & 167 & 23,599 & 1.14 & $(0.90-1.44)$ & 1.17 & $(0.92-1.48)$ \\
\hline Much too salty & 77 & 8,101 & 1.62 & $(1.20-2.18)$ & 1.70 & $(1.24-2.33)$ \\
\hline$P$-trend & & & & 0.001 & & 0.001 \\
\hline \multicolumn{7}{|l|}{ Fluid intake (l/d) } \\
\hline Quintile 1 (1.6/1.5) & 83 & 11,084 & 1.00 & (ref) & 1.00 & (ref) \\
\hline Quintile 2 (1.9/1.8) & 76 & 11,599 & 0.88 & $(0.63-1.22)$ & 0.88 & $(0.62-1.24)$ \\
\hline Quintile $3(2.1 / 2.0)$ & 90 & 12,066 & 1.00 & $(0.73-1.37)$ & 1.01 & $(0.72-1.42)$ \\
\hline Quintile $4(2.4 / 2.2)$ & 89 & 11,686 & 1.02 & $(0.75-1.41)$ & 1.01 & $(0.69-1.47)$ \\
\hline Quintile $5(2.8 / 2.6)$ & 71 & 11,966 & 0.81 & $(0.58-1.14)$ & 0.78 & $(0.49-1.23)$ \\
\hline$P$-trend & & & & 0.49 & & 0.62 \\
\hline Increment per $1 \mathrm{l} / \mathrm{d}$ & & & 0.89 & $(0.72-1.10)$ & 0.83 & $(0.60-1.16)$ \\
\hline \multicolumn{7}{|l|}{ Potassium intake } \\
\hline Quintile $1(2.8 / 2.9)$ & 71 & 11,228 & 1.00 & (ref) & 1.00 & (ref) \\
\hline Quintile $2(3.1 / 3.2)$ & 83 & 11,582 & 1.15 & $(0.82-1.60)$ & 1.16 & $(0.83-1.62)$ \\
\hline Quintile $3(3.4 / 3.6)$ & 91 & 12,195 & 1.20 & $(0.87-1.67)$ & 1.21 & $(0.85-1.71)$ \\
\hline Quintile $4(3.7 / 3.8)$ & 74 & 11,680 & 1.01 & $(0.72-1.42)$ & 1.04 & $(0.72-1.50)$ \\
\hline Quintile $5(4.2 / 4.3)$ & 90 & 11,716 & 1.24 & $(0.89-1.72)$ & 1.28 & $(0.87-1.90)$ \\
\hline$P$-trend & & & & 0.42 & & 0.41 \\
\hline Increment per $1 \mathrm{~g} / \mathrm{d}$ & & & 1.06 & $(0.89-1.27)$ & 1.10 & $(0.87-1.39)$ \\
\hline
\end{tabular}

${ }^{\mathrm{a}} \mathrm{HR}$ adjusted for age at baseline (y) and sex (men/women); ${ }^{\mathrm{b}} \mathrm{HR}$ adjusted for age at baseline (y), sex (men/women), total energy intake ( $\mathrm{kcal} / \mathrm{d})$, alcohol consumption (g ethanol/d), BMI $\left(\mathrm{kg} / \mathrm{m}^{2}\right)$, smoking status (never or ex/current), smoking duration (y), smoking intensity (cig/d) and if applicable for sodium intake $(\mathrm{g} / \mathrm{d})$, discretionary salt intake $(\mathrm{g} / \mathrm{d})$, fluid intake $(\mathrm{l} / \mathrm{d})$, potassium intake $(\mathrm{g} / \mathrm{d})$ and hypertension (no/yes); ${ }^{\mathrm{c}}$ Salt intake refers to sodium-chloride intake; ${ }^{d}$ Saltiness of soups and restaurant food. BMI = body mass index , cig = cigarettes, NLCS = Netherlands Cohort Study. 
In participants without hypertension, the RCC risk for discretionary salt intake ('no' versus quartile 1) was no longer significant [HR(95\% Cl): 1.74(0.84-3.63)]. Excluding the first two years follow-up or participants with low-salt diet did not change results (data not shown). However, the association between sodium intake and RCC risk clearly attenuated over time. We observed a higher HR for quintile 5 (versus 1 ) of sodium intake during the first nine years follow-up and a lower HR during the second nine years follow-up [HR(95\% Cl): 1.71(1.08-2.71) and 1.12(0.69-1.82), respectively]. There was a significant interaction between sodium and fluid intake but not between sodium and potassium intake regarding RCC risk ( $P$-interaction $=0.02$ and 0.73 , respectively; Table 2.3). Participants with high sodium and low fluid intake compared to low sodium and low fluid intake had a high RCC risk [HR(95\% Cl): 1.91(1.10-3.32)]. Other interactions between sodium or discretionary salt intake and RCC risk factors were not significant (data not shown).

\section{DISCUSSION}

To our knowledge, this is the first prospective study to investigate sodium, potassium and fluid intake and their interactions as potential risk factors for RCC. For sodium intake, the association with RCC risk has been reported in a case-control study, showing a decreased risk for higher sodium intake in men, but not in women [9]. In the present study, we observed an increased RCC risk for higher sodium intake and no interaction between sex and sodium intake for RCC risk. In addition, we found no indications for mediation or effect-modification by hypertension, suggesting that sodium intake may be associated with RCC risk independently of hypertension. Fluid intake was not associated with RCC risk, which is in line with previous prospective cohort studies [10,12], but not with a case-control study showing an increased RCC risk for higher fluid intake [11]. All studies, however, ignored potential confounding by or effect-modification through sodium intake. Yet, we observed an interaction between sodium and fluid intake for RCC risk, which supports our hypothesis that the balance between sodium and fluid intake is important in RCC etiology. Potassium intake was not associated with RCC risk, which is similar to previous research [9].

We recognise that salt (sodium-chloride) intake is a difficult concept to measure accurately, particularly with questionnaires. However, our baseline questionnaire was specifically designed to study salt intake as it additionally included specific questions on discretionary salt intake. Although the FFQ was able to rank individuals adequately according to sodium intake when compared to nine-day dietary records $[13,20]$, information on the validity of discretionary salt intake was not available. 


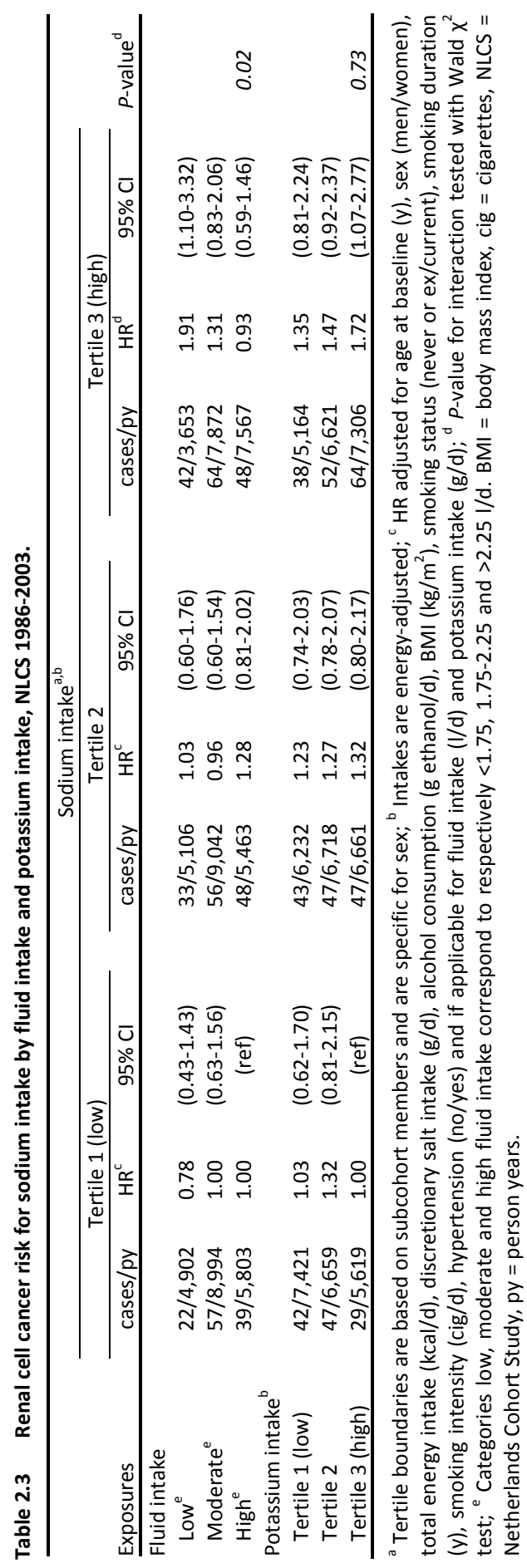


Nevertheless, the mean salt intake (sodium from ready-to-eat foods plus discretionary salt) in our population $(8.7 \mathrm{~g} / \mathrm{d}$ ) is comparable to that of the Dutch population in 1986 [25]. Exposures were only assessed at baseline. Although nutrient intakes were rather stable during the first five years follow-up [14], they may have changed during later follow-up, possibly explaining the attenuation in risk estimate over time.

Compared to sodium intake, which is calculated using standardized measurement units of the FFQ, the inter-individual range of discretionary salt intake is very large (up to factor 10). To capture all variability, it might be desirable to combine both indicators of sodium intake into one overall intake variable. However, discretionary salt intake is highly influenced by habits, attitudes and beliefs [26]. In fact, those who wish to reduce salt intake may particularly reduce discretionary salt intake. The observed u-shape in RCC risk for discretionary salt intake may perhaps reflect one's ability to reduce discretionary salt intake to prevent or control hypertension. Indeed, participants with hypertension were overrepresented in the lowest category of discretionary salt intake (data not shown). Therefore, an overall intake variable was less informative than both individual indicators of sodium intake separately, as HRs for this overall variable fully reflected the arbitrary combination of a linear and u-shaped trend (data not shown).

We used high perceived saltiness as indicator of low salt preference. Salt preference may indicate actual sodium intake, although no consensus has been reached [27]. Indeed, we observed an inverse relation with perceived saltiness for discretionary salt intake $(P$-value $<0.001)$, but not for sodium intake $(P$-value $=0.86)$. The association between high perceived saltiness and RCC risk was, however, in opposite direction as expected, as previously observed for stomach cancer [20]. Perhaps, this association may be explained by the hedonic shift, in which the taste of reduced-sodium products becomes more acceptable over time [27].

The mechanism through which sodium intake may influence RCC risk is unknown. Perhaps, high renal sodium load constitutes to RCC carcinogenesis through inflammation, as sodium is suggested to have inflammatory properties, which can have tumor-promoting consequences $[28,29]$.

In conclusion, sodium intake is a potential risk factor for RCC, particularly if fluid consumption is low, but potassium and fluid intake are not associated with RCC risk. However, these findings await confirmation in other prospective studies and for specific RCC subtypes. Special attention should be given to the role of hypertension and other related diseases, such as end stage renal disease, in the association between sodium intake and RCC risk. 


\section{REFERENCES}

1. Chow WH, Dong LM, Devesa SS. Epidemiology and risk factors for kidney cancer. Nat Rev Urol 2010; 7:245-57.

2. De Wardener HE, MacGregor GA. Sodium and blood pressure. Curr Opin Cardiol 2002;17:360-7.

3. MacGregor GA. Salt--more adverse effects. Am J Hypertens 1997;10:37S-41S.

4. Susic D, Frohlich ED. Salt consumption and cardiovascular, renal, and hypertensive diseases: clinical and mechanistic aspects. Curr Opin Lipidol 2012;23:11-6.

5. de Wardener HE, He FJ, MacGregor GA. Plasma sodium and hypertension. Kidney Int 2004;66: 2454-66.

6. Kotchen TA, Cowley AW Jr, Frohlich ED. Salt in health and disease--a delicate balance. $N$ Engl J Med 2013;368:1229-37.

7. Whelton PK, He J, Cutler JA, Brancati FL, Appel U, Follmann D, Klag MJ. Effects of oral potassium on blood pressure. Meta-analysis of randomized controlled clinical trials. JAMA 1997;277:1624-32.

8. Rose BD, Post TW. Clinical Physiology of acid-base and electrolyte disorders. 5th edition ed. 2001, New York: McGraw-Hill, Medical Publishing Division.

9. Mellemgaard A, McLaughlin JK, Overvad K, Olsen JH. Dietary risk factors for renal cell carcinoma in Denmark. Eur J Cancer 1996; 32a:673-82.

10. Allen NE, Balkwill A, Beral V, Green J, Reeves G; Million Women Study Collaborators. Fluid intake and incidence of renal cell carcinoma in UK women. Br J Cancer 2011; 104:1487-92.

11. Hu J, Mao Y, DesMeules M, Csizmadi I, Friedenreich C, Mery L; Canadian Cancer Registries Epidemiology Research Group. Total fluid and specific beverage intake and risk of renal cell carcinoma in Canada. Cancer Epidemiol 2009;33:355-62.

12. Lee JE, Giovannucci E, Smith-Warner SA, Spiegelman D, Willett WC, Curhan GC. Total fluid intake and use of individual beverages and risk of renal cell cancer in two large cohorts. Cancer Epidemiol Biomarkers Prev 2006;15:1204-11.

13. Goldbohm RA, van den Brandt PA, Brants HA, van't Veer P, Al M, Sturmans F, Hermus RJ. Validation of a dietary questionnaire used in a large-scale prospective cohort study on diet and cancer. Eur J Clin Nutr 1994;48:253-265.

14. Goldbohm RA, van 't Veer P, van den Brandt PA, van 't Hof MA, Brants HA, Sturmans F, Hermus RJ. Reproducibility of a food frequency questionnaire and stability of dietary habits determined from five annually repeated measurements. Eur J Clin Nutr 1995;49:420-9.

15. van den Brandt PA, Goldbohm RA, van 't Veer P, Volovics A, Hermus RJ, Sturmans F. A large-scale prospective cohort study on diet and cancer in The Netherlands. J Clin Epidemiol 1990;43:285-95.

16. Prentice RL. On the design of synthetic case-control studies. Biometrics 1986;42:301-10.

17. Van den Brandt PA, Schouten LJ, Goldbohm RA, Dorant E, Hunen PM. Development of a record linkage protocol for use in the Dutch Cancer Registry for Epidemiological Research. Int J Epidemiol 1990;19:553-8.

18. Goldbohm RA, Van den Brandt PA, Dorant E. Estimation of the coverage of Dutch municipalities by cancer registries and PALGA based on hospital discharge data. Tijdschr Soc Gezondheidsz 1994;72: 80-4.

19. Nevo tabel, Dutch food composition table 1986-1987; Nederlands voedingsstoffenbestand 19861987. 1986, The Hague, The Netherlands: Voorlichtingsbureau voor de Voeding.

20. Van den Brandt PA, Botterweck AA, Goldbohm RA. Salt intake, cured meat consumption, refrigerator use and stomach cancer incidence: a prospective cohort study (Netherlands). Cancer Causes Control 2003;14:427-38.

21. Shepherd R, Farleigh CA, Land DG. Estimation of salt intake by questionnaire. Appetite 1985;6:219-33.

22. Shepherd R, Farleigh CA, Wharf SG. Limited compensation by table salt for reduced salt within a meal. Appetite 1989;13:193-200.

23. Willett W, Stampfer MJ. Total energy intake: implications for epidemiologic analyses. Am J Epidemiol 1986;124:17-27.

24. Barlow WE. Robust variance estimation for the case-cohort design. Biometrics 1994;50:1064-72.

25. Nederlandse Voedingsraad, Vermindering gebruik keukenzout: eindadvies. 1986, Nederlandse Voedingsraad: Den Haag. 
26. Shepherd R, Farleigh CA. Attitudes and personality related to salt intake. Appetite 1986;7:343-54.

27. Mattes RD. The taste for salt in humans. Am J Clin Nutr 1997;65(2 Suppl):692S-697S.

28. Fiore MC, Jimenez PM, Cremonezzi D, Juncos LI, García NH. Statins reverse renal inflammation and endothelial dysfunction induced by chronic high salt intake. Am J Physiol Renal Physiol 2011;301:F263-70.

29. Hanahan D, Weinberg RA. Hallmarks of cancer: the next generation. Cell 2011;144:646-74. 
Suppl Table S2.1 Renal cell cancer risk according to indicators of sodium intake, fluid intake and potassium intake by strata of hypertension, NLCS 1986-2003.

\begin{tabular}{|c|c|c|c|c|c|c|c|}
\hline \multirow{3}{*}{$\begin{array}{l}\text { Exposures in } \mathrm{g} / \mathrm{d} \\
\text { (median in subcohort } \\
\text { (men/women)) }\end{array}$} & \multicolumn{6}{|c|}{ Hypertension } & \multirow[b]{3}{*}{$P$-value ${ }^{b}$} \\
\hline & \multicolumn{3}{|c|}{ No } & \multicolumn{3}{|c|}{ Yes } & \\
\hline & Cases/py & $\mathrm{HR}^{\mathrm{a}}$ & $95 \% \mathrm{Cl}$ & Cases/py & $\mathrm{HR}^{\mathrm{a}}$ & $95 \% \mathrm{Cl}$ & \\
\hline \multicolumn{8}{|l|}{ Sodium intake } \\
\hline Quintile 1 (1.9/1.5) & $48 / 8,765$ & 1.00 & (ref) & $22 / 3,076$ & 1.00 & (ref) & \\
\hline Quintile 2 (2.2/1.8) & $44 / 7,589$ & 1.08 & $(0.70-1.68)$ & $32 / 4,214$ & 1.05 & $(0.58-1.89)$ & \\
\hline Quintile $3(2.5 / 2.0)$ & $50 / 8,203$ & 1.11 & $(0.72-1.72)$ & $31 / 3,630$ & 1.09 & $(0.60-1.99)$ & \\
\hline Quintile $4(2.8 / 2.3)$ & $53 / 7,616$ & 1.27 & (0.84-1.93) & $36 / 3,937$ & 1.27 & $(0.71-2.28)$ & \\
\hline Quintile $5(3.4 / 2.8)$ & $62 / 8,008$ & 1.50 & $(0.99-2.28)$ & $31 / 3,362$ & 1.28 & $(0.70-2.36)$ & 1.00 \\
\hline$P$-trend & & & 0.04 & & & 0.30 & \\
\hline Increment per $1 \mathrm{~g} / \mathrm{d}$ & & 1.08 & (0.99-1.18) & & 1.07 & $(0.95-1.21)$ & \\
\hline \multicolumn{8}{|l|}{ Discretionary salt intake ${ }^{c}$} \\
\hline No salt & $11 / 1,034$ & 1.74 & $(0.84-3.63)$ & $34 / 1,999$ & 2.70 & $(1.57-4.65)$ & \\
\hline Quartile $1(0.7 / 0.7)$ & $51 / 8,974$ & 1.00 & (ref) & $40 / 5,418$ & 1.00 & (ref) & \\
\hline Quartile 2 (2.0/1.7) & $56 / 10,223$ & 0.94 & $(0.63-1.41)$ & $23 / 3,758$ & 0.86 & $(0.50-1.48)$ & \\
\hline Quartile 3 (3.4/2.9) & $71 / 10,088$ & 1.20 & $(0.81-1.77)$ & $29 / 3,897$ & 1.04 & $(0.62-1.75)$ & \\
\hline Quartile 4 (5.5./5.1) & $68 / 9,861$ & 1.19 & $(0.80-1.76)$ & $26 / 3,148$ & 1.19 & $(0.65-1.92)$ & 0.87 \\
\hline$P$-trend & & & 0.52 & & & 0.06 & \\
\hline Increment per $1 \mathrm{~g} / \mathrm{d}$ & & 1.04 & (0.99-1.08) & & 0.97 & $(0.88-1.06)$ & \\
\hline \multicolumn{8}{|l|}{ Perceived saltiness $^{d}$} \\
\hline Not salty enough & $3 / 846$ & 0.46 & $(0.14-1.53)$ & $1 / 239$ & 0.59 & $(0.07-4.70)$ & \\
\hline Good & $112 / 17,186$ & 1.00 & (ref) & $36 / 5,403$ & 1.00 & (ref) & \\
\hline A little too salty & $93 / 15,334$ & 1.03 & (0.77-1.39) & $74 / 8,265$ & 1.45 & $(0.95-2.23)$ & \\
\hline Much too salty & $41 / 4,508$ & 1.75 & $(1.17-2.61)$ & $36 / 3,593$ & 1.65 & $(0.97-2.82)$ & 0.39 \\
\hline$P$-trend & & & 0.01 & & & 0.40 & \\
\hline \multicolumn{8}{|l|}{ Fluid intake $(\mathrm{l} / \mathrm{d})$} \\
\hline Quintile $1(1.6 / 1.5)$ & $53 / 7,593$ & 1.00 & (ref) & $30 / 3,491$ & 1.00 & (ref) & \\
\hline Quintile 2 (1.9/1.8) & $45 / 7,944$ & 0.81 & $(0.52-1.26)$ & $31 / 3,655$ & 0.99 & $(0.56-1.73)$ & \\
\hline Quintile $3(2.1 / 2.0)$ & $59 / 8,259$ & 1.04 & $(0.67-1.60)$ & $31 / 3,807$ & 0.94 & $(0.54-1.66)$ & \\
\hline Quintile $4(2.4 / 2.2)$ & $53 / 7,892$ & 0.95 & (0.59-1.55) & $36 / 3,794$ & 1.10 & $(0.59-2.02)$ & \\
\hline Quintile $5(2.8 / 2.6)$ & $47 / 8,493$ & 0.78 & $(0.44-1.38)$ & $24 / 3,473$ & 0.76 & $(0.25-1.67)$ & 0.90 \\
\hline$P$-trend & & & 0.71 & & & 0.70 & \\
\hline Increment per $1 \mathrm{l} / \mathrm{d}$ & & 0.85 & $(0.57-1.26)$ & & 0.79 & $(0.43-1.44)$ & \\
\hline \multicolumn{8}{|l|}{ Potassium intake } \\
\hline Quintile $1(2.8 / 2.9)$ & $44 / 8,253$ & 1.00 & (ref) & $27 / 2,975$ & 1.00 & (ref) & \\
\hline Quintile $2(3.1 / 3.2)$ & $55 / 8,176$ & 1.31 & $(0.86-2.00)$ & $28 / 3,406$ & 0.91 & $(0.51-1.64)$ & \\
\hline Quintile $3(3.4 / 3.6)$ & $58 / 8,383$ & 1.33 & $(0.86-2.06)$ & $33 / 3,812$ & 0.97 & $(0.54-1.71)$ & \\
\hline Quintile $4(3.7 / 3.8)$ & $46 / 7,749$ & 1.19 & $(0.75-1.90)$ & $28 / 3,931$ & 0.81 & $(0.44-1.48)$ & \\
\hline Quintile $5(4.2 / 4.3)$ & $54 / 7,620$ & 1.47 & $(0.90-2.40)$ & $36 / 4,096$ & 0.97 & $(0.50-1.88)$ & 0.94 \\
\hline$P$-trend & & & 0.25 & & & 0.89 & \\
\hline Increment per $1 \mathrm{~g} / \mathrm{d}$ & & 1.12 & $(0.84-1.50)$ & & 1.04 & $(0.69-1.58)$ & \\
\hline
\end{tabular}

${ }^{a} \mathrm{HR}$ adjusted for age at baseline $(\mathrm{y})$, sex (men/women), total energy intake (kcal/d), alcohol consumption (g ethanol/d), BMI $\left(\mathrm{kg} / \mathrm{m}^{2}\right)$, smoking status (never or ex/current), smoking duration (y), smoking intensity (cig/d) and if applicable for sodium intake $(\mathrm{g} / \mathrm{d})$, discretionary salt intake $(\mathrm{g} / \mathrm{d})$, fluid intake $(\mathrm{l} / \mathrm{d})$ and potassium intake $(\mathrm{g} / \mathrm{d}){ }^{b}{ }^{\mathrm{b}} P$-value for interaction tested with Wald $\chi^{2}$ test; ${ }^{\mathrm{c}}$ Salt intake refers to sodiumchloride intake; ${ }^{d}$ Saltiness of soups and restaurant food. BMI = body mass index, cig = cigarettes, NLCS = Netherlands Cohort Study, py = person years. 
PART II

Gene-environment interactions 


\section{CHAPTER}

Polymorphisms in genes of the renin-angiotensinaldosterone system and renal cell cancer risk: interplay with hypertension and dietary intakes of sodium, potassium and fluid 


\section{ABSTRACT}

\section{Introduction}

Hypertension is an established risk factor for renal cell cancer (RCC). The renin-angiotensinaldosterone system (RAAS) regulates blood pressure and is closely linked to hypertension. RAAS additionally influences homeostasis of electrolytes (e.g. sodium and potassium) and fluid. We investigated single nucleotide polymorphisms (SNPS) in RAAS and their interactions with hypertension and intakes of sodium, potassium and fluid regarding RCC risk.

\section{Methods}

The Netherlands Cohort Study (NLCS) was initiated in 1986 and included 120,852 participants aged 55-69 years. Diet and lifestyle were assessed by questionnaires and toenail clippings were collected. Genotyping of toenail DNA was performed using the SEQUENOM ${ }^{\circledR}$ MasSARRAY $^{\circledR}$ platform for a literature-based selection of 13 candidate SNPs in seven key RAAS genes. After 20.3 years of follow-up, Cox regression analyses were conducted using a case-cohort approach including 3583 subcohort members and 503 RCC cases.

\section{Results}

Two SNPs in AGTR1 were associated with RCC risk. AGTR1_rs1492078 (AA versus GG) decreased RCC risk [hazard ratio (HR) (95\% confidence interval (CI)): 0.70(0.49-1.00)], whereas AGTR1_rs5186 (CC versus AA) increased RCC risk [HR(95\%Cl): 1.49(1.08-2.05)]. Associations were stronger in participants with hypertension. The RCC risk for AGT_rs3889728 (AG+AA versus $\mathrm{GG}$ ) was modified by hypertension ( $P$-interaction $=0.039$ ). SNP-diet interactions were not significant, although HRs suggested interaction between SNPs in ACE and sodium intake.

\section{Conclusion}

SNPs in AGTR1 and AGT influenced RCC susceptibility, and their effects were modified by hypertension. Sodium intake was differentially associated with RCC risk across genotypes of several SNPs, yet some analyses had probably inadequate power to show significant interaction. Results suggest that RAAS may be a candidate pathway in RCC etiology. 


\section{INTRODUCTION}

Hypertension is an established risk factor for renal cell cancer (RCC) [1], yet the underlying biological mechanism is poorly understood. The renin-angiotensinaldosterone system (RAAS), which is a hormonal mechanism that regulates blood pressure, is closely linked to hypertension. Up-regulated RAAS is known to influence the development of hypertension, while inhibition of the RAAS with angiotensinconverting-enzyme (ACE) inhibitors or angiotensin-receptor blockers (ARBs) is commonly used as antihypertensive therapy. Yet, recent developments indicate that deregulated RAAS may also contribute to carcinogenesis, as it may enhance malignant transformation through stimulation of angiogenesis, invasion, cell survival and proliferation [2]. Therefore, it is biologically plausible to consider RAAS as a potential candidate pathway in RCC carcinogenesis. In fact, single nucleotide polymorphisms (SNPs) in genes of the RAAS have been associated with RCC [3].

Recently, we showed that high sodium intake, which is recognized to cause a rise in blood pressure and to influence the development of hypertension [4], might also be a potential risk factor for RCC [5]. Renal sodium homeostasis is regulated by local RAAS processes, for example in the proximal tubule of the kidney, where the concentration of angiotensin II, one of the key factors in RAAS, may be approximately 1000 times higher than that in the circulation to stimulate local sodium reabsorption [6]. Conversely, local RAAS may also be enhanced by a high-salt diet [7]. This suggests that, when considering RAAS in RCC etiology, attention should be given to the interplay between both genetic and environmental factors. In contrast to sodium intake, potassium and fluid intake, which are also related to blood pressure regulation and electrolyte balance $[6,8]$, did not appear to be independent risk factors for RCC [5], yet they may still interact with RAAS genes to influence RCC susceptibility regardless of main effects.

We use a candidate SNP approach to investigate the associations between genetic variation in genes encoding for key factors in RAAS and the risk of RCC in a large population-based cohort study after 20.3 years of follow-up. In addition, we specifically aimed to study gene-environment interactions between these SNPs and factors that may influence RAAS, such as hypertension or the intake of sodium, potassium and fluid in relation to RCC risk.

\section{METHODS}

\section{Study design, study population and follow-up}

The Netherlands Cohort Study on diet and cancer (NLCS) is a prospective cohort study initiated in 1986 to investigate the association between diet and the development of 
cancer [9-11]. The cohort includes 58,279 men and 62,573 women between the ages of 55-69 years at baseline. The case-cohort design was used for efficiency in questionnaire processing and follow-up [12]. Cases were derived from the entire cohort, whereas a subcohort of 5,000 subjects was randomly sampled at baseline to estimate person years at risk for the entire cohort and regularly followed-up for vital status information. All cohort members were followed-up for cancer occurrence through computerized record linkage with the Netherlands cancer registry and the Dutch pathology registry [13]. The completeness of cancer follow-up is over 96\% [14]. Cases and subcohort members with prevalent cancer (excluding skin cancer) at baseline were excluded. After 20.3 years of follow-up, 608 microscopically confirmed RCC cases were identified [International Classification of Diseases for Oncology 3 (ICD-0-3): C64].

\section{Dietary assessment}

All participants returned a mailed, self-administered, baseline questionnaire on diet and other risk factors for cancer such as smoking status and hypertension. A 150-item, semi-quantitative food-frequency questionnaire (FFQ) was used for the dietary assessment. For each food item, participants indicated how often they consumed a standardized unit [9]. We calculated the mean daily item intake by multiplying the consumption frequency and the standardized item unit [9]. Subsequently, we converted mean daily item intakes into nutrient intakes using the Dutch food composition table 1986-87 [15]. Participants with incomplete or inconsistent dietary questionnaires were excluded [9]. The FFQ ranked individuals adequately according to dietary intake when compared to a 9-day dietary record [9], and reflected nutrient intakes for at least 5 years [10]. The daily sodium, potassium and fluid intakes were defined as grams or litres of intake through both foods and beverages per day, including amounts naturally present in foods and beverages plus amounts added during food processing by food manufacturers. Sodium intake did not include sodium from added salt (sodium-chloride), yet the baseline questionnaire included specific questions on salt added during home-preparation and before consumption [16]. Together these variables indicate discretionary salt intake [5]. Sodium and potassium intake were adjusted for total energy intake by using the residual-mean method ${ }^{17}$ and modelled as sex-specific tertile distribution. Fluid intake was modelled as categorical variable using the categories low $(\leq 1.75 \mathrm{l} / \mathrm{d})$, medium $(1.75-2.25 \mathrm{l} / \mathrm{d})$ and high $(>2.25 \mathrm{l} / \mathrm{d})$.

\section{Gene and SNP selection}

We chose to select genes and SNPs on the basis of currently available literature. We selected seven genes from the RAAS because they are known to encode for key factors that cover the essential part of RAAS, namely angiotensin I converting enzyme $(A C E)$, angiotensinogen $(A G T)$, angiotensin II receptor, type 1 (AGTR1), angiotensin II 
receptor, type 2 (AGTR2), cytochrome P450, family 11 , subfamily $\mathrm{B}$, polypeptide 2 (CYP11B2), nuclear receptor subfamily 3, group C, member 2 (NR3C2) and renin (REN) (Figure 3.1).

SNPs were carefully selected through extensive literature search considering the number of previously reported associations with i) the risk of RCC, ii) the risk of hyperor hypotension iii) systolic or diastolic blood pressure, iv) enzymes or proteins in RAAS and $v$ ) salt handling or salt sensitivity and ranked accordingly. We gave priority to SNPs with a minor allele frequency (MAF) $\geq 20 \%$ in Caucasians and SNPs that were not in high linkage disequilibrium (LD) with each other $\left(r^{2}<0.8\right)$. Together, these criteria gave over 100 potential SNPs of interest classified into high and low priority SNPs.

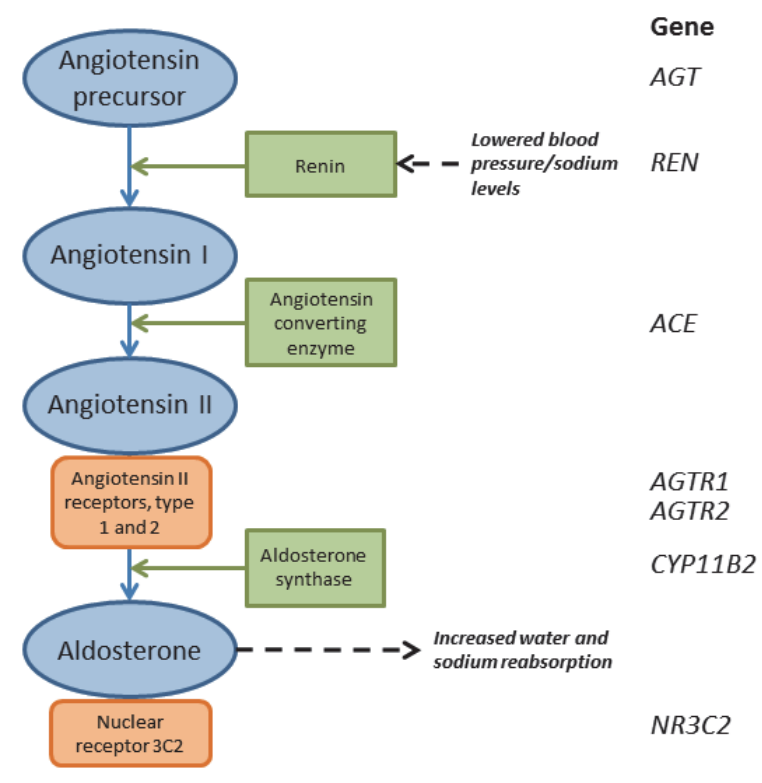

Figure 3.1 Selected key factors in the renin-angiotensin-aldosterone system and the corresponding genes. In response to a low blood pressure the angiotensinogen precursor (AGT), which is expressed in the liver, is cleaved by the enzyme renin (REN). The resulting product, angiotensin I, is then converted into the physiologically active enzyme angiotensin II by the angiotensin converting enzyme (ACE). Angiotensin II is a vasopressor hormone that acts through two membrane receptors, receptor type 1 and type 2 (AGTR1/AGTR2), to induce aldosterone synthesis. Aldosterone synthase (i.e. cytochrome P450 family 11 , subfamily $B$, polypeptide 2; CYP11B2) is a monooxygenase located on the mitochondrial inner membrane. Actions of aldosterone, which are mediated by actions of the nuclear receptor subfamily 3 , group $\mathrm{C}$, member 2 proteins (NR3C2), enhance water and sodium reabsorption and potassium excretion in the kidney, eventually increasing blood pressure. 


\section{DNA isolation}

Approximately 90,000 participants provided toenail clippings at baseline, which have been shown to be a valid source of DNA for the genotyping of germline genetic variants [18]. DNA was isolated using an optimized protocol for DNA isolation based on the method of Cline et al. [18,19]. To increase our case sample, for 67 RCC cases without toenail clippings, DNA was isolated from formalin-fixed paraffin-embedded (FFPE) healthy tissues, as described by van Houwelingen et al. [20] and added to the sample collection of toenail DNA. The use of DNA was approved by the review board of Maastricht University (Maastricht, the Netherlands).

\section{SNP genotyping and quality control}

SNP genotyping was performed on the SEQUENOM ${ }^{\circledR}$ MaSSARRAY $^{\circledR}$ platform using the iPLEX TM assay (Sequenom Inc., Hamburg, Germany), which showed to be suitable for our toenail DNA [21]. This platform allows high-throughput genotyping of up to 40 SNPs at once. Extension primers were designed using MassARRAY ${ }^{\circledR}$ software, version 4.0. Polymerase chain reaction (PCR) amplification and extension reactions were performed according to the manufacturer's instructions. Extension product sizes were determined by mass spectrometry with the use of the iPLEX Gold system [22].

Selected SNPs with high priority were first designated to the assay. Nevertheless, due to potential sequence incompatibilities among primers, not all high priority SNPs could be included in the design. For example, we included CYB11B2_rs7831617 (G>T) as a proxy for CYB11B2_1799998 $\left(T>C, r^{2}=1.0\right.$ and $\left.D^{\prime}=1.0\right)$, which was listed as high priority SNP, but could not be combined with other SNPs on the multiplex. Subsequently, SNPs with less priority were used to fill up the multiplex. We were able to genotype 13 SNPs in seven key RAAS genes (Table 3.1). All SNPs had a call rate of at least $97 \%$.

Genotyping was performed using 100 ng of DNA, which was pipetted onto 384-well plates. In addition, 302 water controls and one duplicate sample for a random selection of $\sim 5 \%$ of the samples $(n=210)$ were scattered across the plates for quality control. The average concordance of the duplicates was $99.6 \%$. One duplicate pair showed highly irreproducible results and was therefore excluded from further analysis. Initially, genotyping data were available for 4,238 samples (excluding duplicates), including $78 \%$ of the subcohort and $88 \%$ of the RCC cases. We excluded 171 samples representing $4 \%$ of the data for further analyses, as those samples called less than $90 \%$ of the SNPs. Because of the case-cohort design, the remaining 4,067 samples correspond to 3583 subcohort members and 503 RCC cases. There were no substantial differences in quality parameters between toenail samples and FFPE healthy tissues samples. 


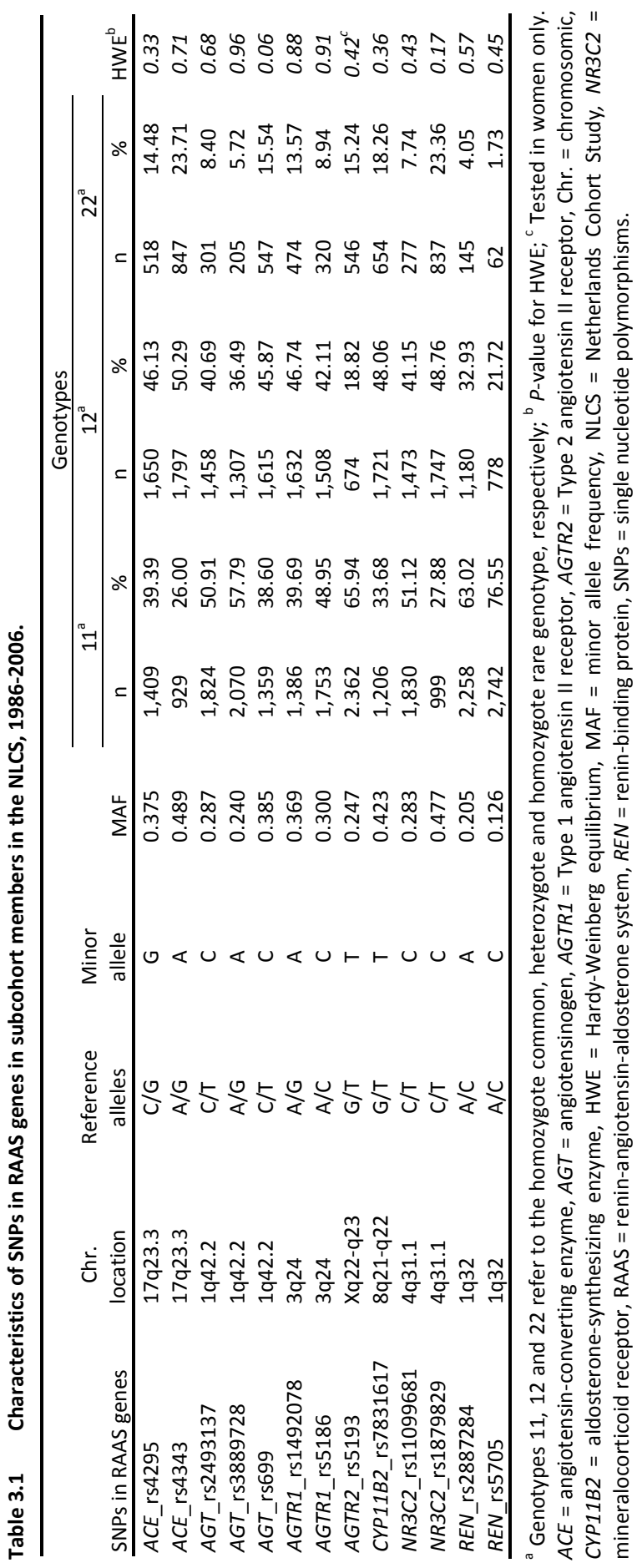




\section{Statistical analyses}

Genotypes were analysed under a co-dominant mode of inheritance, which showed the best model fit according to the Akaike information criterion (AIC), and in an allelic model. SNPs with a MAF $<0.25$ were analysed in a dominant instead of a co-dominant model to maintain optimal power. Hazard ratios (HR) and $95 \%$ confidence intervals (CI) for the independent main effects of each SNP on RCC risk were evaluated in a crude model using Cox proportional hazards analyses adjusted for the case-cohort design [23]. Analyses were conducted in the total population and separately for participants with and without hypertension. Hypertension was defined as a selfreported doctors' diagnosis and/or self-reported use of anti-hypertensive medication. Gene-environment interactions were tested using the Wald $\chi^{2}$ test by including the interaction term into the model. Interaction analyses including dietary exposures were performed for an age- and sex-adjusted model and a multivariable-adjusted model, including a priori selected potential confounders: age at baseline $(\mathrm{y})$, sex (men/women), total energy intake ( $\mathrm{kcal} / \mathrm{d})$, body mass index $\left(\mathrm{BMI} ; \mathrm{kg} / \mathrm{m}^{2}\right)$, smoking status (never or ex/current), smoking duration (y), smoking intensity (cigarettes/d), hypertension status (no/yes) and alcohol consumption (g ethanol/d). We recognise that the FFQ-based sodium intake did not include discretionary salt intake. Earlier we indicated that combining both variables into an overall intake variable was not informative, because both variables represent different aspects of total sodium intake [5]. Instead, in sensitivity analyses, we additionally adjusted each SNP-sodium interaction for discretionary salt intake $(\mathrm{g} / \mathrm{d})$. Cox proportional hazard analyses were conducted using Stata version 12 (Stata Corp., College Station, TX). For all the models including covariates, the proportional hazards assumption was tested using the scaled Schoenfeld residuals. A violation was apparent for age, which was therefore modelled as time dependent covariate. A $P$-value $<0.05$ was considered statistically significant.

Additional analyses were conducted to investigate potential higher-order geneenvironment interactions among all candidate SNPs in RAAS and all environmental exposures of interest (i.e. sodium, discretionary salt, potassium and fluid intake and hypertension status) and, in particular, to investigate the relevance of the candidate SNPs in a previously observed significant interaction between sodium and fluid intake in relation to RCC risk [5]. We used multifactor dimensionality reduction (MDR; version 3.0.2) as analyses technique, as it is a non-parametric and genetic model-free data mining method that is able to detect higher-order interactions in absence of main effects $[24,25]$. We investigated all 2- to 4-way interactions, but only selected models with a testing balanced accuracy $>0.55$ to limit the chance of 'overfitting'. The statistical significance of these models was estimated using permutation testing with 1000 permuted datasets. In addition, an explicit test for interaction has been used to obtain $P$-values for interaction, independent of main effects. MDR analyses did not include the X-chromosomal SNP AGTR2_rs5193, to avoid the strong influence of sex on the results. 


\section{RESULTS}

Genotype and allele frequencies of the RAAS SNPs in subcohort members of the NLCS are given in Table 3.1. All SNPs adhered to the Hardy Weinberg Equilibrium (HWE), as tested with Pearson $\chi^{2}$ test $(P>0.05)$. HWE of the X-chromosomal SNP AGTR2_rs5193 was tested in women only. All SNPs showed no or weak LD with each other $\left(r^{2} \leq 0.50\right)$, except for AGT_rs2493137 which was in moderate LD with AGT_rs3889728 and $A G T$ rs699 $\left(\mathrm{r}^{2}=0.78\right.$ and 0.62, respectively; Haploview, version 4.2).

Table 3.2 Baseline characteristics of subcohort members and RCC cases in the NLCS, 1986 -2006.

\begin{tabular}{|c|c|c|}
\hline Baseline characteristics (mean (SD)) & Subcohort members & RCC Cases \\
\hline Total (n) & 3379 & 480 \\
\hline \multicolumn{3}{|l|}{ Dietary intakes (in g/d) } \\
\hline Sodium ${ }^{a}$ & $2.3(0.6)$ & $2.5(0.7)$ \\
\hline Discretionary salt ${ }^{\mathrm{b}, \mathrm{c}}$ & $2.8(2.7)$ & $2.8(3.0)$ \\
\hline Potassium $^{a}$ & $3.5(0.6)$ & $3.6(0.6)$ \\
\hline Fluid $(\mathrm{l} / \mathrm{d})$ & $2.1(0.5)$ & $2.1(0.5)$ \\
\hline \multicolumn{3}{|l|}{ Potential confounders } \\
\hline Age at baseline (y) & $61.3(4.2)$ & $61.0(4.0)$ \\
\hline Male sex (\%) & 49.8 & 65.2 \\
\hline Total energy intake $(\mathrm{kcal} / \mathrm{d})$ & $1925(506.2)$ & $1994(515.9)$ \\
\hline Alcohol consumption (g ethanol/d) & $13.7(15.0)$ & $15.7(16.1)$ \\
\hline $\mathrm{BMI}\left(\mathrm{kg} / \mathrm{m}^{2}\right)^{\mathrm{c}}$ & $25.0(3.1)$ & $25.5(3.0)$ \\
\hline Current smokers (\%) & 27.4 & 31.9 \\
\hline Smoking duration $(y)^{\mathrm{e}}$ & $38.7(8.7)$ & $39.6(8.5)$ \\
\hline Smoking intensity $(\mathrm{cig} / \mathrm{d})^{\mathrm{e}}$ & $14.7(8.7)$ & $15.9(8.7)$ \\
\hline Hypertension (\%) & 31.8 & 35.4 \\
\hline
\end{tabular}

${ }^{a}$ Intakes are energy-adjusted; ${ }^{b}$ Salt intake refers to sodium-chloride intake; ${ }^{c} \mathrm{n}$ does not correspond with the overall $\mathrm{n}$, due to missing values; ${ }^{\mathrm{d}}$ In consumers only; ${ }^{\mathrm{e}}$ In current smokers. $\mathrm{BMI}=$ body mass index, cig = cigarettes, $\mathrm{RCC}=$ renal cell cancer, $\mathrm{SD}=$ standard deviation .

Baseline characteristics of subcohort members and cases are described in Table 3.2. Compared to subcohort members, RCC cases had a similar mean age at baseline, but were more frequently male. Consequently, RCC cases had a slightly higher BMI, were more frequently smokers and consumed more alcohol. Baseline dietary intakes were comparable between subcohort members and RCC cases, except for sodium intake, which was slightly higher in RCC cases.

\section{Main effects of candidate RAAS SNPs}

Of the 13 candidate RAAS SNPs, two SNPs both in AGTR1 (i.e. AGTR1_rs1492078 and AGTR1_rs5186) were associated with RCC risk (Table 3.3). In the total population, the AA (versus GG) genotype of AGTR1_rs1492078 showed a significantly lower RCC risk [HR(95\% Cl): 0.70(0.49-1.00)], whereas the CC (versus AA) genotype of AGTR1_rs5186 showed a significantly higher RCC risk [HR(95\% Cl): 1.49(1.08-2.05)]. Associations for both SNPs were stronger in participants with hypertension compared to the total 
population and lost significance in participants without hypertension. The remaining candidate RAAS SNPs were neither associated with RCC risk in the total population nor in participants with or without hypertension. However, for AGT_rs3889728, the RCC risk for the $A G+A A$ (versus $G G$ ) genotype was higher in participants without hypertension and lower in participants with hypertension. Indeed, the corresponding SNP-hypertension multiplicative interaction was statistically significant ( $P$-interaction=0.039).

\section{Gene-environment interactions}

None of the investigated multiplicative SNP-sodium interactions significantly influenced RCC risk ( $P$-interaction=0.114-0.988; Table 3.4). Nevertheless, we observed a suggestive interaction with sodium intake for some candidate RAAS SNPs, particularly those in $A C E$, since HRs markedly differed across genotypes and tertiles of sodium intake. For ACE_rs4295, on the one hand, analyses stratified by genotype showed a clear positive association between sodium intake and RCC risk for the CC genotype ( $P$-trend=0.005) and no association for the GG genotype ( $P$-trend=0.949). On the other hand, analyses stratified by tertiles of sodium intake showed a suggestive positive association between the $\mathrm{G}$ allele and RCC risk in participants with a low sodium intake [HR(95\% $\mathrm{Cl}): 1.20(0.91-1.57)]$ and not in those with moderate or high sodium intake. Similarly, the association between sodium intake and RCC risk differed across genotypes of $A C E_{\text {rs }} 4343$ and the A allele of $A C E_{-}$rs4343 was inversely associated with $\mathrm{RCC}$ risk [HR(95\% $\mathrm{Cl}): 0.77(0.59-1.00)]$ only in participants with a low sodium intake. Despite these differences, the SNP-sodium interactions for ACE_rs4295 and $A C E \_r s 4343$ were not significant ( $P$-interaction $=0.385$ and 0.114 , respectively). Different associations between sodium intake and RCC risk were also observed across genotypes of AGT_rs2493137, AGTR1_rs1492078 and AGTR2_rs5193 (women). None of the associations including sodium intake changed after additional adjustment for discretionary salt intake (data not shown). 


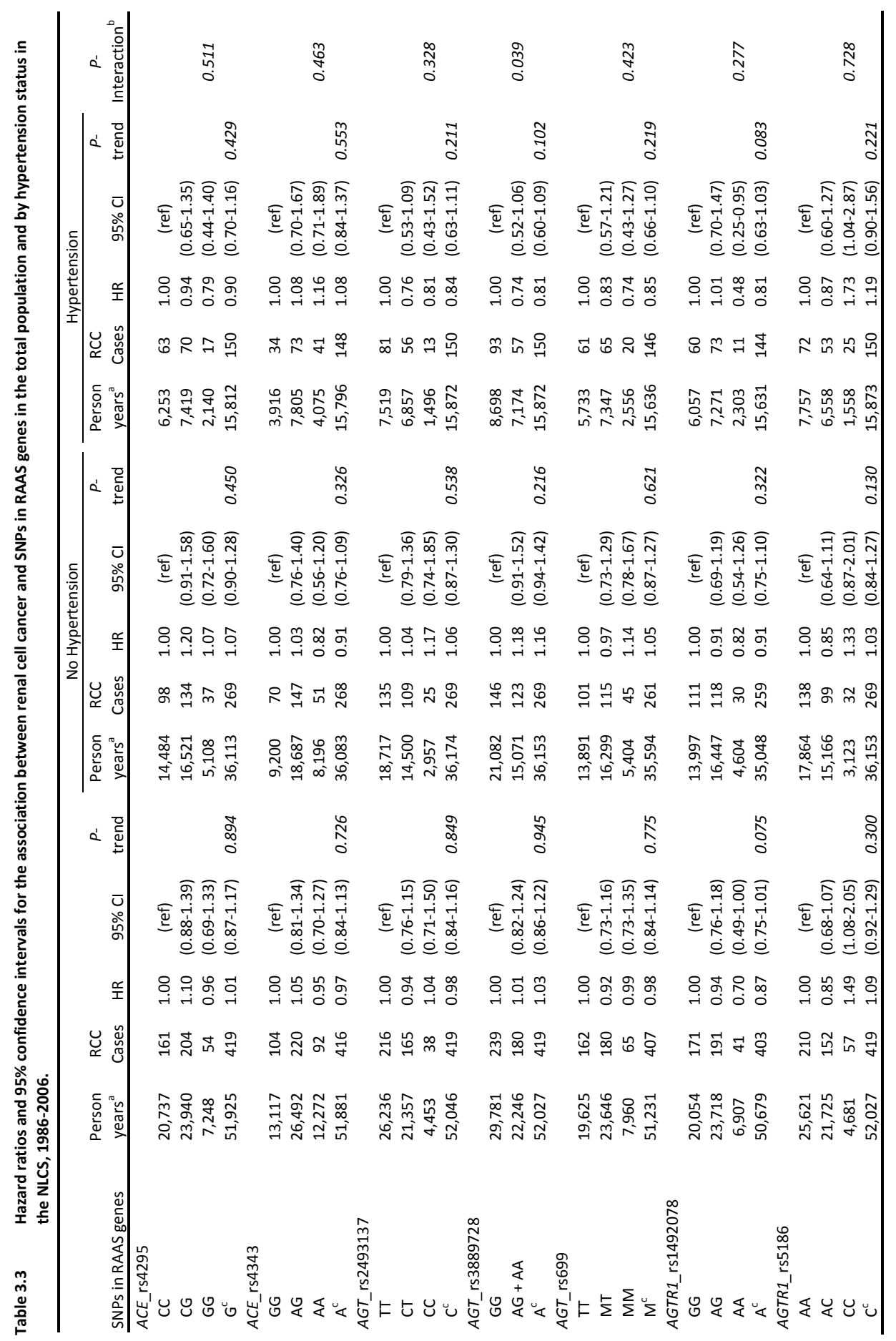




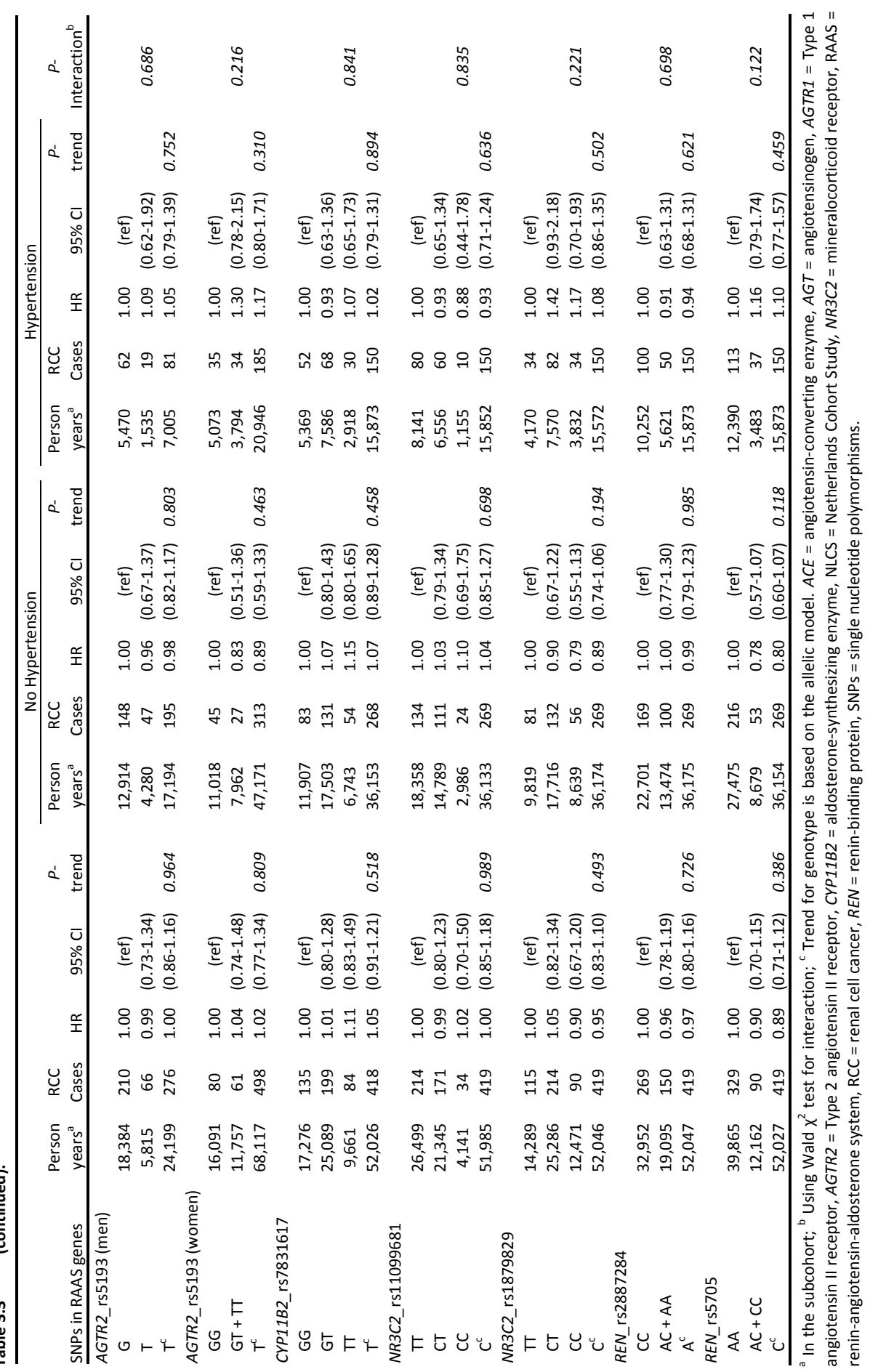




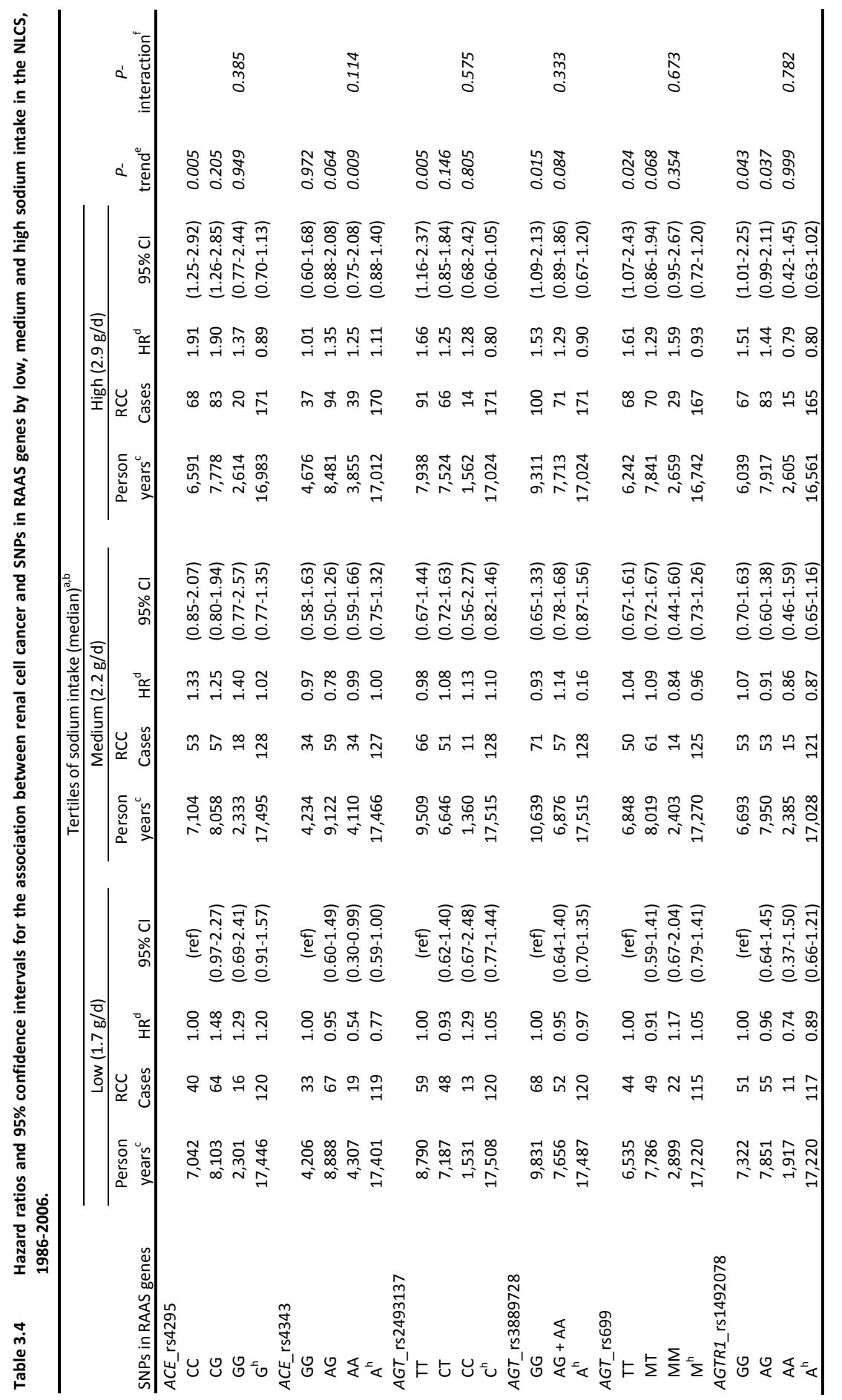


a.

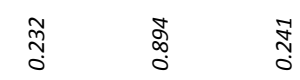

$\infty$
$\infty$
2
0

สุษ

c్m

$2 \stackrel{0}{\frac{0}{0}}$

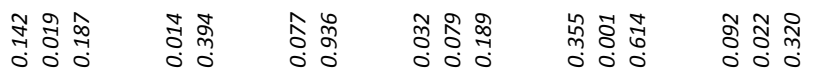

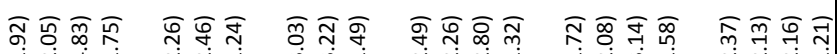

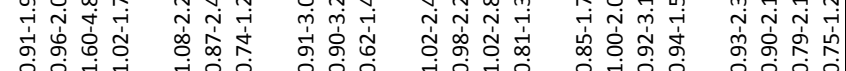

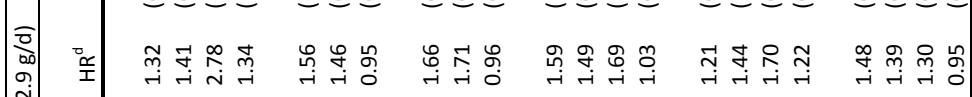

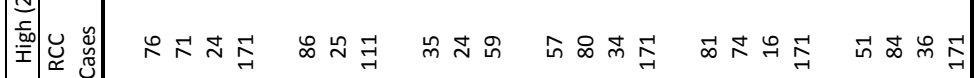

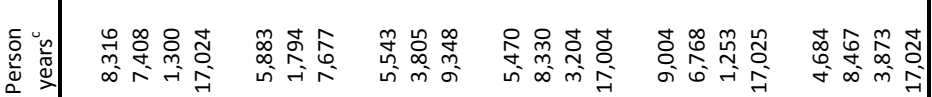

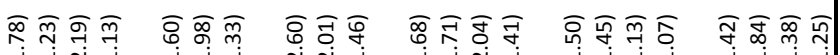

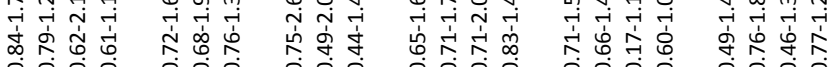

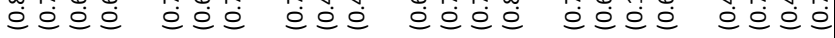

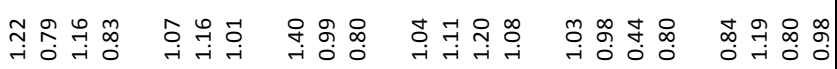

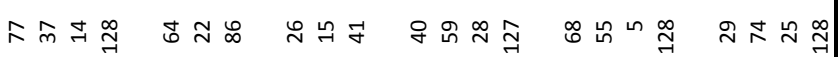

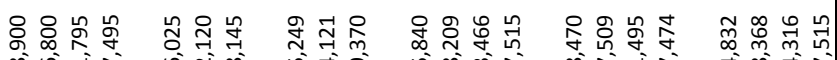

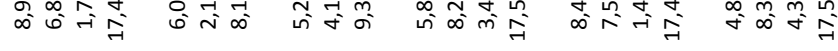

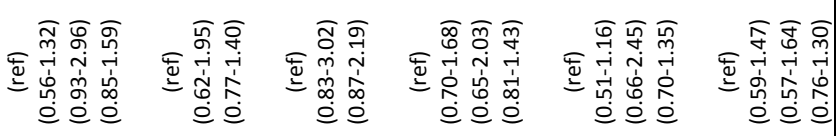

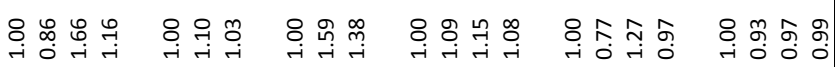

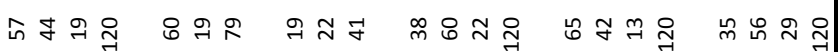

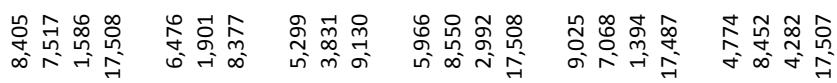

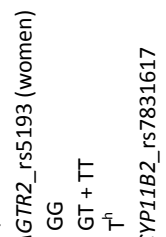

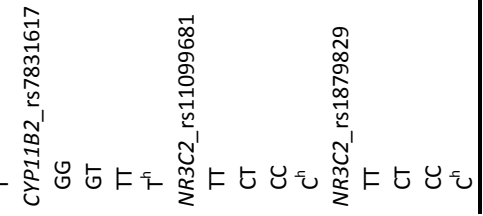




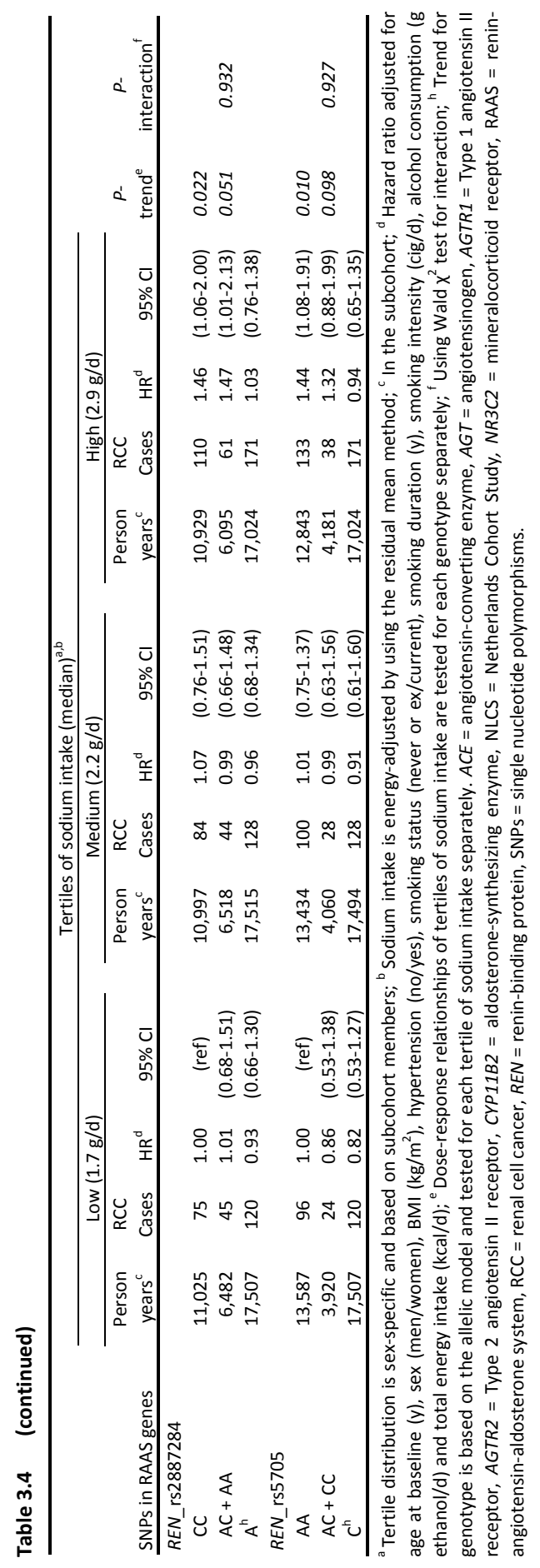


For potassium and fluid intake, none of the multiplicative interactions with candidate RAAS SNPs were statistically significant ( $P$-interaction=0.065-0.976; Suppl Tables S3.1 and S3.2). In general, associations were mainly inconsistent. A borderline significant multiplicative SNP-potassium interaction in relation to RCC risk was observed for $A G T$ rs669 ( $P$-interaction=0.080). RCC risk was particularly low for low potassium consumers with the MM (versus TT) genotype [HR(95\% Cl): 0.59(0.31-1.10)]. The interaction between this SNP and fluid intake did not influence RCC risk $(P$-interaction=0.976). In addition, a borderline significant multiplicative SNP-fluid interaction in relation to RCC risk was observed for AGTR1_rs5186 ( $P$-interaction=0.065). RCC risk was highest for high fluid consumers with the CC (versus AA) genotype $[\mathrm{HR}(95 \% \mathrm{Cl}): 1.89(1.06-3.38)]$. The interaction between this SNP and potassium intake was not statistically significant ( $P$-interaction $=0.586)$, yet a similarly high RCC risk was observed for high potassium consumers with the CC (versus $\mathrm{AA})$ genotype $[\mathrm{HR}(95 \% \mathrm{Cl}): 1.86(1.08-3.21)]$.

\section{Additional analyses}

In additional analyses, MDR identified no 2-way interaction models that met the selection criterion of having a testing balanced accuracy $\geq 0.55$ (Table 3.5). None of the selected 3-way interaction models with a testing balanced accuracy $\geq 0.55$ included both sodium and fluid intake. Among the selected 4-way interaction models, five models did include both sodium and fluid intake, of which the model including sodium intake, fluid intake, AGT_rs2493137 and AGTR1_rs5186 had the highest testing balanced accuracy. High (versus low) risk combinations of this 4-way interaction showed a $[\mathrm{HR}(95 \% \mathrm{Cl}): 2.59(2.07-3.24)]$ in multivariable adjusted Cox proportional hazards analysis. 


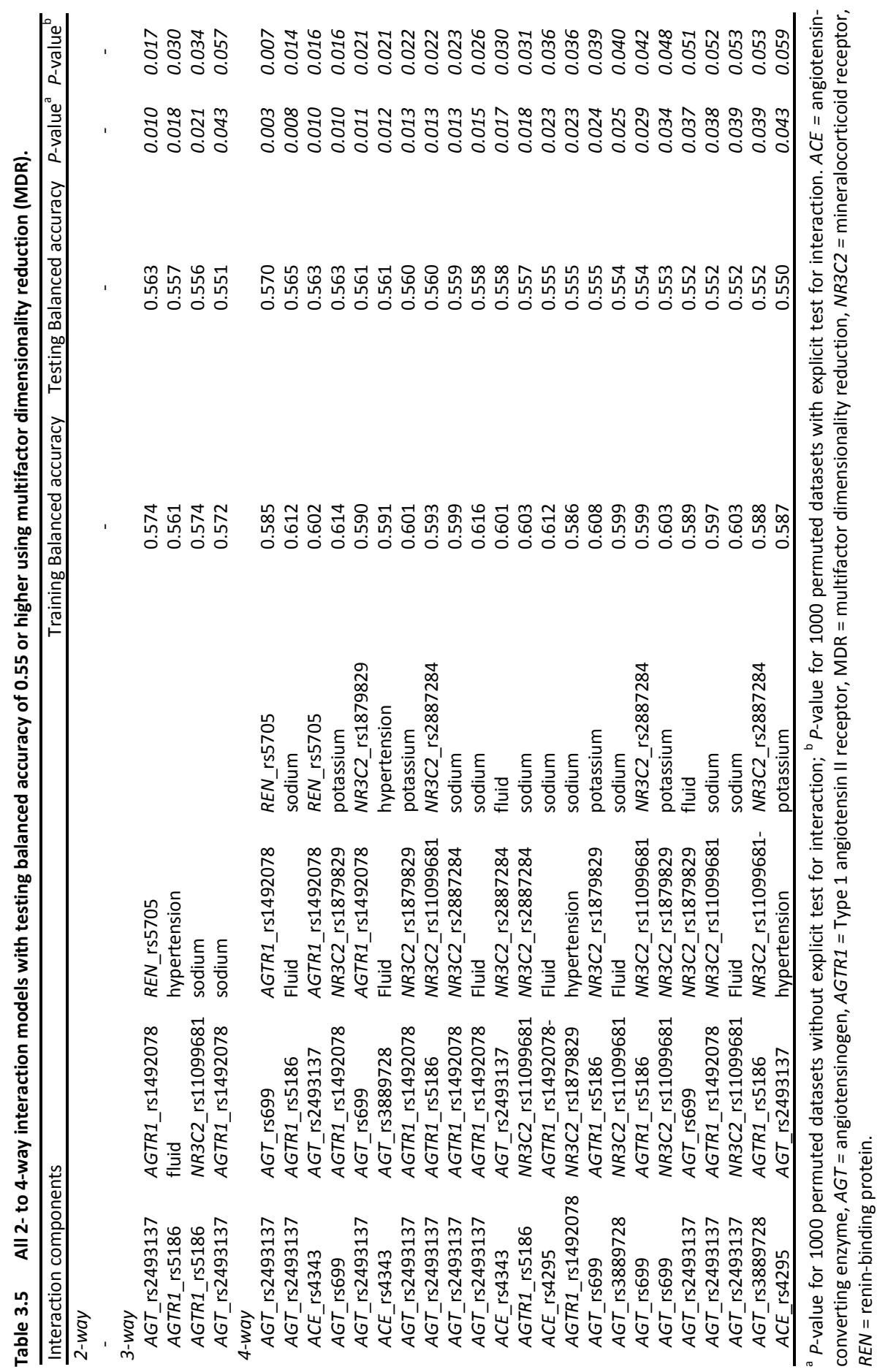




\section{DISCUSSION}

In the present population-based cohort study, we investigated the influence of 13 candidate SNPs in seven key RAAS genes on RCC susceptibility and the potential interplay between these SNPs, hypertension and intakes of dietary sodium, potassium and fluid. We showed for the first time that SNPs in AGTR1 (AGTR1_rs1492078 and AGTR1_rs5186) were associated with RCC risk in the total population and, more strongly, in participants with hypertension. In addition, we found a significant multiplicative interaction between AGT_rs3889728 and hypertension in relation to RCC risk. Together these findings indicate that RAAS may indeed be an underlying candidate pathway explaining previously observed associations between hypertension and RCC risk. Candidate SNPs in ACE, appeared to have no main effect of the RCC risk, yet we observed suggestive interactions between $A C E_{-}$rs4295 and $A C E_{-}$rs4343 and sodium intake. Additionally, differential trends in RCC risk for successive tertiles of sodium intake were present across the genotypes of several RAAS genes, suggesting that the association between sodium intake and RCC risk, which has previously been reported in the NLCS [5], may be influenced by the RAAS.

Actions of angiotensin II, a major component of the RAAS and important regulator of blood pressure, salt homeostasis and hormone secretion, are mediated by the angiotensin II receptors (type 1 and 2). Both angiotensin II receptors are membrane receptors on the epithelial cells of the proximal tubule, the major site of renal sodium reabsorption and the site where the majority of RCC cancers is thought to arise from [26]. Associations between SNPs in the gene encoding for angiotensin II receptor, type 1 (AGTR1) have been reported in relation to RCC susceptibility [3]. For AGTR1_rs12639531 (T>A), the RCC risk was significantly increased under the additive genotypic model ( $P$-trend=0.04) [3]. Two other SNPs in AGTR1 were investigated in the present study; AGTR1_rs5186 (A>C) showing a higher RCC risk and AGTR1_rs1492078 (G>A) showing a lower RCC risk. Associations were more strongly present in participants with hypertension, suggesting that effects of AGTR1 candidate SNPs may be mediated by hypertension. AGTR1_rs5186 (A>C) has previously been associated with breast cancer, where it showed to have protective effects [27]. This inconsistency may be explained by the fact that the impact of SNPs in RAAS may be site-specific, because local RAAS influences local processes [6]. Given that incidence rates of RCC are twice as high in men compared to women, the other gene encoding for an angiotensin II receptor, the AGTR2 gene, was of particular interest as candidate gene for modifying RCC risk, as it is located on the X-chromosome. However, our results indicate no association between AGTR2_rs5193 and RCC susceptibility in men and women.

Our findings on $A G T$, encoding for the angiotensin precursor, suggest that there is interplay between AGT_rs3889728 and hypertension in relation to RCC risk, while no 
main effects of any of the candidate SNPs in AGT were present. The RCC risk for the AG+AA (versus GG) genotype of AGT_rs3889728 was higher in participants without hypertension and lower in participants with hypertension. This association is reversed compared to the association previously reported by Andreotti et al. [3], who showed a higher RCC risk for AG+AA (versus GG) genotype of AGT_rs3889728 particularly in individuals with either hypertension or obesity. It should be noted, however, that the previously reported association was reported in a hospital-based case-control study, in which by study design the likelihood of selection and information bias is higher than in the present prospective cohort study. In addition, both studies only focused on hypertension as a categorical self-reported trait. Although this may not explain such inconsistent associations, it may have masked potential other SNP-hypertension interactions, as it runs the risk of losing information. Another of our candidate SNPs in the AGT gene, $A G T$ rs699 (T>M), has not previously been investigated in relation to RCC susceptibility, but was associated with the risk of hypertension, blood pressure and plasma angiotensin levels in Caucasians [28-31]. In the present study, we found no association between $A G T$ rs 699 and RCC risk. Recently, Lin et al. concluded in their meta-analysis that $A G T$ rs699 was not associated with cancer risk in general [32].

In general, our results indicate that the association between sodium intake and RCC risk, which has previously been reported in the NLCS [5], differs across genotypes of several of the investigated candidate RAAS SNPs. Despite this, tests for multiplicative SNP-diet interaction were never significant. Perhaps, a lack of adequate power may have caused insignificant tests; we examined SNP-diet interactions using the Wald test, which is a relative conservative test when it comes to rejecting the nullhypothesis. Alternatively, risk differences across genotypes may represent biologic interaction, which may best be defined as participation of two component causes in the same sufficient cause [33], rather than as statistical interaction ('effectmodification' or 'heterogeneity of effect'). Biological interaction is not tested as such, yet may still be present when the test for multiplicative interaction is not statistically significant. In particular, SNPs in ACE showed a suggestive interaction with sodium intake in relation to RCC risk. For $A C E_{-}$rs4343, we observed that a trend in RCC risk over successive tertiles of sodium intake was only present among participants with the AA genotype and that an inverse association between the A allele and RCC risk was only present among participants with a low sodium intake, while a main effect of the $A$ allele was absent in the total population. Similarly, a meta-analyses on the risk of hypertension also failed to show an overall significant effect of $A C E \_r s 4343(G>A)$, potentially because of this SNP-sodium interaction [34]. For potassium and fluid intake, which were not associated with RCC risk in previous research in the total population [5], multiplicative interactions with candidate RAAS SNPs were not significant and associations across genotypes not consistent, indicating that neither statistical nor biologic interaction may be present. 
RCC risks were investigated regardless of histological subtype. It is plausible that risk estimates and associations may have differed across the different histological subtypes, but it is unlikely that our results would have changed dramatically when restricting current analyses to the main histological RCC subtype (i.e. clear-cell subtype), as it accounts for approximately $80 \%$ of the RCC cases.

As RAAS is a complex mechanism, in which proteins, enzymes and receptors work together, it is plausible that higher-order gene-gene or gene-environment interactions may contribute to the risk of RCC, which is a multi-factorial disease. In particular, we sought to investigate the role of genetic variation in RAAS genes in our previously found interaction between sodium and fluid intake [5]. There is no consensus on the best strategy for detecting higher-order gene-gene and gene-environment interactions in humans. We took an endeavor in investigating such interactions among the candidate SNPs and several environmental factors using MDR. In the present study, we identified several potentially relevant 3- and 4-way interaction models, yet none of the 2-way interaction models met the selection criterion. This suggests that, when investigating the RAAS in relation to RCC etiology, interactions of higher-order may indeed be of particular interest. Out of the selected 4-way interaction models, five models represented a potentially relevant sodium-fluid-SNP-SNP interaction, of which the model including sodium and fluid intake and the SNPs AGT_rs2493137 and AGTR1_rs5186 represented the best model. In Cox proportional hazard analyses, risk estimates of this specific binary MDR model (high versus low risk) were highly significant. Interpretation of the individual risks based on such MDR model is, however, challenging [24], and becomes exponentially more difficult with each increasing order of interaction. Moreover, the significance of the models should be interpreted with caution, since results from MDR analyses in general have hardly been validated in external settings.

In the present study, we use a candidate SNP approach to study gene-environment interactions, in which we selected SNPs in a common pathway (i.e. RAAS) based on prior biological knowledge from current literature. None of the selected candidate SNPs have previously been identified as SNPs of interest in genome-wide association studies (GWAS), indicating the complementary nature of both approaches. Using the hypothesis-driven selection makes interaction models potentially more plausible and better interpretable compared to a genome-wide association study (GWAS) approach [35]. In addition, it limits the number of tests performed and can therefore be used as an approach to limit the chance of type 1 errors. Although we selected the SNPs carefully, using a candidate SNP approach runs the risk of investigating SNPs that may be a marker of disease linked to another disease-causing SNP, rather than the diseasecausing SNP itself. In addition, considering the complexity of the genetic and environmental network in which the investigated SNPs are included, true effects might still be diluted or masked by effects of those not included in the present study. 
In conclusion, we showed that candidate SNPs in several RAAS genes (i.e. AGT, AGTR1 and $A C E$ ), potentially modified by hypertension or sodium intake, were associated with RCC risk, indicating that RAAS may be a candidate pathway in RCC etiology. Nevertheless, confirmation of these results in other, large prospective studies is warranted. 


\section{REFERENCES}

1. Chow WH, Dong LM, Devesa SS. Epidemiology and risk factors for kidney cancer. Nat Rev Urol 2010; 7:245-57.

2. George AJ, Thomas WG, Hannan RD, The renin-angiotensin system and cancer: old dog, new tricks. Nat Rev Cancer 2010;10:745-59.

3. Andreotti G, Boffetta P, Rosenberg PS, Berndt SI, Karami S, Menashe I, Yeager M, Chanock SJ, Zaridze D, Matteev V, Janout V, Kollarova H, Bencko V, Navratilova M, Szeszenia-Dabrowska N, Mates D, Rothman N, Brennan P, Chow WH, Moore LE. Variants in blood pressure genes and the risk of renal cell carcinoma. Carcinogenesis 2010;31:614-20.

4. De Wardener HE, MacGregor GA. Sodium and blood pressure. Curr Opin Cardiol 2002;17:360-7.

5. Deckers IA, van den Brandt PA, van Engeland M, Soetekouw PM, Baldewijns MM, Goldbohm RA, Schouten LJ. Long-term dietary sodium, potassium and fluid intake; exploring potential novel risk factors for renal cell cancer in the Netherlands Cohort Study on diet and cancer. Br J Cancer 2014; 110:797-801.

6. Rose BD, Post TW. Clinical Physiology of acid-base and electrolyte disorders. 5th edition ed. 2001, New York: McGraw-Hill, Medical Publishing Division.

7. Sato A, Saruta T. Aldosterone-induced organ damage: plasma aldosterone level and inappropriate salt status. Hypertens Res 2004;27:303-10.

8. Whelton PK, He J, Cutler JA, Brancati FL, Appel L, Follmann D, Klag MJ. Effects of oral potassium on blood pressure. Meta-analysis of randomized controlled clinical trials. JAMA 1997;277:1624-32.

9. Goldbohm RA, van den Brandt PA, Brants HA, van't Veer P, Al M, Sturmans F, Hermus RJ. Validation of a dietary questionnaire used in a large-scale prospective cohort study on diet and cancer. Eur J Clin Nutr 1994;48:253-65.

10. Goldbohm RA, van 't Veer P, van den Brandt PA, van 't Hof MA, Brants HA, Sturmans F, Hermus RJ. Reproducibility of a food frequency questionnaire and stability of dietary habits determined from five annually repeated measurements. Eur J Clin Nutr 1995;49:420-9.

11. Van den Brandt PA, Goldbohm RA, van 't Veer P, Volovics A, Hermus RJ, Sturmans F. A large-scale prospective cohort study on diet and cancer in The Netherlands. J Clin Epidemiol 1990;43:285-95.

12. Prentice RL. On the design of synthetic case-control studies. Biometrics 1986;42:301-10.

13. Van den Brandt PA, Schouten LJ, Goldbohm RA, Dorant E, Hunen PM. Development of a record linkage protocol for use in the Dutch Cancer Registry for Epidemiological Research. Int J Epidemiol 1990;19:553-8.

14. Goldbohm RA, Van den Brandt PA, Dorant E. Estimation of the coverage of Dutch municipalities by cancer registries and PALGA based on hospital discharge data. Tijdschr Soc Gezondheidsz 1994;72: 80-4.

15. Nevo tabel, Dutch food composition table 1986-1987; Nederlands voedingsstoffenbestand 19861987. 1986, The Hague, The Netherlands: Voorlichtingsbureau voor de Voeding.

16. Van den Brandt PA, Botterweck AA, Goldbohm RA. Salt intake, cured meat consumption, refrigerator use and stomach cancer incidence: a prospective cohort study (Netherlands). Cancer Causes Control 2003;14:427-38.

17. Willett W, Stampfer MJ. Total energy intake: implications for epidemiologic analyses. Am J Epidemiol 1986;124:17-27.

18. van Breda SG, Hogervorst JG, Schouten L, Knaapen AM, van Delft JH, Goldbohm RA, van Schooten FJ, van den Brandt PA. Toenails: an easily accessible and long-term stable source of DNA for genetic analyses in large-scale epidemiological studies. Clin Chem 2007;53:1168-70.

19. Cline RE, Laurent NM, Foran DR. The fingernails of Mary Sullivan: developing reliable methods for selectively isolating endogenous and exogenous DNA from evidence. J Forensic Sci 2003;48:328-33.

20. van Houwelingen KP, van Dijk BA, Hulsbergen-van de Kaa CA, Schouten LJ, Gorissen HJ, Schalken JA, van den Brandt PA, Oosterwijk E. Prevalence of von Hippel-Lindau gene mutations in sporadic renal cell carcinoma: results from The Netherlands cohort study. BMC Cancer 2005;5:57. 
21. Schouten, L.J., et al. DNA isolated from toenails: A new and valid source for high-throughput genotyping in large-scale epidemiological studies. [abstract]. in In: Proceedings of the AACR Special Conference on Post-GWAS Horizons in Molecular Epidemiology: Digging Deeper into the Environment. 2012. Hollywood, FL. Philadelphia (PA): AACR; Cancer Epidemiol Biomarkers Prev. 2012; 21(11 Suppl): Abstract nr 72.

22. Oeth P. iPLEX TM Assay: Increased Plexing Efficiency and Flexibility for MassARRAY ${ }^{\circledR}$ System Through Single Base Primer Extension with Mass-Modified Terminators.

23. Barlow WE. Robust variance estimation for the case-cohort design. Biometrics 1994;50:1064-72.

24. Moore JH, Gilbert JC, Tsai CT, Chiang FT, Holden T, Barney N, White BC. A flexible computational framework for detecting, characterizing, and interpreting statistical patterns of epistasis in genetic studies of human disease susceptibility. J Theor Biol 2006;241:252-61.

25. Ritchie MD, Hahn LW, Roodi N, Bailey LR, Dupont WD, Parl FF, Moore JH. Multifactor-dimensionality reduction reveals high-order interactions among estrogen-metabolism genes in sporadic breast cancer. Am J Hum Genet 2001;69:138-47.

26. Baldewijns MM, van Vlodrop IJ, Schouten LJ, Soetekouw PM, de Bruïne AP, van Engeland M. Genetics and epigenetics of renal cell cancer. Biochim Biophys Acta 2008; 1785:133-55.

27. Xi B, Zeng T, Liu L, Liang Y, Liu W, Hu Y, Li J. Association between polymorphisms of the reninangiotensin system genes and breast cancer risk: a meta-analysis. Breast Cancer Res Treat 2011;130: 561-8.

28. Kunz R, Kreutz R, Beige J, Distler A, Sharma AM. Association between the angiotensinogen 235Tvariant and essential hypertension in whites: a systematic review and methodological appraisal. Hypertension 1997;30:1331-7.

29. Sethi AA, Nordestgaard BG, Tybjaerg-Hansen A. Angiotensinogen gene polymorphism, plasma angiotensinogen, and risk of hypertension and ischemic heart disease: a meta-analysis. Arterioscler Thromb Vasc Biol 2003;23:1269-75.

30. Mondry A, Loh M, Liu P, Zhu AL, Nagel M. Polymorphisms of the insertion / deletion ACE and M235T AGT genes and hypertension: surprising new findings and meta-analysis of data. BMC Nephrol 2005;6:1.

31. Sethi AA, Nordestgaard BG, Grønholdt ML, Steffensen R, Jensen G, Tybjaerg-Hansen A. Angiotensinogen single nucleotide polymorphisms, elevated blood pressure, and risk of cardiovascular disease. Hypertension 2003;41:1202-11.

32. Lin J, Chen J, Liu C. AGT M235T variant is not associated with risk of cancer. J Renin Angiotensin Aldosterone Syst 2013 Jul 11. [Epub ahead of print].

33. Rothman KJ, Greenland S. Modern Epidemiology. 2nd ed. ed. 1998, Philadelphia: Lippincott-Raven Publishers.

34. Niu, W.Q., et al., Association between angiotensin converting enzyme G2350A polymorphism and hypertension risk: a meta-analysis. Journal of the Renin-Angiotensin-Aldosterone System, 2011. 12(1): p. 8-14.

35. Ritchie MD. Using biological knowledge to uncover the mystery in the search for epistasis in genomewide association studies. Ann Hum Genet 2011;75:172-82. 


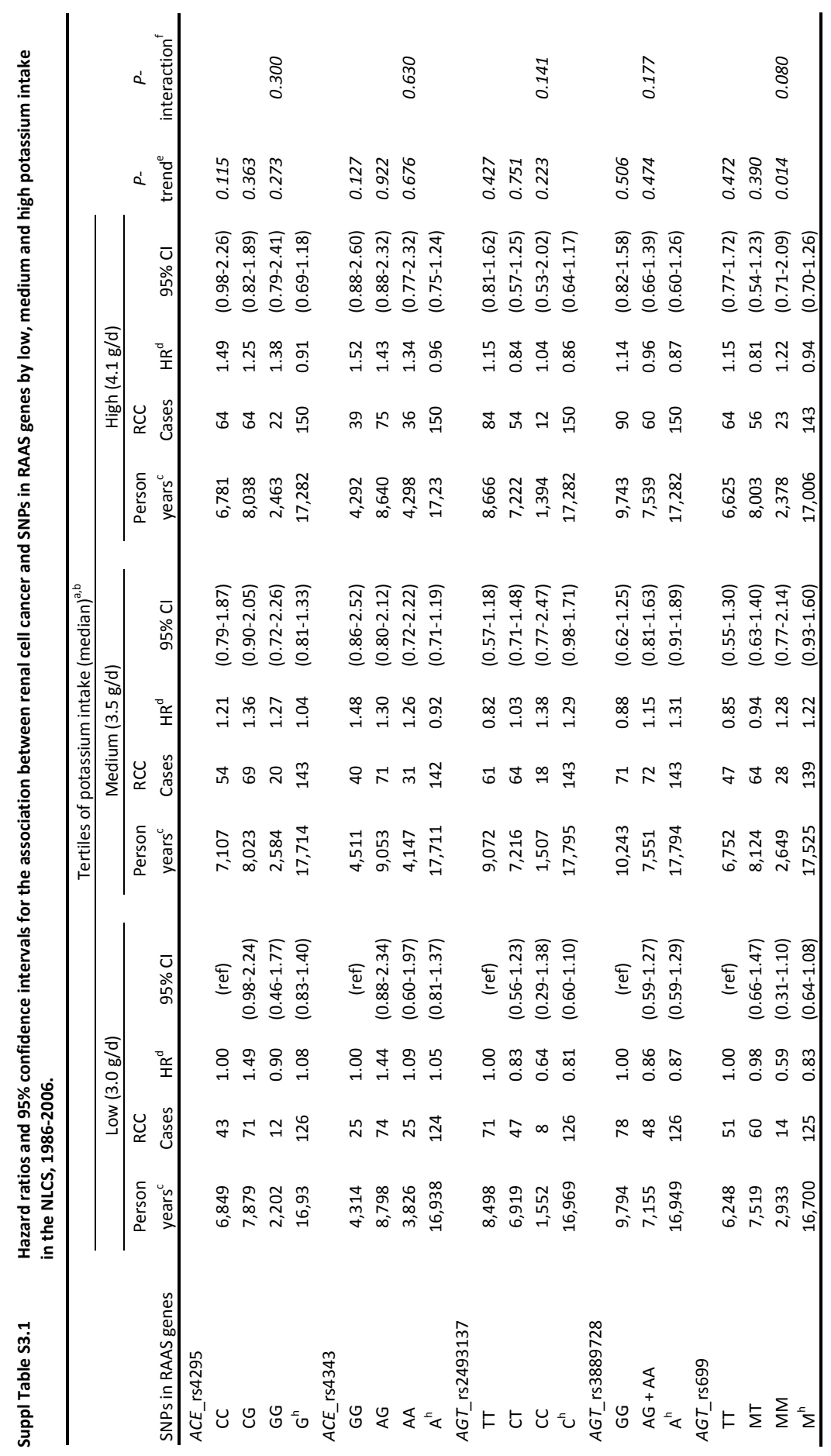




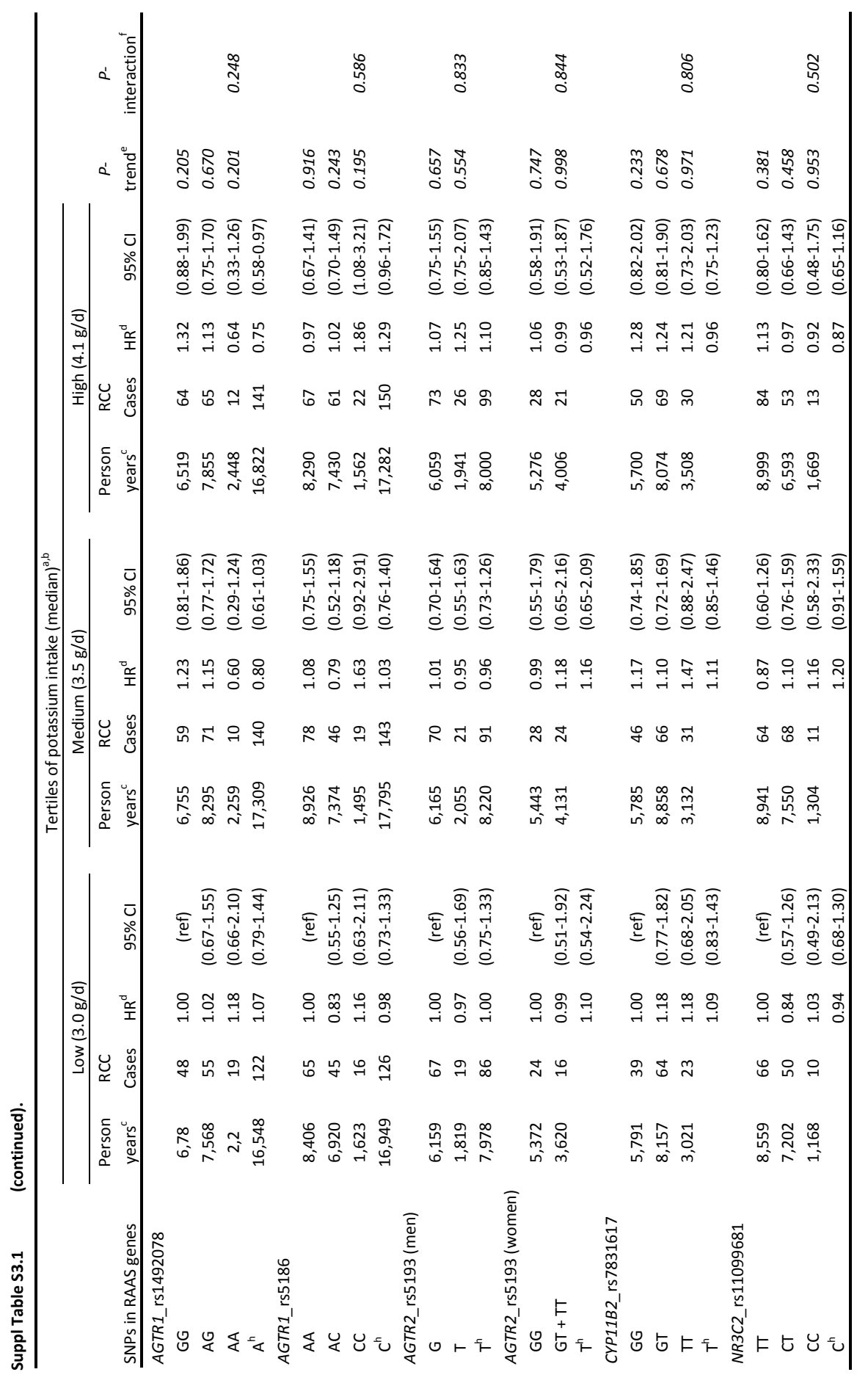




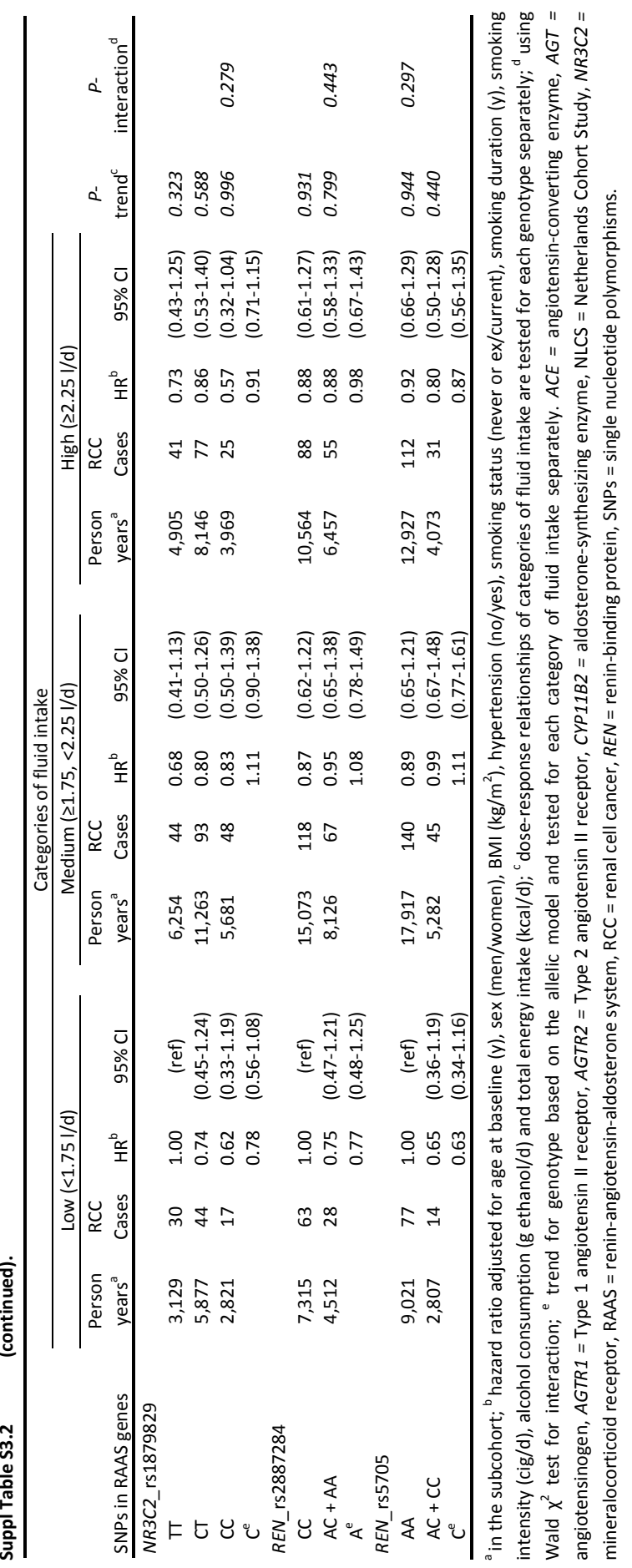




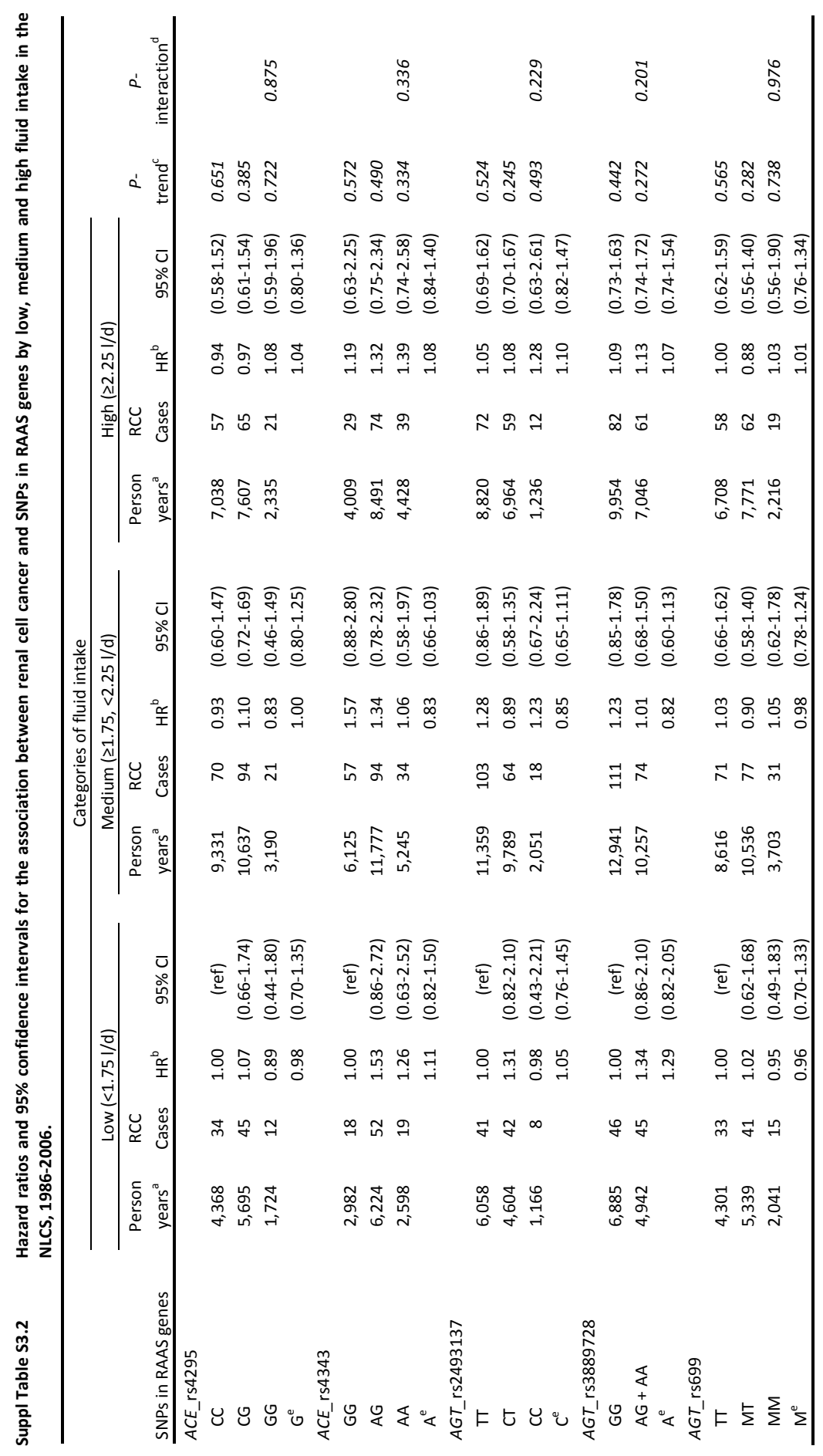




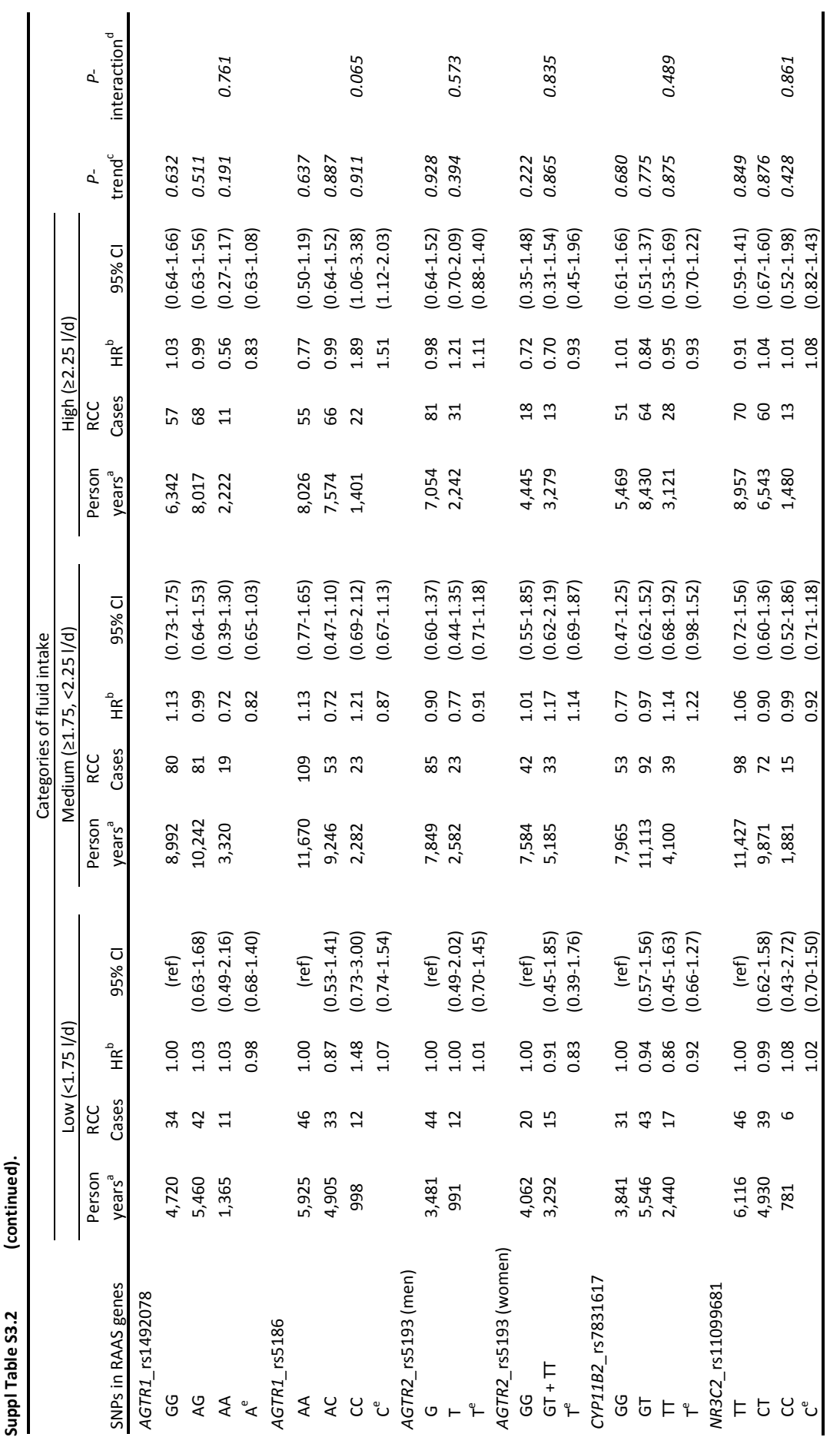




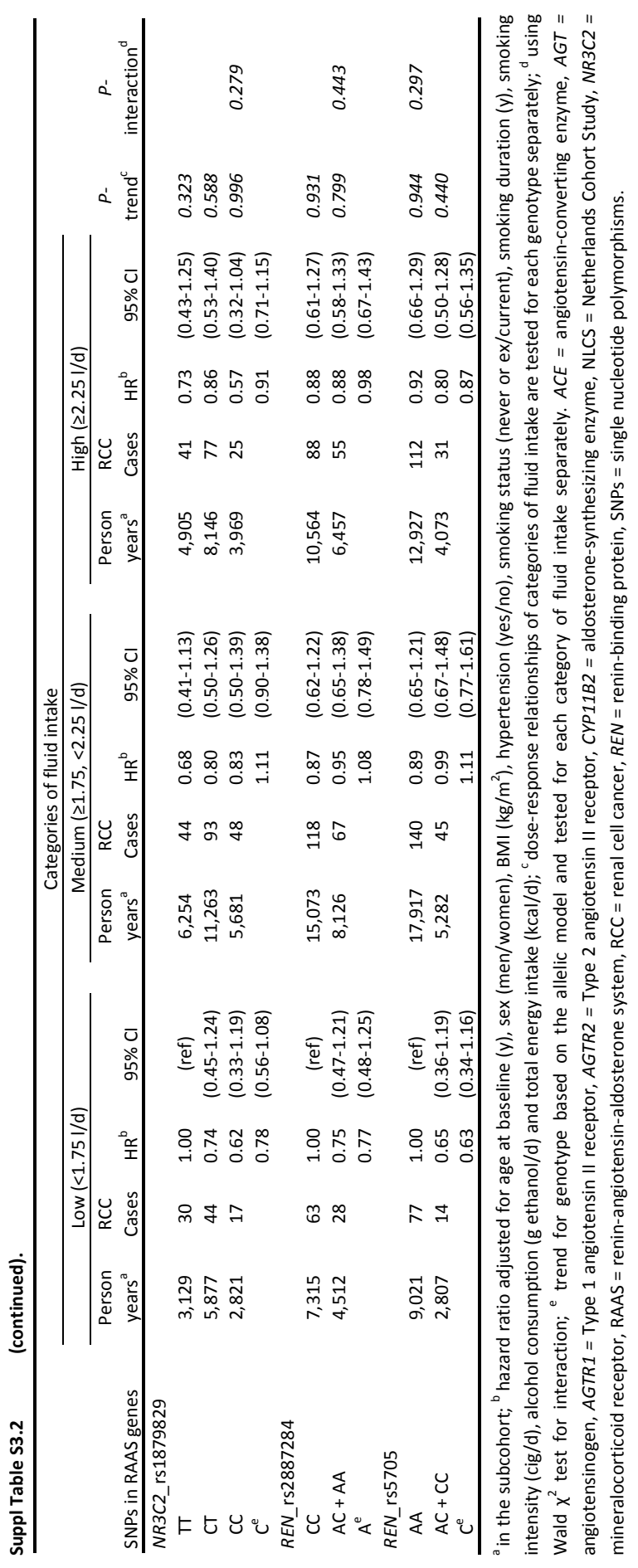




\section{CHAPTER 4}

Gene-environment interactions in ion transport mechanisms in relation to renal cell cancer risk

Ivette AG Deckers, Piet A van den Brandt, Manon van Engeland, Frederik J van Schooten, Roger WL Godschalk, András P Keszei and Leo J Schouten Submitted 


\section{ABSTRACT}

\section{Introduction}

Gene-environment interactions help to unravel mechanisms underlying complex diseases, such as renal cell cancer (RCC). Ion transport mechanisms (ITMs) are related to renal homeostasis, the pathogenesis of hypertension and might be involved in carcinogenesis. We investigated ITMs as potential disease mechanism in RCC etiology using gene-environment interactions between candidate single nucleotide polymorphisms (SNPS) in ITM genes and associated environmental factors, including dietary intakes of sodium, potassium and fluid, hypertension and diuretic medication.

\section{Methods}

A literature-based selection of 13 SNPs in ten ITM genes were successfully genotyped in toenail DNA of 3,583 subcohort members and 503 RCC cases from the Netherlands Cohort Study (NLCS) using the AGENA MassARRAY ${ }^{\circledR}$ iPLEX platform. Diet and lifestyle were measured with baseline questionnaires. Cox regression analyses were conducted for the main effects of each SNP and for gene-environment interactions.

\section{Results}

$A D D 1$ rs4961 was significantly associated with RCC risk, showing a hazard ratio (HR) of 1.24 (95\% confidence interval (Cl): 1.01-1.53) for the GT+TT (versus GG) genotype. Four of 65 tested gene-environment interactions were statistically significant. Three of these interactions clustered in SLC9A3_rs4957061, including the interactions with fluid intake, potassium intake, and diuretic medication. For high versus low fluid intake, the RCC risk was significantly lower in participants with the $\mathrm{CC}$ genotype $[\mathrm{HR}(95 \% \mathrm{Cl}): 0.47(0.26-0.86)]$, but not in participants with the $\mathrm{CT}+\mathrm{TT}$ genotype $(P$-interaction $=0.002)$.

\section{Conclusion}

Data show first indications of involvement of ADD1_rs4961 and SLC9A3_rs4957061 in RCC susceptibility, but do not support the general hypothesis that ITMs are underlying disease mechanisms in RCC etiology. 


\section{INTRODUCTION}

Several modifiable risk factors have been confirmed to increase the risk of renal cell cancer (RCC), including obesity, cigarette smoking and hypertension, while increasing evidence suggests that moderate alcohol consumption may be inversely associated with RCC risk [1]. In addition to environmental factors, genetic susceptibility to RCC has been evaluated in numerous candidate-gene association studies, in which several single nucleotide polymorphisms (SNP) from relevant biologic pathways have been associated with RCC risk [1]. In addition, genome-wide association studies (GWAS) have identified several novel susceptibility loci for RCC [2-5]. However, in complex diseases such as RCC, a substantial part of the phenotypic variation may be explained by the modifying effects of genetic variations on lifestyle risk factors (geneenvironment interactions) [6]. In addition, gene-environment interactions help to unravel mechanisms underlying carcinogenesis [7].

Recently, we reported that high sodium intake was associated with a higher risk of RCC [8] and that this association may differ by genetic variation in genes involved in the renin-angiotensin-aldosterone system (RAAS) [9], which is a hormonal mechanism that regulates blood pressure and renal sodium homeostasis [10]. Renal sodium homeostasis and the homeostatic balance of other solutes is maintained through renal reabsorption and secretion. This process of ion transport is facilitated by protein carriers or ion-specific channels and is essential, as free diffusion of ions through the renal tubules is limited [10]. These ion channels, transporters, exchanger pumps and associated enzymes are collectively referred to as ion transport mechanisms (ITMs) and have recently been put forward as potential novel mechanism underlying carcinogenesis [11]. Perhaps, genetic variation in ITMs may be associated with RCC risk or modify effects of sodium intake in relation to RCC risk.

Ion transport not only involves regulation of sodium homeostasis. Throughout the kidney, renal sodium reabsorption is linked to the reabsorption or secretion of other solutes, such as potassium [10]. Moreover, ITMs are a major focus in the pathogenesis of hypertension, as several forms of antihypertensive therapy intervene on various aspects of ion transport [12]. For example, diuretic medication increases the excretion of fluid and sodium from the kidneys. Therefore, potassium and fluid intake, hypertension and the use of diuretic medication are, in addition to sodium intake, relevant environmental factors in the context of gene-environment interactions in ITMs.

In the present study, we used data from the prospective Netherlands Cohort Study on diet and cancer (NLCS) to investigate the association between candidate SNPs in ITM genes, their interplay with associated environmental factors and RCC risk. 


\section{METHODS}

\section{Study design, study population and follow-up}

The NLCS is a prospective cohort study initiated in 1986 when 58,279 men and 62,573 women between the ages of 55-69 years were included [13-15]. The case-cohort design was used for efficiency in questionnaire processing and follow-up. Cases were derived from the entire cohort, whereas a subcohort of 5,000 subjects was randomly sampled at baseline to estimate person years at risk [16]. Subcohort members were regularly followed up for vital status information. All cohort members were followed up for cancer occurrence through computerized record linkage with the Netherlands cancer registry and the Dutch pathology registry (PALGA) [17]. The coverage of cohort members by the Netherlands cancer registry and PALGA to establish cancer follow-up is estimated to be over 96\% [18]. Cases and subcohort members with prevalent cancer (excluding skin cancer) at baseline were excluded. After 20.3 years of followup, 608 microscopically confirmed RCC cases were identified [International Classification of Diseases for Oncology 3 (ICD-O-3): C64].

\section{Toenail DNA for genotyping}

Approximately 90,000 participants provided toenail clippings at baseline. DNA was isolated from these toenails as described previously [19]. To increase our case sample, for 67 RCC cases without toenail clippings, DNA was isolated from formalin-fixed paraffin-embedded (FFPE) normal kidney tissues, as described by van Houwelingen et al. [20] and added to the sample collection of toenail DNA. Toenail DNA has shown to be a valid source of DNA for the genotyping of a limited set of SNPs when using the AGENA $^{\circledR}$ MassARRAY ${ }^{\circledR}$ platform using the iPLEX TM assay (Agena, Hamburg, Germany) $[21,22]$.

\section{SNP selection and multiplex design}

Genes were of interest if they were involved in ITMs in the kidney and have been associated with the regulation of blood pressure or hypertension. The following candidate genes were included: adducin1 (ADD1), ATPase $\mathrm{Na}+\mathrm{K}+$ transporting alpha and beta 1 polypeptide (ATP1A1 and ATP1B1), guanine nucleotide binding protein (G protein), beta polypeptide 3 (GNB3), regulator of G-protein signaling 5 (RGS5), sodium channel non-voltage-gated 1 beta and gamma subunit (SCNN1B and SCNN1G), solute carrier family 9, subfamily A (NHE3, cation proton antiporter 3 ) member 3 (SLC9A3), serine threonine kinase 39 (STK39) and WNK lysine deficient protein kinase 1 (WNK1). For these genes, SNPs were selected through extensive literature search considering the number of previously reported associations with i) the risk of RCC, ii) the risk of hyper- or hypotension iii) systolic or diastolic blood pressure, iv) enzymes or proteins in the renin-angiotensin-aldosterone system and v) salt handling, ion transport or salt sensitivity. This search strategy rendered over 100 potential SNPs of 
interest. A maximum of 40 SNPs could be included in the multiplex design. We gave priority to SNPs with more than one previously reported association, a minor allele frequency (MAF) $\geq 20 \%$ in Caucasians and to SNPs that were not in high linkage disequilibrium (LD) with each other $\left(r^{2}<0.8\right)$. SNPs with the highest priority were first allocated to the assay. Nevertheless, due to potential sequence incompatibilities among primers, not all high priority SNPs could be included in the design. For example, we included WNK1_rs10849563 (A>G) as a proxy for our high priority SNP WNK1_rs765250 ( $>C, r^{2}=1.0$ and $\left.D^{\prime}=1.0\right)$, which has been associated with essential hypertension and blood pressure, but could not be combined with other SNPs on the multiplex. Subsequently, SNPs with less priority were used to fill the multiplex. Our final multiplex design included 31 SNPs.

\section{SNP genotyping}

For one SNP, ADD1_rs17833172, the genotyping completely failed for unknown reasons. The remaining 30 SNPs were successfully genotyped: $96 \%$ of the samples had a call rate of at least $90 \%$ and the genotype concordance between duplicate toenail samples and between toenail samples and FFPE healthy tissues samples was respectively $99.6 \%$ and $99.1 \%$ on average. For 4,067 samples corresponding to 3,583 subcohort members and 503 RCC cases, complete genotyping data were available for further analyses. The entire multiplex included SNPs in $>20$ genes involved in several pathways. For this study, 13 SNPs in ten ITM genes were successfully genotyped. All SNP call rates were at least 99.9\%, except for SCNN1G_rs4299163, SLC9A3_rs4957061 and WNK1_rs10849563, which had a SNP call rate of $95.4 \%, 94.0 \%$ and $98.7 \%$, respectively (Table 4.1 ).

\section{Baseline questionnaire}

All participants returned a mailed, self-administered, baseline questionnaire on diet and other risk factors for cancer. This baseline questionnaire included a 150-item, semi-quantitative food frequency questionnaire (FFQ), which was used for the assessment of dietary habits. Participants with an incomplete or inconsistent FFQ were excluded, leaving 3,379 subcohort members and 480 cases eligible for further analyses [13]. The FFQ ranked individuals adequately according to dietary intakes when compared to a 9-day dietary records [13], and reflected nutrient intakes for at least 5 years [14]. Nutrient intakes were calculated using the Dutch food composition table 1986-87 [23]. The daily sodium, potassium and fluid intakes were defined as intakes through both foods and beverages per day, including amounts naturally present in foods and beverages plus amounts added during food processing by food manufacturers. Sodium and potassium intake were adjusted for total energy intake by using the residual-mean method [24] and modelled as sex-specific tertile distributions. Fluid intake was modelled as categorical variable using the categories low $(\leq 1.75 \mathrm{l} / \mathrm{d})$, moderate $(1.75-2.25 \mathrm{l} / \mathrm{d})$ and high $(>2.25 \mathrm{l} / \mathrm{d})$ intake. 


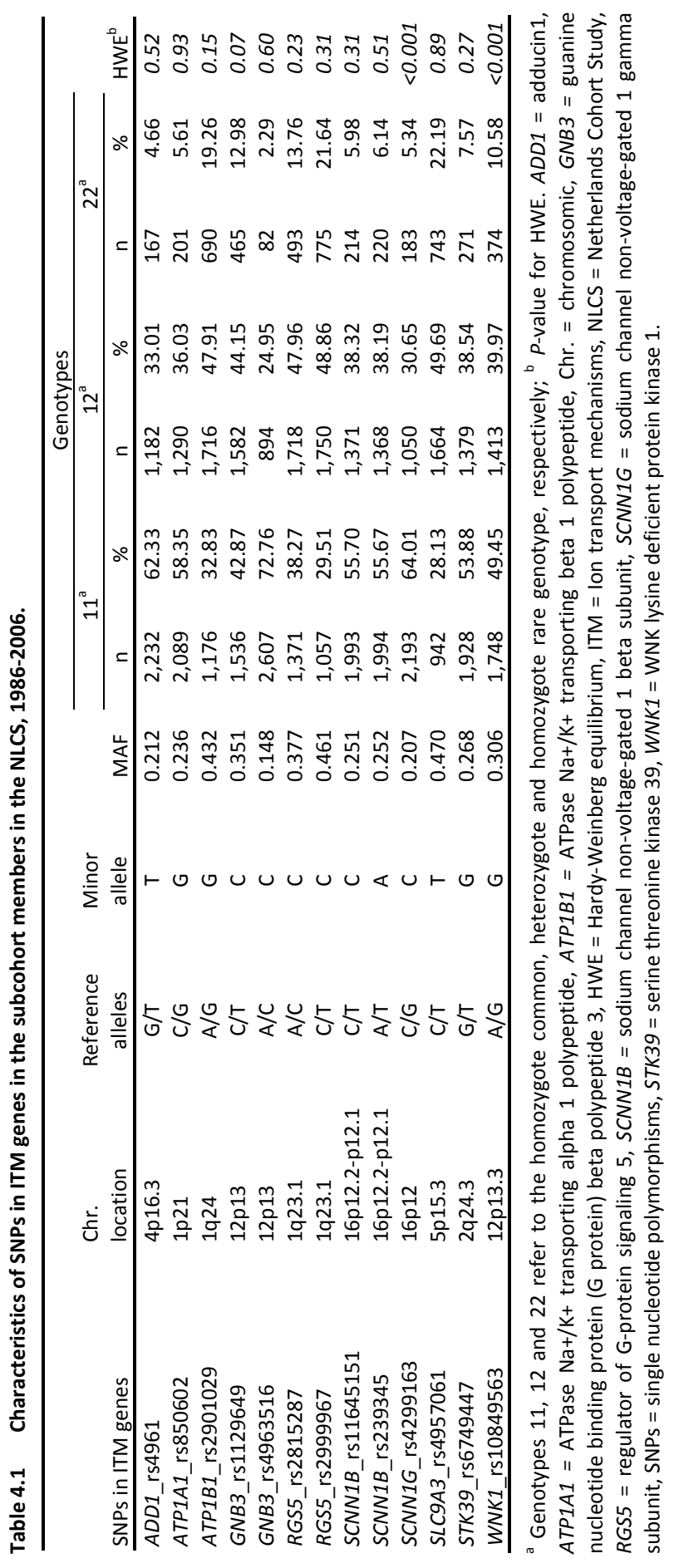


In addition to the FFQ, the baseline questionnaire included specific questions on salt added during home-preparation and before consumption (i.e. discretionary salt intake), which could not be measured using the 150 food items [8,25]. Furthermore, the baseline questionnaire included two questions on the saltiness of restaurant food and soups from package or can (ranging from "not salty enough" to "much too salty"), which were used to assess salt preference, as this may influence total salt (sodium) intake. Finally, participants were asked to report whether they had ever been diagnosed with 'high blood pressure' by a physician, whether they used any medication for more than six months and, if so, for which medical condition they used what kind of medication. Diuretic medication was defined according to the Anatomical Therapeutic Chemical (ATC) classification of the World health organisation (WHO) Collaborative Centre for Drug Statistical Methodology [26,27].

\section{Statistical analyses}

All analyses were conducted using Stata version 12 (Stata Corp., College Station, TX). Hazard ratios (HR) and 95\% confidence intervals $(\mathrm{Cl})$ for the independent main effects of each SNP on RCC risk were evaluated in a crude model and an age and sex adjusted model using Cox proportional hazards analyses adjusted for the case-cohort design [28]. Genotypes were analysed in a dominant model to maintain optimal power and in an allelic model. In subcohort members, we evaluated whether SNPs in genes that have previously been associated with taste responses in mice, including SCNN1B and SCNN1G [29], were associated with perceived saltiness at baseline using the $\chi^{2}$ test.

Gene-environment interactions including the candidate SNPs and the intakes of sodium, potassium and fluid, hypertension and the use of diuretic medication were tested using the Wald $\chi^{2}$ test by including the interaction term into the model. Risk estimates were only presented for the significant gene-environment interactions. Interaction analyses were performed in a multivariable-adjusted model, including $a$ priori selected potential confounders: age at baseline $(\mathrm{y})$, sex (men/women), total energy intake $(\mathrm{kcal} / \mathrm{d})$, body mass index $\left(\mathrm{BMI}, \mathrm{kg} / \mathrm{m}^{2}\right.$ ), smoking status (never or ex/current), smoking duration (y), smoking intensity (cigarettes/d), alcohol consumption (g ethanol/d), hypertension (no/yes) and use of diuretic medication (no/yes). Analyses including sodium intake were additionally adjusted for discretionary salt intake $(\mathrm{g} / \mathrm{d})$ in sensitivity analyses.

For all the models including covariates, the proportional hazards assumption was tested using the scaled Schoenfeld residuals. A violation was apparent for age, which was therefore modelled as time dependent covariate. All tests were two-sided and a $P$-value $<0.05$ was considered statistically significant. 


\section{RESULTS}

Genotype and allele frequencies of SNPs in ITM genes in subcohort members of the NLCS are presented in Table 4.1. Two SNPs, SCNN1G_rs4299163 and WNK1_rs10849563, showed a deviation from Hardy-Weinberg Equilibrium (HWE), as tested with Pearson $\chi^{2}$ test $(P<0.001$ and $P<0.001$, respectively). Despite our priority criteria for multiplex design, i.e. SNPs with MAF $\geq 20 \%$ in Caucasians and SNPs that were not in high LD $\left(r^{2}<0.8\right)$, some of the SNPs had a low MAF (GNB3_rs4963516; $M A F=0.148$ ) or a high LD (SCNN1B_rs239345 and SCNN1B_rs11645151; $r^{2}=0.93$, $D^{\prime}=0.96$;) in this study population (Haploview, version 4.2 [30]).

At baseline, cases and subcohort members did not substantially differ in dietary intakes (Table 4.2). However, the proportion of men, cigarette smokers, participants with a diagnosis of hypertension and users of diuretic medication, was higher among cases than among subcohort members. Perceived saltiness, an inverse indicator of salt preference, was higher in cases than in subcohort members. Among subcohort members, there was no association between the three candidate SNPs in two genes that have previously been associated with taste responses in mice, including SCNN1B and SCNN1G [29], and perceived saltiness, as tested with the $\chi^{2}$ test (range $P$-values $=0.516-0.846)$.

Table 4.2 Baseline characteristics of subcohort members and renal cell cancer cases in the NLCS, 1986-2006.

\begin{tabular}{|c|c|c|}
\hline Baseline characteristics (mean (SD)) & Subcohort members & RCC Cases \\
\hline Total (n) & 3379 & 480 \\
\hline \multicolumn{3}{|l|}{ Dietary intakes (in g/d) } \\
\hline Sodium ${ }^{a}$ & $2.3(0.6)$ & $2.5(0.7)$ \\
\hline Discretionary salt ${ }^{b, c}$ & $2.8(2.7)$ & $2.8(3.0)$ \\
\hline \multicolumn{3}{|l|}{ Perceived saltiness (\%) } \\
\hline Not salty enough & 1.9 & 2.0 \\
\hline Good & 41.9 & 36.7 \\
\hline A little too salty & 41.6 & 41.2 \\
\hline Much too salty & 14.7 & 20.2 \\
\hline Potassium ${ }^{a}$ & $3.5(0.6)$ & $3.6(0.6)$ \\
\hline Fluid $(\mathrm{l} / \mathrm{d})$ & $2.1(0.5)$ & $2.1(0.5)$ \\
\hline \multicolumn{3}{|l|}{ Potential confounders } \\
\hline Age (y) & $61.3(4.2)$ & $61.0(4.0)$ \\
\hline Male sex (\%) & 49.8 & 65.2 \\
\hline Total energy intake (kcal/d) & $1925(506.2)$ & $1994.0(515.9)$ \\
\hline Alcohol consumption (g ethanol/d) ${ }^{d}$ & $13.7(15.0)$ & $15.7(16.1)$ \\
\hline $\mathrm{BMI}\left(\mathrm{kg} / \mathrm{m}^{2}\right)^{\mathrm{c}}$ & $25.0(3.1)$ & $25.5(3.0)$ \\
\hline Current smokers (\%) & 27.4 & 31.9 \\
\hline Smoking duration $(y)^{e}$ & $38.7(8.7)$ & $39.6(8.5)$ \\
\hline Smoking intensity $(\mathrm{cig} / \mathrm{d})^{\mathrm{e}}$ & $14.7(8.7)$ & $15.9(8.7)$ \\
\hline Hypertension (\%) & 26.2 & 31.9 \\
\hline Use of diuretic medication (\%) & 10.8 & 13.1 \\
\hline
\end{tabular}


Out of the 13 investigated candidate SNPs, only ADD1_rs4961 was significantly associated with RCC risk (Table 4.3). Results were similar for the crude and age- and sex-adjusted model. In the latter model, the $\mathrm{HR}(95 \% \mathrm{Cl})$ for the $\mathrm{GT}+\mathrm{TT}$ (versus $\mathrm{GG}$ ) genotype was 1.24(1.01-1.53), whereas the $\mathrm{HR}(95 \% \mathrm{Cl})$ for each $\mathrm{T}$ allele was 1.19(1.00-1.41). We tested 65 gene-environment interactions between the candidate SNPs and the exposures under study, including the dietary intakes of sodium, potassium and fluid, hypertension status and the use of diuretic medication, in relation to RCC risk (Table 4.4). Four gene-environment interactions were significant. In fact, the number of significant gene-environment interaction was not much higher than expected based on chance. Additional adjustment for discretionary salt intake in sensitivity analyses did not change the results. However, three out of the four observed significant gene-environment interactions included the same SNP, i.e. SLC9A3_rs4957061. RCC risk estimates by genotype of this SNP are presented in Table 4.5. A significantly lower RCC risk was observed for the highest (versus the lowest) category of fluid intake in participants with the CC genotype $[\mathrm{HR}(95 \% \mathrm{Cl})$ : 0.47(0.26-0.86)], whereas no such lower RCC risk was observed for participants with the highest fluid intake and the CT+TT genotype [HR(95\% $\mathrm{Cl}): 1.03(0.64-1.65)$, $P$-interaction=0.002]. This is in line with results from continuous analysis $(P$-interaction $=0.031)$. For potassium intake, in continuous analyses, the RCC risk for each additional gram of potassium intake per day showed a subtle difference between the CC and CT+TT genotypes [HR(95\% Cl): 0.77(0.54-1.12) and 1.18(0.94-1.49), respectively; $P$-interaction=0.028)]. However, the interaction could not be confirmed in the analyses using tertiles ( $P$-interaction=0.978). Moreover, the interaction between SLC9A3_rs4957061 and the use of diuretic medication was statistically significant ( $P$-interaction=0.013). The RCC risk was highest for participants with the CC genotype who used diuretic medication [HR(95\%Cl): 2.15(1.23-3.75)]. High sodium intake (tertiles and increment of $1 \mathrm{~g} / \mathrm{d}$ ) and hypertension were associated with a higher risk of RCC, regardless of the SLC9A3_rs4957061 genotype ( $P$-interaction $=0.808,0.827$ and 0.399 , respectively).

Table 4.3 Associations between SNPs in ITM genes and renal cell cancer risk in the NLCS, 1986-2006.

\begin{tabular}{|c|c|c|c|c|c|c|}
\hline \multirow[b]{2}{*}{ SNPs in ITM genes } & \multirow{2}{*}{$\begin{array}{l}\text { Person } \\
\text { years }^{\text {a }}\end{array}$} & \multirow{2}{*}{$\begin{array}{c}\text { RCC } \\
\text { cases }\end{array}$} & \multicolumn{2}{|c|}{ Crude model } & \multicolumn{2}{|c|}{ Age- and sex-adjusted model } \\
\hline & & & $\mathrm{HR}$ & $95 \% \mathrm{Cl}$ & $\mathrm{HR}$ & $95 \% \mathrm{Cl}$ \\
\hline \multicolumn{7}{|l|}{$\overline{A D D 1 \_r s 4961}$} \\
\hline GG & 32,542 & 240 & 1.00 & (ref) & 1.00 & (ref) \\
\hline $\mathrm{GT}+\mathrm{TT}$ & 19,590 & 178 & 1.23 & $(1.00-1.52)$ & 1.24 & $(1.01-1.53)$ \\
\hline$T^{b}$ & 52,133 & 418 & 1.17 & $(0.99-1.38)$ & 1.19 & $(1.00-1.41)$ \\
\hline \multicolumn{7}{|l|}{ ATP1A1_rs850602 } \\
\hline $\mathrm{CC}$ & 30,051 & 239 & 1.00 & (ref) & 1.00 & (ref) \\
\hline$C G+G G$ & 22,064 & 179 & 1.02 & $(0.83-1.25)$ & 1.03 & $(0.84-1.27)$ \\
\hline$G^{b}$ & 52,115 & 418 & 1.06 & $(0.89-1.26)$ & 1.07 & $(0.90-1.27)$ \\
\hline
\end{tabular}


Table $4.3 \quad$ (continued)

\begin{tabular}{|c|c|c|c|c|c|c|}
\hline \multirow[b]{2}{*}{ SNPs in ITM genes } & \multirow{2}{*}{$\begin{array}{l}\text { Person } \\
\text { years }^{a}\end{array}$} & \multirow{2}{*}{$\begin{array}{c}\mathrm{RCC} \\
\text { cases }\end{array}$} & \multicolumn{2}{|c|}{ Crude model } & \multicolumn{2}{|c|}{ Age- and sex-adjusted model } \\
\hline & & & $\mathrm{HR}$ & $95 \% \mathrm{Cl}$ & $\mathrm{HR}$ & $95 \% \mathrm{Cl}$ \\
\hline \multicolumn{7}{|l|}{ ATP1B1_rs2901029 } \\
\hline AA & 17,296 & 135 & 1.00 & (ref) & 1.00 & (ref) \\
\hline$A G+G G$ & 34,847 & 283 & 1.04 & $(0.84-1.30)$ & 1.07 & $(0.85-1.33)$ \\
\hline$G^{b}$ & 52,143 & 418 & 0.97 & $(0.84-1.12)$ & 0.99 & $(0.86-1.14)$ \\
\hline \multicolumn{7}{|l|}{ GNB3_rs1129649 } \\
\hline TT & 22,427 & 192 & 1.00 & (ref) & 1.00 & (ref) \\
\hline $\mathrm{CT}+\mathrm{CC}$ & 29,729 & 227 & 0.89 & $(0.73-1.10)$ & 0.90 & $(0.73-1.10)$ \\
\hline$c^{b}$ & 52,156 & 419 & 0.94 & $(0.81-1.10)$ & 0.96 & $(0.82-1.12)$ \\
\hline \multicolumn{7}{|l|}{ GNB3_rs4963516 } \\
\hline AA & 38,191 & 293 & 1.00 & (ref) & 1.00 & (ref) \\
\hline$A C+C C$ & 13,965 & 126 & 1.18 & $(0.94-1.47)$ & 1.15 & $(0.92-1.45)$ \\
\hline$C^{b}$ & 52,156 & 419 & 1.18 & $(0.96-1.43)$ & 1.16 & $(0.95-1.42)$ \\
\hline \multicolumn{7}{|l|}{ RGS51_rs2815287 } \\
\hline $\mathrm{AA}$ & 20,255 & 1514 & 1.00 & (ref) & 1.00 & (ref) \\
\hline$A C+C C$ & 31,887 & 267 & 1.12 & $(0.91-1.39)$ & 1.13 & $(0.91-1.40)$ \\
\hline$C^{b}$ & 52,142 & 418 & 1.12 & $(0.96-1.30)$ & 1.12 & $(0.96-1.30)$ \\
\hline \multicolumn{7}{|l|}{ RGS5_rs2999967 } \\
\hline TT & 15,541 & 111 & 1.00 & (ref) & 1.00 & (ref) \\
\hline $\mathrm{CT}+\mathrm{CC}$ & 36,594 & 308 & 1.18 & $(0.94-1.49)$ & 1.23 & $(0.97-1.56)$ \\
\hline$c^{b}$ & 52,135 & 419 & 1.10 & $(0.95-1.27)$ & 1.13 & $(0.98-1.31)$ \\
\hline \multicolumn{7}{|c|}{ SCNN1B_rs11645151 } \\
\hline TT & 28,984 & 235 & 1.00 & (ref) & 1.00 & (ref) \\
\hline $\mathrm{CT}+\mathrm{TT}$ & 23,084 & 184 & 0.98 & $(0.80-1.21)$ & 0.99 & $(0.80-1.22)$ \\
\hline$C^{b}$ & 52,069 & 419 & 1.04 & $(0.87-1.23)$ & 1.04 & $(0.87-1.24)$ \\
\hline \multicolumn{7}{|l|}{ SCNN1B_rs239345 } \\
\hline TT & 29,081 & 233 & 1.00 & (ref) & 1.00 & (ref) \\
\hline$A T+A A$ & 23,075 & 186 & 1.01 & $(0.82-1.24)$ & 1.01 & $(0.82-1.24)$ \\
\hline$A^{b}$ & 52,156 & 419 & 1.04 & $(0.88-1.23)$ & 1.04 & $(0.87-1.23)$ \\
\hline \multicolumn{7}{|l|}{ SCNN1G_rs4299163 } \\
\hline GG & 31,805 & 248 & 1.00 & (ref) & 1.00 & (ref) \\
\hline $\mathrm{GC}+\mathrm{CC}$ & 17,990 & 146 & 1.04 & $(0.84-1.29)$ & 1.05 & $(0.86-1.38)$ \\
\hline$C^{b}$ & 49,795 & 394 & 0.99 & $(0.83-1.18)$ & 0.99 & $(0.83-1.17)$ \\
\hline \multicolumn{7}{|l|}{ SLC9A3_rs4957061 } \\
\hline $\mathrm{CC}$ & 13,797 & 109 & 1.00 & (ref) & 1.00 & (ref) \\
\hline $\mathrm{CT}+\mathrm{TT}$ & 35,129 & 297 & 1.07 & $(0.85-1.35)$ & 1.09 & $(0.86-1.38)$ \\
\hline$T^{b}$ & 48,926 & 406 & 0.96 & $(0.84-1.11)$ & 0.97 & $(0.84-1.12)$ \\
\hline \multicolumn{7}{|l|}{ STK39_rs6749447 } \\
\hline $\mathrm{TT}$ & 28,255 & 240 & 1.00 & (ref) & 1.00 & (ref) \\
\hline $\mathrm{GT}+\mathrm{GG}$ & 23,819 & 179 & 0.89 & $(0.72-1.09)$ & 0.88 & $(0.71-1.08)$ \\
\hline$G^{b}$ & 52,075 & 419 & 0.90 & $(0.76-1.06)$ & 0.90 & $(0.76-1.06)$ \\
\hline \multicolumn{7}{|l|}{ WNK1_rs10849563 } \\
\hline AA & 25,065 & 200 & 1.00 & (ref) & 1.00 & (ref) \\
\hline$A G+G G$ & 26,333 & 213 & 1.01 & $(0.82-1.25)$ & 1.01 & $(0.82-1.24)$ \\
\hline$G^{b}$ & 51,398 & 413 & 0.97 & $(0.83-1.12)$ & 0.97 & $(0.83-1.12)$ \\
\hline
\end{tabular}

${ }^{a}$ In the subcohort; ${ }^{b}$ Trend for genotype based on the allelic model. ADD1 = adducin1, ATP1A1 = ATPase $\mathrm{Na}+/ \mathrm{K}+$ transporting alpha 1 polypeptide, ATP1B1 = ATPase $\mathrm{Na}+\mathrm{K}+$ transporting beta 1 polypeptide, GNB3 = guanine nucleotide binding protein (G protein) beta polypeptide 3, ITM = lon transport mechanisms, NLCS = Netherlands Cohort Study, RCC = renal cell cancer, RGS5 = regulator of G-protein signaling 5, SCNN1B = sodium channel non-voltage-gated 1 beta subunit, $S C N N 1 G$ = sodium channel non-voltage-gated 1 gamma subunit, SNPs = single nucleotide polymorphisms, STK39 = serine threonine kinase 39, WNK1 = WNK lysine deficient protein kinase 1. 
Table 4.4 Summary of $P$-values for interaction between dietary intakes, hypertension and use of diuretic medication and SNPs in ITM genes for renal cell cancer risk in the NLCS, 1986-2006.

\begin{tabular}{|c|c|c|c|c|c|}
\hline \multirow[b]{2}{*}{ SNPs in ITM genes ${ }^{c}$} & \multicolumn{5}{|c|}{$P$-interaction ${ }^{\mathrm{a}, \mathrm{b}}$} \\
\hline & $\begin{array}{c}\text { Sodium intake } \\
(\mathrm{g} / \mathrm{d})^{\mathrm{d}}\end{array}$ & $\begin{array}{l}\text { Potassium } \\
\text { intake }(\mathrm{g} / \mathrm{d})^{\mathrm{d}}\end{array}$ & $\begin{array}{l}\text { Fluid intake } \\
(\mathrm{l} / \mathrm{d})\end{array}$ & $\begin{array}{c}\text { Use of diuretic } \\
\text { medication }\end{array}$ & $\begin{array}{c}\text { Doctors' diagnosis } \\
\text { of hypertension }\end{array}$ \\
\hline$A D D 1$ rs4961 & 0.101 & 0.279 & 0.346 & 0.875 & 0.990 \\
\hline ATP1A1_rs850602 & 0.336 & 0.684 & 0.847 & 0.535 & 0.091 \\
\hline ATP1B1_rs2901029 & 0.854 & 0.363 & 0.710 & 0.605 & 0.187 \\
\hline GNB3_rs1129649 & 0.355 & 0.942 & 0.706 & 0.276 & 0.026 \\
\hline GNB3_rs4963516 & 0.518 & 0.529 & 0.895 & 0.633 & 0.552 \\
\hline RGS5_rs2815287 & 0.353 & 0.061 & 0.701 & 0.863 & 0.692 \\
\hline RGS5_rs2999967 & 0.742 & 0.723 & 0.356 & 0.285 & 0.356 \\
\hline SCNN1B_rs11645151 & 0.481 & 0.275 & 0.797 & 0.326 & 0.498 \\
\hline SCNN1B_rs239345 & 0.507 & 0.268 & 0.647 & 0.699 & 0.376 \\
\hline SCNN1G_rs4299163 & 0.233 & 0.069 & 0.860 & 0.059 & 0.109 \\
\hline SLC9A3_rs4957061 & 0.827 & 0.028 & 0.031 & 0.013 & 0.399 \\
\hline STK39_rs6749447 & 0.279 & 0.751 & 0.498 & 0.147 & 0.338 \\
\hline WNK1_rs10849563 & 0.496 & 0.727 & 0.881 & 0.290 & 0.068 \\
\hline
\end{tabular}

${ }^{a}$ Using Wald $\chi^{2}$ test for interaction; ${ }^{b}$ Interaction adjusted for age at baseline (y), sex (men/women), total energy intake (kcal/d), smoking status (never or ex/current), smoking intensity (cig/d), smoking duration (v), BMI $\left(\mathrm{kg} / \mathrm{m}^{2}\right.$ ), alcohol intake (g ethanol/d), hypertension (no/yes) and use of diuretic medication (no/yes); ${ }^{c}$ SNPs are analyzed in a dominant model; ${ }^{d}$ Intakes are energy-adjusted by using the residual mean method. $A D D 1=$ adducin1, ATP1A1 = ATPase $\mathrm{Na}+/ \mathrm{K}+$ transporting alpha 1 polypeptide, $A T P 1 B 1=$ ATPase $\mathrm{Na}+/ \mathrm{K}+$ transporting beta 1 polypeptide, GNB3 = guanine nucleotide binding protein ( $G$ protein) beta polypeptide 3, ITM = Ion transport mechanisms, NLCS = Netherlands Cohort Study, RGS5 = regulator of G-protein signaling $5, S C N N 1 B$ = sodium channel non-voltage-gated 1 beta subunit, SCNN1G = sodium channel non-voltage-gated 1 gamma subunit, SLC9A3 = solute carrier family 9, subfamily A (NHE3, cation proton antiporter 3) member 3, SNPs = single nucleotide polymorphisms, STK39 = serine threonine kinase 39, $W N K 1=$ WNK lysine deficient protein kinase 1 
Table 4.5 Interactions between dietary intakes, hypertension and use of diuretic medication and SLC9A3_rs4957061 for renal cell cancer risk in the NLCS, 1986-2006.

\begin{tabular}{|c|c|c|c|c|c|c|c|c|}
\hline & \multirow{3}{*}{$\begin{array}{c}\text { Person } \\
\text { years }\end{array}$} & \multicolumn{6}{|c|}{ SLC9A3_rs4957061 } & \multirow[b]{3}{*}{$P$-interaction ${ }^{b}$} \\
\hline & & \multicolumn{3}{|c|}{$\mathrm{CC}$} & \multicolumn{3}{|c|}{$\mathrm{CT}+\mathrm{TT}$} & \\
\hline & & Cases & $\mathrm{HR}^{\mathrm{a}}$ & $95 \% \mathrm{Cl}$ & Cases & $H R^{a}$ & $95 \% \mathrm{Cl}$ & \\
\hline \multicolumn{9}{|l|}{ Sodium intake $e^{c, d}$} \\
\hline $\mathrm{T} 1$ & 16,402 & 30 & 1.00 & (ref) & 85 & 1.19 & $(0.77-1.87)$ & \\
\hline $\mathrm{T} 2$ & 16,621 & 34 & 1.13 & $(0.66-1.91)$ & 92 & 1.25 & $(0.80-1.95)$ & \\
\hline T3 & 15,903 & 45 & 1.69 & $(1.02-2.79)$ & 120 & 1.67 & $(1.09-2.56)$ & 0.808 \\
\hline Increment of $1 \mathrm{~g} / \mathrm{d}$ & 48,926 & 109 & 1.33 & (0.91-1.93) & 297 & 1.20 & $(0.99-1.45)$ & 0.827 \\
\hline \multicolumn{9}{|l|}{ Potassium intake $e^{c, d}$} \\
\hline $\mathrm{T} 1$ & 15,969 & 36 & 1.00 & (ref) & 87 & 1.07 & $(0.70-1.63)$ & \\
\hline $\mathrm{T} 2$ & 16,642 & 33 & 1.03 & $(0.62-1.72)$ & 104 & 1.11 & $(0.73-1.68)$ & \\
\hline T3 & 16,316 & 40 & 1.06 & $(0.65-1.73)$ & 106 & 1.20 & $(0.79-1.81)$ & 0.978 \\
\hline Increment of $1 \mathrm{~g} / \mathrm{d}$ & 48,926 & 109 & 0.77 & $(0.54-1.12)$ & 297 & 1.18 & $(0.94-1.49)$ & 0.028 \\
\hline \multicolumn{9}{|l|}{ Fluid intake } \\
\hline Low & 11,281 & 28 & 1.00 & (ref) & 59 & 0.82 & $(0.50-1.34)$ & \\
\hline Moderate & 21,686 & 58 & 1.01 & $(0.61-1.67)$ & 120 & 0.81 & $(0.51-1.28)$ & \\
\hline High & 15,959 & 23 & 0.47 & $(0.26-0.86)$ & 118 & 1.03 & $(0.64-1.65)$ & 0.002 \\
\hline Increment of $1 \mathrm{l} / \mathrm{d}$ & 48,926 & 109 & 0.60 & $(0.36-1.02)$ & 297 & 1.10 & $(0.83-1.46)$ & 0.031 \\
\hline \multicolumn{9}{|l|}{ Hypertension } \\
\hline No & 36,292 & 68 & 1.00 & (ref) & 204 & 1.18 & $(0.88-1.59)$ & \\
\hline Yes & 12,635 & 41 & 1.57 & $(1.01-2.42)$ & 93 & 1.49 & $(1.03-2.15)$ & 0.399 \\
\hline \multicolumn{9}{|c|}{ Use of diuretic medication } \\
\hline No & 43,944 & 85 & 1.00 & (ref) & 267 & 1.25 & $(0.96-1.62)$ & \\
\hline yes & 4,982 & 24 & 2.15 & $(1.23-3.75)$ & 30 & 1.16 & $(0.71-1.87)$ & 0.013 \\
\hline
\end{tabular}

${ }^{\mathrm{a}}$ HRs are adjusted for age at baseline (y), sex (men/women), total energy intake (kcal/d), smoking status (never or ex/current), smoking intensity (cig/d), smoking duration (y), BMI $\left(\mathrm{kg} / \mathrm{m}^{2}\right)$, alcohol intake $(\mathrm{g}$ ethanol/d), hypertension (no/yes) and use of diuretic medication (no/yes); ${ }^{b}$ Using Wald $\chi^{2}$ test for interaction; ${ }^{c}$ Tertile distribution is sex-specific and based on subcohort members; ${ }^{d}$ Intakes are energyadjusted by using the residual mean method. $\mathrm{BMI}=$ body mass index, cig = cigarettes, NLCS $=$ Netherlands Cohort Study, SLC9A3 = solute carrier family 9, subfamily A (NHE3, cation proton antiporter 3 ) member 3

\section{DISCUSSION}

In the present population-based cohort study, we investigated 13 candidate SNPs in ten ITM genes in relation to RCC risk. Data does not support the general hypothesis that genetic variation in ITM genes may influence RCC susceptibility, because only one of these SNPs, ADD1_rs4961, was significantly associated with RCC risk. We additionally investigated potential gene-environment interactions between these genes and exposures that may also be implicated in ion transport in the kidney, including dietary intakes of sodium, potassium and fluid, hypertension and the use of diuretic medication. Although significant gene-environment interactions clustered in one SNP, SLC9A3_rs4957061, data does not support the general hypothesis that geneenvironment interactions related to ITMs are of interest in RCC etiology. 
Of the 13 investigated candidate SNPs, only ADD1_rs4961 was significantly associated with RCC risk. The $A D D 1$ gene encodes for $\alpha$-adducin, a ubiquitously expressed cytoskeleton protein implicated in the formation of actin-spectrin complex, actin polymerization and cell signal transduction [31,32] and has, to our knowledge, not previously been investigated in relation to RCC risk. Lin et al. concluded that the $\mathrm{G}$ allele of $A D D 1$ rs4961 might modulate the decline of renal function in healthy elderly Chinese [33]. In contrast, we observed the highest RCC risk for the GT+TT (versus GG) genotype. The $A D D 1$ gene was selected as candidate gene, because genetic variations in this gene have been associated with hypertension [34-36]. We observed no significant gene-environment interaction between the candidate SNP, ADD1_rs4961, and hypertension in relation to RCC risk. In addition, the variant genotype of $A D D 1$ rs4961 is believed to induce proximal tubule sodium reabsorption [37], but we observed no significant interactions between this SNP and sodium intake.

The observed significant gene-environment interactions were all clustered in one SNP, i.e. SLC9A3_rs4957061. The SLC9A3 gene encodes the $\mathrm{Na}^{+} / \mathrm{H}^{+}$exchanger 3 (NHE3), which is the major sodium transporter on the apical membrane of the renal proximal tubule cells [38]. This is of particular importance for RCC, as the majority of RCC tumors are thought to arise from the proximal renal tubule [39]. Animal studies, as well as studies in hypertensive patients suggest that this gene is important in the control of blood pressure through its effect on sodium transport [40-42]. It is however remarkable that the observed gene-environment interactions for SLC9A3_rs4957061 did not include hypertension or sodium intake, but potassium intake, fluid intake and use of diuretic medication. In Cox regression analyses, RCC risk estimates for fluid intake were similar in both continuous and categorical analyses; the highest intake was associated with a lower RCC risk for participants with the SLC9A3_rs4957061 reference genotype and not for participants with the variant genotype. Previously, we reported that there was no overall association between fluid intake and RCC risk present in this study population, after 17.3 years of follow-up [8].

Some of the candidate SNPs investigated in the present study are SNPS in SCNN1B and $S C N N 1 G$. These genes may be involved in the salty taste transduction pathway in the KEGG pathway database [43] and have previously been associated with salt taste responses in mice [29]. Therefore, these genes may be of particular importance in the association between sodium intake and RCC risk. We hypothesised that SNP-related interindividual variation in the SCNN1B and SCNN1G genes may determine one's perceived saltiness and ultimately the actual sodium intake. We could not confirm our hypothesis, because none of the SNPS in SCNN1B and SCNN1G were associated with perceived saltiness in the subcohort.

Several methodological considerations should be noted as to interpret the results of the present study. Given the prospective study design and the high ascertainment of 
RCC cases, selection bias and information bias are unlikely in the NLCS. The long follow-up provided sufficient number of cases for the current analyses, but may also have introduced some random misclassification regarding dietary intakes, which were calculated from a single measurement at baseline. In addition, it is possible that the proportions of participants with hypertension and diuretic medication use may slightly be underestimated using this single measurement. Both might have resulted in attenuation of the investigated gene-environment interactions. Moreover, different action mechanisms of various diuretics (e.g. potassium sparing) may have influenced the results. Information on the exact type of diuretic medication was not available. Finally, the results of two SNPS in particular, i.e. SCNN1G_rs4299163 and WNK1_rs10849563, should be interpreted with care, as they were not in HWE in our subcohort.

For the present study, we used a candidate SNP approach and selected SNPs based on prior knowledge from current literature. SNPs were not selected based on GWAS results, as these SNPs tend to have a relatively lower MAF and higher penetrance, while SNPs with high MAF and low penetrance may be the ones to be more likely involved in gene-environment interactions [6]. Our initial SNP selection rendered too many potential SNPs of interest for the limited space available on the multiplex design. The 13 SNPs in ten ITM genes that were successfully genotyped cover only a fraction of the large and complex network of genetic and environmental factors in which the investigated SNPs are included. As a result, true effects might still be diluted or masked by effects of those SNPs not included in the present study. In addition, the null results in the present study do not exclude the possibility that other SNPs in these genes or SNPs in other ITM genes may influence RCC susceptibility.

In conclusion, results from the present study show some first indications of involvement of ADD1_rs4961 and SLC9A3_rs4957061 in RCC susceptibility. However, results do not support the general hypothesis that the ITMs are a type of underlying disease mechanism in RCC etiology, since SNPs in ITM genes and gene-environment interactions among these SNPs with related exposures were mostly not associated with RCC risk. 


\section{REFERENCES}

1. Chow WH, Dong LM, Devesa SS. Epidemiology and risk factors for kidney cancer. Nat Rev Urol 2010; 7:245-57.

2. Wu X, Scelo G, Purdue MP, Rothman N, Johansson M, Ye Y, Wang Z, Zelenika D, Moore LE, Wood CG, Prokhortchouk E, Gaborieau V, Jacobs KB, Chow WH, Toro JR, Zaridze D, Lin J, Lubinski J, Trubicka J, Szeszenia-Dabrowska N, Lissowska J, Rudnai P, Fabianova E, Mates D, Jinga V, Bencko V, Slamova A, Holcatova I, Navratilova M, Janout V, Boffetta P, Colt JS, Davis FG, Schwartz KL, Banks RE, Selby PJ, Harnden P, Berg CD, Hsing AW, Grubb RL 3rd, Boeing H, Vineis $P$, Clavel-Chapelon F, Palli D, Tumino R, Krogh V, Panico S, Duell EJ, Quirós JR, Sanchez MJ, Navarro C, Ardanaz E, Dorronsoro M, Khaw KT, Allen NE, Bueno-de-Mesquita HB, Peeters PH, Trichopoulos D, Linseisen J, Ljungberg B, Overvad K, Tjønneland A, Romieu I, Riboli E, Stevens VL, Thun MJ, Diver WR, Gapstur SM, Pharoah PD, Easton DF, Albanes D, Virtamo J, Vatten L, Hveem K, Fletcher T, Koppova K, Cussenot O, Cancel-Tassin G, Benhamou S, Hildebrandt MA, Pu X, Foglio M, Lechner D, Hutchinson A, Yeager M, Fraumeni JF Jr, Lathrop M, Skryabin KG, McKay JD, Gu J, Brennan P, Chanock SJ. A genome-wide association study identifies a novel susceptibility locus for renal cell carcinoma on 12p11.23. Hum Mol Genet 2012;21: 456-62.

3. Purdue MP, Johansson M, Zelenika D, Toro JR, Scelo G, Moore LE, Prokhortchouk E, Wu X, Kiemeney LA, Gaborieau V, Jacobs KB, Chow WH, Zaridze D, Matveev V, Lubinski J, Trubicka J, SzeszeniaDabrowska N, Lissowska J, Rudnai P, Fabianova E, Bucur A, Bencko V, Foretova L, Janout V, Boffetta P, Colt JS, Davis FG, Schwartz KL, Banks RE, Selby PJ, Harnden P, Berg CD, Hsing AW, Grubb RL 3rd, Boeing $\mathrm{H}$, Vineis $\mathrm{P}$, Clavel-Chapelon F, Palli D, Tumino R, Krogh V, Panico S, Duell EJ, Quirós JR, Sanchez MJ, Navarro C, Ardanaz E, Dorronsoro M, Khaw KT, Allen NE, Bueno-de-Mesquita HB, Peeters PH, Trichopoulos D, Linseisen J, Ljungberg B, Overvad K, Tjønneland A, Romieu I, Riboli E, Mukeria A, Shangina O, Stevens VL, Thun MJ, Diver WR, Gapstur SM, Pharoah PD, Easton DF, Albanes D, Weinstein SJ, Virtamo J, Vatten L, Hveem K, Njølstad I, Tell GS, Stoltenberg C, Kumar R, Koppova K, Cussenot O, Benhamou S, Oosterwijk E, Vermeulen SH, Aben KK, van der Marel SL, Ye Y, Wood CG, Pu $X$, Mazur AM, Boulygina ES, Chekanov NN, Foglio M, Lechner D, Gut I, Heath S, Blanche H, Hutchinson A, Thomas G, Wang Z, Yeager M, Fraumeni JF Jr, Skryabin KG, McKay JD, Rothman N, Chanock SJ, Lathrop $M$, Brennan P. Genome-wide association study of renal cell carcinoma identifies two susceptibility loci on 2p21 and 11q13.3. Nat Genet 2011;43:60-5.

4. Henrion M, Frampton M, Scelo G, Purdue M, Ye Y, Broderick P, Ritchie A, Kaplan R, Meade A, McKay J, Johansson M, Lathrop M, Larkin J, Rothman N, Wang Z, Chow WH, Stevens VL, Ryan Diver W, Gapstur SM, Albanes D, Virtamo J, Wu X, Brennan P, Chanock S, Eisen T, Houlston RS. Common variation at 2q22.3 (ZEB2) influences the risk of renal cancer. Hum Mol Genet 2013;22:825-31.

5. Gudmundsson J, Sulem P, Gudbjartsson DF, Masson G, Petursdottir V, Hardarson S, Gudjonsson SA, Johannsdottir H, Helgadottir HT, Stacey SN, Magnusson OT, Helgason H, Panadero A, van der Zanden LF, Aben KK, Vermeulen SH, Oosterwijk E, Kong A, Mayordomo JI, Sverrisdottir A, Jonsson E, Gudbjartsson T, Einarsson GV, Kiemeney LA, Thorsteinsdottir U, Rafnar T, Stefansson K. A common variant at 8q24.21 is associated with renal cell cancer. Nat Commun 2013;4:2776.

6. Shields PG, Harris CC. Cancer risk and low-penetrance susceptibility genes in gene-environment interactions. J Clin Oncol 2000;18:2309-15.

7. Hunter DJ. Gene-environment interactions in human diseases. Nat Rev Genet 2005;6:287-98.

8. Deckers IA, van den Brandt PA, van Engeland M, Soetekouw PM, Baldewijns MM, Goldbohm RA, Schouten LJ. Long-term dietary sodium, potassium and fluid intake; exploring potential novel risk factors for renal cell cancer in the Netherlands Cohort Study on diet and cancer. Br J Cancer 2014; 110:797-801.

9. Deckers IA, van den Brandt PA, van Engeland M, van Schooten FJ, Godschalk RW, Keszei AP, Schouten $\sqcup$. Polymorphisms in genes of the renin-angiotensin-aldosterone system and renal cell cancer risk: Interplay with hypertension and intakes of sodium, potassium and fluid. Int J Cancer 2015;113: 1104-16.

10. Rose BD, Post TW. Clinical Physiology of acid-base and electrolyte disorders. 5th edition ed. 2001, New York: McGraw-Hill, Medical Publishing Division. 
11. Djamgoz MB, Coombes RC, Schwab A. Ion transport and cancer: from initiation to metastasis. Philos Trans R Soc Lond B Biol Sci 2014;369:20130092.

12. Dupont AG. The place of diuretics in the treatment of hypertension: a historical review of classical experience over 30 years. Cardiovasc Drugs Ther 1993;7 Suppl 1:55-62.

13. Goldbohm RA, van den Brandt PA, Brants HA, van't Veer P, Al M, Sturmans F, Hermus RJ. Validation of a dietary questionnaire used in a large-scale prospective cohort study on diet and cancer. Eur J Clin Nutr 1994;48:253-65.

14. Goldbohm RA, van 't Veer P, van den Brandt PA, van 't Hof MA, Brants HA, Sturmans F, Hermus RJ. Reproducibility of a food frequency questionnaire and stability of dietary habits determined from five annually repeated measurements. Eur J Clin Nutr 1995;49:420-9.

15. Van den Brandt PA1, Goldbohm RA, van 't Veer P, Volovics A, Hermus RJ, Sturmans F. A large-scale prospective cohort study on diet and cancer in The Netherlands. J Clin Epidemiol 1990;43:285-95.

16. Prentice RL. On the design of synthetic case-control studies. Biometrics 1986;42:301-10.

17. Van den Brandt PA, Schouten LJ, Goldbohm RA, Dorant E, Hunen PM. Development of a record linkage protocol for use in the Dutch Cancer Registry for Epidemiological Research. Int J Epidemiol 1990;19:553-8.

18. Goldbohm RA, Van den Brandt PA, Dorant E. Estimation of the coverage of Dutch municipalities by cancer registries and PALGA based on hospital discharge data. Tijdschr Soc Gezondheidsz 1994;72: 80-4.

19. van Breda SG, Hogervorst JG, Schouten L, Knaapen AM, van Delft JH, Goldbohm RA, van Schooten FJ, van den Brandt PA. Toenails: an easily accessible and long-term stable source of DNA for genetic analyses in large-scale epidemiological studies. Clin Chem 2007;53:1168-70.

20. van Houwelingen KP, van Dijk BA, Hulsbergen-van de Kaa CA, Schouten LJ, Gorissen HJ, Schalken JA, van den Brandt PA, Oosterwijk E. Prevalence of von Hippel-Lindau gene mutations in sporadic renal cell carcinoma: results from The Netherlands cohort study. BMC Cancer 2005;5:57.

21. Oeth P. iPLEX TM Assay: Increased Plexing Efficiency and Flexibility for MassARRAY ${ }^{\circledR}$ System Through Single Base Primer Extension with Mass-Modified Terminators.

22. Hogervorst JG, Godschalk RW, van den Brandt PA, Weijenberg MP, Verhage BA, Jonkers L, Goessens J, Simons CC, Vermeesch JR, van Schooten FJ, Schouten LJ. DNA from Nails for Genetic Analyses in Large-Scale Epidemiologic Studies. Cancer Epidemiol Biomarkers Prev 2014;23:2703-12.

23. Nevo tabel, Dutch food composition table 1986-1987; Nederlands voedingsstoffenbestand 19861987. 1986, The Hague, The Netherlands: Voorlichtingsbureau voor de Voeding.

24. Willett W, Stampfer MJ. Total energy intake: implications for epidemiologic analyses. Am J Epidemiol 1986;124:17-27.

25. van den Brandt PA, Botterweck AA, Goldbohm RA. Salt intake, cured meat consumption, refrigerator use and stomach cancer incidence: a prospective cohort study (Netherlands). Cancer Causes Control 2003;14:427-38.

26. Anonymous. About the ATC/DDD system. 2004 [cited 200425 october 2004]; Available from: http://www.whocc.no/atcddd/.

27. Van den Brandt PA, Petri H, Dorant E, Goldbohm RA, Van de Crommert S. Comparison of questionnaire information and pharmacy data on drug use. Pharm Weekbl [Sci] 1991;13:91-6.

28. Barlow WE. Robust variance estimation for the case-cohort design. Biometrics 1994;50:1064-72.

29. Shigemura N, Ohkuri T, Sadamitsu C, Yasumatsu K, Yoshida R, Beauchamp GK, Bachmanov AA, Ninomiya $\mathrm{Y}$. Amiloride-sensitive $\mathrm{NaCl}$ taste responses are associated with genetic variation of $\mathrm{ENaC}$ alpha-subunit in mice. Am J Physiol Regul Integr Comp Physiol 2008;294:R66-75.

30. Barrett JC, Fry B, Maller J, Daly MJ. Haploview: analysis and visualization of LD and haplotype maps. Bioinformatics 2005;21:263-5.

31. Hughes CA, Bennett V. Adducin: a physical model with implications for function in assembly of spectrin-actin complexes. J Biol Chem 1995;270:18990-6.

32. Matsuoka Y, Li X, Bennett V. Adducin: structure, function and regulation. Cell Mol Life Sci 2000; 57:884-95.

33. Lin TH, Chiu HC, Wang CL, Hsu PC, Su HM, Voon WC, Lai WT, Sheu SH. The Gly460Trp polymorphism of alpha-adducin gene as a predictor of renal function decline over 4 years of follow-up in an apparently healthy Chinese population. Transl Res 2012;160:162-3. 
34. Casari G, Barlassina C, Cusi D, Zagato L, Muirhead R, Righetti M, Nembri P, Amar K, Gatti M, Macciardi F, et al. Association of the alpha-adducin locus with essential hypertension. Hypertension 1995;25: 320-6.

35. Cusi D, Barlassina C, Azzani T, Casari G, Citterio L, Devoto M, Glorioso N, Lanzani C, Manunta P, Righetti M, Rivera R, Stella P, Troffa C, Zagato L, Bianchi G. Polymorphisms of alpha-adducin and salt sensitivity in patients with essential hypertension. Lancet 1997;349:1353-7.

36. Wang JG, Liu L, Zagato L, Xie J, Fagard R, Jin K, Wang J, Li Y, Bianchi G, Staessen JA, Liu L. Blood pressure in relation to three candidate genes in a Chinese population. J Hypertens 2004;22:937-44.

37. Manunta P, Cusi D, Barlassina C, Righetti M, Lanzani C, D'Amico M, Buzzi L, Citterio L, Stella P, Rivera $\mathrm{R}$, Bianchi $\mathrm{G}$. Alpha-adducin polymorphisms and renal sodium handling in essential hypertensive patients. Kidney Int 1998; 53:1471-8.

38. Schultheis PJ, Clarke LL, Meneton P, Miller ML, Soleimani M, Gawenis LR, Riddle TM, Duffy JJ, Doetschman T, Wang T, Giebisch G, Aronson PS, Lorenz JN, Shull GE. Renal and intestinal absorptive defects in mice lacking the NHE3 Na+/H+ exchanger. Nat Genet 1998;19:282-5.

39. Pavlovich CP, Schmidt LS. Searching for the hereditary causes of renal-cell carcinoma. Nat Rev Cancer 2004;4:381-93.

40. Burnier M, Biollaz J, Magnin JL, Bidlingmeyer M, Brunner HR. Renal sodium handling in patients with untreated hypertension and white coat hypertension. Hypertension 1994;23:496-502.

41. Hayashi M, Yoshida T, Monkawa T, Yamaji Y, Sato S, Saruta T. Na+/H+-exchanger 3 activity and its gene in the spontaneously hypertensive rat kidney. J Hypertens 1997;15:43-8.

42. Kelly MP, Quinn PA, Davies JE, Ng LL. Activity and expression of $\mathrm{Na}(+)-\mathrm{H}+$ exchanger isoforms 1 and 3 in kidney proximal tubules of hypertensive rats. Circ Res 1997;80:853-60.

43. Laboratories, K. KEGG pathway database. 1995-2014 January 28, 2014 [cited 2014 February 17]; Available from: http://www.kegg.jp/kegg/pathway.html. 
PART III

Tumor heterogeneity 


\section{CHAPTER 5}

\section{Promoter CpG island methylation in ion transport mechanisms and associated dietary intakes jointly influence the risk of clear-cell renal cell cancer}

Ivette AG Deckers, Manon van Engeland, Piet A van den Brandt, Leander Van Neste, Patricia MMB Soetekouw, Maureen JB Aarts, Marcella MLL Baldewijns, András P Keszei and Leo J Schouten 


\section{ABSTRACT}

\section{Introduction}

Sodium intake, but not potassium and fluid intake, has been associated with higher renal cell cancer (RCC) risk. However, risk factors may differ by molecular subtypes of the tumor. In renal physiology, electrolyte and water homeostasis is facilitated by ion transport mechanisms (ITMs). Aberrant regulation of ITM genes, for example by promoter CpG island methylation, may modify associations between sodium, potassium and fluid intake and RCC risk.

\section{Methods}

We identified ARHGDIG, ATP1A1, SCNN1B and SLC8A3 as ITM genes exhibiting RCC-specific promoter methylation and down-regulation. Methylation-specific PCR was used to analyze promoter CpG island methylation in tumor DNA of 453 RCC cases from the Netherlands Cohort Study $(n=120,852)$ after 20.3 years of follow-up. Diet was measured at baseline using foodfrequency questionnaires. Cox regression analyses were restricted to clear-cell (cc)RCC ( $n=306)$ and stratified by tumors with no, low (1 gene) and high ( $\geq 2$ genes) methylation.

\section{Results}

Sodium intake (high versus low) increased ccRCC risk particularly in tumors with a high methylation index $[\mathrm{HR}(95 \% \mathrm{Cl}): 2.04(1.16-3.58)]$, while heterogeneity across the methylation index was not significant $(P$-heterogeneity $=0.26)$. Potassium intake was differentially associated with ccRCC risk ( $P$-heterogeneity=0.008); the risk for high (versus low) potassium intake was low for unmethylated tumors $[\mathrm{HR}(95 \% \mathrm{Cl}): 0.60(0.36-1.01)]$, but high for tumors with a high methylation index [HR(95\% $\mathrm{Cl}): 1.60(0.96-2.65)]$. Risks similarly differed for fluid intake, though not significantly $(P$-heterogeneity $=0.54)$.

\section{Conclusion}

Our findings suggest for the first time a joint influence of dietary intakes and ITM gene-specific promoter methylation in relation to ccRCC risk, indicating a role for ITMs in ccRCC etiology. 


\section{INTRODUCTION}

The regulation of electrolyte and water homeostasis is a key aspect of renal physiology and is, in the kidney, achieved by tubular reabsorption and secretion of water and solutes, such as sodium and potassium [1]. Transcellular reabsorption and secretion of solutes is facilitated by protein carriers or ion-specific channels [1]. Iontransport mechanisms (ITMs), including ion channels, transporters, exchangers, pumps and associated enzymes, have recently been put forward as novel mechanisms underlying carcinogenesis [2]. Given their role in renal physiology, ITMs may be involved in the pathophysiology of renal cell cancer (RCC).

Previously, we reported that sodium intake, but not potassium or fluid intake, was associated with RCC risk in the Netherlands Cohort Study on diet and cancer (NLCS) [3]. However, consensus has emerged that to better understand the etiological mechanisms of human cancers the molecular characterization of the tumor should be considered [4]. Therefore, it is worthwhile to further investigate these risk factors based on such characterization.

Promoter $\mathrm{CpG}$ island methylation is a frequently observed mechanism in gene silencing and occurs more often than genetic inactivation in many tumor types [5-7]. Few studies have focused on promoter CpG island methylation of genes involved in ITMs in relation to RCC [8,9]. Promoter CpG island methylation of genes involved in ITMs may be particularly useful for the molecular characterization of RCC when studying risk factors related to ITMs, as aberrant regulation of ITM gene expression by promoter CpG island methylation may sensitize individuals to the effects of dietary intakes of sodium, potassium and fluid.

In the present study, we use data from the NLCS to investigate if associations between dietary intakes of sodium, potassium and fluid and the RCC risk differ among tumors according to a promoter $\mathrm{CpG}$ island methylation index of genes regulating iontransport or homeostasis.

\section{METHODS}

\section{Study design and study population}

The NLCS is a prospective cohort study that was initiated in 1986 and included 120,852 participants aged 55-69 years at baseline [10]. The NLCS was designed as case-cohort study for efficiency in questionnaire processing and follow-up. Cases were derived from the entire cohort, whereas a subcohort of 5,000 subjects was randomly sampled at baseline to estimate person years at risk for the entire cohort [11]. 
Subcohort members were regularly followed up for vital status information, whereas all cohort members were followed up for cancer occurrence using record linkage with the Netherlands cancer registry and with the Dutch pathology registry (PALGA) [12]. The coverage of cohort members by the Netherlands cancer registry and PALGA to establish cancer follow-up is estimated to be over 96\% [13]. Cases and subcohort members with prevalent cancer (excluding skin cancer) at baseline were excluded. A unique population-based collection of DNA material of RCC cases is nested within the NLCS. Initially, this collection of DNA material included only cases from the first 11.3 years of follow-up [14], yet recently efforts were made to expand the collection up to 20.3 years of follow-up.

\section{Tissue collection and DNA isolation}

A total of 608 RCC cases were identified within the NLCS between 1986 and 2006. Only histologically confirmed epithelial RCC cases $(n=568)$ were eligible for the collection of formalin-fixed paraffin-embedded (FFPE) tumor tissues from $\sim 50$ pathology laboratories throughout the Netherlands. Overall, $79.8 \%$ of the FFPE tumor tissues were retrieved $(n=453)$. Inclusion was lowest for cases identified during the first 5 -years of follow-up (71.3\%), because the Dutch pathology registry (PALGA) had incomplete coverage during this period and some pathological laboratories had problems to locate older tissues in particular. The inclusion over the 5-year follow-up periods $1991-1995$ and $1996-2000$ was $87.7 \%$ and $84.6 \%$, respectively. In the period between 2001 and 2006 the inclusion was $73.7 \%$, because we were unable to retrieve tissues from two pathology laboratories in our recent efforts to expand the collection. In total, the collection of FFPE tumor tissues was unsuccessful for 115 cases; 46 cases had no surgery, for 24 cases the availability or location of their tissues was unknown from the Dutch pathology registry (PALGA) and, for 45 cases the pathological laboratory refused or was unable to send their tissues. There were no differences on potential confounders and exposures under study (i.e. age, sex, BMI, smoking, alcohol intake, hypertension, energy intake and dietary sodium, potassium and fluid intake) between eligible incident RCC cases with and without successful DNA collection. Haematoxylin and eosin (HE)-stained slides of all the collected FFPE tumor tissues were assessed by an experienced genitourinary pathologist (Marcella MLL Baldewijns) to confirm tumor histology based on the WHO-classification of tumors [15]. Based on this assessment, our collection of RCC cases includes 365 (80.6\%) clear-cell (cc)RCC cases, 60 (13.3\%) papillary (p)RCC cases, 15 (3.3\%) chromophobe (chr)RCC cases and $13(2.8 \%)$ other or undefined RCC cases. Additional classification of pRCC cases, resulted in 35 (7.7\%) type 1 pRCC, 24 (5.3\%) type 2 pRCC and $1(0.2 \%)$ undefined pRCC.

Methods used for DNA isolation of FFPE tissues from RCC cases identified during the first 11.3 years of follow-up included in the initial collection have been described 
previously [14]. For recently added RCC cases, vital tissue areas were dissected before DNA isolation. DNA was isolated using the QIAamp DNA Mini Kit (Qiagen), according to manufacturer's instructions.

\section{Dietary assessment}

All NLCS participants returned a mailed, self-administered, baseline questionnaire, including a 150-item, semi-quantitative food-frequency questionnaire (FFQ), which was used to assess intakes of sodium, potassium and fluid before diagnosis. Participants with incomplete dietary questionnaires were excluded, leaving 4,439 subcohort members and 434 cases eligible for analyses [16]. The FFQ ranked individuals adequately according to dietary intakes when compared to a nine-day dietary records [16], and reflected nutrient intakes for at least 5 years [17]. Average daily nutrient intakes were calculated using the Dutch food composition table 1986-87 [18] and defined as intakes through foods and beverages per day, including amounts naturally present in foods and beverages plus amounts added during food processing by food manufacturers. Salt (sodium-chloride) added during home-preparation and before consumption (i.e. discretionary salt intake) was assessed separately using specific questions $[3,19]$.

\section{Gene selection}

The KEGG pathway database was used to identify candidate genes involved in ITMs [20]. Genes were of interest if exhibiting 1) promoter CpG island methylation (-2000 to +500 bp from transcription start site) in ccRCC cell lines (SKRC1, SKRC10, SKRC52 and SKRC59) and not in a normal kidney cell line (HK-2) in a genome-wide methylation screen (MBD-affinity massive parallel sequencing; data not shown) and 2) cancerspecific down-regulation among ccRCC and adjacent normal tissues in publically available expression data. Using this selection strategy we selected: Rho GDP dissociation inhibitor gamma (ARHGDIG), which is involved in vasopressin-related water reabsorption; ATPase $\mathrm{Na}+\mathrm{K}+$ transporting alpha 1 polypeptide (ATP1A1) and sodium channel non-voltage-gated 1 beta subunit (SCNN1B), which are involved in aldosterone-regulated sodium reabsorption and; solute carrier family 8 member 3 (SLC8A3), which is a sodium to calcium exchanger in the calcium signaling pathway.

\section{Promoter methylation}

Promoter $\mathrm{CpG}$ island hypermethylation, in short promoter methylation, was analyzed using nested methylation-specific PCR (MSP), as previously described elsewhere [21-23]. MSP primer design was based on the MBD-affinity massive parallel sequencing data. Primer sequences and MSP conditions are shown in Suppl Table S5.1. MSP analyses of ARHGDIG, ATP1A1, SCNN1B and SLC8A3 were performed successfully for $98.5 \%, 97.8 \%, 92.7 \%$ and $96.7 \%$ out of the 453 RCC cases, respectively. 
A methylation index was calculated combining all four individual genes into three subgroups representing tumors with no ( 0 of 4 genes methylated), low ( 1 of 4 genes methylated) and high ( $\geq 2$ of 4 genes methylated) methylation. Proportions of promoter methylation are shown in Table 5.1. Additionally, we successfully performed MSP analyses of all genes in adjacent normal FFPE tissues of 42 ccRCC cases selected to represent the full spectrum of the methylation index to evaluate if the observed promoter methylation was cancer-specific.

Table 5.1 Proportions of promoter methylation of ARHGDIG, ATP1A1, SCNN1B and SLC8A3 in renal cell tumors and in histological subtypes of renal cell tumors, NLCS 1986-2006.

\begin{tabular}{|c|c|c|c|c|c|}
\hline \multirow[b]{2}{*}{ Gene } & \multirow[b]{2}{*}{ Overall RCC (n (\%)) } & \multicolumn{4}{|c|}{ Histological subtypes } \\
\hline & & $\operatorname{ccRCC}(\mathrm{n}(\%))$ & $\mathrm{pRCC}(\mathrm{n}(\%))$ & $\operatorname{chrRCC}(\mathrm{n}(\%))$ & $P$-value ${ }^{\mathrm{a}}$ \\
\hline Total (n) & $453(100.0)$ & $365(80.6)$ & $60(13.3)$ & $15(3.3)$ & - \\
\hline \multicolumn{6}{|l|}{ ARHGDIG } \\
\hline no & $351(78.7)$ & 277 (76.9) & $54(91.5)$ & $9(60.0)$ & \\
\hline yes & $95(21.3)$ & $83(23.1)$ & $5(8.5)$ & $6(40.0)$ & 0.005 \\
\hline \multicolumn{6}{|l|}{ ATP1A1 } \\
\hline no & $373(84.2)$ & $301(84.1)$ & $48(82.8)$ & $14(93.3)$ & \\
\hline yes & $70(15.8)$ & $57(15.9)$ & $10(17.2)$ & $1(6.7)$ & 0.68 \\
\hline \multicolumn{6}{|l|}{ SCNN1B } \\
\hline no & $237(56.4)$ & $182(54.0)$ & $39(67.2)$ & $10(71.4)$ & \\
\hline yes & $183(43.6)$ & $155(46.0)$ & $19(32.8)$ & $4(28.6)$ & 0.09 \\
\hline \multicolumn{6}{|l|}{ SLC8A3 } \\
\hline no & $369(84.3)$ & $288(81.8)$ & $57(96.6)$ & $14(93.3)$ & \\
\hline yes & $69(15.8)$ & $64(18.2)$ & $2(3.4)$ & $1(6.7)$ & 0.004 \\
\hline \multicolumn{6}{|c|}{ Methylation index ${ }^{b}$} \\
\hline 0 & $178(44.1)$ & $134(41.2)$ & $32(58.2)$ & $7(50.0)$ & \\
\hline 1 & $107(26.5)$ & $88(27.1)$ & $14(25.5)$ & $4(28.6)$ & \\
\hline $2-4$ & $119(29.5)$ & $103(31.7)$ & $9(16.4)$ & $3(21.4)$ & 0.109 \\
\hline
\end{tabular}

${ }^{\mathrm{a}} P$-value for difference among histological subtypes calculated using Fisher's exact test; ${ }^{\mathrm{b}}$ Numbers do not add up to total due to missing values. $A R H G D I G=$ Rho GDP dissociation inhibitor gamma, ATP1A1 = ATPase $\mathrm{Na}+/ \mathrm{K}+$ transporting alpha 1 polypeptide, $c \mathrm{RCC}=$ clear-cell $\mathrm{RCC}, \mathrm{chrRCC}=$ chromophobe $\mathrm{RCC}, \mathrm{pRCC}=$ papillary RCC, RCC = renal cell cancer, $S C N N 1 B=$ sodium channel non-voltage-gated 1 beta subunit, SLC8A3 $=$ solute carrier family 8 member 3 .

\section{Statistical analyses}

All analyses were conducted in Stata version 12 (Stata Corp., College Station, TX). Associations between sodium, potassium and fluid intake and RCC risk, were performed for total RCC and by histological subtype. Analyses including the methylation index were restricted to ccRCC cases, as for other histological subtypes the statistical power was too low. Hazard ratios (HR) and 95\% confidence intervals (CI) were estimated using Cox proportional hazards analyses adjusted for the case-cohort design [24]. Analyses were performed for an age- and sex-adjusted model and a multivariable-adjusted model, including a priori selected potential confounders: age at baseline (y), sex (men/women), total energy intake (kcal/d), body mass index $\left(\mathrm{BMl} ; \mathrm{kg} / \mathrm{m}^{2}\right)$, smoking status (never or ex/current), smoking duration $(\mathrm{y})$, smoking 
intensity (cigarettes/d), self-reported doctors' diagnosis of hypertension and/or use of antihypertensive medication (no/yes) and alcohol consumption (g ethanol/d). Analyses regarding sodium intake $(\mathrm{g} / \mathrm{d})$ were additionally adjusted for discretionary salt intake in sensitivity analyses. The proportional hazards assumption was tested using the scaled Schoenfeld residuals. A violation was apparent for alcohol consumption, which was therefore analysed as time dependent covariate. Tests for heterogeneity were performed to evaluate differences across tumors with different promoter methylation profiles, using an adapted version of the competing risks procedure in Stata developed for the case-cohort design, as described previously $[25,26]$. All tests were two-sided. A $P$-value $<0.05$ is considered statistically significant.

\section{RESULTS}

The prevalence of promoter methylation of ARHGDIG, ATP1A1, SCNN1B and SLC8A3 in ccRCC tumors was $23.1 \%, 15.9 \%, 46.0 \%$ and $18.2 \%$, respectively (Table 5.1 ). To verify these proportions, probes matching the MSP regions were identified in The Cancer Genome Atlas (TCGA) CCRCC database. For SLC8A3 a probe in the same region as the MSP amplicon indicated a prevalence of 16.6-22.5\%. Neighboring probes were identified for ARHGDIG and SCNN1B, with estimated prevalence's of $12.8-22.1 \%$ and 22.0-27.8\%, respectively. For ATP1A1 no suitable probes could be identified. We observed substantial differences in proportions of promoter methylation among the histological subtypes of RCC, though these differences only statistically significant for ARHGDIG and SLC8A3 ( $P$-value $=0.005$ and 0.004, respectively). The methylation index did not significantly differ across the histological subtypes ( $P$-value $=0.109)$.

At baseline, ccRCC cases and subcohort members are relatively similar, except that ccRCC cases were more frequently male (Table 5.2). Among ccRCC cases, those with a high methylation index had a higher baseline potassium intake, a higher BMI and less frequently hypertension, compared to those without promoter methylation.

The overall associations between sodium, potassium and fluid intake and ccRCC risk showed a higher HR for high (versus low) sodium intake [HR(95\% $\mathrm{Cl}): 1.42(1.06-1.89)]$ and a significantly increasing trend in HRs over the successive tertiles ( $P$-trend $=0.02$; Table 5.3). There was no association between potassium and fluid intake and ccRCC risk. Associations regarding pRCC and chrRCC are shown in Suppl Table S5.2.

Heterogeneous associations between dietary intakes and ccRCC risks for tumors with a different methylation index were particularly observed for potassium intake ( $P$-heterogeneity $=0.008$, Table 5.3). In tumors without promoter methylation, high (versus low) potassium intake was associated with a lower ccRCC risk $[\mathrm{HR}(95 \% \mathrm{Cl})$ : $0.60(0.36-1.01), P$-trend=0.05], whereas in tumors with a high methylation index, high 
(versus low) potassium intake was associated with a higher $\mathrm{cCRCC}$ risk $[\mathrm{HR}(95 \% \mathrm{Cl})$ : 1.60(0.96-2.65), $P$-trend=0.06]. For fluid intake, ccRCC risks were not statistically different by tumors with a different methylation index ( $P$-heterogeneity $=0.54)$, though HRs for high (versus low) fluid intake varied between tumors without promoter methylation and tumors with a high methylation index in the same direction as for potassium intake $[\mathrm{HR}(95 \% \mathrm{Cl}): 0.66(0.39-1.12)$ and $1.53(0.79-3.01), P$-trend $=0.15$ and 0.22; respectively]. High (versus low) sodium intake was associated with a higher cCRCC risk particularly in tumors with a high methylation index $[\mathrm{HR}(95 \% \mathrm{Cl})$ : 2.04(1.16-3.58), $P$-trend=0.01], however heterogeneity across the methylation index was not significant $(P$-heterogeneity $=0.26)$. High (versus low) sodium intake was also associated with a higher ccRCC risk for tumors without promoter methylation and for tumors with a low methylation index [HR(95\% Cl): 1.29(0.81-2.05) and 1.55(0.90-2.65), $P$-trend $=0.29$ and 0.10 ; respectively], though risk estimates were much lower and not significant compared to tumors with a high methylation index.

Table 5.2 Baseline characteristics of subcohort members, total clear-cell renal cell cancer cases and clear-cell renal cell cancer cases according to a methylation index in the NLCS, 1986-2006.

\begin{tabular}{|c|c|c|c|c|c|c|}
\hline \multirow[b]{2}{*}{$\begin{array}{l}\text { Baseline characteristics } \\
\text { (mean (SD)) }\end{array}$} & \multirow[b]{2}{*}{$\begin{array}{l}\text { Subcohort } \\
\text { members }\end{array}$} & \multirow[b]{2}{*}{$\begin{array}{l}\text { Total } \\
\text { ccRCC }\end{array}$} & \multicolumn{3}{|c|}{ Methylation index ${ }^{a, b}$} & \multirow[b]{2}{*}{$P$-value } \\
\hline & & & $\begin{array}{c}\text { No } \\
\text { methylation }\end{array}$ & $\begin{array}{c}\text { Low } \\
\text { methylation }\end{array}$ & $\begin{array}{c}\text { High } \\
\text { methylation }\end{array}$ & \\
\hline Total (n) & 3980 & 306 & 110 & 74 & 90 & \\
\hline Age at baseline (y) & $61.3(4.2)$ & 60.7 (3.9) & $60.7(3.7)$ & $61.4(4.0)$ & 60.4 (3.9) & 0.26 \\
\hline Male sex (\%) & 49.1 & 63.7 & 62.7 & 62.2 & 66.7 & 0.79 \\
\hline \multicolumn{7}{|l|}{ Dietary intakes } \\
\hline Sodium $(g / d)^{d}$ & $2.3(0.6)$ & $2.5(0.6)$ & $2.4(0.7)$ & $2.5(0.6)$ & $2.5(0.6)$ & 0.22 \\
\hline Discretionary salt $(\mathrm{g} / \mathrm{d})^{\mathrm{e}}$ & $2.8(2.7)$ & $2.7(2.9)$ & $2.6(2.6)$ & $2.7(3.6)$ & $2.5(2.6)$ & 0.79 \\
\hline Fluid (ml/d) & $2,087(487)$ & $2,103(471)$ & $2,077(525)$ & $2,102(361)$ & $2,139(455)$ & 0.50 \\
\hline Potassium $(\mathrm{mg} / \mathrm{d})^{d}$ & $3,529(602)$ & $3,607(651)$ & $3,490(633)$ & $3,614(674)$ & $3,742(636)$ & 0.02 \\
\hline Alcohol (g ethanol/d) ${ }^{f}$ & $13.5(15.1)$ & $15.1(15.0)$ & $16.5(17.2)$ & $14.8(15.2)$ & $14.0(12.1)$ & 0.91 \\
\hline Total energy (kcal/d) & $1,926(515)$ & 1,987 (507) & $2,024(581)$ & $1,946(446)$ & $1,978(473)$ & 0.68 \\
\hline \multicolumn{7}{|l|}{ Lifestyle factors } \\
\hline BMI $\left(\mathrm{kg} / \mathrm{m}^{2}\right)$ & $25.0(3.1)$ & $25.5(3.0)$ & $24.8(2.8)$ & $25.9(3.5)$ & $25.8(2.8)$ & 0.04 \\
\hline Current smokers (\%) & 27.3 & 29.4 & 28.2 & 33.8 & 30.0 & 0.72 \\
\hline Smoking duration $(y)^{\mathrm{g}}$ & $38.7(9.7)$ & $39.7(7.7)$ & $40.3(7.8)$ & 41.0 (7.9) & $37.7(8.4)$ & 0.16 \\
\hline Smoking intensity $(\mathrm{cig} / \mathrm{d})^{\mathrm{g}}$ & $15.2(8.8)$ & $15.9(7.8)$ & $17.3(8.1)$ & $16.3(8.5)$ & $13.6(6.5)$ & 0.24 \\
\hline Hypertension (\%) & 32.1 & 35.6 & 44.6 & 35.1 & 25.6 & 0.02 \\
\hline Low-salt diet (\%) & 7.6 & 9.5 & 10.0 & 8.1 & 8.9 & 0.91 \\
\hline
\end{tabular}

${ }^{a}$ The methylation index of a tumor is based on frequencies of methylation in ARHGDIG, ATP1A1, SCNN1B and SCL8A3; no, low and high methylation index correspond to methylation in 0,1 and $\geq 2$ genes, respectively; ${ }^{b} \mathrm{n}$ does not correspond with the overall $\mathrm{n}$, due to missing values; ${ }^{\mathrm{c}}$ Differences tested using Kruskal Wallis test (continuous) and $\chi^{2}$-test (categorical); ${ }^{d}$ Intakes are energy-adjusted by using the residual mean method; ${ }^{\mathrm{e}}$ Salt intake refers to sodium-chloride intake; ${ }^{\mathrm{f}}$ In consumers only (n subcohort $=3,033$ ); ${ }^{\mathrm{g}}$ In current smokers. $A R H G D I G=$ Rho GDP dissociation inhibitor gamma, $A T P 1 A 1=$ ATPase $\mathrm{Na}+\mathrm{K}+$ transporting alpha 1 polypeptide, $\mathrm{BMI}=$ body mass index, $\mathrm{cCRCC}=$ clear-cell renal cell cancer, cig = cigarettes, NLCS = Netherlands Cohort Study, SCNN1B = sodium channel non-voltage-gated 1 beta subunit, SD = standard deviation, SLC8A3 = solute carrier family 8 member 3 . 
The contribution of each of the four individual genes to the methylation index is evaluated in single gene analyses (Tables 5.4 and 5.5). High (versus low) sodium intake increased ccRCC risk, regardless of promoter methylation of any of the genes, but in tumors with ATP1A1 promoter methylation, the CCRCC risk for high (versus low) sodium intake was markedly high [HR(95\% Cl): 3.19(1.43-7.12)]. However, the number of cases with ATP1A1 promoter methylation in this analysis was low and the test for heterogeneity not significant. Furthermore, the observed heterogeneity in the association between high (versus low) potassium intake and cCRCC risk by the methylation index was largely determined by the promoter methylation of SCNN1B ( $P$-heterogeneity<0.001). In tumors without SCNN1B methylation, high (versus low) potassium intake decreased the $\mathrm{cCRCC}$ risk $[\mathrm{HR}(95 \% \mathrm{Cl})$ : $0.59(0.38-0.91)$, $P$-trend=0.02)], whereas in tumors with SCNN1B methylation high (versus low) potassium intake increased the ccRCC risk [HR(95\%Cl): 1.68(1.10-2.56), $P$-trend=0.01)]. Similarly, differential ccRCC risks for high (versus low) potassium intake were observed by promoter methylation of the three other genes, yet only for ATP1A1 heterogeneity was significant $(P$-heterogeneity=0.02). For high (versus low) fluid intake, differential CCRCC risks were only, though not significantly, observed by promoter methylation of SCNN1B [HR(95\% Cl): $0.65(0.40-1.05)$ and $1.58(0.90-2.78)$ with $P$-trend=0.08 and 0.12 in tumors without and with SCNN1B methylation, respectively]. 


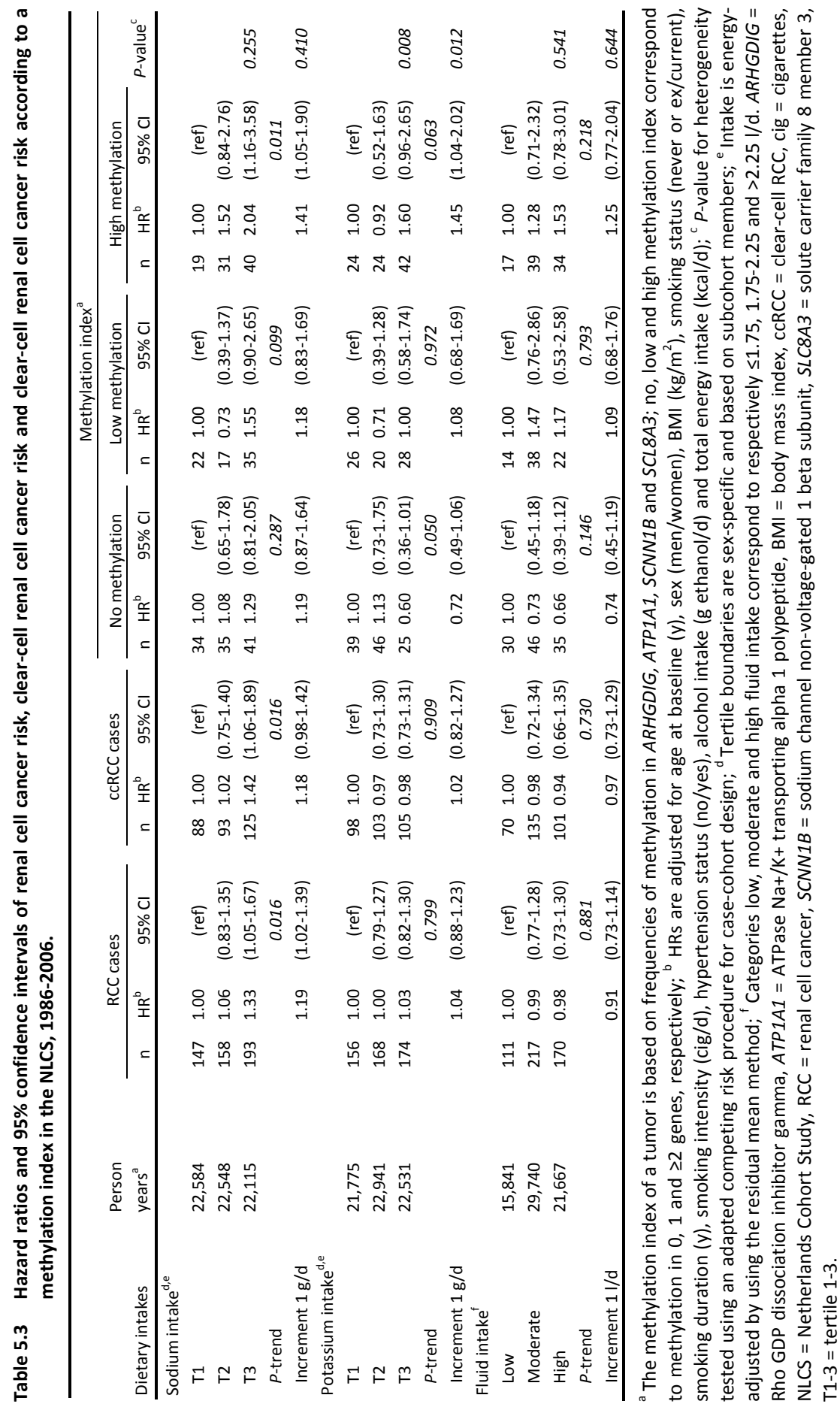




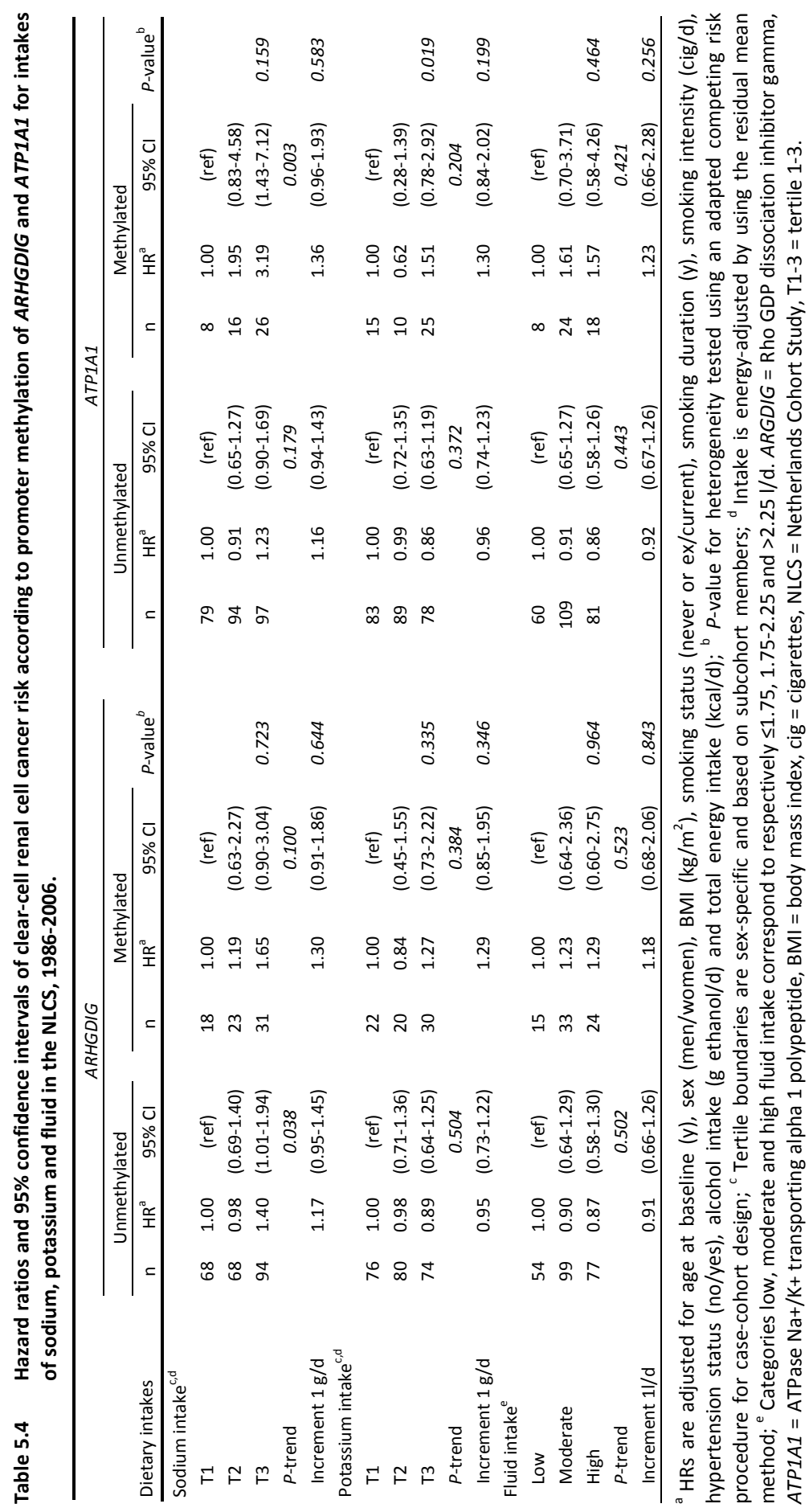




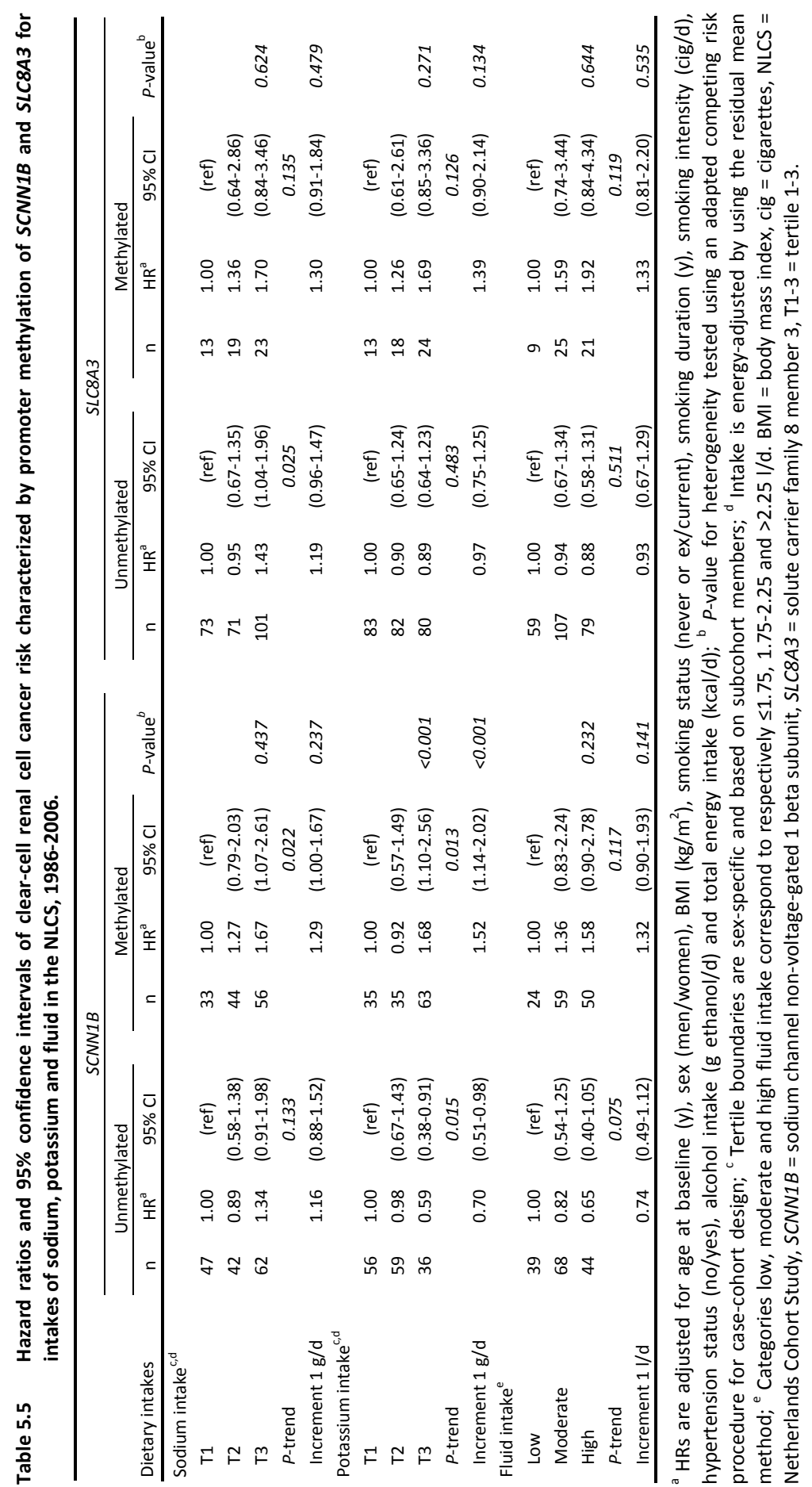




\section{DISCUSSION}

To our knowledge, this is the first study that reported on dietary sodium, potassium and fluid intake and a methylation index of four ITM genes in relation CCRCC risk. We previously reported the overall associations between these dietary intakes and RCC risk in the same study population, only then using 17.3 years of follow-up and including all RCC cases regardless of histological and molecular subtype [3]. The present study suggests that high sodium intake may increase cCRCC risk, regardless of the methylation index, while high potassium and fluid intake may be differentially associated with ccRCC risk across the methylation index.

Here, we used a hypothesis-driven, integrated approach including a pathway analysis, an epigenome-wide screen and an exhaustive search in publically available data to identify genes of interest with ccRCC-specific properties. Thereby, we sought to select the most relevant set of candidate genes to study the modifying effect of genespecific promoter methylation in the association between dietary intakes and CCRCC risk - i.e. ARHGDIG, ATP1A1, SCNN1B and SLC8A3. In 42 selected CCRCC tumors and their adjacent normal tissues promoter methylation was present in the tumor, but not in the normal tissues, indicating that methylation of these genes may be indeed cancer-specific (data not shown). We are the first to report the prevalence of promoter methylation of these genes in a population-based series of RCC tumors. For $S C N N 1 B$, hyper-methylation and down-regulation in CCRCC has previously been reported in tissues [8].

Although potassium intake was not associated with the overall ccRCC risk, we show significant differential associations between potassium intake and ccRCC risk by the methylation index. This highlights the crucial role of molecular characterization of the tumor to better understand etiology [27].

Heterogeneity for this association was particularly present for SCNN1B and to lesser extent for ATP1A1. There are many observations that have lent theoretical plausibility for a link between potassium and these ion-transporters and their role in the development of CCRCC. SCNN1B encodes for the epithelial Na+ channel beta subunit $(\mathrm{ENaC}-\beta)$, which is located on the cell surface in many organs including the kidney and, together with other ENaC subunits, ENaC- $\beta$ mediates the first step of active sodium reabsorption and controls electrolyte and water homeostasis [28]. Furthermore, mutations in SCNN1B have been associated with plasma potassium levels [29] and hyper- and hypokalemia [30,31]. ATP1A1 encodes for $\mathrm{Na}^{+}-\mathrm{K}^{+}-\mathrm{ATPase}$, which is responsible for maintaining the electrochemical gradients of sodium and potassium ions across the plasma membrane. This transmembrane potential is influenced by potassium concentrations in intracellular and extracellular fluid, which are determined by dietary intakes and urinary excretion [32]. Changes in potassium concentrations 
and the transmembrane potential may disturb or may be disturbed by any condition that enhances cell breakdown or cell production, such as cancer, because the transmembrane potential influences the progression through the cell-cycle [32,33]. However, concentration changes are related to the ability of the kidney to augment potassium excretion [32]. Under normal conditions, urinary potassium excretion increases after potassium load. Aberrant regulation of ion-channel expression and function may diminish the kidneys' ability to regulate potassium excretion and may be a functional element in carcinogenesis [33].

Given the sodium-potassium exchange mechanisms in the kidney, there is a theoretical link between the intake of potassium and sodium in relation to cCRCC. Although for sodium intake the ccRCC risk increased particularly in tumors with a high methylation index, we did not observe a significant heterogeneity across the methylation index, as was found for potassium intake. Several methodological reasons might explain the lack of heterogeneity in ccRCC risk for sodium intake. Our FFQbased measurement of sodium intake may be less accurate than that of potassium intake, as total sodium intake consists for approximately $30 \%$ of the intake of sodium from discretionary salt (sodium-chloride) and no such discretionary intake is common for potassium [3]. As a result, the FFQ may partially misclassify sodium intake of some participants leading to compromised power in the analyses. This is particularly relevant when using the Wald test as test for heterogeneity, because it is relatively conservative when it comes to rejecting the null-hypothesis. Nevertheless, sodium intake performed not markedly worse in validation against nine-day dietary records than did potassium intake ( $r=0.64$ and 0.67 , respectively) and additional analyses provided no evidence for residual confounding by discretionary salt intake.

Using the present study design, it is not possible to investigate the temporal relationship between the dietary intakes and the methylation index of the tumor. It is plausible that gene-specific promoter methylation, as early event in carcinogenesis, sensitizes the renal environment to the dietary intakes under study, so promoting the development of the ccRCC tumor. However, we cannot exclude that the observed promoter methylation of the carefully selected genes represent a general CpG island methylator phenotype (CIMP), which has been widely studied for other cancer types [34]. Neither can we exclude the possibility that the dietary intakes may have caused gene-specific promoter methylation in the tumor, although there is no evidence for any methylation-promoting effects of sodium, potassium or fluid intake.

The prospective study design and the completeness of cancer follow-up make selection bias and information bias unlikely. Furthermore, we were able to retrieve tumor material of an exceptional amount of RCC cases (i.e. 80\%) and found no indication for selection bias due to the unsuccessful retrieval of the remaining cases; risk factors and potential confounders did not differ between cases with and without 
tumor material. This study is among the largest prospective studies on RCC and, so far, the only prospective study including FFPE tumor tissues, yet the number of cases for some RCC subtypes is still too low to conduct analyses with adequate power. Moreover, risk estimates may be attenuated due random misclassification on the dietary intakes, introduced by the long follow-up and single baseline measurement, even though intakes were rather stable during the first five years of follow-up [17].

In conclusion, potassium intake was differentially associated with ccRCC risk only when the methylation index of the investigated genes was considered, indicating a joint influence of specific dietary intakes and gene-specific promoter methylation in relation to ccRCC risk. Using this approach of molecular pathological epidemiology, this study provides the first evidence of a biological rational for the role of ITMs in the development of ccRCC. However, the temporal relationship between the dietary intakes and promoter methylation and the exact mechanism by which such iontransporters may be involved ccRCC etiology remains to be determined. 


\section{REFERENCES}

1. Rose BD, Post TW. Clinical Physiology of acid-base and electrolyte disorders. 5th edition ed. 2001, New York: McGraw-Hill, Medical Publishing Division.

2. Djamgoz MB, Coombes RC, Schwab A. Ion transport and cancer: from initiation to metastasis. Philos Trans R Soc Lond B Biol Sci 2014;369 20130092.

3. Deckers IA, van den Brandt PA, van Engeland M, Soetekouw PM, Baldewijns MM, Goldbohm RA, Schouten LJ. Long-term dietary sodium, potassium and fluid intake; exploring potential novel risk factors for renal cell cancer in the Netherlands Cohort Study on diet and cancer. Br J Cancer 2014; 110:797-801.

4. Ogino S, Fuchs CS, Giovannucci E. How many molecular subtypes? Implications of the unique tumor principle in personalized medicine. Expert Rev Mol Diagn 2012;12:621-8.

5. Morris MR, Ricketts CJ, Gentle D, McRonald F, Carli N, Khalili H, Brown M, Kishida T, Yao M, Banks RE, Clarke N, Latif F, Maher ER. Genome-wide methylation analysis identifies epigenetically inactivated candidate tumour suppressor genes in renal cell carcinoma. Oncogene 2011;30:1390-401.

6. Schuebel KE, Chen W, Cope L, Glöckner SC, Suzuki H, Yi JM, Chan TA, Van Neste L, Van Criekinge W, van den Bosch S, van Engeland M, Ting AH, Jair K, Yu W, Toyota M, Imai K, Ahuja N, Herman JG, Baylin SB. Comparing the DNA hypermethylome with gene mutations in human colorectal cancer. PLoS Genet 2007;3:1709-23.

7. Dalgliesh GL, Furge K, Greenman C, Chen L, Bignell G, Butler A, Davies H, Edkins S, Hardy C, Latimer C, Teague J, Andrews J, Barthorpe S, Beare D, Buck G, Campbell PJ, Forbes S, Jia M, Jones D, Knott H, Kok CY, Lau KW, Leroy C, Lin ML, McBride DJ, Maddison M, Maguire S, McLay K, Menzies A, Mironenko T, Mulderrig L, Mudie L, O'Meara S, Pleasance E, Rajasingham A, Shepherd R, Smith R, Stebbings L, Stephens P, Tang G, Tarpey PS, Turrell K, Dykema KJ, Khoo SK, Petillo D, Wondergem B, Anema J, Kahnoski RJ, Teh BT, Stratton MR, Futreal PA. Systematic sequencing of renal carcinoma reveals inactivation of histone modifying genes. Nature 2010;463:360-3.

8. Dalgin GS, Drever M, Williams T, King T, DeLisi C, Liou LS. Identification of novel epigenetic markers for clear cell renal cell carcinoma. J Urol 2008;180:1126-30.

9. Selvakumar P, Owens TA, David JM, Petrelli NJ, Christensen BC, Lakshmikuttyamma A, Rajasekaran AK. Epigenetic silencing of $\mathrm{Na}, \mathrm{K}-\mathrm{ATPa} e$ beta subunit gene by methylation in clear cell renal cell carcinoma. Epigenetics 2014;9:579-86.

10. van den Brandt PA, Goldbohm RA, van 't Veer P, Volovics A, Hermus RJ, Sturmans F. A large-scale prospective cohort study on diet and cancer in The Netherlands. J Clin Epidemiol 1990;43:285-95.

11. Prentice RL. On the design of synthetic case-control studies. Biometrics 1986;42:301-10.

12. Van den Brandt PA, Schouten LJ, Goldbohm RA, Dorant E, Hunen PM. Development of a record linkage protocol for use in the Dutch Cancer Registry for Epidemiological Research. Int J Epidemiol 1990;19:553-8.

13. Goldbohm RA, Van den Brandt PA, Dorant E. Estimation of the coverage of Dutch municipalities by cancer registries and PALGA based on hospital discharge data. Tijdschr Soc Gezondheidsz 1994;72: 80-4.

14. van Houwelingen KP1, van Dijk BA, Hulsbergen-van de Kaa CA, Schouten LJ, Gorissen HJ, Schalken JA, van den Brandt PA, Oosterwijk E. Prevalence of von Hippel-Lindau gene mutations in sporadic renal cell carcinoma: results from The Netherlands cohort study. BMC Cancer 2005;5:57.

15. Eble J, et al. World Health Organization Classification of Tumours. Pathology and Genetics. Tumours of the Urinary System and Male Genital Organs. 2004, Lyon: IARC Press.

16. Goldbohm RA, van den Brandt PA, Brants HA, van't Veer P, Al M, Sturmans F, Hermus RJ. Validation of a dietary questionnaire used in a large-scale prospective cohort study on diet and cancer. Eur J Clin Nutr 1994;48:253-65.

17. Goldbohm RA, van 't Veer P, van den Brandt PA, van 't Hof MA, Brants HA, Sturmans F, Hermus RJ. Reproducibility of a food frequency questionnaire and stability of dietary habits determined from five annually repeated measurements. Eur J Clin Nutr 1995;49:420-9.

18. Nevo tabel, Dutch food composition table 1986-1987; Nederlands voedingsstoffenbestand 19861987. 1986, The Hague, The Netherlands: Voorlichtingsbureau voor de Voeding. 
19. van den Brandt PA, Botterweck AA, Goldbohm RA. Salt intake, cured meat consumption, refrigerator use and stomach cancer incidence: a prospective cohort study (Netherlands). Cancer Causes Control 2003;14:427-38.

20. Laboratories K. KEGG pathway database. 1995-2014 January 28, 2014 [cited 2014 February 17]; Available from: http://www.kegg.jp/kegg/pathway.html.

21. Derks S, Lentjes $M H$, Hellebrekers DM, de Bruïne AP, Herman JG, van Engeland M.Methylationspecific PCR unraveled. Cell Oncol 2004;26:291-9.

22. Herman JG, Graff JR, Myöhänen S, Nelkin BD, Baylin SB. Methylation-specific PCR: a novel PCR assay for methylation status of CpG islands. Proc Natl Acad Sci U S A 1996;93:9821-6.

23. van Engeland M, Roemen GM, Brink M, Pachen MM, Weijenberg MP, de Bruïne AP, Arends JW, van den Brandt PA, de Goeij AF, Herman JG. K-ras mutations and RASSF1A promoter methylation in colorectal cancer. Oncogene 2002;21:3792-5.

24. Barlow WE. Robust variance estimation for the case-cohort design. Biometrics 1994;50:1064-72.

25. de Vogel S, Bongaerts BW, Wouters KA, Kester AD, Schouten LJ, de Goeij AF, de Bruïne AP, Goldbohm RA, van den Brandt PA, van Engeland M, Weijenberg MP. Associations of dietary methyl donor intake with MLH1 promoter hypermethylation and related molecular phenotypes in sporadic colorectal cancer. Carcinogenesis 2008;29:1765-73.

26. Wacholder, S., et al., Alternative variance and efficiency calculations for the case-cohort design Biometrika 1989;76:117-123.

27. Ogino S, Chan AT, Fuchs CS, Giovannucci E. Molecular pathological epidemiology of colorectal neoplasia: an emerging transdisciplinary and interdisciplinary field. Gut 2011;60:397-411.

28. Garty H, Palmer LG. Epithelial sodium channels: function, structure, and regulation. Physiol Rev 1997; 77:359-96.

29. Gaukrodger N, Avery PJ, Keavney B. Plasma potassium level is associated with common genetic variation in the beta-subunit of the epithelial sodium channel. Am J Physiol Regul Integr Comp Physiol 2008;294:R1068-72.

30. Chang SS, Grunder S, Hanukoglu A, Rösler A, Mathew PM, Hanukoglu I, Schild L, Lu Y, Shimkets RA, Nelson-Williams C, Rossier BC, Lifton RP. Mutations in subunits of the epithelial sodium channel cause salt wasting with hyperkalaemic acidosis, pseudohypoaldosteronism type 1. Nat Genet 1996;12: 248-53.

31. Shimkets RA1, Warnock DG, Bositis CM, Nelson-Williams C, Hansson JH, Schambelan M, Gill JR Jr, Ulick S, Milora RV, Findling JW, et al. Liddle's syndrome: heritable human hypertension caused by mutations in the beta subunit of the epithelial sodium channel. Cell 1994;79:407-14.

32. Aronson PS, Giebisch G. Effects of pH on potassium: new explanations for old observations. J Am Soc Nephrol 2011;22:1981-9.

33. Blackiston DJ, McLaughlin KA, Levin M. Bioelectric controls of cell proliferation: ion channels, membrane voltage and the cell cycle. Cell Cycle 2009;8:519-28.

34. Hughes LA, Melotte V, de Schrijver J, de Maat M, Smit VT, Bovée JV, French PJ, van den Brandt PA, Schouten LJ, de Meyer T, van Criekinge W, Ahuja N, Herman JG, Weijenberg MP, van Engeland M. The CpG island methylator phenotype: what's in a name? Cancer Res 2013;73:5858-68. 
Suppl Table S5.1 Primer sequences and sequence condition used to analyze promoter methylation of ARHGDIG, ATP1A1, SCNN1B and SLC8A3 in renal cell tumors in the NLCS, 1986-2006.

\begin{tabular}{|c|c|c|c|c|}
\hline \multirow{2}{*}{$\frac{\text { Gene }}{A R H G D I G}$} & \multirow[t]{2}{*}{ Primer sequence } & \multicolumn{3}{|c|}{$\operatorname{Tm}\left({ }^{\circ} \mathrm{C}\right)$ Cycles $(\mathrm{n})$ Length $(\mathrm{bp})$} \\
\hline & & & & \\
\hline Flanking primer, upstream & GGGGTAGTTTTGTTGGTTAGAGT & 56 & 35 & 23 \\
\hline Flanking primer, downstream & ACCAAAACCCCRCACAAAAA & 56 & 35 & 20 \\
\hline Unmethylated sense strand & TTGGTTAGAGTTGGGTATGGGTT & 66 & 30 & 23 \\
\hline Methylated sense strand & GGTTAGAGTCGGGTACGGGTC & 66 & 30 & 21 \\
\hline Unmethylated antisense strand & CCACACAAAAACACCCAAACA & 66 & 30 & 21 \\
\hline Methylated antisense strand & CACAAAAACGCCCGAACG & 66 & 30 & 18 \\
\hline \multicolumn{5}{|l|}{ ATP1A1 } \\
\hline Flanking primer, upstream & AGGAGGYGGATAYGTGGTAATAG & 56 & 35 & 23 \\
\hline Flanking primer, downstream & CCAAATAAAAAAAACTAAAACTACC & 56 & 35 & 25 \\
\hline Unmethylated sense strand & GTGGTAATAGTGGTAGTAGTTTGGGT & 64 & 35 & 26 \\
\hline Methylated sense strand & GTAATAGCGGTAGTAGTTCGGGC & 64 & 35 & 23 \\
\hline Unmethylated antisense strand & AAAAAAACTAAAACTACCACAAAACA & 64 & 35 & 26 \\
\hline Methylated antisense strand & AAACTAAAACTACCGCGAAACG & 64 & 35 & 22 \\
\hline \multicolumn{5}{|l|}{ SCNN1B } \\
\hline Flanking primer, upstream & TYGGGTGTTTTAGTGTTATTAATATT & 56 & 35 & 26 \\
\hline Flanking primer, downstream & AAACCRAATACRAACCAAAATTC & 56 & 35 & 23 \\
\hline Unmethylated sense strand & GTGTTTTAAGTGTTATTAATATTTGGTTGTT & 64 & 35 & 30 \\
\hline Methylated sense strand & GTTTTAGTGTTATTAATATTCGGTCGTC & 64 & 35 & 28 \\
\hline Unmethylated antisense strand & AАATTCACСАТСАТАССТАСТСААACA & 64 & 35 & 27 \\
\hline Methylated antisense strand & GCCGTCATACCTACTCGAACG & 64 & 35 & 21 \\
\hline \multicolumn{5}{|l|}{ SLC8A3 } \\
\hline Flanking primer, upstream & YGGTAGTTTAATGGGTAAAGTTTTT & 56 & 35 & 25 \\
\hline Flanking primer, downstream & ССТАААСТTТСССТАААСТАААAАС & 56 & 35 & 25 \\
\hline Unmethylated sense strand & GTAGTTTAATGGGTAAAGTTTTTTTGTTT & 68 & 35 & 29 \\
\hline Methylated sense strand & AGTTTAATGGGTAAAGTTTTTCGTTC & 68 & 35 & 26 \\
\hline Unmethylated antisense strand & TAAACTAAAAACACACCAAАТСТССА & 68 & 35 & 26 \\
\hline Methylated antisense strand & AAACGCGCCGAATCTCCG & 68 & 35 & 18 \\
\hline
\end{tabular}

ARHGDIG = Rho GDP dissociation inhibitor gamma, ATP1A1 = ATPase $\mathrm{Na}+/ \mathrm{K}+$ transporting alpha 1 polypeptide, NLCS = Netherlands Cohort Study, $S C N N 1 B=$ sodium channel non-voltage-gated 1 beta subunit, $S L C 8 A 3=$ solute carrier family 8 member 3 . 
Suppl Table S5.2 Hazard ratios and 95\% confidence intervals of papillary renal cell cancer risk and chromophobe renal cell cancer risk for intakes of sodium, potassium and fluid in the NLCS, 1986-2006.

\begin{tabular}{|c|c|c|c|c|c|c|c|}
\hline \multirow[b]{2}{*}{ Exposure } & \multirow[b]{2}{*}{ Person years ${ }^{a}$} & \multicolumn{3}{|c|}{ pRCC cases } & \multicolumn{3}{|c|}{ chrRCC cases } \\
\hline & & $\mathrm{n}$ & $\mathrm{HR}^{\mathrm{b}}$ & $95 \% \mathrm{Cl}$ & $\mathrm{n}$ & $H R^{b}$ & $95 \% \mathrm{Cl}$ \\
\hline \multicolumn{8}{|l|}{ Sodium intake $e^{\mathrm{c,d}}$} \\
\hline $\mathrm{T} 1$ & 22,584 & 8 & 1.00 & (ref) & 6 & - & - \\
\hline $\mathrm{T} 2$ & 22,548 & 25 & 3.10 & $(1.39-6.93)$ & 1 & - & - \\
\hline T3 & 22,115 & 13 & 1.70 & $(0.70-4.10)$ & 5 & - & - \\
\hline$P$-trend & & & & 0.252 & & & - \\
\hline Increment $1 \mathrm{~g} / \mathrm{d}$ & & & 1.45 & $(0.90-2.35)$ & & 0.84 & $(0.32-2.22)$ \\
\hline \multicolumn{8}{|l|}{ Potassium intake $e^{c, d}$} \\
\hline $\mathrm{T} 1$ & 21,775 & 19 & 1.00 & (ref) & 2 & - & - \\
\hline $\mathrm{T} 2$ & 22,941 & 9 & 0.44 & $(0.20-0.99)$ & 6 & - & - \\
\hline T3 & 22,531 & 18 & 0.88 & $(0.45-1.70)$ & 4 & - & - \\
\hline$P$-trend & & & & 0.722 & & & - \\
\hline Increment $1 \mathrm{~g} / \mathrm{d}$ & & & 0.99 & $(0.62-1.59)$ & & 1.37 & $(0.82-2.30)$ \\
\hline \multicolumn{8}{|l|}{ Fluid intake } \\
\hline Low & 15,841 & 10 & 1.00 & (ref) & 3 & - & - \\
\hline Moderate & 29,740 & 19 & 1.03 & $(0.48-2.23)$ & 5 & - & - \\
\hline High & 21,667 & 17 & 1.17 & $(0.51-2.67)$ & 4 & - & - \\
\hline$P$-trend & & & & 0.699 & & & - \\
\hline Increment $1 \mathrm{l} / \mathrm{d}$ & & & 0.82 & $(0.43-1.57)$ & & 0.49 & $(0.17-1.46)$ \\
\hline
\end{tabular}

${ }^{\mathrm{a}}$ In the subcohort; ${ }^{\mathrm{b}} \mathrm{HRs}$ are adjusted for age at baseline (y), sex (men/women), BMI $\left(\mathrm{kg} / \mathrm{m}^{2}\right)$, smoking status (never or ex/current), smoking duration (y), smoking intensity (cig/d), hypertension status (no/yes), alcohol intake (g ethanol/d) and total energy intake $(\mathrm{kcal} / \mathrm{d}) ;{ }^{\mathrm{c}}$ Tertile boundaries are sex-specific and based on subcohort members; ${ }^{d}$ Intake is energy-adjusted by using the residual mean method; ${ }^{e}$ Categories low, moderate and high fluid intake correspond to respectively $\leq 1.75,1.75-2.25$ and $>2.25 \mathrm{l} / \mathrm{d}$. BMI = body mass index, chrRCC = chromophobe RCC, cig = cigarettes, NLCS = Netherlands Cohort Study, pRCC = papillary RCC, $\mathrm{RCC}=$ renal cell cancer, $\mathrm{T} 1-3=$ tertile $1-3$. 


\section{CHAPTER 6}

\section{Alcohol and dietary folate intake and gene promoter methylation in clear-cell renal cell cancer}

Leo J Schouten, Ivette AG Deckers, Piet A van den Brandt, Marcella MLL Baldewijns and Manon van Engeland

Submitted 


\section{ABSTRACT}

\section{Introduction}

High alcohol intake and low folate intake are hypothesized to be associated with promoter $\mathrm{CpG}$ island hypermethylation. We investigated whether alcohol and dietary folate intakes were associated with promoter methylation in clear-cell renal cell cancer (ccRCC).

\section{Methods}

The Netherlands Cohort Study with case-cohort design included 120,852 subjects aged 55-69 years in 1986. Diet was measured with a food-frequency questionnaire. After 20.3 years of follow-up, paraffin-embedded tumor blocks were collected. Methylation-specific PCR was used to analyze promoter methylation of eleven, frequently methylated genes in ccRCC. The ccRCC cases were classified into low, intermediate and high methylation, representing a methylation frequency of $0-19 \%, 20-39 \%$ and more than $40 \%$, respectively. Multivariable Cox regression analyses were stratified according to this methylation index and included 3,980 subcohort members and 297 ccRCC cases.

\section{Results}

Higher intakes of alcohol were associated with a decreased ccRCC risk in all cases, but multivariable adjusted hazard ratios (HR) and $95 \%$ confidence intervals $(\mathrm{Cl})$ were not statistically significant $[\mathrm{HR}(95 \% \mathrm{Cl})$ for $\geq 30 \mathrm{~g} / \mathrm{d}$ versus $0 \mathrm{~g} / \mathrm{d}$ : $0.78(0.48-1.24), P$-trend=0.46]. Dietary folate intake was not associated with $\mathrm{ccRCC}$ risk $[\mathrm{HR}(95 \% \mathrm{Cl})$ for high versus low intake: $1.07(0.70-1.64), P$-trend=0.59)]. There was no significant heterogeneity in $c c R C C$ risk for alcohol and dietary folate intake according to categories of the methylation index and there was no effect-modification of alcohol and dietary folate intake on ccRCC risk.

\section{Conclusion}

Our findings do not support the hypothesis that alcohol and dietary folate intake are involved in ccRCC carcinogenesis through promoter methylation of our methylation index. 


\section{INTRODUCTION}

Cigarette smoking, excess body weight, a diagnosis of hypertension and familial cancer syndromes are established risk factors of renal cell cancer (RCC) [1]. Recent evidence suggests that alcohol consumption may be inversely associated with RCC risk [1-4], although the mechanism explaining the inverse association has not been established yet.

One of the suggested mechanisms that may link alcohol to cancer is DNA methylation [5]. Aberrant promoter CpG island hypermethylation, in short promoter methylation, has been observed in many cancers, including RCC $[6,7]$. It has been suggested that there is a specific subtype of cancer that is characterized by extensive promoter methylation of tumor suppressor and DNA repair genes and referred to as CpG island methylator phenotype (CIMP) [8]. CIMP has been investigated extensively in colorectal cancer, but may also exist in other cancers, such as RCC $[8,9]$. However, no definition for CIMP in RCC has been established so far.

An adequate folate metabolism is necessary for maintaining DNA methylation and a high intake of alcohol is associated with folate reduction by different mechanisms. High alcohol intake decreases the absorption of folate from the intestinal lumen $[10,11]$. Alcohol may also increase urinary excretion of folate and influences proteins involved in folate metabolism [10,11]. Heavy abusers of alcohol often have a diet with a deficient folate intake [10]. The combination of high alcohol intake and a low dietary folate intake, may be a specific subgroup of the population that is at risk for adverse effects of folate deficiency [10-13].

In a previous analysis we investigated whether alcohol intake was associated with promoter methylation in the Von Hippel-Lindau (VHL) gene in RCC [14]. Alcohol intake was inversely associated with the RCC subtype without $V H L$ promoter methylation, however, the number of RCC cases with VHL promoter methylation was too low for reliable point estimates.

If high alcohol and low folate intake are associated with promoter methylation in RCC, the association of these dietary exposures with RCC risk might differ by molecular subtypes of RCC defined by promoter methylation status. The overall association of alcohol with RCC risk is inverse, but this might not be true in the subgroup of RCC characterized by a high promoter methylation status. We therefore investigated whether associations between alcohol and dietary folate intake are different in RCC subgroups defined by levels of promoter methylation of $\mathrm{CpG}$ islands in a specifically selected gene panel in a large prospective study. 


\section{METHODS}

\section{Study design and study population}

The Netherlands Cohort Study on Diet and Cancer (NLCS) is a prospective cohort study that was initiated in 1986 and included 120,852 participants aged 55-69 years at baseline [15]. The NLCS was designed as case-cohort study for efficiency in questionnaire processing and follow-up. Cases were derived from the entire cohort, whereas a subcohort of 5,000 subjects was randomly sampled at baseline to estimate person years at risk for the entire cohort [15]. Subcohort members were regularly followed up for vital status information, whereas all cohort members were followed up for cancer occurrence using record linkage with the Netherlands Cancer Registry and the Netherlands Pathology Registry (PALGA) [16]. Only one male subcohort member was lost to follow-up. The completeness of cancer follow-up by the Netherlands cancer registry and PALGA is estimated to be over 96\% [17]. Cases and subcohort members who reported prevalent cancer (excluding skin cancer) at baseline were excluded. A unique population-based collection of DNA isolated from formalin-fixed paraffin-embedded (FFPE) tissues of RCC cases is nested within the NLCS. Initially, this collection of DNA material included only cases from the first 11.3 years of follow-up [18], yet recently the collection was expanded to 20.3 years of follow-up.

\section{Tissue collection and DNA isolation}

A total of 608 RCC cases were identified within the NLCS during 20.3 years of followup (between 1986 and 2006). Only histologically confirmed epithelial RCC cases $(n=568)$ were eligible for the collection of FFPE tumor tissues from $\sim 50$ pathology laboratories throughout the Netherlands. Tumor blocks of appromimately $80 \%$ of the eligible cases could be retrieved. The RCC cases were classified according to the World Health Organization (WHO) Classification of Tumors of 2004 [19] by two experienced urogenital pathologists (C.A. Hulsbergen-van de Kaa and M.M.L.L. Baldewijns). Overall, $81 \%$ of the cases were classified as clear-cell RCC (ccRCC) [19].

Methods used for DNA isolation of FFPE tissues from RCC cases identified during the first 11.3 years of follow-up included in the initial collection have been described previously [18]. For the recently added RCC cases, vital tissue areas were dissected before DNA isolation. DNA was isolated using the QIAamp DNA Mini Kit (Qiagen), according to manufacturer's instructions.

\section{Dietary assessment}

All NLCS participants returned a mailed, self-administered, baseline questionnaire, including a 150-item, semi-quantitative food-frequency questionnaire (FFQ), which 
concentrated on habitual consumption of foods and beverages in the year before the start of the study.

Consumption of alcoholic beverages was addressed by questions on beer, red wine, white wine, sherry, other fortified wines, liqueur, and liquor. Respondents who consumed alcoholic beverages less than once a month were considered non-users. Four items from the questionnaire (i.e., red wine, white wine, sherry, and liqueur) were combined into one wine variable, since these items were substantially correlated [20]. Mean daily alcohol consumption was calculated using the Dutch food composition table [21]. Based on a pilot study, standard glass sizes were defined as $200 \mathrm{ml}$ for beer, $105 \mathrm{ml}$ for wine, $80 \mathrm{ml}$ for sherry, and $45 \mathrm{ml}$ for both liqueur and liquor, corresponding to $8,10,11,7$, and 13 grams of alcohol, respectively.

Mean daily intakes of other nutrients were calculated by multiplying the frequencies and portion sizes of all food items and their tabulated nutrient contents from the Dutch Food Consumption table from 1986 [21]. Folate data were derived from a validated liquid chromatography trienzyme method [22] used to analyze the 125 most important Dutch foods contributing to folate intake [23]. Although the FFQ contained questions on the use of dietary supplements, dietary supplement use of folic acid was not accounted for in the analyses, as dietary supplements in general did not contain folic acid in the Netherlands in the late 1980s. Participants with incomplete or inconsistent dietary questionnaires were excluded [24]. The FFQ ranked individuals adequately according to dietary intakes when compared to a nine-day dietary records [24], and reflected nutrient intakes for at least 5 years [25].

\section{Gene selection and promoter methylation}

To date, no definition for CpG island methylator phenotype (CIMP) in ccRCC has been established. Therefore, we carefully selected CPG islands of interest in ccRCC as a measure for promoter methylation. Besides the $V H L$-gene [14], genes were selected exhibiting 1) promoter $\mathrm{CpG}$ island methylation (-2000 to $+500 \mathrm{bp}$ from transcription start site) in cCRCC cell lines (SKRC1, SKRC10, SKRC52 and SKRC59) and not in a normal kidney cell line (HK-2) in a genome-wide methylation screen (MBD-affinity massive parallel sequencing) [26] and 2) cancer-specific down-regulation among ccRCC in publically available expression data from The Cancer Genome Atlas. Using this selection strategy we selected eleven genes: Cysteine Dioxygenase type 1 (CDO1); Follistatin (FST); Frizzled Class Receptor 10 (FZD10); Gremlin 1, DAN family BMP antagonist (GREM1); Ladinin 1 (LAD1); Neurofilament, heavy polypeptide (NEFH); Neuralized E3 Ubiquitin Protein Ligase 1 (NEURL); Ras-specific Guanine Nucleotidereleasing Factor 2 (RASGFR2); Stratifin (SFN); Secreted Frizzled-Related Protein 1 (SFRP1) and $V H L$ as candidate markers. 
Promoter methylation of the $\mathrm{CPG}$ islands was analyzed using nested methylationspecific PCR (MSP), as previously described elsewhere [27-29]. MSP primer design was based on the MBD-affinity massive parallel sequencing data. Primer sequences and MSP conditions are shown in Suppl Table S6.1. From 45 cases, MSP-analysis was repeated in order to measure reproducibility. After excluding missing values due to genotyping failures, only one discrepancy in one gene was recorded $199.7 \%$ reproducibility).

A sum score representing promoter methylation was calculated combining promoter methylation in all eleven individual genes dividing the ccRCC cases into three categories that were approximately the same size. The categories low, intermediate and high methylation represent cases with a methylation frequency of 0-19\%, $20-39 \%$ and more than $40 \%$, respectively.

\section{Statistical analyses}

All analyses were conducted in Stata version 11 (Stata Corp., College Station, TX). Associations between alcohol and folate intake and RCC risk were performed for total RCC and for ccRCC. Hazard ratios (HR) and 95\% confidence intervals (Cl) were estimated using Cox proportional hazards analyses adjusted for the case-cohort design [30]. The proportional hazards assumption was tested using the scaled Schoenfeld residuals and by introducing time-covariate interactions into the models. The proportional hazards assumption in the analyses using time on study as timescale for the variable age was not fulfilled. Therefore, all models were carried out using age as the timescale. Analyses were performed for a simple model (adjusted for sex and year of birth) and a multivariable adjusted model, including a priori selected potential confounders: year of birth (1916-20, 1921-25 and 1926-31), sex (men/women), total energy intake ( $\mathrm{kcal} / \mathrm{d})$, body mass index $\left(\mathrm{BMl} ; \mathrm{kg} / \mathrm{m}^{2}\right.$ ), smoking status (never or ex/current), smoking intensity (cigarettes/d), smoking duration (y), and self-reported doctors' diagnosis of hypertension and/or use of antihypertensive medication (no/yes). In a previous publication, we investigated the association between alcohol intake and RCC risk after 11.3 years of follow-up [14]. Current analyses were split into $<11.3$ and $\geq 11.3$ years of follow-up, to compare the results with the previous publication [14].

The $P$-interaction was assessed by including cross-product terms in the models and performing a Wald $\chi^{2}$ test. Because of the limited number of cases in stratified interaction analyses, alcohol and folate intake were each categorized into two categories (referred to as high versus low intake); alcohol intake was categorized into $<15$ and $\geq 15 \mathrm{~g} / \mathrm{d}$ and folate intake into higher and lower than median intake in the subcohort (median intake in men $212.07 \mu \mathrm{g} / \mathrm{d}$ and in women $188.71 \mu \mathrm{g} / \mathrm{d}$ ). 
Tests for heterogeneity were performed to evaluate differences across tumors with different promoter methylation profiles, using an adapted version of the competing risks procedure in Stata developed for the case-cohort design, as described previously $[31,32]$. All tests were two-sided. A $P$-value $<0.05$ is considered statistically significant.

\section{RESULTS}

After exclusion of cohort members with incomplete and/or inconsistent foodfrequency questionnaires or with missing data on confounders, 3,980 subcohort members and 498 RCC cases were available for analysis. For 297 ccRCC cases promoter methylation could be genotyped of at least four genes.

Of the 297 ccRCC cases, MSP analyses of gene promoter regions were successful for 91\% (RASGRF2) to 99\% (NEURL). Proportions of promoter methylation per investigated gene are shown in Table 6.1. This proportion was on average 36\%, but varied from $8 \%(V H L)$ to $97 \%(S F N)$. In 112 cases, less than $20 \%$ of the eleven investigated genes were methylated (referred to as low methylation), in 81 cases between $20 \%$ and $40 \%$ of the genes were methylated (intermediate methylation) and in 104 cases more than $40 \%$ of the genes were methylated (high methylation).

The proportion of non-users of alcohol was slightly higher in the subcohort (23.8\%) than in the total group of RCC cases (22.3\%) (Table 6.2). Mean alcohol intake in users was similar in subcohort and RCC cases (15.1 and $15.0 \mathrm{~g} / \mathrm{d})$. Intake of folate was slightly lower in the subcohort than in RCC cases $(211.8$ and $218.6 \mu \mathrm{g} / \mathrm{d})$. RCC cases were more often men, had a slightly higher BMI, were more often smokers, and had more often a diagnosis of hypertension or diabetes at baseline than subcohort members.

Multivariable adjusted HRs for categories of alcohol intake and RCC risk were all lower than one, but not statistically significant (Table 6.3). The multivariable adjusted $\mathrm{HR}(95 \% \mathrm{Cl})$ for participants with $30+\mathrm{g} / \mathrm{d}$ alcohol intake was $0.79(0.54-1.16)$ compared to non-users and the $P$-trend was 0.27 . When analyses were restricted to CCRCC, multivariable HRs were comparable. When ccRCC cases were stratified according to methylation status, heterogeneity of associations between alcohol intake and ccRCC risk was not statistically significant $(P$-heterogeneity $=0.29)$. 
Table 6.1 Descriptive data on methylation in clear-cell renal cell cancer cases in the NLCS, 1986-2006.

\begin{tabular}{|c|c|c|c|c|c|c|c|c|}
\hline \multirow[b]{3}{*}{ Gene } & \multirow[b]{2}{*}{$\begin{array}{l}\text { Successfully } \\
\text { Genotyped }^{\text {a }}\end{array}$} & \multirow[b]{2}{*}{$\begin{array}{c}\text { Proportion of } \\
\text { methylation }\end{array}$} & \multicolumn{6}{|c|}{ Proportion of methylation by methylation index ${ }^{\mathrm{b}}$} \\
\hline & & & \multicolumn{2}{|c|}{ Low } & \multicolumn{2}{|c|}{ Intermediate } & \multicolumn{2}{|c|}{ High } \\
\hline & n $\%$ & n \% & $\mathrm{n}$ & $\%$ & $\mathrm{n}$ & $\%$ & $\mathrm{n}$ & $\%$ \\
\hline Total & 297 & 297 & 112 & & 81 & & 104 & \\
\hline FZD10 & 27793.3 & 14652.7 & 20 & 20.4 & 50 & 66.7 & 76 & 73.1 \\
\hline FST & 29097.6 & 3612.4 & 0 & 0.0 & 4 & 5.1 & 32 & 31.1 \\
\hline SFRP1 & 29097.6 & 5519.0 & 0 & 0.0 & 4 & 5.1 & 51 & 49.0 \\
\hline SFN & 28495.6 & 27496.5 & 90 & 90.0 & 81 & 100.0 & 103 & 100.0 \\
\hline$C D O 1$ & 27993.9 & $114 \quad 40.9$ & 2 & 2.0 & 27 & 35.1 & 85 & 84.2 \\
\hline NEURL & 29599.3 & 12141.0 & 10 & 9.1 & 26 & 32.1 & 85 & 81.7 \\
\hline GREM1 & 28596.0 & 11440.0 & 4 & 3.9 & 26 & 32.9 & 84 & 81.6 \\
\hline$N E F H$ & 27090.9 & $76 \quad 28.2$ & 2 & 2.0 & 13 & 18.6 & 61 & 60.4 \\
\hline$\angle A D 1$ & 28897.0 & 8730.2 & 5 & 4.8 & 18 & 22.5 & 64 & 61.5 \\
\hline RASGFR2 & 26990.6 & $63 \quad 23.4$ & 0 & 0.0 & 4 & 5.4 & 59 & 57.8 \\
\hline$V H L$ & 29298.3 & $23 \quad 7.9$ & 1 & 0.9 & 3 & 3.8 & 19 & 18.3 \\
\hline
\end{tabular}

${ }^{a}$ Only ccRCC cases with at least four genes successfully genotyped; ${ }^{b}$ Categories of the methylation index low, intermediate and high represent $0-19 \%, 20-39 \%$ and $40 \%$ or more methylation, respectively. ccRCC = clear-cell renal cell cancer, $C D O 1=$ Cysteine Dioxygenase type $1, F S T=$ Follistatin, $F Z D 10=$ Frizzled Class Receptor 10, GREM1 = Gremlin 1, DAN family BMP antagonist, $L A D 1$ = Ladinin 1, NEFH = Neurofilament, heavy polypeptide, NEURL = Neuralized E3 Ubiquitin Protein Ligase 1, NLCS = Netherlands Cohort Study, RASGFR2 = Ras-specific Guanine Nucleotide-releasing Factor 2, SFN = Stratifin, SFRP1 = Secreted FrizzledRelated Protein 1, VHL = von Hippel-Lindau.

The $\mathrm{HR}(95 \% \mathrm{Cl})$ of $\mathrm{ccRCC}$ risk by low, intermediate and high methylation for $\geq 30$ versus $0 \mathrm{~g}$ alcohol/d was $1.29(0.65-2.58)$ with $P$-trend=0.97, 0.46(0.17-1.25) with $P$-trend $=0.25$ and $0.55(0.24-1.27)$ with $P$-trend $=0.76$, respectively. There was no heterogeneity with respect to the association between the alcohol intake from beer, wine and liquor and risk of ccRCC, overall or stratified according to methylation (Suppl Table S6.2).

Multivariable adjusted HRs of dietary folate intake and RCC risk were all close to one (Table 6.3). In ccRCC, the multivariable $\mathrm{HR}(95 \% \mathrm{Cl})$ for participants with the highest quintile of folate intake was $1.07(0.70-1.64)$ compared to the lowest quintile ( $P$-trend=0.59). In addition, there was no indication for heterogeneity according to methylation status ( $P$-heterogeneity $=0.80)$. The $\mathrm{HR}(95 \% \mathrm{Cl})$ of $\mathrm{ccRCC}$ risk by low, intermediate and high methylation for high versus low dietary folate intake was 1.09(0.56-2.13) with $P$-trend=0.77, 1.15(0.52-2.57) with $P$-trend $=0.74$ and $0.93(0.45$ 1.93) with $P$-trend $=0.72$, respectively. 


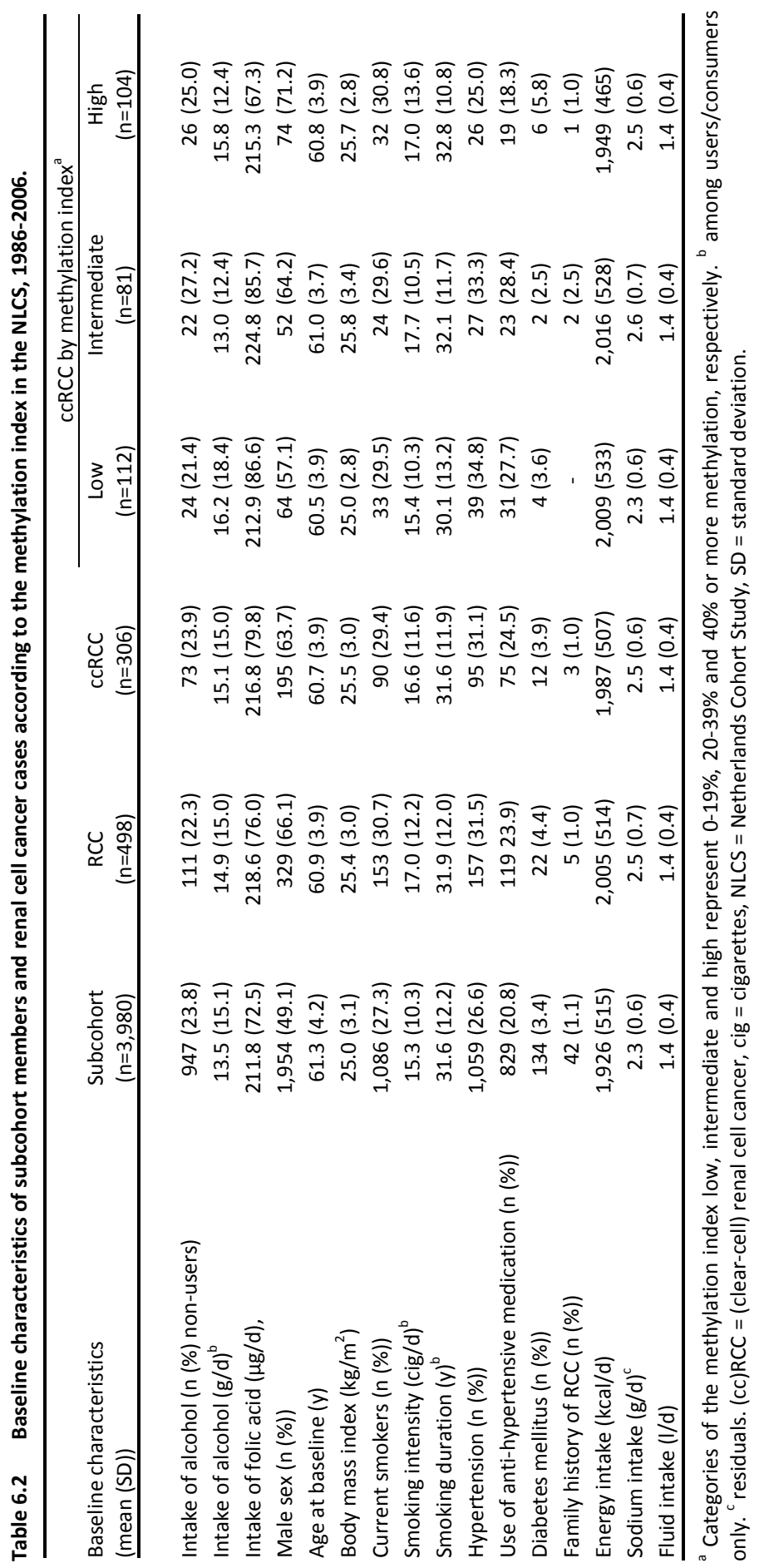




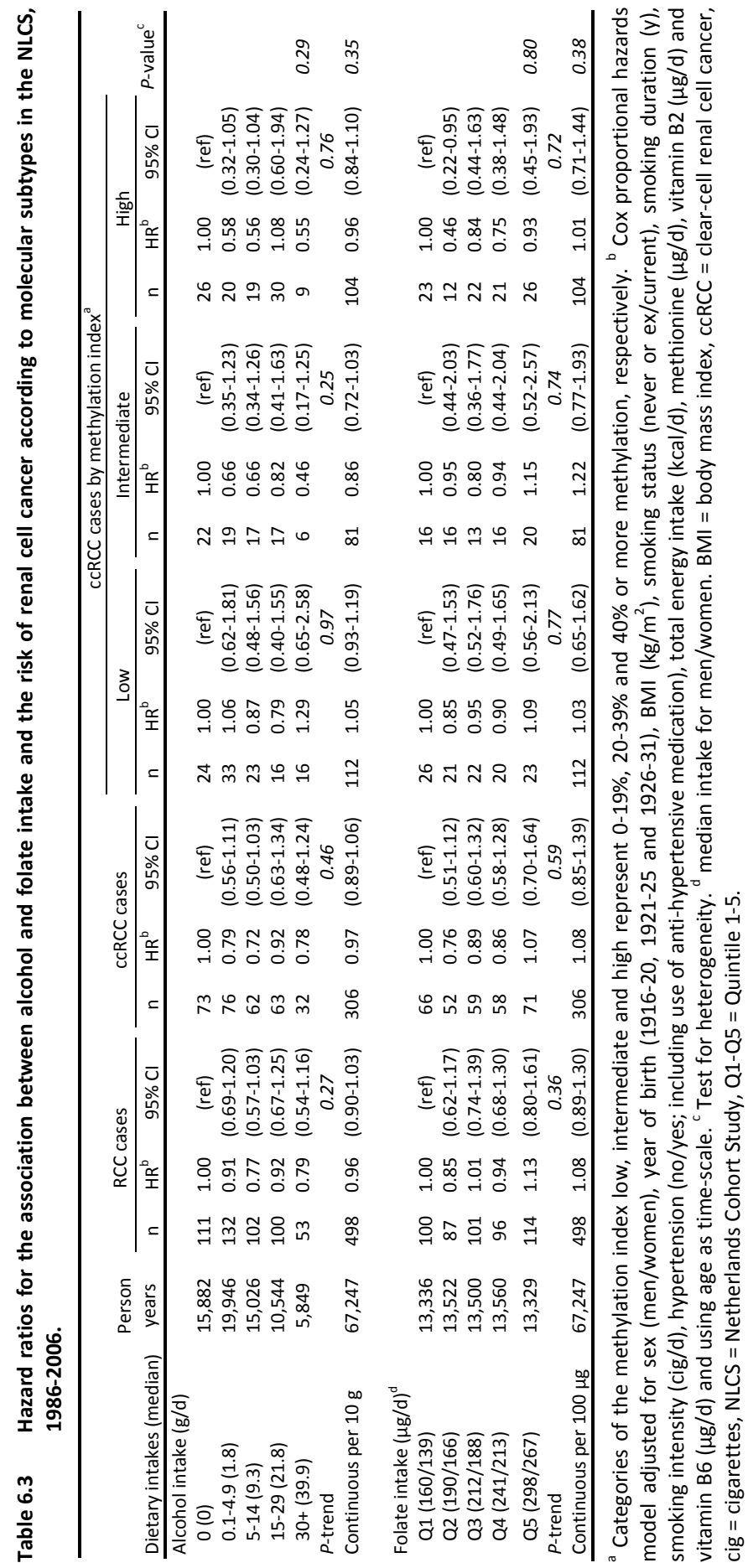


In interaction analyses on the combined effect of alcohol and folate intake in Table 6.4, we observed that the ccRCC risk for high alcohol/low folate consumers was not increased compared to low alcohol/high folate consumers [multivariable $\mathrm{HR}(95 \% \mathrm{Cl}): 0.87(0.56-1.35), P$-interaction $=0.08]$. The $\mathrm{HR}(95 \% \mathrm{Cl})$ of $\mathrm{ccRCC}$ risk stratified according to low, intermediate and high methylation for high alcohol/low folate consumers compared to low alcohol/high folate consumers was $0.73(0.36-1.46)$ with $P$-interaction $=0.32,0.89(0.39-2.04)$ with $P$-interaction $=0.47$ and $1.09(0.51-2.33)$ with $P$-interaction $=0.16$, respectively.

When the analyses of alcohol intake and RCC risk were split according to follow-up duration $(<11.3$ and $\geq 11.3$ years of follow-up), heterogeneity was observed (Table 6.5). During the first 11.3 years of follow-up, HRs of alcohol consumers were inversely associated with risk of RCC overall and CCRCC, compared to non-users of alcohol. Analyses using data from 11.3 until 20.3 years of follow-up, showed that alcohol consumption was positively associated with risk of RCC overall and CCRCC. In CCRCC, the $\mathrm{HR}(95 \% \mathrm{Cl})$ for $>15 \mathrm{~g}$ alcohol/d was $0.59(0.39-0.91)$ with $P$-trend $=0.02$ and 1.91(1.02-3.57) with $P$-trend=0.04 for the first 11.3 years and remaining follow-up years, respectively. Analyses of cCRCC stratified according to strata of promoter methylation showed similar patterns as in ccRCC overall. There was no heterogeneity in the association between dietary folate intake and RCC risk according to period of follow-up (data not shown). 


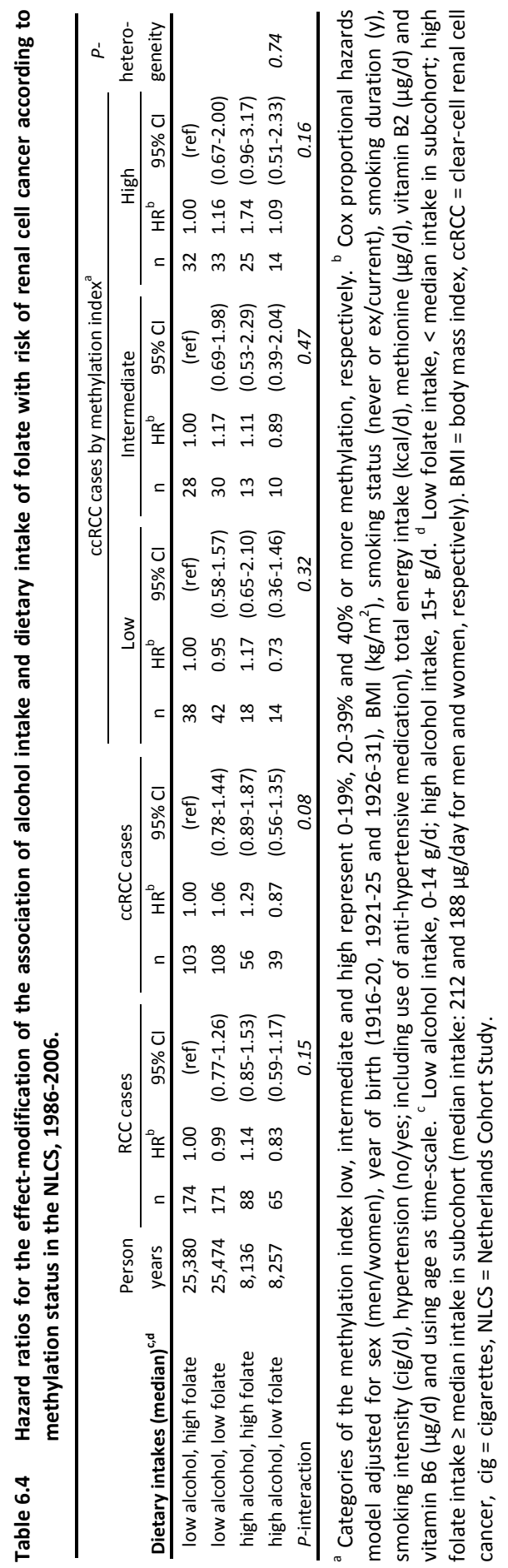




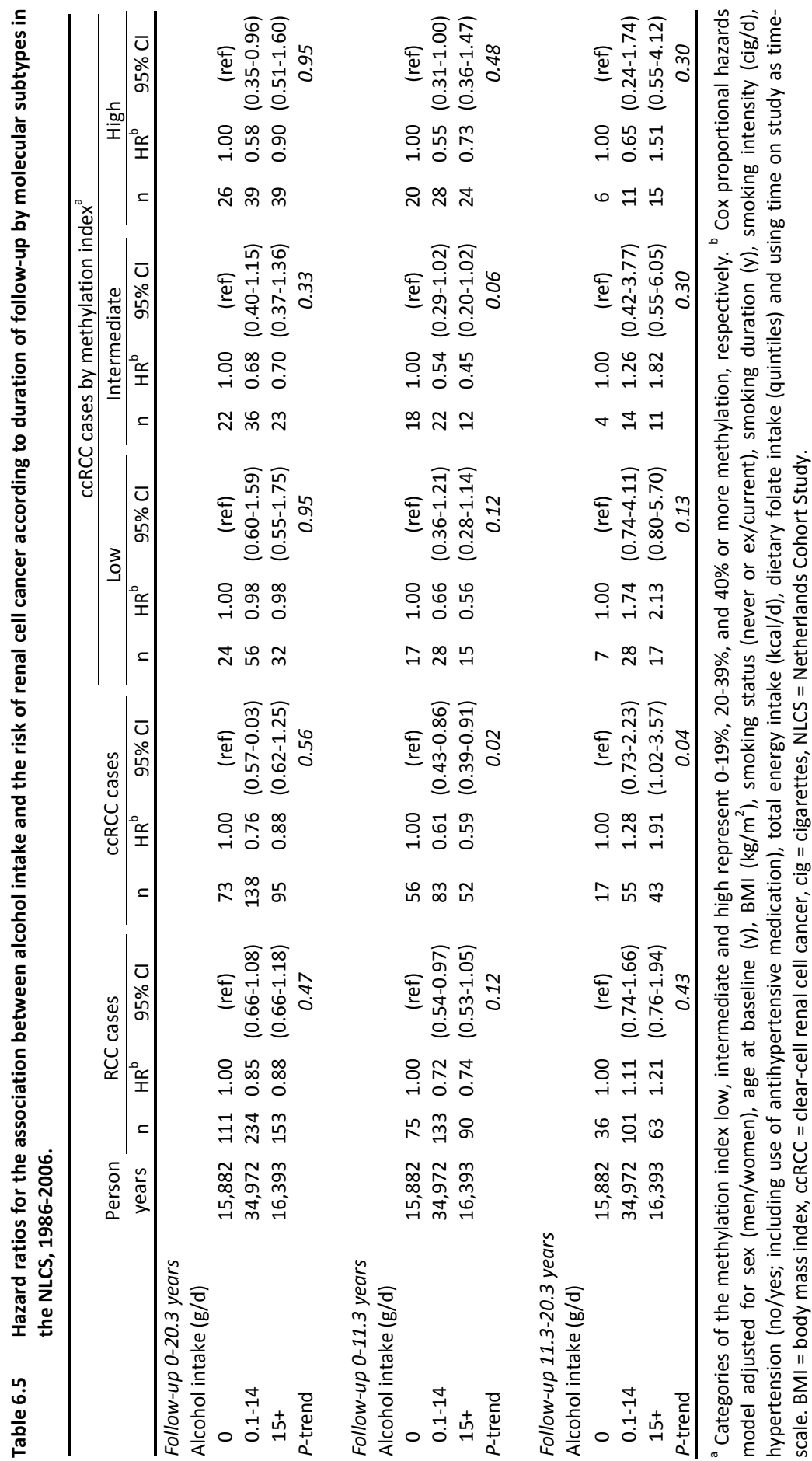




\section{DISCUSSION}

In this large prospective cohort study, alcohol intake was associated with a decreased RCC risk, although not statistically significant, and folate intake was not associated with RCC risk. There was no heterogeneity between alcohol or folate intake and ccRCC risk stratified according to categories of the methylation index.

Most prospective studies that investigated the association between alcohol intake and RCC risk have observed an inverse association with a clear dose-response effect $[3,4,14,33,34]$. Data from the NLCS were included in two previous publications with a shorter follow-up [4,14]. In the analysis of the Pooling Project of Prospective Studies on Diet and Cancer [4] 7.3 years of follow-up, and in the other [14] 11.3 years of follow-up were used. In the current analysis, with longer follow-up, the inverse association is weaker. When the analysis was split according to duration of follow-up, heterogeneity was observed. Alcohol consumption was associated with a decreased risk during the first 11.3 years of follow-up and with an increased risk after 11.3 years of follow-up. This heterogeneity may be explained by the fact that alcohol intake was measured only once at baseline and that lifestyle, including alcohol intake, of participants may have changed during follow-up. Alternatively, the latency period of the inverse association between alcohol intake and the occurrence of RCC could be short (i.e. $\sim<10$ years). It is also possible that the decreased HRs in the first period and the increased HRs in the second period of follow-up are due to chance.

Several studies have investigated the association between folate intake and RCC risk. A hospital-based case-control study, with a limited number of RCC cases, observed a statistically significant inverse association between folate intake and RCC risk [35]. Other studies, including two case-control studies [36,37] and a previous publication from the NLCS with shorter follow-up [38], did not observe an association between folate intake and RCC risk, although most point estimates were lower than one. In a nested case-control study in a cohort of Finnish smokers, serum levels of folate were not statistically significantly associated with RCC risk [39]. However, participants with the lowest levels of serum folate were at increased risk, compared to participants with higher serum folate levels [39]. In the hospital-based case-control study, in which questionnaires were used, participants with the lowest dietary intake of folate were also at increased risk [36]. In a large Central and Eastern European hospital-based case-control study, polymorphisms in genes involved in folate metabolism [methylenetetrahydrofolate reductase (MTHFR) and solute carrier family 19 (folate transporter), member 1 (SLC19A1)] were associated with increased risk of RCC, especially in participants with the lowest tertile of vegetable intake, an important source of folate $[40,41]$. The observations from these studies may be explained by a threshold effect in which only participants with the lowest intake of folate have an 
increased risk. However, in the current study no association (including no indication of a threshold effect) between dietary folate intake and RCC risk was observed.

The aim of this study was to investigate whether alcohol and folate intake play a role in promoter methylation in genes frequently methylated in ccRCC. It has been suggested that there is a specific subtype of cancer that is characterized by extensive promoter methylation of tumor suppressor and DNA repair genes and referred to as CPG island methylator phenotype (CIMP) [8]. CIMP has been investigated extensively in colorectal cancer, but may also exist in other cancers, such as ccRCC $[8,9]$. Since no definition for CIMP in ccRCC has been established so far, we used a methylation index of CpG islands frequently methylated in $\mathrm{ccRCC}$ as a measure for general promoter methylation. Although we recognize that the Infinium 450K platform would for example be a more comprehensive way to analyse promoter methylation of CpG islands in ccRCC, our selection strategy to include particular genes of interest is much more efficient in large epidemiological studies.

Different cancer phenotypes may be associated with different pathways of carcinogenesis, including etiology. However, the current study did not uncover such pathway, because no heterogeneity was observed in associations between alcohol and folate intake and different molecular subtypes of ccRCC defined by the methylation index of selected genes inactivated by promoter methylation in cCRCC. There are several explanations for the absence of heterogeneity. First, the participants of the NLCS reported moderate alcohol consumption and less than $10 \%$ of the subcohort reported a consumption of more than 30 grams of alcohol per day. It is conceivable that only a high level of alcohol intake is associated with promoter methylation, and that the subgroup of high alcohol consumers in the current study is too small to demonstrate this. Second, since there is no clear definition of CIMP in ccRCC or in other cancers, we developed a methylation index to define subgroups of ccRCC defined by promoter methylation. Our definition of 'high methylation' included ccRCC cases with promoter methylation of more than $40 \%$ of the eleven selected genes. This subgroup constituted $35 \%$ of the ccRCC cases in our series. In the study of Arai et al. 14 out of 104 cases (13.5\%) were characterized by high promoter methylation, using DNA methylation levels of $801 \mathrm{CpG}$ islands [9]. More research is needed to confirm whether CIMP exists in CCRCC and what panel of markers can be used to classify CIMP accurately. Third, risk estimates may be attenuated due to random misclassification of dietary intakes, caused by a single baseline measurement and the long follow-up, even though intakes were rather stable during the first five years of follow-up [25]. Finally, only dietary folate intake was investigated. Other nutrients, such as choline, vitamin B and methionine, are also involved in folate metabolism $[13,42]$, and might influence adequate methylation status as well. 
The current study also has several strengths. Loss to follow-up was very limited and cancer follow-up was very complete (>96\%) [17]. Furthermore, we collected tumor samples from $\sim 80 \%$ of the cases. This, combined with the prospective study design, makes selection and information bias unlikely. The study is among the largest prospective studies on RCC and, so far, the only prospective study including FFPE tumor tissues.

In conclusion, in this study we did not observe an association between alcohol, folate intake and promoter CpG island hypermethylation in ccRCC using a methylation index as tool to define methylation-specific subgroups ccRCC. Therefore, this study does not support the hypothesis that alcohol and folate intake are involved in ccRCC carcinogenesis through promoter methylation of our methylation index. 


\section{REFERENCES}

1. Chow WH, Dong LM, Devesa DD. Epidemiology and risk factors for kidney cancer. Nat Rev Urol 2010; 7:245-57.

2. Song DY, Song S, Song Y, Lee JE. Alcohol intake and renal cell cancer risk: a meta-analysis. Br J Cancer 2012;106:1881-90.

3. Bellocco R, Pasquali E, Rota M, Bagnardi V, Tramacere I, Scotti L, Pelucchi C, Boffetta P, Corrao G, La Vecchia C. Alcohol drinking and risk of renal cell carcinoma: results of a meta-analysis. Ann Oncol 2012;23:2235-44.

4. Lee JE, Hunter DJ, Spiegelman D, Adami HO, Albanes D, Bernstein L, van den Brandt PA, Buring JE, Cho E, Folsom AR, Freudenheim JL, Giovannucci E, Graham S, Horn-Ross PL, Leitzmann MF, McCullough ML, Miller AB, Parker AS, Rodriguez C, Rohan TE, Schatzkin A, Schouten LJ, Virtanen M, Willett WC, Wolk A, Zhang SM, Smith-Warner SA. Alcohol intake and renal cell cancer in a pooled analysis of 12 prospective studies. J Nat/ Cancer Inst 2007;99:801-10.

5. IARC Working Group on the Evaluation of Carcinogenic Risks to Humans, Alcohol consumption and ethyl carbamate. IARC Monogr Eval Carcinog Risks Hum 2010;96:3-1383.

6. $\quad$ Esteller M. Epigenetics in cancer. N Engl J Med 2008;358:1148-59.

7. Baldewijns MM, van Vlodrop IJ, Schouten LJ, Soetekouw PM, de Bruïne AP, van Engeland M. Genetics and epigenetics of renal cell cancer. Biochim Biophys Acta 2008;1785:133-55.

8. Hughes LA, Melotte V, de Schrijver J, de Maat M, Smit VT, Bovée JV, French PJ, van den Brandt PA, Schouten LJ, de Meyer T, van Criekinge W, Ahuja N, Herman JG, Weijenberg MP, van Engeland M. The CpG island methylator phenotype: what's in a name? Cancer Res 2013;73:5858-68.

9. Arai E, Chiku S, Mori T, Gotoh M, Nakagawa T, Fujimoto H, Kanai Y. Single-CpG-resolution methylome analysis identifies clinicopathologically aggressive CpG island methylator phenotype clear cell renal cell carcinomas. Carcinogenesis 2012;33:1487-93.

10. Mason, J.B. and S.W. Choi, Effects of alcohol on folate metabolism: implications for carcinogenesis. Alcohol 2005;35:235-41.

11. McKay JA, Mathers JC. Diet induced epigenetic changes and their implications for health. Acta Physiol (Oxf) 2011;202:103-18.

12. Supic G, Jagodic M, Magic Z. Epigenetics: a new link between nutrition and cancer. Nutr Cancer 2013; 65:781-92.

13. Varela-Rey M, Woodhoo A, Martinez-Chantar ML, Mato JM, Lu SC. Alcohol, DNA methylation, and cancer. Alcohol Res 2013;35:25-35.

14. Schouten LJ, van Dijk BA, Oosterwijk E, van Engeland M, Hulsbergen-van de Kaa CA, Kiemeney LA, Goldbohm RA, Kester A, de Vogel S, Schalken JA, van den Brandt PA. Alcohol consumption and mutations or promoter hypermethylation of the von Hippel-Lindau gene in renal cell carcinoma. Cancer Epidemiol Biomarkers Prev 2008;17:3543-50.

15. Van den Brandt PA, Goldbohm RA, van 't Veer P, Volovics A, Hermus RJ, Sturmans F. A large-scale prospective cohort study on diet and cancer in The Netherlands. J Clin Epidemiol 1990;43:285-95.

16. Van den Brandt PA, Schouten LJ, Goldbohm RA, Dorant E, Hunen PM. Development of a record linkage protocol for use in the Dutch Cancer Registry for Epidemiological Research. Int J Epidemiol 1990;19:553-8.

17. Goldbohm RA, Van den Brandt PA, Dorant E. Estimation of the coverage of Dutch municipalities by cancer registries and PALGA based on hospital discharge data. Tijdschr Soc Gezondheidsz 1994;72: 80-4.

18. van Houwelingen KP, van Dijk BA, Hulsbergen-van de Kaa CA, Schouten $L$, Gorissen HJ, Schalken JA, van den Brandt PA, Oosterwijk E. Prevalence of von Hippel-Lindau gene mutations in sporadic renal cell carcinoma: results from The Netherlands cohort study. BMC Cancer 2005;5:57.

19. Eble J, et al. World Health Organization Classification of Tumours. Pathology and Genetics. Tumours of the Urinary System and Male Genital Organs. 2004, Lyon: IARC Press.

20. Goldbohm RA, Van den Brandt PA, Van 't Veer P, Dorant E, Sturmans F, Hermus RJ. Prospective study on alcohol consumption and the risk of cancer of the colon and rectum in the Netherlands. Cancer Causes Control 1994;5:95-104. 
21. Nevo tabel, Dutch food composition table 1986-1987; Nederlands voedingsstoffenbestand 19861987. 1986, The Hague, The Netherlands: Voorlichtingsbureau voor de Voeding.

22. Konings EJ. A validated liquid chromatographic method for determining folates in vegetables, milk powder, liver, and flour. J AOAC Int 1999;82:119-27.

23. Konings EJ, Roomans HH, Dorant E, Goldbohm RA, Saris WH, van den Brandt PA. Folate intake of the Dutch population according to newly established liquid chromatography data for foods. Am J Clin Nutr 2001;73:765-76.

24. Goldbohm RA, van den Brandt PA, Brants HA, van't Veer P, Al M, Sturmans F, Hermus RJ. Validation of a dietary questionnaire used in a large-scale prospective cohort study on diet and cancer. Eur J Clin Nutr 1994;48:253-65.

25. Goldbohm RA, van 't Veer P, van den Brandt PA, van 't Hof MA, Brants HA, Sturmans F, Hermus RJ. Reproducibility of a food frequency questionnaire and stability of dietary habits determined from five annually repeated measurements. Eur J Clin Nutr 1995;49:420-9.

26. van Vlodrop IJ, Baldewijns MM, Smits KM, Schouten L, van Neste L, van Criekinge W, van Poppel H, Lerut E, Schuebel KE, Ahuja N, Herman JG, de Bruïne AP, van Engeland M. Prognostic significance of Gremlin1 (GREM1) promoter CpG island hypermethylation in clear cell renal cell carcinoma. Am J Pathol 2010;176:575-84.

27. Derks S, Lentjes $M H$, Hellebrekers DM, de Bruïne AP, Herman JG, van Engeland M. Methylationspecific PCR unraveled. Cell Oncol 2004;26:291-9.

28. Herman JG1, Graff JR, Myöhänen S, Nelkin BD, Baylin SB. Methylation-specific PCR: a novel PCR assay for methylation status of CpG islands. Proc Natl Acad Sci U S A 1996;93:9821-6.

29. van Engeland $M$, Roemen GM, Brink M, Pachen MM, Weijenberg MP, de Bruïne AP, Arends JW, van den Brandt PA, de Goeij AF, Herman JG. K-ras mutations and RASSF1A promoter methylation in colorectal cancer. Oncogene 2002;21:3792-5.

30. Barlow, W.E., Robust variance estimation for the case-cohort design. Biometrics 1994;50:1064-72.

31. de Vogel S, Bongaerts BW, Wouters KA, Kester AD, Schouten LJ, de Goeij AF, de Bruïne AP, Goldbohm RA, van den Brandt PA, van Engeland M, Weijenberg MP. Associations of dietary methyl donor intake with MLH1 promoter hypermethylation and related molecular phenotypes in sporadic colorectal cancer. Carcinogenesis 2008;29:1765-73.

32. Wacholder $S$, et al. Alternative variance and efficiency calculations for the case-cohort design Biometrika 1989;76:117-23.

33. Lew JQ, Chow WH, Hollenbeck AR, Schatzkin A, Park Y. Alcohol consumption and risk of renal cell cancer: the NIH-AARP diet and health study. Br J Cancer 2011;104:537-41.

34. Allen NE, Beral V, Casabonne D, Kan SW, Reeves GK, Brown A, Green J; Million Women Study Collaborators. Moderate alcohol intake and cancer incidence in women. J Natl Cancer Inst 2009;101: 296-305.

35. Aune D1, Deneo-Pellegrini H, Ronco AL, Boffetta P, Acosta G, Mendilaharsu M, De Stefani E. Dietary folate intake and the risk of 11 types of cancer: a case-control study in Uruguay. Ann Oncol 2011;22: 444-51.

36. Bosetti C, Scotti L, Maso LD, Talamini R, Montella M, Negri E, Ramazzotti V, Franceschi S, La Vecchia C. Micronutrients and the risk of renal cell cancer: a case-control study from Italy. Int J Cancer 2007; 120:892-6.

37. Brock KE, Ke L, Gridley G, Chiu BC, Ershow AG, Lynch CF, Graubard BI, Cantor KP. Fruit, vegetables, fibre and micronutrients and risk of US renal cell carcinoma. Br J Nutr 2012;108:1077-85.

38. van Dijk BA, Schouten L, Oosterwijk E, Hulsbergen-van de Kaa CA, Kiemeney LA, Goldbohm RA, Schalken JA, van den Brandt PA. Carotenoid and vitamin intake, von Hippel-Lindau gene mutations and sporadic renal cell carcinoma. Cancer Causes Control 2008;19:125-34.

39. Gibson TM, Weinstein SJ, Mayne ST, Pfeiffer RM, Selhub J, Taylor PR, Virtamo J, Albanes D, Stolzenberg-Solomon R. A prospective study of one-carbon metabolism biomarkers and risk of renal cell carcinoma. Cancer Causes Control 2010;21:1061-9.

40. Moore LE, Hung R, Karami S, Boffetta P, Berndt S, Hsu CC, Zaridze D, Janout V, Kollarova H, Bencko V, Navratilova M, Szeszenia-Dabrowska N, Mates D, Mukeria A, Holcatova I, Yeager M, Chanock S, Garcia-Closas M, Rothman N, Chow WH, Brennan P. Folate metabolism genes, vegetable intake and renal cancer risk in central Europe. Int J Cancer 2008;122:1710-5. 
41. Gibson TM, Brennan P, Han S, Karami S, Zaridze D, Janout V, Kollarova H, Bencko V, Navratilova M, Szeszenia-Dabrowska N, Mates D, Slamova A, Pfeiffer RM, Stolzenberg-Solomon RZ, Mayne ST, Yeager M, Chanock S, Rothman N, Chow WH, Rosenberg PS, Boffetta P, Moore LE. Comprehensive evaluation of one-carbon metabolism pathway gene variants and renal cell cancer risk. PLoS One 2011;6: e26165.

42. Anderson OS, Sant KE, Dolinoy DC. Nutrition and epigenetics: an interplay of dietary methyl donors, one-carbon metabolism and DNA methylation. J Nutr Biochem 2012;23:853-9. 
Suppl Table S6.1 Primer sequences and sequence condition used to analyse promoter CpG island methylation of selected genes in clear-cell renal cell cancer in the NLCS, 1986-2006.

\begin{tabular}{|c|c|c|c|}
\hline Gene & Primer sequence & $\operatorname{Tm}\left({ }^{\circ} \mathrm{C}\right)$ & Cycles (n) \\
\hline \multicolumn{4}{|l|}{$\overline{C D O 1}$} \\
\hline Flanking primer, upstream & GGGAGAGATTGYGYGGAGTTTA & 56 & 35 \\
\hline Flanking primer, downstream & AAAACCACCCAAAAAAAATAAC & 56 & 35 \\
\hline Unmethylated sense strand & GATTTTTGGGATGTTGGAGATAAT & 64 & 30 \\
\hline Methylated sense strand & TTTTTGGGACGTCGGAGATAAC & 64 & 30 \\
\hline Unmethylated antisense strand & AAAACAAAAAAACCCTACAAACACA & 64 & 30 \\
\hline Methylated antisense strand & CGAAAAAACCCTACGAACACG & 64 & 30 \\
\hline \multicolumn{4}{|l|}{ FST } \\
\hline Flanking primer, upstream & TGTAAAGTTAGGTATTTATAGATTTAGATATA & 56 & 35 \\
\hline Flanking primer, downstream & CRCTCCAAAAAAACTTTTAACAAAC & 56 & 35 \\
\hline Unmethylated sense strand & TTTGTGTTTAGGTTGTGGGTGTTT & 66 & 30 \\
\hline Methylated sense strand & CGTTTAGGTTGCGGGTGTTC & 66 & 30 \\
\hline Unmethylated antisense strand & TACAAACAACCAAAAAACCCCA & 66 & 30 \\
\hline Methylated antisense strand & AAACGACCGAAAAACCCCG & 66 & 30 \\
\hline \multicolumn{4}{|l|}{ FZD10 } \\
\hline Flanking primer, upstream & GGGTTGTTTYGGGGTTGG & 56 & 35 \\
\hline Flanking primer, downstream & CCRCCRCTACTTTACATAAAAAAAC & 56 & 35 \\
\hline Unmethylated sense strand & TGTGGGTGGGATTAGGTGTTGT & 64 & 35 \\
\hline Methylated sense strand & GGCGGGATTAGGCGTTGC & 64 & 35 \\
\hline Unmethylated antisense strand & TTTACATAAAAAAACACAACAACCCA & 64 & 35 \\
\hline Methylated antisense strand & TAAAAAAACGCAACGACCCG & 64 & 35 \\
\hline \multicolumn{4}{|l|}{ GREM1 } \\
\hline Flanking primer, upstream & GGGGTTTTTTTTTGTTGAGGT & 56 & 35 \\
\hline Flanking primer, downstream & СТАСТАССАССАACACCAAAAAC & 56 & 35 \\
\hline Unmethylated sense strand & TTTTTTTGTTGAGGTTGTGGATATT & 65 & 30 \\
\hline Methylated sense strand & TTTGTTGAGGTCGCGGATATC & 65 & 30 \\
\hline Unmethylated antisense strand & CAAAAACATATTСАAАAАССТССА & 65 & 30 \\
\hline Methylated antisense strand & AAAACGTATTCGAAAACCTCCG & 65 & 30 \\
\hline \multicolumn{4}{|l|}{$L A D 1$} \\
\hline Flanking primer, upstream & ATTGGTTTTTGAGTAGGAAGTTTTT & 56 & 35 \\
\hline Flanking primer, downstream & CCRCATTAATTACAACCCAAA & 56 & 35 \\
\hline Unmethylated sense strand & GAGTAGGAAGTTTTTTGTTTTTTGTTTT & 63 & 35 \\
\hline Methylated sense strand & GTAGGAAGTTTTTCGTTTTCGTTTC & 63 & 35 \\
\hline Unmethylated antisense strand & AACCCAAACCAACCCAACCA & 63 & 35 \\
\hline Methylated antisense strand & CCAAACCGACCCGACCG & 63 & 35 \\
\hline \multicolumn{4}{|l|}{$N E F H$} \\
\hline Flanking primer, upstream & TTTATTGTTAAGGGGTTGGATT & 56 & 35 \\
\hline Flanking primer, downstream & CRAAACTCATCATAACTAAACAAATAC & 56 & 35 \\
\hline Unmethylated sense strand & GTTAAGGGGTTGGATTTGGTTGT & 62 & 35 \\
\hline Methylated sense strand & GGGGTTGGATTCGGTCGC & 62 & 35 \\
\hline Unmethylated antisense strand & САТСATAACTAAACAAATACACAAAACCA & 62 & 35 \\
\hline Methylated antisense strand & AACTAAACAAATACGCGAAACCG & 62 & 35 \\
\hline
\end{tabular}


Suppl Table S6.1 (continued)

\begin{tabular}{|c|c|c|c|}
\hline Gene & Primer sequence & $\operatorname{Tm}\left({ }^{\circ} \mathrm{C}\right)$ & Cycles (n) \\
\hline \multicolumn{4}{|l|}{ NEURL } \\
\hline Flanking primer, upstream & GGTTTAGGGTTTTGTTTGTGG & 56 & 35 \\
\hline Flanking primer, downstream & ССТСААСТТССТТТСТСТАААСТТ & 56 & 35 \\
\hline Unmethylated sense strand & TTGTTTGTGGTTTTTGTTTTTGTTAT & 65 & 35 \\
\hline Methylated sense strand & GTTTGTGGTTTTCGTTTTCGTTAC & 65 & 35 \\
\hline Unmethylated antisense strand & СТTТСТСТАААСТTСАСААТССТТААСА & 65 & 35 \\
\hline Methylated antisense strand & TCTAAACTTCGCGATCCTTAACG & 65 & 35 \\
\hline \multicolumn{4}{|l|}{ RASGFR2 } \\
\hline Flanking primer, upstream & TATTTTTTGGAGGGTTGTAGTTG & 56.1 & 35 \\
\hline Flanking primer, downstream & CCCTAATCCCCRAATTAAAA & 56.2 & 35 \\
\hline Unmethylated sense strand & AACGTTCGCGTTATTTAGGGTC & 60.3 & 30 \\
\hline Methylated sense strand & GAATGAATGTTTGTGTTATTTAGGGTT & 60.3 & 30 \\
\hline Unmethylated antisense strand & ATTAAAACGACAAAAAAATACGACG & 60.1 & 30 \\
\hline Methylated antisense strand & CAAATTAAAACAACAAAAAAATACAACA & 60.1 & 30 \\
\hline \multicolumn{4}{|l|}{ SFN } \\
\hline Flanking primer, upstream & GTTYGGAGGAGAAGGGGTT & 56 & 35 \\
\hline Flanking primer, downstream & СТTСАТСТTСАААТААААААССС & 56 & 35 \\
\hline Unmethylated sense strand & GGGGTTTGAGGTGTGTGAGTATT & 64 & 35 \\
\hline Methylated sense strand & GGTTCGAGGTGCGTGAGTATC & 64 & 35 \\
\hline Unmethylated antisense strand & САААТАAАAААСССААСТСТСААСА & 64 & 35 \\
\hline Methylated antisense strand & AAAAAACCCGACTCTCGACG & 64 & 35 \\
\hline \multicolumn{4}{|l|}{ SFRP1 } \\
\hline Flanking primer, upstream & TTTAGTTTTGTAGTTTTYGGAGTTAG & 56 & 35 \\
\hline Flanking primer, downstream & CCCCRACCAATAACRACCCTC & 56 & 35 \\
\hline Unmethylated sense strand & GTTTTGTAGTTTTTGGAGTTAGTGTTGTGT & 66 & 25 \\
\hline Methylated sense strand & TGTAGTTTTCGGAGTTAGTGTCGCGC & 66 & 25 \\
\hline Unmethylated antisense strand & СТСААССТАСААТСАААAАСАACACAAACA & 66 & 25 \\
\hline Methylated antisense strand & CCTACGATCGAAAACGACGCGAACG & 66 & 25 \\
\hline \multicolumn{4}{|l|}{ VHL } \\
\hline Flanking primer, upstream & GGAGGGYGGAGAATTGGGA & 56 & 35 \\
\hline Flanking primer, downstream & CCTCRACRCCCAATTCCTCC & 56 & 35 \\
\hline Unmethylated sense strand & AATTGGGATGAGGTTGAGGTAGGT & 66 & 30 \\
\hline Methylated sense strand & GGGACGAGGTCGAGGTAGGC & 66 & 30 \\
\hline Unmethylated antisense strand & TTCСТССАААССАААСТСТTССА & 66 & 30 \\
\hline Methylated antisense strand & CTCCGA ACCGAA CTCTCCG & 66 & 30 \\
\hline
\end{tabular}

CDO1 = cysteine dioxygenase type $1, F S T=$ follistatin, $F Z D 10=$ frizzled class receptor $10, G R E M 1=$ gremlin 1 , DAN family BMP antagonist, $L A D 1=$ Ladinin $1, N E F H=$ neurofilament, heavy polypeptide, $N E U R L=$ neuralized E3 ubiquitin protein ligase 1, NLCS = Netherlands Cohort Study, RASGFR2 = ras-specific guanine nucleotide-releasing factor $2, S F N=$ stratifin, $S F R P 1=$ secreted frizzled-related protein $1, V H L=$ von HippelLindau. 


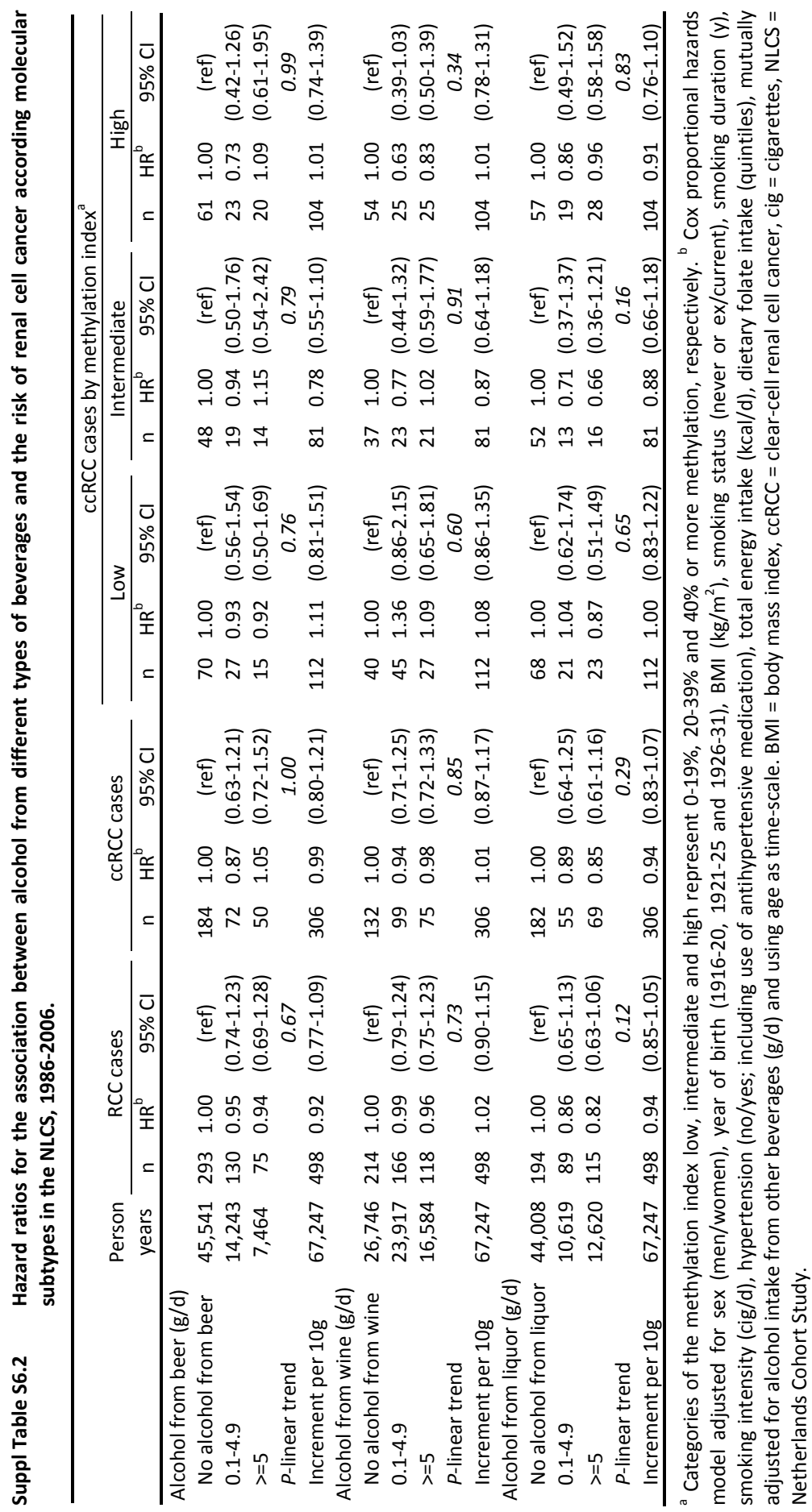




\section{CHAPTER 7}

\section{Promoter methylation of CDO1 identifies clear-cell renal cell cancer patients with poor survival outcome}

Ivette AG Deckers, Leo J Schouten, Leander Van Neste, Iris JH van Vlodrop, Patricia MMB Soetekouw, Marcella MLL Baldewijns, Jana Jeschke, Nita Ahuja, James $G$ Herman, Piet A van den Brandt and Manon van Engeland 


\section{ABSTRACT}

\section{Introduction}

In this era of molecular diagnostics, prediction of clear-cell renal cell cancer (ccRCC) survival requires optimization, as current prognostic markers fail to determine individual patient outcome. Epigenetic events are promising molecular markers. Promoter CpG island methylation of cysteine dioxygenase type 1 (CDO1), which was identified as prognostic marker for breast cancer, is studied as potential marker for ccRCC survival.

\section{Methods}

We collected primary tissues of 365 ccRCC cases identified within the prospective Netherlands Cohort Study (NLCS). In this population-based series, CDO1 promoter methylation was observed in 124 of 324 (38.3\%) patients with successful methylation-specific PCR analysis. Kaplan-Meier curves and Wilcoxon tests were used to evaluate 10-year ccRCC-specific survival. Cox regression analysis was used to obtain crude and multivariate hazard ratios (HR) and $95 \%$ confidence intervals $(\mathrm{Cl})$. The relative prognostic value of multivariate models with and without $C D O 1$ promoter methylation was compared using Likelihood-Ratio tests.

\section{Results}

Patients with $C D O 1$ promoter methylation have a significantly poorer survival than those without (Wilcoxon $P=0.006$ ). Differences in survival were independent of other prognostic factors, including age and sex $[\mathrm{HR}(95 \% \mathrm{Cl})=1.66(1.12-2.45)]$ and TNM stage, tumor size and Fuhrman grade $[\mathrm{HR}(95 \% \mathrm{Cl})=1.89(1.25-2.85)]$. Multivariate models performed better with than without $C D O 1$ promoter methylation status (Likelihood-Ratio $P=0.003$ ). Survival curves were validated in an independent series of $280 \mathrm{ccRCC}$ cases from the Cancer Genome Atlas (TCGA; Wilcoxon $P<0.001$ ).

\section{Conclusion}

CDO1 promoter methylation may not substitute common prognostic markers to predict ccRCC survival, but offers additional, relevant prognostic information, indicating that it could be a novel molecular marker to determine ccRCC prognosis. 


\section{INTRODUCTION}

Major improvements in the understanding of the molecular biology of tumors increased the possibilities for targeted therapies, such as tyrosine kinase inhibitors (TKIs) and mammalian target of rapamycin (mTOR) inhibitors in clear-cell renal cell cancer (ccRCC) patients. In this era of personalized therapies and molecular diagnostics, current prognostic parameters, such as patient performance status, tumor size, cancer stage, and nuclear grade, fail to determine individual patient outcome and optimization of prognostic parameters is thus necessary.

Promoter CpG island methylation markers are promising tools for early detection of tumors, therapeutic stratification and to determine clinical prognosis. Promoter CpG island methylation occurs early and frequently in carcinogenesis, providing selective advantage to neoplastic cells and, therefore, contributing to both disease development and progression [1-4]. For ccRCC, genetic and epigenetic alterations in the Von Hippel-Lindau (VHL) tumor suppressor gene (TSG) appeared to have little value in the prediction of $c \mathrm{RCC}$ prognosis, even though inactivation of the $V H L$ gene is an early and key event in the development of ccRCC [5].

Recently, promoter CpG island methylation of cysteine dioxygenase type 1 (CDO1) has been found in primary tissues of multiple tumor types, including colon, breast, esophagus, ovary, lung, bladder, pancreas and stomach tumors [6,7], cholangiocarcinoma [8] and lung squamous cell carcinoma [9]. In addition, it has been identified as prognostic marker for breast cancer $[7,10,11]$, but CDO1 promoter CpG island methylation and its potential association with prognosis has not yet been investigated in ccRCC.

CDO1 is thought to be involved in carcinogenesis, as it plays a role in oxidative stress response of cancer cells by reducing antioxidant capacity [7]. Moreover, CDO1 is a key enzyme in the taurine biosynthetic pathway, in which it oxidizes cysteine into cysteine sulfinic acid (CSA), eventually converting into taurine (2-aminoethanesulfonic acid) [12-14]. Taurine is a major intracellular amino acid and is involved in many physiological and biological processes in the kidney, including osmoregulation and regulation of renal blood flow and renal cell cycle and apoptosis [15]. Given that, epigenetic silencing of $C D O 1$ through promoter $\mathrm{CpG}$ island methylation may be of particular interest for renal carcinogenesis.

In the present study, we investigated the prognostic utility of CDO1 promoter CpG island methylation in a population-based series of ccRCC patients embedded within the prospective Netherlands Cohort Study (NLCS) and in an independent series of cCRCC patients from The Cancer Genome Atlas (TCGA). 


\section{METHODS}

\section{Study population}

The population-based series of ccRCC cases is derived from the prospective NLCS, which was initiated in 1986 and included 120,852 men and women in the ages of 55-69 years at baseline [16]. After 20.3 years of follow-up, 608 incident microscopically confirmed RCC cases (ICD-O: M8010-8119, 8140-8570) were identified within the NLCS using computerized record linkage with the Netherlands Cancer registry and the Dutch Pathology registry PALGA $[17,18]$. Only histologically confirmed RCC cases ( $n=568$ ) were eligible for the collection of formalin-fixed paraffin-embedded (FFPE) tumor tissues from $\sim 50$ pathology laboratories throughout the Netherlands. The collection was conducted in two phases; initially only cases from the first 11.3 years of NLCS follow-up were included [19], however recent efforts were made to expand the series. This study was approved by the review board of Maastricht University (Maastricht, the Netherlands).

\section{Tissue collection}

Tumor tissues were available for $79.8 \%$ of the RCC cases $(n=453)$. Inclusion ranged over 5 -years follow-up periods from $71.3 \%$ to $87.7 \%$. For cases identified between 1986 and 1990 retrieval was lowest, because the Dutch pathology registry (PALGA) had incomplete coverage during this period and some pathological laboratories had problems to locate older tissues in particular. In total, the retrieval was unsuccessful for 115 cases; 46 cases had no surgery, for 24 cases the availability or location of their tissues was unknown from the Dutch pathology registry (PALGA) and, for 45 cases the pathological laboratory refused or was unable to send their tissues. Hematoxylin and eosin (HE) stained slides of tumor tissues were assessed by an experienced genitourinary pathologist to confirm tumor histology based on the WHO classification of tumors and Fuhrman grade $[20,21]$. The entire series of collected tumor tissues included $80.6 \%$ ( $n=365$ ) tumors with clear-cell histology. Information on patient and tumor characteristics, such as age at diagnosis, gender, TNM stage, tumor size and initial treatment was available from the pathological reports and cancer registries. Follow-up was accomplished by record linkage to the municipal population registries and the causes of death registry from Statistics Netherlands. ccRCC cases of which tissues were collected after autopsy were excluded. In total, 356 ccRCC cases were eligible for survival analyses.

\section{DNA isolation and CDO1 promoter CpG island methylation}

Methods used for DNA isolation of material from cCRCC cases included in the initial, 11.3 years follow-up collection have been described previously [19]. For recently added cases, vital tumor areas of the FFPE tumor tissues were dissected before DNA 
isolation. DNA was isolated using the QIAamp DNA Mini Kit for isolation of Genomic DNA from Tissue (Qiagen), according to manufacturer's instructions.

CDO1 promoter CpG island hypermethylation, in short CDO1 promoter methylation, was analyzed by nested methylation-specific PCR (MSP), as previously described in detail elsewhere [22-24]. All PCRs were done with controls for unmethylated alleles [DNA from normal lymphocytes or DNA from human umbilical vein endothelial cells (HUVEC)], methylated alleles [normal lymphocyte DNA treated in vitro with Sssl methyltransferase (New England Biolabs, Ipswich, MA)], and a no template control. Reproducibility of MSP analysis in 53 cases was 89\%. Primer sequences and MSP conditions are provided in Suppl Table S7.1. MSP analyses were performed successfully for 324 out of 356 cases (91.0\%).

\section{Statistical analyses}

Statistical analyses were conducted in STATA version 12 (STATA Corp., College Station, TX). Patient and tumor characteristics of CCRCC cases with and without CDO1 methylation were compared using the Kruskal-Wallis tests (for continuous variables) or $\chi^{2}$ tests (for categorical variables). Survival was defined as the time from diagnosis until death or until the end of follow-up. However, for some cases follow-up up to 20 years has been established. As we do not consider such long follow-up relevant for ccRCC-specific survival, follow-up was truncated after 10 years. Kaplan-Meier curves and Wilcoxon tests were used to evaluate 10-year survival of ccRCC cases with and without CDO1 promoter methylation. In addition, Cox proportional hazards analyses were used to obtain hazard ratios (HR) and corresponding $95 \%$ confidence intervals (CI) for the association between CDO1 promoter methylation and 10-year ccRCCspecific survival. HRs were adjusted for age at diagnosis (y) and sex (men/women) and, in a multivariable-adjusted model, additionally for a set of a priori selected confounders known for their prognostic value in cCRCC survival; TNM stage [I-II, III, IV; $4^{\text {th }}$ version (1987)], tumor size (mm) and Fuhrman grade (I, II, III, IV). Cases with missing data on any of the confounders were excluded for Cox proportional hazards analyses $(n=17)$. The relative prognostic value of CDO1 promoter methylation compared to the known prognostic factors was assessed using Likelihood-Ratio tests for nested models and the Akaike information criterion (AIC) for non-nested models. In general, a lower AIC is considered a better model. Tests using Schoenfeld residuals and visual inspection of $-\ln (-\ln$ (survival)) plots showed no indications of violation of the proportional hazard assumption. In sensitivity analyses, all analyses were repeated after exclusion of patients with distant metastasis (TNM stage IV), patients with (neo)adjuvant treatment and patients with sarcomatoid differentiation. In addition, in subgroup analyses, analyses were conducted by categories of age at diagnosis; $\geq 55$ to $<65$ years, $\geq 65$ to $<75$ years and $\geq 75$ years. 
To independently validate the findings obtained in the population-based ccRCC series, all Kaplan-Meier curves and Wilcoxon tests were re-evaluated in 280 ccRCC cases from the TCGA series with full data available on patient and tumor characteristics and survival, only then using a maximum of 5-year survival, as longer follow-up was not available. In the TCGA data, promoter methylation was measured on the Illumina Human Methylation 450K platform as a quantitative treat. We identified three probes near our primer region and determined a composite CDO1 methylation level by taking the maximum beta value of those three probes. We defined methylated samples as those with a composite methylation level of at least $30 \%$. A two-sided $P$-value of 0.05 or less was considered statistically significant.

\section{RESULTS}

The median ccRCC-specific survival in the population-based series was 4.5 years. For $13.7 \%$ of the patients a distant metastasis was reported (TNM stage IV, Table 7.1). The majority of patients $(94.1 \%)$ had no (neo)adjuvant treatment. CDO1 promoter methylation was observed in 124 out of 324 patients (38.3\%). CDO1 promoter methylation was more frequent in male patients $(P$-value $=0.001)$ and in those with a longer duration and a higher intensity of cigarette smoking ( $P$-value $=0.002$ and 0.002 ). However, age at diagnosis and other lifestyle indicators including body mass index (BMI), hypertension and alcohol intake, did not differ by CDO1 promoter methylation. Tumors with CDO1 promoter methylation were similar in TNM stage and tumor size compared to those without, yet they showed a significantly higher Fuhrman grade $(P$-value<0.001). Interestingly, for none of the tumors without CDO1 promoter methylation sarcomatoid differentiation was observed, whereas $6.5 \%$ of tumors with CDO1 promoter methylation had signs of such sarcomatoid differentiation.

To independently validate our findings from the population-based series of ccRCC patients, we used data of ccRCC patients from the TCGA (Table 7.2). Compared to the population-based series, cCRCC patients in the TCGA series had a lower mean age at diagnosis, but with a considerably larger standard deviation (70.6 \pm 5.9 and $61.5 \pm 12.0$ years, respectively), and a shorter median survival time (4.5 and 2.8 years). In the TCGA series, 54 out of 280 patients (19.3\%) showed a distant metastasis (TNM stage IV) and 7 out of 280 patients (2.5\%) had a history of (neo)adjuvant treatment. CDO1 promoter methylation was present in 122 out of $280 \mathrm{ccRCC}$ patients (43.6\%). Patients with CDO1 promoter methylation were significantly older $(P$-value $<0.001)$, more frequently male $(P$-value $=0.03)$ and their tumor characteristics, i.e. TNM stage and Fuhrman grade were less favorable compared to those without $(P$-value $<0.001$ and $<0.001$, respectively). 
Table 7.1 Characteristics of clear-cell renal cell cancer patients overall and by promoter methylation of CDO1 in the NLCS, 1986-2006.

\begin{tabular}{|c|c|c|c|c|}
\hline \multirow{2}{*}{$\begin{array}{l}\text { Characteristics } \\
\text { (mean (SD)) } \\
\end{array}$} & \multirow{2}{*}{$\begin{array}{c}\text { Total ccRCC } \\
(n=324)\end{array}$} & \multicolumn{3}{|c|}{ CDO1 promoter methylation } \\
\hline & & No $(n=200)$ & Yes $(n=124)$ & $P$-value ${ }^{a}$ \\
\hline \multicolumn{5}{|l|}{ Patient } \\
\hline Age at diagnosis (y) & $70.6(5.9)$ & 70.6 (5.9) & $70.6(6.1)$ & 0.78 \\
\hline Male sex (\%) & $194(59.9)$ & $105(52.5)$ & 899 (71.8) & 0.001 \\
\hline ccRCC-specific survival (y) & $5.9(5.0)$ & $6.43(5.1)$ & $5.0(4.8)$ & 0.005 \\
\hline \multicolumn{5}{|l|}{ Tumor } \\
\hline \multicolumn{5}{|l|}{ TNM stage $^{\mathrm{b}}(\%, \mathrm{n}=321)$} \\
\hline Stage 1 and 2 & 189 (58.9) & $124(62.0)$ & $65(53.7)$ & \\
\hline Stage 3 & $88(27.4)$ & $50(25.0)$ & $38(31.4)$ & \\
\hline Stage 4 & $44(13.7)$ & $26(13.0)$ & $18(14.9)$ & 0.33 \\
\hline Tumor size (mm, $\mathrm{n}=309$ ) & $67.6(32.9)$ & $66.5(32.2)$ & $69.4(34.0)$ & 0.48 \\
\hline \multicolumn{5}{|l|}{ Fuhrman grade (\%) } \\
\hline Grade 1 & 44 (13.9) & 39 (19.5) & $5(4.0)$ & \\
\hline Grade 2 & $129(39.8)$ & $85(42.5)$ & $44(35.5)$ & \\
\hline Grade 3 & $103(31.8)$ & $55(27.5)$ & $48(38.7)$ & \\
\hline Grade 4 & $48(14.8)$ & $21(10.5)$ & $27(21.8)$ & $<0.001$ \\
\hline CDO1 methylation (\%) & $124(38.3)$ & $0(0.0)$ & $124(100.0)$ & - \\
\hline Sarcomatoid differentiation (\%) & $8(2.5)$ & $0(0.0)$ & $8(6.5)$ & $<0.001$ \\
\hline Eosinophilic variant $(\%, n=155)$ & $2(1.3)$ & $1(1.0)$ & $1(1.8)$ & 1.0 \\
\hline No (neo)adjuvant treatment $(\%, n=322)$ & $303(94.1)$ & $185(93.4)$ & $118(95.2)$ & 0.63 \\
\hline \multicolumn{5}{|l|}{ Lifestyle } \\
\hline Body mass index $\left(\mathrm{kg} / \mathrm{m}^{2}, \mathrm{n}=309\right)$ & $25.5(2.9)$ & $25.4(2.9)$ & $25.7(16.2)$ & 0.30 \\
\hline Hypertension (\%) & $110(34.0)$ & $71(35.5)$ & $39(31.5)$ & 0.45 \\
\hline Current smokers (\%) & 105 (32.6) & $62(31.2)$ & $43(35.0)$ & 0.48 \\
\hline Smoking duration $(y, n=318)^{c}$ & $23.3(17.6)$ & $20.8(18.0)$ & $27.4(16.2)$ & 0.002 \\
\hline Smoking intensity $(\mathrm{cig} / \mathrm{d}, \mathrm{n}=306)^{\mathrm{c}}$ & $11.9(12.3)$ & $10.0(10.3)$ & $14.9(14.4)$ & 0.002 \\
\hline Alcohol intake (g ethanol/d, $n=307$ ) & $11.4(15.1)$ & $10.5(15.4)$ & $12.7(14.6)$ & 0.22 \\
\hline
\end{tabular}

Figure 7.1 shows the Kaplan-Meier curve for CDO1 promoter methylation and 10-year ccRCC-specific survival in our population-based series of ccRCC patients. We observed a significantly poorer survival for patients with $C D O 1$ promoter methylation compared to patients without CDO1 promoter methylation (Wilcoxon $P=0.006$ ). In Cox proportional hazards analyses, $C D O 1$ promoter methylation was also associated with unfavorable patient outcome [HR(95\%Cl): 1.66(1.13-2.44), Table 7.3]. HRs did not substantially change after adjustment for age at diagnosis and sex $[\mathrm{HR}(95 \% \mathrm{Cl})$ : 1.66(1.12-2.45)] and after additional adjustment for relevant clinicopathologial parameters, including TNM stage, tumor size and Fuhrman grade $[\mathrm{HR}(95 \% \mathrm{Cl})$ : 1.89(1.25-2.85)]. In sensitivity analyses, both Kaplan-Meier curves (Figure 7.2) and multivariable-adjusted Cox proportional hazards analyses (Table 7.3) showed that the exclusion of TNM stage IV patients resulted in a slight attenuation of the association between CDO1 promoter methylation and CCRCC-specific 10-year survival [Wilcoxon $P=0.09, \mathrm{HR}(95 \% \mathrm{Cl}): 1.44(0.90-2.30)]$ and that the restriction to patients without (neo)adjuvant treatment did not substantially change survival [Wilcoxon $P=0.007$; 
$\mathrm{HR}(95 \% \mathrm{Cl})$ : $1.86(1.22-2.86)]$. However, after excluding patients with sarcomatoid differentiation, the association between CDO1 promoter methylation and CCRCC survival was in the multivariable adjusted model stronger than in the total population [HR(95\%Cl): 1.94(1.27-2.97)].

Table 7.2 Characteristics of clear-cell renal cell cancer patients overall and by promoter methylation of CDO1 - The Cancer Genome Atlas (TCGA).

\begin{tabular}{|c|c|c|c|c|}
\hline \multirow{2}{*}{$\begin{array}{l}\text { Characteristics } \\
\text { (mean (SD)) } \\
\end{array}$} & \multirow{2}{*}{$\begin{array}{c}\text { Total ccRCC } \\
(n=280)\end{array}$} & \multicolumn{3}{|c|}{ CDO1 promoter methylation } \\
\hline & & No $(n=158)$ & Yes $(n=122)$ & $P$-value \\
\hline \multicolumn{5}{|l|}{ Patient } \\
\hline Age at diagnosis (y) & $61.5(12.0)$ & $59.3(12.6)$ & $64.3(10.6)$ & $<0.001$ \\
\hline Male sex (\%) & $85(66.1)$ & $96(60.8)$ & $89(73.0)$ & 0.033 \\
\hline Overall survival (y) & $2.8(2.3)$ & $2.7(2.3)$ & $2.9(2.2)$ & 0.38 \\
\hline \multicolumn{5}{|l|}{ Tumor } \\
\hline \multicolumn{5}{|l|}{ TNM stage (\%) } \\
\hline Stage 1 and 2 & $153(54.6)$ & $115(72.8)$ & $38(31.2)$ & \\
\hline Stage 3 & $73(26.1)$ & $25(15.8)$ & $48(39.3)$ & \\
\hline Stage 4 & $54(19.3)$ & $18(11.4)$ & $36(29.5)$ & $<0.001$ \\
\hline Tumor size $(\mathrm{mm})$ & - & - & - & - \\
\hline \multicolumn{5}{|l|}{ Fuhrman grade $(\%, n=277)$} \\
\hline Grade 1 & $5(1.8)$ & $5(3.2)$ & $0(0.0)$ & \\
\hline Grade 2 & $113(40.8)$ & $82(52.6)$ & $31(25.6)$ & \\
\hline Grade 3 & $111(40.1)$ & $58(37.2)$ & $53(43.8)$ & \\
\hline Grade 4 & $48(17.3)$ & $11(7.1)$ & $37(30.6)$ & $<0.001$ \\
\hline CDO1 methylation (\%) & $122(43.6)$ & $0(0.0)$ & $122(100.0)$ & - \\
\hline Sarcomatoid differentiation (\%) & - & 0.0 & 6.5 & - \\
\hline Eosinophilic variant (\%) & - & 1.0 & 1.8 & 0.67 \\
\hline No neoadjuvant treatment(\%) & $273(97.5)$ & $152(96.2)$ & $121(99.2)$ & 0.14 \\
\hline
\end{tabular}

${ }^{a} P$-value tested with Kruskal-Wallis test (for continuous variables) or $\chi^{2}$ test (for categorical variables). $\operatorname{ccRCC}=$ clear-cell renal cell cancer, $C D O 1=$ cysteine dioxygenase type $1, \mathrm{SD}=$ standard deviation.

In line with the results from the population-based series, Kaplan-Meier curves in the TCGA series showed a significantly poorer 5-year survival for patients with CDO1 promoter methylation compared to those without (Wilcoxon $P<0.001$, Figure $7.2 \mathrm{~A}$ ). In sensitivity analyses, the 5-year survival attenuated after the exclusion of TNM stage IV patients, but was still significantly different by $C D O 1$ promoter methylation status (Wilcoxon $P=0.047$, Figure $7.2 B$ ). In addition, the 5 -year survival did not change after restricting the population to patients without (neo)adjuvant treatment (Wilcoxon $P<0.001$, Figure $7.2 \mathrm{C}$ ). 
A

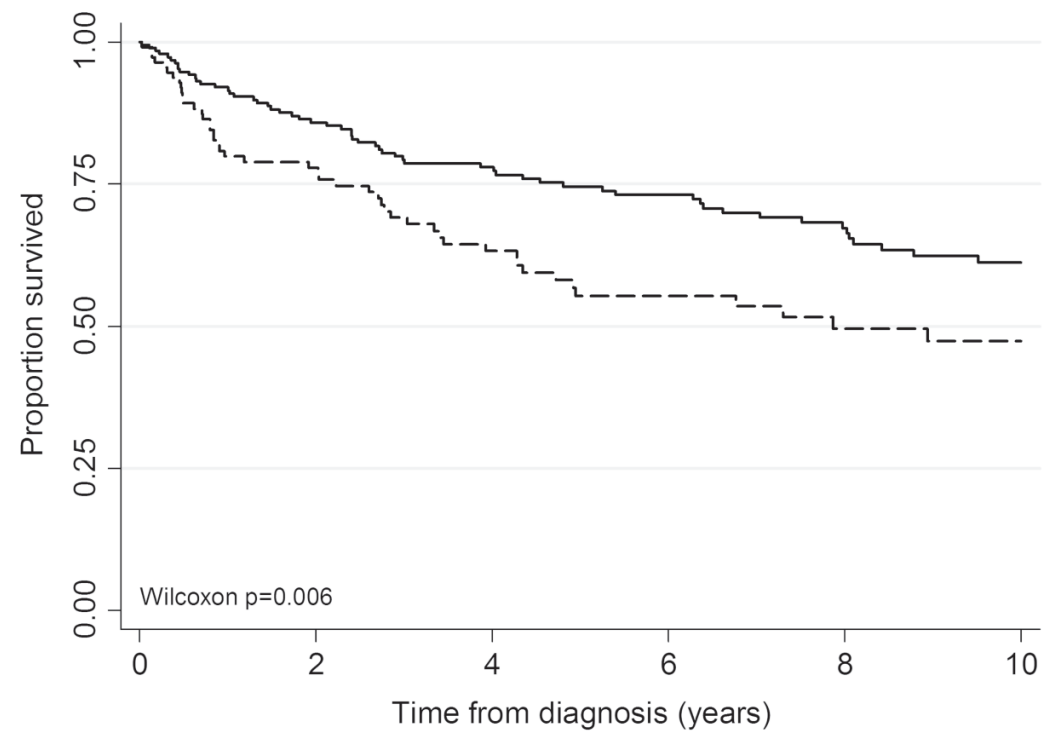

Number at risk

No methylation $\quad 194$

116
51

71
25

49

\section{B}

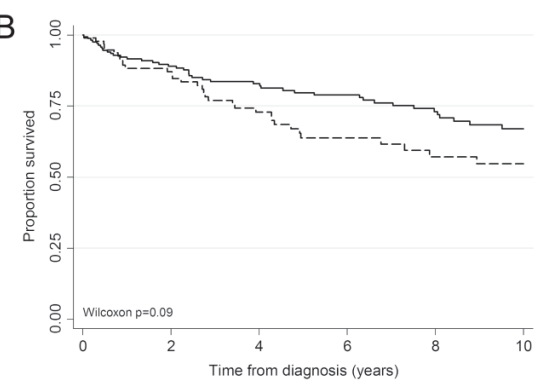

Number at risk

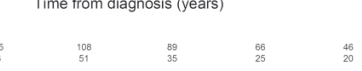

Figure 7.1 Ten-year survival of clear-cell renal cell cancer patients from a population-based case series according to CDO1 methylation A) in the total population, B) in patients with TNM stage I-III and $C$ ) in patients without (neo)adjuvant treatment.

In Table 7.4 we show the goodness-of-fit of five relevant models, in order to indicate each model's prognostic value. In the population-based series, CDO1 methylation status alone (Model 1 ) is better in predicting prognosis than the models including age at diagnosis and sex (Model 2 and 3). In fact, all models with CDO1 methylation status performed significantly better in predicting survival than the same models without CDO1 methylation status (e.g. Model 4 versus $5, P$-value $=0.003$ ). In the TCGA series, CDO1 promoter methylation only improved the model including age at diagnosis and 
sex (Model 2 versus 3, $P$-value $=0.001$ ) and not the model including all other prognostic variables (Model 4 versus $5, P$-value $=0.40$ ).

A

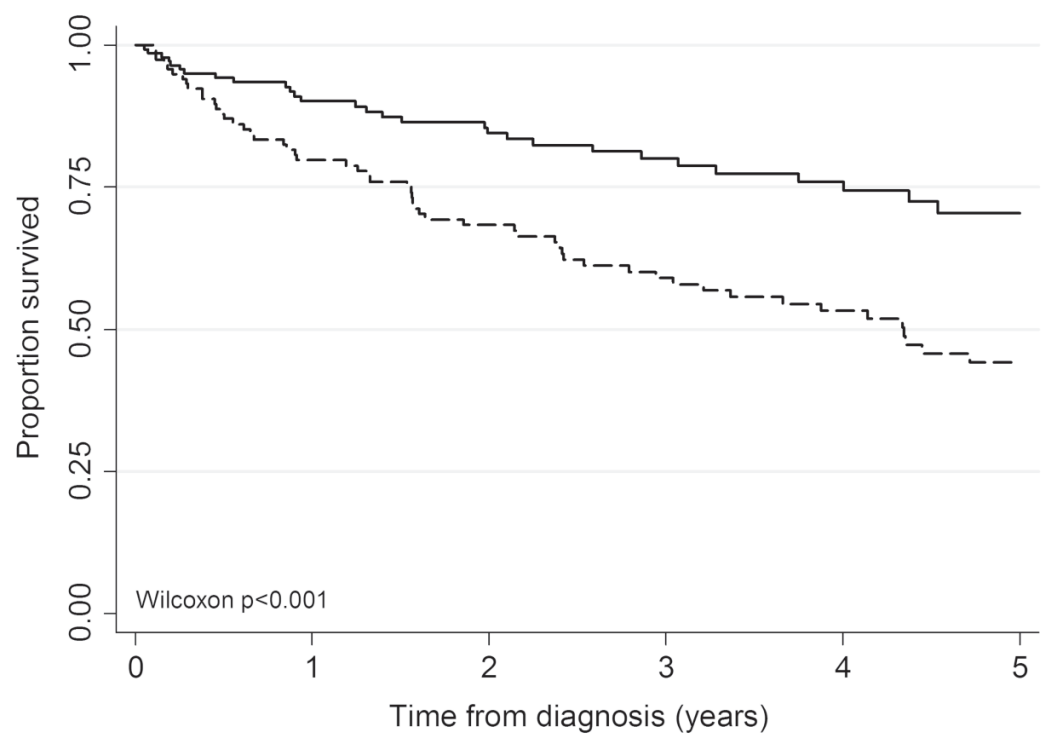

Number at risk

No methylation 158

84
68

63
55

49

29
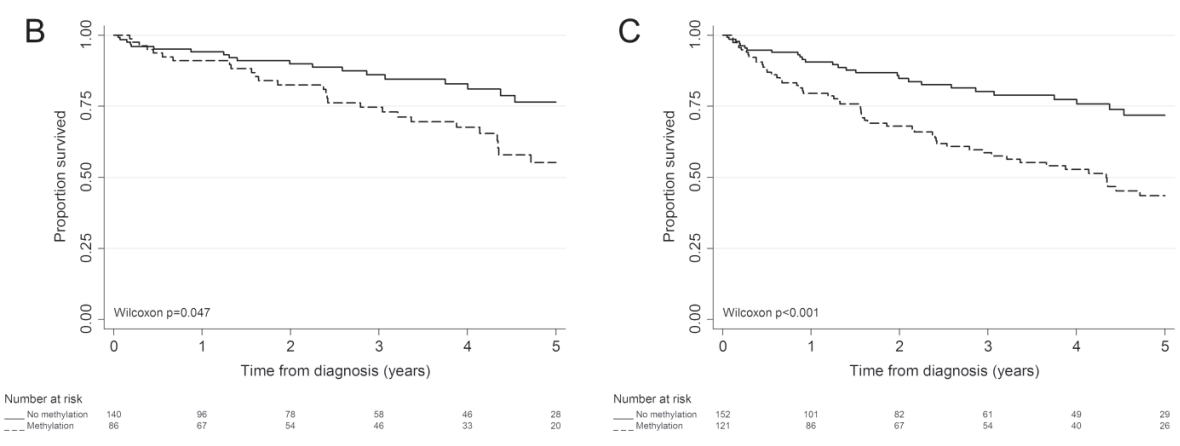

Number at risk
- No methylation
kethylation

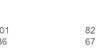

Figure 7.2 Five-year survival of clear-cell renal cell cancer patients from the TCGA A) in the total population, B) in patients with TNM stage I-III and C) in patients without (neo)adjuvant treatment.

In our population-based series of ccRCC patients, subgroup analyses by categories of age at diagnosis showed substantially different Kaplan-Meier curves; a poorer survival by $C D O 1$ promoter methylation was observed for patients aged $\geq 55$ to $<65$ years at diagnosis (Wilcoxon $P=0.009$ ), but not for patients aged $\geq 65$ to $<75$ or $>75$ years at 
diagnosis (Wilcoxon $P=0.20$ and 0.20 , respectively; Suppl Figure S7.1). Although there is no significant interaction between age at diagnosis and $C D O 1$ promoter methylation in relation to survival in multivariable-adjusted analyses ( $P$-interaction $=0.68)$, risk estimates of unfavorable patient outcome were also substantially different by categories of age at diagnosis. For ccRCC patients aged $\geq 55$ to $<65$ years at diagnosis the $\mathrm{HR}(95 \% \mathrm{Cl})$ was $3.21(1.25-8.23)$ in the age- and sex-adjusted model and, as a result of limited statistical power, 2.81(0.67-11.71) in the multivariable-adjusted model. In older patients, none of risk estimates were statistically significant. In the validation series, subgroup analyses by categories of age at diagnosis showed the strongest association between CDO1 promoter methylation and 5-year survival in the youngest patients ( $<55$ years at diagnosis, Wilcoxon $P<0.013$, Suppl Figure S7.2). In all other age categories, the observed difference in Kaplan-Meier curves was not significant.

Table 7.3 Hazard ratios and $95 \%$ confidence intervals of 10 -year clear-cell renal cell cancer survival for promoter methylation of CDO1 in the NLCS, 1986-2006.

\begin{tabular}{|c|c|c|c|c|c|c|}
\hline \multirow[b]{2}{*}{ Population } & \multicolumn{2}{|c|}{ Crude model } & \multicolumn{2}{|c|}{$\begin{array}{c}\text { Age- and sex- } \\
\text { adjusted model }^{\text {a }}\end{array}$} & \multicolumn{2}{|c|}{$\begin{array}{c}\text { Multivariable } \\
\text { adjusted model }^{\mathrm{b}}\end{array}$} \\
\hline & HR & $(95 \% \mathrm{Cl})$ & $\mathrm{HR}$ & $(95 \% \mathrm{Cl})$ & $\mathrm{HR}$ & $(95 \% \mathrm{Cl})$ \\
\hline Total population $(n=307)$ & 1.66 & $(1.13-2.44)$ & 1.66 & $(1.12-2.45)$ & 1.89 & $(1.25-2.85)$ \\
\hline TNM stage I-III ( $n=268)$ & 1.55 & $(0.98-2.44)$ & 1.56 & $(0.98-2.48)$ & 1.44 & $(0.90-2.30)$ \\
\hline No (neo)adjuvant treatment $(n=291)$ & 1.76 & $(1.17-2.64)$ & 1.76 & $(1.16-2.66)$ & 1.86 & $(1.22-2.86)$ \\
\hline No sarcomatoid differentiation $(n=300)$ & 1.61 & $(1.09-2.39)$ & 1.61 & $(1.08-2.41)$ & 1.94 & $(1.27-2.97)$ \\
\hline \multicolumn{7}{|l|}{ Total population $(n=307)^{c}$} \\
\hline Age at diagnosis $>55, \leq 65 \quad(n=40)$ & 3.10 & $(1.24-7.77)$ & 3.21 & $(1.25-8.23)$ & 2.81 & $(0.67-11.71)$ \\
\hline Age at diagnosis $>65, \leq 75 \quad(n=183)$ & 1.34 & $(0.81-2.23)$ & 1.34 & $(0.80-2.25)$ & 1.43 & $(0.81-2.54)$ \\
\hline Age at diagnosis $>75(n=84)$ & 1.73 & $(0.77-3.85)$ & 1.62 & $(0.72-3.66)$ & 2.01 & $(0.81-5.01)$ \\
\hline
\end{tabular}

${ }^{a}$ Adjusted for age at diagnosis (y) and sex (men/women); ${ }^{b}$ Adjusted for age at diagnosis (y), sex (men/women), TNM stage (I-II, III, IV; 1987), tumor size $(\mathrm{mm})$ and Fuhrman grade (I-IV); ${ }^{\mathrm{c}} P$-interaction=0.68 in multivariable adjusted model. CDO1 = cysteine dioxygenase type 1, NLCS = Netherlands Cohort Study.

Table 7.4 Model fit among five models including prognostic factors in relation to survival of clear-cell renal cell cancer patients.

\begin{tabular}{|c|c|c|c|c|c|c|c|c|}
\hline \multirow[b]{2}{*}{ Models } & \multicolumn{4}{|c|}{ NLCS } & \multicolumn{4}{|c|}{ TCGA } \\
\hline & $\mathrm{n}$ & Df & AIC & $P$-value ${ }^{a}$ & $\mathrm{n}$ & Df & AIC & $P$-value ${ }^{a}$ \\
\hline Model $1^{b}$ & 307 & 1 & 1117.76 & & 277 & 1 & 832.65 & \\
\hline Model $2^{\mathrm{C}}$ & 307 & 2 & 1126.05 & & 277 & 2 & 842.77 & \\
\hline Model $3^{d}$ & 307 & 3 & 1121.76 & 0.012 & 277 & 3 & 834.24 & 0.001 \\
\hline Model $4^{\mathrm{e}}$ & 307 & 8 & 1073.19 & & 277 & 6 & 775.80 & \\
\hline Model $5^{f}$ & 307 & 9 & 1066.26 & 0.003 & 277 & 7 & 777.40 & 0.40 \\
\hline
\end{tabular}

${ }^{a}$ P-value for Likelihood-Ratio test, current model compared to model above; ${ }^{\text {b }}$ Model including CDO1 methylation (no/yes); ${ }^{c}$ Model including age at diagnosis (y) and sex (men/women); ${ }^{d}$ Model including age at diagnosis (y), sex (men/women) and CDO1 methylation (no/yes); ${ }^{\mathrm{e}}$ Model including age at diagnosis (y), sex (men/women), TNM stage (I-II, III, IV) and Fuhrman grade (I-IV). The NLCS uses the 1987 version of the TNM classification and includes also tumor size $(\mathrm{mm}) ;{ }^{f}$ Model including age at diagnosis (y), sex (men/women), TNM stage (I-II, III, IV), Fuhrman grade (I-IV) and CDO1 methylation (no/yes). The NLCS uses the 1987 version of the TNM classification and includes also tumor size $(\mathrm{mm})$. AIC = Akaike information criterion, CDO1 = cysteine dioxygenase type $1, \mathrm{Df}=$ degrees of freedom, NLCS = Netherlands Cohort Study, TCGA = The Cancer Genome Atlas. 


\section{DISCUSSION}

In the present study, we reported for the first time that $C D O 1$ promoter $\mathrm{CpG}$ island methylation is associated with poorer survival in a population-based series of ccRCC patients and validated these finding in an independent series of ccRCC patients from the TCGA. Therefore, data suggests that CDO1 promoter methylation may be a relevant marker for ccRCC prognosis.

The investigated association between CDO1 promoter methylation and $\mathrm{CCRCC}$ survival remained significant after adjustment for age at diagnosis, sex and other clinicopathological parameters, including TNM stage, tumor size and Fuhrman grade. Thus, the association appeared to be independent of current prognostic factors. Moreover, based on results from the population-based series, CDO1 promoter methylation status may be included in the model as prognostic marker to assess survival, in addition to common clinicopathological parameters. The additional value of $C D O 1$ promoter methylation in the model including sex and age, but not in the extended model, was confirmed in cCRCC patients from the TCGA. Thus, although CDO1 promoter methylation status by itself is not suitable to substitute common clinicopathological parameters in the prediction of ccRCC survival, it offers additional, relevant prognostic information. It has been suggested that prognostic risk models, such as the University of California Los Angeles integrated staging system (UISS) and the Stage Size Grade Necrosis (SSIGN) risk score, which combine independent prognostic factors, may be more accurate in predicting survival than TNM stage and Fuhrman grade alone [25]. However, the UISS requires information on patient performance stage and the SSIGN risk score requires information on necrosis, which are both not available in the NLCS.

Several conditions can be hypothesized that might influence the association between CDO1 promoter methylation and CCRCC survival, which were addressed in sensitivity and subgroup analyses. First, it can be argued that in patients with distant metastases, i.e. TNM stage IV, poor prognosis may be predominantly determined by the presence of the distant metastasis rather than by their $C D O 1$ promoter methylation status. We observed a slight attenuation in HRs in both series when excluding these patients. Second, the choice of treatment may, on the one hand, influence a patient's survival regardless of the $C D O 1$ promoter methylation status and thus conceal the potential effect of CDO1 promoter methylation on cCRCC survival. On the other hand, the choice of treatment may be based on the expected patient's survival (e.g. adjuvant treatment for patients with the worst prognostic profile) and bias the association under study. However, no substantial changes in the results were observed after restricting the population to patients without (neo)adjuvant treatment. It should, however, be noted that surgery has been the primary and only treatment with curative intent for long, as ccRCC tumors are refractory to cytotoxic chemotherapy 
and immunotherapy, and that consequently the proportion of patients with (neo)adjuvant treatment is very low. Moreover, the inclusion of patients depended on the availability of FFPE tumor tissues. We were able to evaluate this phenomenon of selection during the inclusion process in the population-based series by comparing ccRCC cases with and without tissue material. Indeed, we observed that the proportion of patients with TNM stage IV or with (neo)adjuvant treatment was lower for the ccRCC cases for which tissue retrieval was successful. Third, the presence of a sarcomatoid differentiation in the ccRCC tumor portends a worse prognosis [26]. Information on sarcomatoid differentiation was only available in the population-based series. As we observed that for all ccRCC tumors with a sarcomatoid component CDO1 promoter methylation was present, poor prognosis may be predominantly determined by the presence of the sarcomatoid differentiation rather than by the CDO1 promoter methylation itself. However, in contrast to this hypothesis, the association between CDO1 promoter methylation and CCRCC-specific survival was stronger when excluding cases with sarcomatoid differentiation. Excluding these cases did not substantially change Kaplan-Meier curves (Wilcoxon $P=0.01$ ).

Finally, it has been hypothesized that global promoter methylation is associated with age [27]. As both series had a considerably different age range at diagnosis, we evaluated the Kaplan-Meier curves by categories of age at diagnosis. Generally, the association between CDO1 promoter methylation and CCRCC survival was stronger in the lowest age category. For the TCGA data, it is plausible that smaller effects of CDO1 methylation may be observed in older patients, as in this series survival was defined as overall survival rather than RCC-specific survival and RCC is likely a smaller contributor to total deaths in the elderly population than in the younger one. However, in the population-based series, survival was RCC-specific. For this series, we cannot exclude the possibility that confounding factors have influenced differential observations by categories of age at baseline, as the multivariable-adjusted interaction between $C D O 1$ promoter methylation and the age categories was not statistically significant.

Although both series of ccRCC patients included in this study generally showed the same results, some methodological differences are of particular interest. The population-based series of cCRCC patients, which is derived from the NLCS, has the advantage of including $\sim 80 \%$ of all incident cases from a representative base population, hereby limiting the likelihood of selection bias. Any selection criterion for the inclusion of patients runs the risk of overestimating the effect of a particular marker, in this case CDO1 promoter methylation. Indeed, associations between CDO1 promoter methylation and CCRCC survival were stronger in the hospital-based TCGA series compared to the population-based series. In addition, in the population-based series, cancer stage was classified according to the 1987 version of the TNM classification [28]. A uniform cancer stage increases consistency within the series over 
time, as the TNM classification regularly changes. However, old TNM classifications lack important information that allows recoding into more recent versions. The difference in tumor size between the 1987 version and the more recent versions of the TNM classification was addressed by the inclusion of the tumor size as covariate with TNM stage in the statistical models.

Promoter methylation of the $C D O 1$ gene has previously been associated with downregulation of CDO1 mRNA expression [7]. Moreover, in the TCGA dataset a negative correlation was observed for all three individual $\mathrm{CpG}^{\mathrm{s}} \mathrm{s}$ present at the Infinium human methylation 450k platform, with only one CpG being significantly correlated (Pearson $\mathrm{r}=0.12 ; \quad P$-value=0.036). Interestingly, the expression of exon 1 was significantly lower in the methylated samples when adhering to the binary classification applied in the paper by integrating the ß-values of all three $\mathrm{CpG}^{\prime} \mathrm{s}$ $(P$-value $=0.020)$. CDO1 catalyzes the oxidation of cysteine to cysteine sulfinic acid (CSA) [29], and is thus crucial for the removal of excess cysteine in the body. Deficient CDO1 activity and subsequent high cysteine levels may be cytotoxic and have been associated with multiple human diseases, such as Parkinson's and Alzheimer's disease [30] and rheumatoid arthritis [31]. Importantly, high cysteine levels may also be related to cancer, as higher cysteine levels have been found in prostate cancer tissues compared to benign prostate tissues [32]. Furthermore, CDO1 may indirectly regulate intracellular redox homeostasis [14]. Dominy et al. demonstrated that glutathione levels, a major antioxidant molecule, and its major substrate, intracellular cysteine, were lowered in presence of CDO1 [29], suggesting that CDO1 may be able to diminish antioxidant capacity. Loss of CDO1 function in cancer cells may thus help these cells to escape oxidative damage and cell death due to enhanced antioxidant capacity, as cancer cells tend to develop enhanced antioxidant capacity under excessive and toxic amounts of reactive oxygen species (ROS) [33]. The principle of increased ROS detoxification capacity and its advantage for cancer cell survival as a result of DNA methylation of the CDO1 gene was demonstrated by Jeschke et al. in breast cancer cells [7]. Whether this mechanism may also apply for ccRCC cells has not been elucidated.

CDO1 promoter methylation status may, in addition to its prognostic value, also have predictive value and have clinical implications for cancer therapy. In breast cancer, CDO1 methylation is suggested to be a useful marker for prediction of resistance to the commonly used treatment with anthracyclines, as reactivation of epigenetically silenced CDO1 sensitized breast cancer cells to anthracycline therapy [7]. Interestingly, cytotoxic chemotherapy, including anthracyclines, was never found to be effective in ccRCC [34]. It has been suggested that the resistance of ccRCC to chemotherapeutic agents may partly be due to increased levels of the transcription factor nuclear factor- $\kappa \mathrm{B}[35,36]$, yet $C D O 1$ promoter methylation may play a role too. 
In conclusion, CDO1 promoter methylation could be a relevant marker for cCRCC prognosis as it is a significant predictor of poor ccRCC-related survival in two independent series of ccRCC patients. However, further research needs to evaluate potential age-related differences in this association and the potential use of CDO1 promoter methylation in therapeutic stratification. 


\section{REFERENCES}

1. Jones PA, Baylin SB. The fundamental role of epigenetic events in cancer. Nat Rev Genet 2002;3: 415-28.

2. Wolffe AP, Matzke MA. Epigenetics: regulation through repression. Science 1999;286:481-6.

3. Fukushige $S$, Horii A. DNA methylation in cancer: a gene silencing mechanism and the clinical potential of its biomarkers. Tohoku J Exp Med 2013;229:173-85.

4. Das PM, Singal R. DNA methylation and cancer. J Clin Oncol 2004;22:4632-42.

5. Smits KM, Schouten L, van Dijk BA, Hulsbergen-van de Kaa CA, Wouters KA, Oosterwijk E, van Engeland $M$, van den Brandt PA. Genetic and epigenetic alterations in the von hippel-lindau gene: the influence on renal cancer prognosis. Clin Cancer Res 2008;14:782-7.

6. Brait M, Ling S, Nagpal JK, Chang X, Park HL, Lee J, Okamura J, Yamashita K, Sidransky D, Kim MS. Cysteine dioxygenase 1 is a tumor suppressor gene silenced by promoter methylation in multiple human cancers. PloS One 2012;7:e44951.

7. Jeschke J, O'Hagan HM, Zhang W, Vatapalli R, Calmon MF, Danilova L, Nelkenbrecher C, Van Neste L, Bijsmans IT, Van Engeland M, Gabrielson E, Schuebel KE, Winterpacht A, Baylin SB, Herman JG, Ahuja $\mathrm{N}$. Frequent inactivation of cysteine dioxygenase type 1 contributes to survival of breast cancer cells and resistance to anthracyclines. Clin Cancer Res 2013;19:3201-11.

8. Andresen K, Boberg KM, Vedeld HM, Honne H, Hektoen M, Wadsworth CA, Clausen OP, Karlsen TH, Foss A, Mathisen O, Schrumpf E, Lothe RA, Lind GE. Novel target genes and a valid biomarker panel identified for cholangiocarcinoma. Epigenetics 2012;7:1249-57.

9. Kwon YJ, Lee SJ, Koh JS, Kim SH, Lee HW, Kang MC, Bae JB, Kim YJ, Park JH. Genome-wide analysis of DNA methylation and the gene expression change in lung cancer. $J$ Thorac Oncol 2012;7:20-33.

10. Jeschke J, Van Neste L, Glöckner SC, Dhir M, Calmon MF, Deregowski V, Van Criekinge W, Vlassenbroeck I, Koch A, Chan TA, Cope L, Hooker CM, Schuebel KE, Gabrielson E, Winterpacht A, Baylin SB, Herman JG, Ahuja N. Biomarkers for detection and prognosis of breast cancer identified by a functional hypermethylome screen. Epigenetics 2012;7:701-9.

11. Dietrich D, Krispin M, Dietrich J, Fassbender A, Lewin J, Harbeck N, Schmitt M, Eppenberger-Castori S, Vuaroqueaux V, Spyratos F, Foekens JA, Lesche R, Martens JW. CDO1 promoter methylation is a biomarker for outcome prediction of anthracycline treated, estrogen receptor-positive, lymph nodepositive breast cancer patients. BMC Cancer 2010;10:247.

12. Satsu H, Terasawa E, Hosokawa $Y$, Shimizu M. Functional characterization and regulation of the taurine transporter and cysteine dioxygenase in human hepatoblastoma HepG2 cells. Biochem J 2003;375:441-7.

13. Joseph CA, Maroney MJ. Cysteine dioxygenase: structure and mechanism. Chem Commun 2007;(32): 3338-49.

14. Stipanuk MH, Ueki I, Dominy JE Jr, Simmons CR, Hirschberger LL. Cysteine dioxygenase: a robust system for regulation of cellular cysteine levels. Amino Acids 2009;37:55-63.

15. Chesney RW, Han X, Patters AB. Taurine and the renal system. J Biomed Sci 2010;17 Suppl 1:S4.

16. van den Brandt PA, Goldbohm RA, van 't Veer P, Volovics A, Hermus RJ, Sturmans F. A large-scale prospective cohort study on diet and cancer in The Netherlands. J Clin Epidemiol 1990;43:285-95.

17. Goldbohm RA, Van den Brandt PA, Dorant E. Estimation of the coverage of Dutch municipalities by cancer registries and PALGA based on hospital discharge data. Tijdschr Soc Gezondheidsz 1994;72: 80-4.

18. Van den Brandt PA, Schouten LJ, Goldbohm RA, Dorant E, Hunen PM. Development of a record linkage protocol for use in the Dutch Cancer Registry for Epidemiological Research. Int J Epidemiol 1990;19:553-8.

19. van Houwelingen KP, van Dijk BA, Hulsbergen-van de Kaa CA, Schouten $L$, Gorissen HJ, Schalken JA, van den Brandt PA, Oosterwijk E. Prevalence of von Hippel-Lindau gene mutations in sporadic renal cell carcinoma: results from The Netherlands cohort study. BMC Cancer 2005;5:57.

20. Fuhrman S, Lasky L, Limas C. Prognostic significance of morphologic parameters in renal cell carcinoma. Am J Surg Pathol 1982;6:655-63.

21. Eble J, et al. World Health Organization Classification of Tumours. Pathology and Genetics. Tumours of the Urinary System and Male Genital Organs. 2004, Lyon: IARC Press. 
22. Derks S, Lentjes $\mathrm{MH}$, Hellebrekers DM, de Bruïne AP, Herman JG, van Engeland M. Methylationspecific PCR unraveled. Cell Oncol 2004;26:291-9.

23. Herman JG, Graff JR, Myöhänen S, Nelkin BD, Baylin SB. Methylation-specific PCR: a novel PCR assay for methylation status of CpG islands. Proc Natl Acad Sci U S A 1996;93:9821-6.

24. van Engeland M1, Roemen GM, Brink M, Pachen MM, Weijenberg MP, de Bruïne AP, Arends JW, van den Brandt PA, de Goeij AF, Herman JG. K-ras mutations and RASSF1A promoter methylation in colorectal cancer. Oncogene 2002;21:3792-5.

25. Ljungberg B, Cowan NC, Hanbury DC, Hora M, Kuczyk MA, Merseburger AS, Patard JJ, Mulders PF, Sinescu IC; European Association of Urology Guideline Group. EAU guidelines on renal cell carcinoma: the 2010 update. Eur Urol 2010;58:398-406.

26. de Peralta-Venturina M1, Moch H, Amin M, Tamboli P, Hailemariam S, Mihatsch M, Javidan J, Stricker $\mathrm{H}$, Ro JY, Amin MB. Sarcomatoid differentiation in renal cell carcinoma: a study of 101 cases. Am J Surg Pathol 2001;25:275-84.

27. Ahuja N, Issa JP. Aging, methylation and cancer. Histol Histopathol 2000;15:835-42.

28. Hermanek P, Sobin L. TNM Classification of Malignant Tumours. Fourth, fully revised edition ed. 1987: Springer-Verlag.

29. Dominy JE Jr, Hwang J, Stipanuk MH. Overexpression of cysteine dioxygenase reduces intracellular cysteine and glutathione pools in HepG2/C3A cells. Am J Physiol Endocrinol Metab 2007;293:E62-9.

30. Heafield MT, Fearn S, Steventon GB, Waring RH, Williams AC, Sturman SG. Plasma cysteine and sulphate levels in patients with motor neurone, Parkinson's and Alzheimer's disease. Neurosci Lett 1990;110:216-20.

31. Bradley H, Gough A, Sokhi RS, Hassell A, Waring R, Emery P. Sulfate metabolism is abnormal in patients with rheumatoid arthritis. Confirmation by in vivo biochemical findings. I Rheumatol 1994;21:1192-6.

32. Sreekumar A, Poisson LM, Rajendiran TM, Khan AP, Cao Q, Yu J, Laxman B, Mehra R, Lonigro RJ, Li Y, Nyati MK, Ahsan A, Kalyana-Sundaram S, Han B, Cao X, Byun J, Omenn GS, Ghosh D, Pennathur S, Alexander DC, Berger A, Shuster JR, Wei JT, Varambally S, Beecher C, Chinnaiyan AM. Metabolomic profiles delineate potential role for sarcosine in prostate cancer progression. Nature 2009;457:910-4.

33. Trachootham D, Alexandre J, Huang P. Targeting cancer cells by ROS-mediated mechanisms: a radical therapeutic approach? Nat Rev Drug Discov 2009;8:579-91.

34. Yagoda A, Abi-Rached B, Petrylak D. Chemotherapy for advanced renal-cell carcinoma: 1983-1993. Semin Oncol 1995;22:42-60.

35. Oya M, Ohtsubo M, Takayanagi A, Tachibana M, Shimizu N, Murai M. Constitutive activation of nuclear factor-kappaB prevents TRAIL-induced apoptosis in renal cancer cells. Oncogene 2001;20: 3888-96.

36. Oya M, Takayanagi A, Horiguchi A, Mizuno R, Ohtsubo M, Marumo K, Shimizu N, Murai M. Increased nuclear factor-kappa B activation is related to the tumor development of renal cell carcinoma. Carcinogenesis 2003;24:377-84. 
Suppl Table S7.1 Primer sequences and PCR conditions used to analyze promoter methylation of CDO1 in a population-based series of clear-cell renal cancer patients in the NLCS, 1986-2006.

\begin{tabular}{llcc}
\hline CDO1 primer & Primer sequence & Tm $\left({ }^{\circ} \mathrm{C}\right)$ & Cycles $(\mathrm{n})$ \\
\hline Flanking primer, upstream & GGGAGAGATTGYGYGGAGTTTA & 56 & 35 \\
Flanking primer, downstream & AAAACCACCCAAAAAAAATAAC & 56 & 35 \\
Unmethylated sense strand & GATTTTTGGGATGTTGGAGATAAT & 64 & 30 \\
Methylated sense strand & TTTTTGGGACGTCGGAGATAAC & 64 & 30 \\
Unmethylated antisense strand & AAAACAAAAAAACCCTACAAACACA & 64 & 30 \\
Methylated antisense strand & CGAAAAAACCCTACGAACACG & 64 & 30 \\
\hline
\end{tabular}

CDO1 = cysteine, dioxygenase type 1, NLCS = Netherlands Cohort Study.

Suppl Table S7.2 Genomic information of the CDO1 probes selected from TCGA data.

\begin{tabular}{lcccc}
\hline Probe ID & Chromosome & Probe start & Distance to TSS & CpG Island \\
\hline $\operatorname{cg} 08516516$ & 5 & 115152491 & 160 & yes \\
$\operatorname{cg} 11036833$ & 5 & 115152493 & 158 & yes \\
$\operatorname{cg} 23180938$ & 5 & 115152484 & 167 & yes \\
\hline
\end{tabular}

CDO1 = cysteine dioxygenase type 1, TCGA = The Cancer Genome Atlas.

A
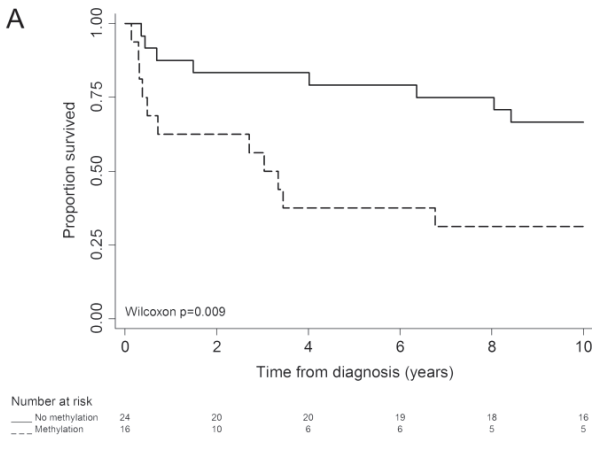

C

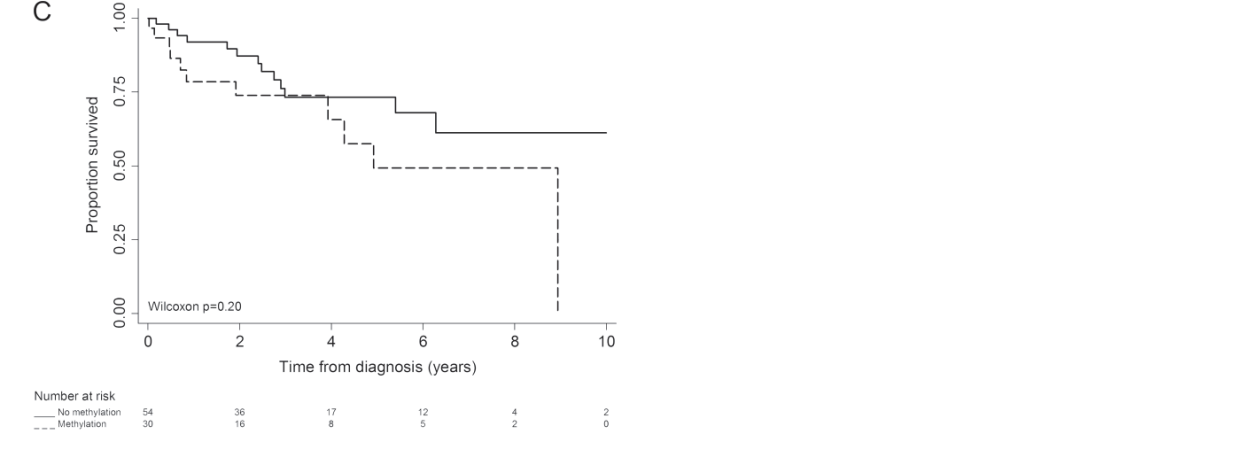

B

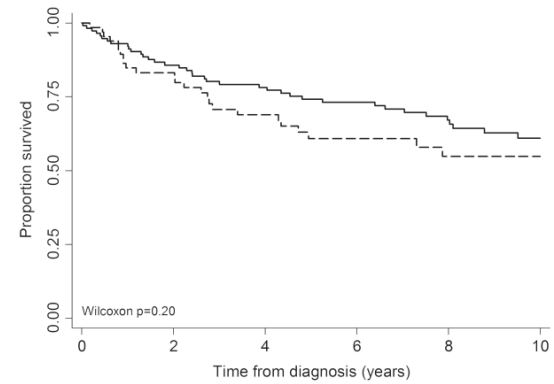

Number at risk

Suppl Figure S7.1 Ten-year survival of clear-cell renal cell cancer patients from the population-based series according to $C D O 1$ methylation in patients A) aged $\geq 55$ to $<65$ years, B) aged $\geq$ 65 to $<75$ years and C) aged $\geq 75$ years at diagnosis. 
A

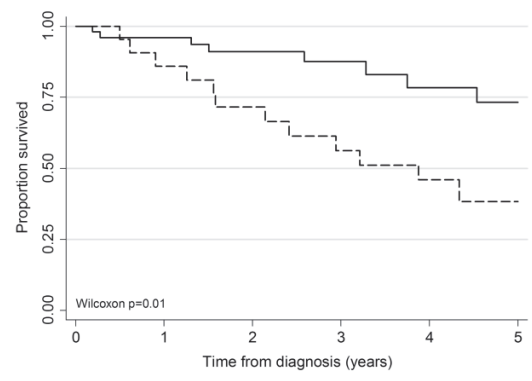

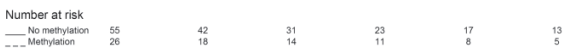

C

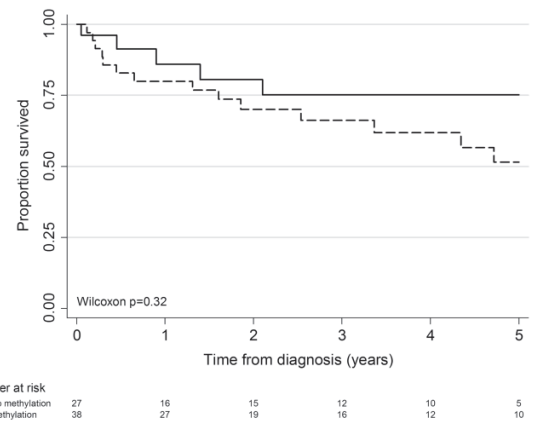

B

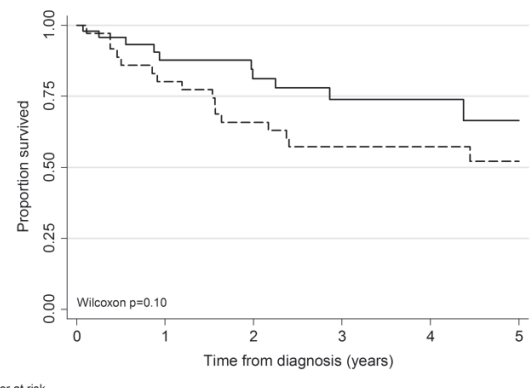

Number at risk
- No methylation

D

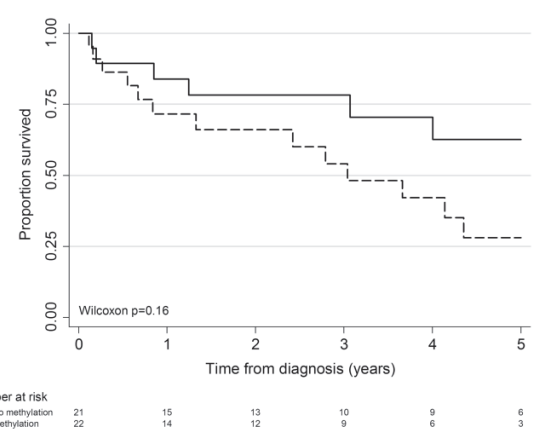

Suppl Figure S7.2 Five-year survival of clear-cell renal cell cancer patients from the TCGA according to CDO1 methylation in patients A) aged $<55$ years, B) aged $\geq 55$ to $<65$ years, C) aged $\geq 65$ to $<75$ years and $D$ ) aged $\geq 75$ years at diagnosis. 


\section{CHAPTER 8}

General discussion 
This final chapter first summarizes the main findings of all chapters in this thesis. In addition, the most important methodological issues are discussed, in order to interpret these main findings and draw overall conclusions. Finally, our view on future directions in renal cell cancer (RCC) research is described.

\section{SUMMARY OF MAIN FINDINGS}

In this thesis, we identified that the dietary intake of sodium, but not fluid and potassium, is a potential novel risk factor for RCC, particularly if fluid consumption is low (Chapter 2). We found no indications for modifying or mediating effects of hypertension in this association. Furthermore, we found evidence that genes involved in the renin-angiotensin-aldosterone (RAAS) system may influence RCC risk (Chapter 3), because we showed that AGTR1_rs1492078 and AGTR1_rs5186, two single nucleotide polymorphisms (SNPs) in RAAS genes, were associated with RCC risk and that hypertension modified the association between AGT_rs3889728 and RCC risk. Interactions between SNPs in RAAS genes and sodium, potassium and fluid intake were not significant. However, sodium intake was differentially associated with RCC risk defined by genotypes of several SNPs. In chapter 4 we investigated the role of gene-environment interactions in ion transport mechanisms (ITMs) as potential cancer-causing disease mechanism in RCC etiology. We describe a association between ADD1_rs4961 and RCC risk and a few significant gene-environment interactions between SNPs and dietary intakes of sodium, potassium and fluid, hypertension and diuretic medication, particularly in SLC9A3_rs4957061. Compared to the relatively large the number of tests performed, this evidence was too weak to support the general hypothesis that ITMs are important disease mechanisms in RCC etiology. In chapter $\mathbf{5}$ we found that the intake of potassium, but not sodium or fluid, was differentially associated with molecular subtypes of clear-cell RCC. In this study clear-cell RCC was classified according to a promoter CpG island hypermethylation index of genes specifically selected for their involved in ITMs. However, promoter methylation in a larger, more general panel of genes was not influenced by dietary intakes that may be linked to the general mechanism of methylation, i.e. alcohol and folate intake, in clear-cell RCC in Chapter 6. Finally, in chapter 7, we demonstrated that patients with promoter methylation of cysteine dioxygenase type 1 (CDO1) gene have a significantly poorer clear-cell RCC-specific 10-year survival than those without and that this association was independent of other prognostic factors. 


\section{METHODOLOGICAL CONSIDERATIONS}

Results of observational studies might be influenced by several types of bias [1]. Before interpreting the overall results of this thesis, the most important methodological issues potentially influencing exposures and outcomes will be discussed.

\section{Assessment of dietary exposures}

Throughout this thesis, the food frequency questionnaire (FFQ) was the primary method used to assess habitual intake of dietary exposures. The FFQ has long been considered the appropriate dietary assessment instrument in large-scale epidemiological studies due to its ability to rank participants at reasonable costs [2]. Moreover, compared to other dietary assessment measures, such as the $24 \mathrm{~h}$-recall method, the FFQ has the advantage to be less sensitive to day-to-day variations. Therefore, the FFQ may better determine long-term dietary habits, which is particularly important when investigating complex diseases such as cancer that may develop over longer time [3]. Nevertheless, dietary exposure assessment using the FFQ may be influenced by two types of measurement errors, i.e. random measurement error and systematic measurement error [1]. Random measurement error may result in underestimation of the associations under study, whereas systematic measurement error may result in either over- or underestimation of the associations under study [1]. Random dietary measurement error is a potential source of bias, because participants may not accurately remember their average intake of food items of the preceding year. In addition, it has been shown that persons with high body mass index systematically tend to underestimate (unhealthy) food intake compared to persons with normal weight [3]. In order to minimize the effects of this systematic dietary measurement error, we have adjusted the results for energy intake and other variables that have been shown to influence self-report of dietary intakes [3].

In addition to these general limitations of the FFQ, the combination of the single baseline measurement in the NLCS and the long follow-up used in this thesis, may have introduced some misclassification of the exposure. Although a reproducibility study showed that dietary intakes in the NLCS were rather stable during the first 5 years of follow-up [4], it is possible that intakes may have changed in the later follow-up. Given the prospective design of the NLCS and the fact that participants are generally unaware of the amount of nutrients they consume, it is most likely that changes in diet may have occurred independently of the outcome (i.e. at random). If random classification error was present in our data, it might have resulted in an underestimation of the reported associations [1]. In order to evaluate this potential 
underestimation, we separately investigated early and late follow-up in chapter 2 and confirmed that risk estimates were much higher in early compared to late follow-up.

In particular, it has been recognized that exposure to sodium is difficult to measure accurately. The method of multiple 24h-urine collection is considered the gold standard, as this biomarker method is suitable to assess the absolute amount of intakes of a population and to capture total salt intake, including sodium intake from foods as well as added salt intake [5]. Generally, FFQs may underestimate the total amount of sodium intake, because they do not consider added salt intake [5]. The NLCS is one of the few prospective cohort studies that have a special salt module included in its questionnaire to assess added salt intake and salt preference. Therefore, we obtained more comprehensive data on salt consumption than the only other study investigating dietary sodium intake and RCC risk [6].

An important issue to consider when investigating sodium intake, is the phenomenon of reverse causation (i.e. when the outcome influences the exposure). Reverse causation typically occurs in a cross-sectional setting in populations that are at high disease risk prior to the start of the study [1]. Even though our study is prospective and population-based, reverse causation between the exposure (salt intake) and intermediate factor (hypertension) may have influenced the baseline RCC risk of some participants. Indeed, we observed that, at baseline, participants with hypertension were overrepresented in the lowest category of added salt intake. Because hypertension is an established risk factor for RCC [7], participants in the lowest category of added salt intake may have had a high baseline RCC risk. Therefore, we cannot exclude the possibility that reverse causation may have resulted in a u-shaped association between added salt intake and RCC risk.

\section{Selection of genes and methods to assess gene-environment interactions}

Many approaches can be used to study gene-environment interactions, ranging from agnostic to hypothesis driven approaches [8]. Traditionally, most gene-environment interaction studies are candidate gene studies, starting from an established association with an environmental factor and proceeding to explore genes in pathways of interest [9]. Currently, more and more gene-environment interactions are studied using an agnostic approach in a genome-wide setting [i.e. genome-wide environmental interaction studies (GWEIS)], as advances in technologies make genotyping and phenotyping more easily available at reasonable costs [10]. Because our aim was to unravel potential novel pathways underlying the association between sodium, potassium and fluid intake and RCC risk, we chose a hypothesis-based, candidate gene approach and we selected genes and SNPs based on currently available literature. We considered the RAAS and ITMs as two potentially cancer- 
causing, biologic mechanisms of interest, because they have been implicated in both renal (patho)physiology and carcinogenesis. Our final selection included 13 SNPs in seven RAAS genes and 13 SNPs in ten ITM genes.

When aiming to explore genes in pathways of interest, helpful tools to select genes are pathway databases, such as the KEGG database [11]. Although our search strategy initially resulted in more than 100 potential SNPs of interest, we could only include a limited number of SNPs in our final selection. Since the candidate gene selection strategy does not exist, the selection process is subject to carefully considered, predefined selection criteria. The criteria we used and their consequences have been discussed in chapters 3 and 4 of this thesis and included, amongst others, the cut-off value for the minor allele frequency (MAF). In order to warrant optimal power, we only included SNPs with MAF of at least $20 \%$. However, since populations differ in genetic make-up, and because reference data on the genetic make-up of the Dutch population are not yet available, the MAF of some SNPs in our population turned out to be lower than expected based on other Caucasian populations. We tried to minimize the problem of limited power by analyzing these SNPs under the assumption of a dominant mode of inheritance (homogeneous common genotype versus heterogeneous and homozygote rare genotype). Consequently we could have missed gene-environment interactions with SNPs that for example have a recessive mode of inheritance (homogeneous common and heterogeneous genotype versus homozygote rare genotype).

In addition to the mode of inheritance, our decisions regarding the type of interaction may also have influenced the results of this thesis. Many types of interaction may be distinguished depending on the context, including statistical interaction, quantitative interaction, qualitative interaction, public health synergy and biological interaction [9]. Biological interaction results from physical interactions between biomolecules (e.g. DNA, RNA, proteins, enzymes, etc.) and occurs at the cellular level in an individual, whereas statistical interaction occurs at the population level and is realized when there is inter-individual variation in DNA sequences [12]. In addition to these pathophysiologic models, different measurement scales should be considered; the multiplicative scale is generally used to study disease etiology, whereas the additive scale may best be used to predict the number of cases in a population [13]. The question of which scale should be used to define interaction has been intensely debated upon. Since we were in this thesis mainly interested in inter-individual variation in DNA sequences in RCC etiology, we tested for statistical interaction on a multiplicative scale. Therefore, we cannot exclude the possibility that we might have missed interesting findings related to other types of interactions.

In candidate gene-environment interaction studies, several limitations and pitfalls have been recognized a main challenge, including limited power and multiple testing 
[9]. One way to overcome these issues is by using a sum score of unfavorable alleles, because such approach will limit the number of associations tested and optimize the power. Moreover, it is biologically more plausible to study the relationship between a complex pathway and a multidimensional disease as a whole. However, currently available evidence should be used to appoint these unfavorable alleles and avoid 'overfitting' of the sum score. Due to the explorative nature of our study, the candidate SNPs have rarely been investigated in relation to RCC. Instead, our selection of candidate genes was mainly based on associations with blood pressure, hypertension, and sodium handling and, therefore, no external information was available to construct a solid sum score of unfavorable alleles. Alternatively, we explored the potential of multifactor dimensionality reduction (MDR) to fit a better model to our complex data than we could achieve by using a single-marker approach. MDR is a non-parametric, data mining method that allows for higher-order interactions, including all SNPs and exposures of interest $[12,14]$. This approach simultaneously limits the concerns regarding sample size and multiple testing. Moreover, these types of methods do not assume a mode of inheritance [12]. Although we were faced with major challenges with respect to our case-cohort design and the interpretation of the results while using MDR at this stage, we feel that this type of machine learning methods are worthwhile to consider in future research, particularly given the developments in GWEIS.

Taken together, it should be noted that a certain degree of inevitable subjectivity in the selection of our approach, the genes and SNPs and the analyses techniques, is a major challenge in gene-environment interaction studies and that, despite all our careful considerations, we cannot exclude the possibility that we missed some important observations. Given the hypothesis-generating nature of studies in this thesis, this may even outweigh common criticism on candidate gene studies on falsepositive findings.

\section{Selection bias and classification of the RCC tumor in molecular (pathological) epidemiology}

In general, studies in the NLCS using traditional epidemiological methods are unlikely to be influenced by selections bias, because of the prospective design, which assures that participants are not included as a consequence of their disease status, and the limited loss-to-follow-up [1]. However, in molecular (pathological) epidemiological studies, the incomplete collection of tumor material for histological and molecular classification, if differential, may lead to selection bias. There are several reasons why tumor tissue may not be available in molecular epidemiological studies [15]. In our study, we observed that for a reasonable amount of the cases without tissues material no material exists. As the primary therapy for RCC is surgery, it can be expected that material is available to large extent [16]. However, the percentage of surgical 
procedures is lower for stage IV tumors. To minimize the potential effects of these stage IV tumors, we excluded this subgroup in sensitivity analyses regarding survival (chapter 7). Secondly, no record linkage with the Dutch Pathology Register (PALGA) may have been possible, due to record linkage errors or incompleteness of PALGA before 1991 [17] and, thirdly, particularly older tissues may have been lost or destroyed. In our study, inclusion was indeed slightly lower for cases identified during the first 5-years of follow-up. Nevertheless, we were able to collect tumor material of an exceptional amount of eligible histologically confirmed epithelial RCC cases (i.e. $80 \%)$. In addition, our collection of RCC cases is embedded within the NLCS and thus population-based. Therefore, we considered the likelihood of selection bias in our series of RCC cases to be low.

The collection of tumor material provided the opportunity to conduct molecular pathological analyses separately for each histological subtype (i.e. clear-cell RCC, papillary RCC and chromophobe RCC). Haematoxylin and eosin (HE)-stained slides of all the collected FFPE tumor tissues were assessed by two experienced genitourinary pathologist to confirm tumor histology based on the WHO-classification of tumors [18]. Based on this assessment, our collection of RCC cases includes 365 (80.6\%) clearcell (cc)RCC cases, 60 (13.3\%) papillary (p)RCC cases, 15 (3.3\%) chromophobe (chr)RCC cases and $13(2.8 \%)$ other or undefined RCC cases. This is important when investigating molecular tumor heterogeneity, because different molecular pathways are thought to be involved in different subtypes [19]. RCC cases of the clear-cell subtype were further classified according to the degree to which promoter methylation in a set of candidate genes was present in the tumor. However, there is no accepted way to classify tumors according to these genes in particular and for RCC in general, such as CpG island methylator phenotype (CIMP) in colorectal cancer [20]. Therefore, it is possible that the selected genes intended to represent CIMP may not be generalizable to general promoter methylation status. Neither can we exclude the possibility that our panel of genes involved in ITMs may represent CIMP instead.

\section{Multidimensional approach to study ion transport mechanisms (ITMs)}

In order to investigate the role of ITMs in the associations between sodium, potassium and fluid intake and RCC risk, we used a multidimensional approach, including molecular data on both SNPs (for gene-environment interactions) and promoter CpG island methylation (for tumor heterogeneity). As previously explained, the candidate gene selection strategy does not exist and thereby the selection process is subject to carefully considered, pre-defined selection criteria. Different criteria are applicable when assessing gene-environment interactions compared to molecular tumor heterogeneity. As a result, in both types of molecular analyses, the final gene panel differed. For example, not all genes exhibited CpG islands in or near the promoter region and could not be included by definition, when studying tumor heterogeneity by 
means of promoter $\mathrm{CpG}$ island methylation. Inversely, genes of interest for studying promoter CpG island methylation do not necessarily have SNPs of interest to study gene-environment interactions.

In addition to the differences in genes selected, this multidimensional approach highlights two distinct mechanisms by which the genes involved in ITMs may be aberrantly regulated or silenced, including a genetic (SNPs) and epigenetic (promoter methylation) mechanism. SNPs may influence the expression of the gene modestly, but potentially bidirectional mechanism (higher and lower expression), whereas promoter methylation tends to silence the whole gene (no expression). Moreover, SNPs are germline variations that may provide information on genetic predisposition, which may be relevant for the development of RCC, whereas promoter methylation may both influence the development and the progression of RCC. Together this multidimensional approach provides a broader view of the role of ITMs in RCC carcinogenesis.

\section{OVERALL INTERPRETATION OF THE RESULTS}

The aims of this thesis were to evaluate dietary intakes of sodium, potassium and fluid as novel risk factors for RCC and to unravel novel disease pathways implicated in renal (patho)physiology in the etiology and prognosis of RCC. After extensive considerations of the most important methodological issues, we conclude that the present thesis provides the first evidence that sodium intake is a novel risk factor for RCC, particularly if fluid consumption is low. This interaction between sodium and fluid intake supports our hypothesis that the link between sodium and fluid in renal physiology, and perhaps renal (patho)physiology in general, is important in RCC etiology. However, replication of these findings in other prospective studies is warranted.

Moreover, we hypothesized that dietary sodium intake may influence RCC risk, through hypertension. In this thesis, we found no indications for modifying or mediating effects of hypertension in the association between dietary sodium intake and RCC risk. This suggests that sodium intake may increase RCC risk independently of hypertension. Additionally, we observed that the RCC risk for participants with 'no added salt intake' was different between those with and without hypertension, suggesting that hypertension may specifically influence the association between added salt intake and RCC risk. As discussed previously, we cannot exclude the possibility that this association may be influenced by reverse causation. Importantly, we also found evidence that hypertension modified the association between some SNPs in RAAS genes, particularly AGT and AGTR1, and RCC risk. Given the key role of the RAAS in both sodium homeostasis and hypertension, we conclude that it is 
worthwhile to further investigate the exact role of hypertension in the association between sodium intake and RCC risk.

In the second part of this thesis, two biological mechanisms involved in renal physiology, including the RAAS and ITMs, have been put forward as potential cancercausing mechanisms that may explain the association between high sodium intake and RCC risk or that may be involved in RCC etiology otherwise. The RAAS regulates blood pressure and sodium homeostasis in the kidney and may, therefore, reflect a mechanism potentially underlying associations between sodium intake and RCC risk. As discussed previously, we tested for statistical interaction on a multiplicative scale. None of the SNP-diet interactions were statistically significant. Nevertheless, several polymorphisms in RAAS genes, particularly in $A C E$, showed suggestive interaction in the association between sodium intake and RCC risk. These results in combination with the results regarding RAAS SNPS and hypertension have led us to conclude that the RAAS is a likely candidate pathway in RCC etiology.

This thesis shows differential results regarding the role of ITMs in RCC carcinogenesis. As previously discussed, given the differences regarding the nature of the events studied (genetic versus epigenetic) and the selected genes, a one-to-one comparison of the results of the studies investigating the ITMs (Chapter 4 and 5) is not possible. However, more importantly, this multidimensional approach provides a broader view on the role of ITMs in RCC carcinogenesis. In chapter 4, evidence regarding geneenvironment interactions with SNPs in ITM genes was too weak to support the hypothesis that ITMs are important in RCC etiology. However, in chapter 5, the intake of potassium was differentially associated with molecular subtypes of clear-cell RCC classified according to a promoter methylation index of ITM genes. Together, these results regarding ITMs suggest that promoter methylation plays a more dominant role in RCC than SNPs. This is plausible because promoter methylation tends to silence the whole gene (no expression), while SNPs may influence the expression of the gene only modestly and potentially bidirectional (higher and lower expression). Moreover, we were not able to include all potential interesting SNPs in our analyses and might have missed some interesting findings with other SNPs in ITM genes involved. Overall, we concluded that promoter methylation status may be used to classify the RCC tumor in terms of molecular heterogeneity and that ITMs may play a role in the etiology of RCC.

In the third part of the thesis, we studied promoter methylation in a larger, more general context in the etiology of RCC and in relation to RCC survival. We could not show that promoter methylation is a potential cancer-causing mechanism in the association between dietary intakes of folate and alcohol and RCC risk. Therefore, we concluded that the associations between alcohol and folate intake and RCC risk are not influenced by promoter methylation. However, the complexity of the relationship 
under study and the generalizability of the gene panel towards CIMP, may have contributed to this negative finding. Moreover, promoter methylation is thought to contribute to both cancer development and progression [21-24]. Therefore, we hypothesized that promoter methylation may, in addition to RCC etiology, also play a role in the prognosis of RCC. We demonstrated that promoter methylation of cysteine dioxygenase type 1 (CDO1) gene did matter in relation to RCC survival, as patients with CDO1 promoter methylation had a significantly poorer clear-cell RCC-specific 10-year survival than those without.

\section{FUTURE DIRECTIONS IN RENAL CELL CANCER RESEARCH}

Based on the results of this thesis, we recommend future research to focus, firstly, on reproducing the association between dietary sodium intake and RCC risk in other populations as well as on the exact role of hypertension in this association. To further elucidate the role of the RAAS and ITMs underlying these associations, future geneenvironment interaction studies may benefit from current developments in molecular epidemiology, such as advanced bioinformatics analysis techniques, which enable the complexity of these mechanisms to be incorporated into the analyses. As a result, future gene-environment interaction studies may want to combine hypothesis-based pathway selection with a more agnostic approach to select SNPs and genes. In addition to the biological mechanisms explored in this thesis, other pathways are suggested to play a role in the development of RCC, such as the oxygen-sensing pathway. Future research may focus on the role of the oxygen-sensing pathway in RCC etiology, as it has been recognized that loss of function of the Von Hippel-Lindau (VHL) gene, which is involved in the oxygen-sensing pathway [25], is an important event in the development of clear-cell RCC [26].

More generally, to advance in the field of RCC research and gain insight into RCC etiology and prognosis, future RCC research should benefit from the identification of genetic and epigenetic subtypes. In large measure, the genetic basis of the RCC tumor has been established [27-34], yet before this information can be used in future research and in a clinical setting, efforts should be made to integrate this genetic data with information on lifestyle, tumor characteristics, treatment and prognosis. In this context, the emerging field of molecular pathological epidemiology (MPE), which integrates molecular subgroups into traditional epidemiological research [35], provides great opportunities to explain observed differences in risk factors across populations and studies and to increase our knowledge on the underlying biologic pathways [35]. A better understanding of tumor heterogeneity is crucial to eventually develop tools that may be used for early detection and to guide clinical decisions on treatment and eventually move closer towards personalized cancer medicine and prevention. 


\section{CONCLUDING REMARKS}

This thesis describes, for the first time, that dietary sodium intake and renal (patho)physiological mechanisms (i.e. the RAAS and ITMs) were associated RCC risk. Thus, this thesis shows that (molecular) epidemiological research in RCC may benefit from a more renal (patho)physiologic perspective. We illustrated that molecular (pathological) epidemiology is a promising new field of research that can be used to provide insight into underlying biologic pathways of disease. While faced with several limitations regarding exposure, outcome and analyses, this is not an easy task. Nevertheless, the population-based nature of our collection of RCC cases and the availability of extensive information on demographic and dietary characteristics of the patients, tumor characteristics and survival status, make this series, to date, the best available infrastructure in the world to study molecular pathological epidemiological research questions in the field of RCC. 


\section{REFERENCES}

1. Rothman KJ, Greenland S. Modern Epidemiology. 2nd ed. ed. 1998, Philadelphia: Lippincott-Raven Publishers.

2. Illner AK, Nöthlings $\mathrm{U}$, Wagner $\mathrm{K}$, Ward $\mathrm{H}$, Boeing $\mathrm{H}$. The assessment of individual usual food intake in large-scale prospective studies. Ann Nutr Metab 2010;56:99-105.

3. Willett W. Nutritional Epidemiology. 1990, New York: Oxford University Press.

4. Goldbohm RA, van 't Veer P, van den Brandt PA, van 't Hof MA, Brants HA, Sturmans F, Hermus RJ. Reproducibility of a food frequency questionnaire and stability of dietary habits determined from five annually repeated measurements. Eur J Clin Nutr 1995;49:420-9.

5. Elliott P, Brown I. Sodium intakes around the world. Background document prepared for the Forum and Technical meeting on Reducing Salt Intake in Population (paris 5-7th October 2006). 2007, World Health Orginisation (WHO).

6. Mellemgaard A, McLaughlin JK, Overvad K, Olsen JH. Dietary risk factors for renal cell carcinoma in Denmark. Eur J Cancer 1996;32a:673-82.

7. Chow WH, Dong LM, Devesa SS. Epidemiology and risk factors for kidney cancer. Nat Rev Urol 2010; 7:245-57.

8. Hutter CM, Mechanic LE, Chatterjee N, Kraft P, Gillanders EM; NCl Gene-Environment Think Tank. Gene-environment interactions in cancer epidemiology: a National Cancer Institute Think Tank report. Genet Epidemiol 2013;37:643-57.

9. Thomas D. Gene--environment-wide association studies: emerging approaches. Nature reviews. Genetics 2010;11:259-72.

10. Aschard H, Lutz S, Maus B, Duell EJ, Fingerlin TE, Chatterjee N, Kraft P, Van Steen K. Challenges and opportunities in genome-wide environmental interaction (GWEI) studies. Hum Genet 2012;131: 1591-613.

11. Orlowski J, Grinstein S. Na+/H+ exchangers of mammalian cells. J Biol Chem 1997;272:22373-6.

12. Moore JH, Gilbert JC, Tsai CT, Chiang FT, Holden T, Barney N, White BC. A flexible computational framework for detecting, characterizing, and interpreting statistical patterns of epistasis in genetic studies of human disease susceptibility. J Theor Biol 2006;241:252-61.

13. Ottman R. Gene-environment interaction: definitions and study designs. Prev Med 1996;25:764-70.

14. Ritchie MD, Hahn LW, Roodi N, Bailey LR, Dupont WD, Parl FF, Moore JH. Multifactor-dimensionality reduction reveals high-order interactions among estrogen-metabolism genes in sporadic breast cancer. Am J Hum Genet 2001;69:138-47.

15. Hoppin JA, Tolbert PE, Taylor JA, Schroeder JC, Holly EA. Potential for selection bias with tumor tissue retrieval in molecular epidemiology studies. Ann Epidemiol 2002;12:1-6.

16. Ljungberg B, Cowan NC, Hanbury DC, Hora M, Kuczyk MA, Merseburger AS, Patard JJ, Mulders PF, Sinescu IC; European Association of Urology Guideline Group. EAU guidelines on renal cell carcinoma: the 2010 update. Eur Urol 2010;58:398-406.

17. Casparie M, Tiebosch AT, Burger G, Blauwgeers $H$, van de Pol A, van Krieken JH, Meijer GA. Pathology databanking and biobanking in The Netherlands, a central role for PALGA, the nationwide histopathology and cytopathology data network and archive. Cell Oncol 2007;29:19-24.

18. Eble J, et al. World Health Organization Classification of Tumours. Pathology and Genetics. Tumours of the Urinary System and Male Genital Organs. 2004, Lyon: IARC Press.

19. Baldewijns MM, van Vlodrop IJ, Schouten LJ, Soetekouw PM, de Bruïne AP, van Engeland M. Genetics and epigenetics of renal cell cancer. Biochim Biophys Acta 2008;1785:133-55.

20. Ogino S, Cantor M, Kawasaki T, Brahmandam M, Kirkner GJ, Weisenberger DJ, Campan M, Laird PW, Loda M, Fuchs CS. CpG island methylator phenotype (CIMP) of colorectal cancer is best characterised by quantitative DNA methylation analysis and prospective cohort studies. Gut 2006;55:1000-6.

21. Jones PA, Baylin SB. The fundamental role of epigenetic events in cancer. Nat Rev Genet 2002;3: 415-28.

22. Wolffe AP, Matzke MA. Epigenetics: regulation through repression. Science 1999;286:481-6.

23. Fukushige $S$, Horii A. DNA methylation in cancer: a gene silencing mechanism and the clinical potential of its biomarkers. Tohoku J Exp Med 2013;229:173-85.

24. Das PM, Singal R. DNA methylation and cancer. J Clin Oncol 2004;22:4632-42. 
25. Maynard MA, Ohh M. Molecular targets from VHL studies into the oxygen-sensing pathway. Curr Cancer Drug Targets 2005;5:345-56.

26. Richards FM. Molecular pathology of von Hippel-Lindau disease and the VHL tumour suppressor gene. Expert Rev Mol Med 2001;2001:1-27.

27. Dalgliesh GL, Furge K, Greenman C, Chen L, Bignell G, Butler A, Davies H, Edkins S, Hardy C, Latimer C, Teague J, Andrews J, Barthorpe S, Beare D, Buck G, Campbell PJ, Forbes S, Jia M, Jones D, Knott H, Kok CY, Lau KW, Leroy C, Lin ML, McBride DJ, Maddison M, Maguire S, McLay K, Menzies A, Mironenko T, Mulderrig L, Mudie L, O'Meara S, Pleasance E, Rajasingham A, Shepherd R, Smith R, Stebbings L, Stephens P, Tang G, Tarpey PS, Turrell K, Dykema KJ, Khoo SK, Petillo D, Wondergem B, Anema J, Kahnoski RJ, Teh BT, Stratton MR, Futreal PA. Systematic sequencing of renal carcinoma reveals inactivation of histone modifying genes. Nature 2010;463:360-3.

28. Guo G, Gui Y, Gao S, Tang A, Hu X, Huang Y, Jia W, Li Z, He M, Sun L, Song P, Sun X, Zhao X, Yang S, Liang C, Wan S, Zhou F, Chen C, Zhu J, Li X, Jian M, Zhou L, Ye R, Huang P, Chen J, Jiang T, Liu X, Wang Y, Zou J, Jiang Z, Wu R, Wu S, Fan F, Zhang Z, Liu L, Yang R, Liu X, Wu H, Yin W, Zhao X, Liu Y, Peng H, Jiang B, Feng Q, Li C, Xie J, Lu J, Kristiansen K, Li Y, Zhang X, Li S, Wang J, Yang H, Cai Z, Wang J. Frequent mutations of genes encoding ubiquitin-mediated proteolysis pathway components in clear cell renal cell carcinoma. Nat Genet 2012;44:17-9.

29. Varela I, Tarpey P, Raine K, Huang D, Ong CK, Stephens P, Davies H, Jones D, Lin ML, Teague J, Bignell G, Butler A, Cho J, Dalgliesh GL, Galappaththige D, Greenman C, Hardy C, Jia M, Latimer C, Lau KW, Marshall J, McLaren S, Menzies A, Mudie L, Stebbings L, Largaespada DA, Wessels LF, Richard S, Kahnoski RJ, Anema J, Tuveson DA, Perez-Mancera PA, Mustonen V, Fischer A, Adams DJ, Rust A, Chan-on W, Subimerb C, Dykema K, Furge K, Campbell PJ, Teh BT, Stratton MR, Futreal PA. Exome sequencing identifies frequent mutation of the SWI/SNF complex gene PBRM1 in renal carcinoma. Nature 2011;469:539-42.

30. Duns G, Hofstra RM, Sietzema JG, Hollema H, van Duivenbode I, Kuik A, Giezen C, Jan O, Bergsma JJ, Bijnen $\mathrm{H}$, van der Vlies $\mathrm{P}$, van den Berg $\mathrm{E}$, Kok $\mathrm{K}$. Targeted exome sequencing in clear cell renal cell carcinoma tumors suggests aberrant chromatin regulation as a crucial step in ccRCC development. Hum Mutat 2012;33:1059-62.

31. Gerlinger M, Rowan AJ, Horswell S, Larkin J, Endesfelder D, Gronroos E, Martinez $P$, Matthews N, Stewart A, Tarpey P, Varela I, Phillimore B, Begum S, McDonald NQ, Butler A, Jones D, Raine K, Latimer C, Santos CR, Nohadani M, Eklund AC, Spencer-Dene B, Clark G, Pickering L, Stamp G, Gore M, Szallasi Z, Downward J, Futreal PA, Swanton C. Intratumor heterogeneity and branched evolution revealed by multiregion sequencing. N Engl J Med 2012;366:883-92.

32. Peña-Llopis $S$, Vega-Rubín-de-Celis $S$, Liao A, Leng N, Pavía-Jiménez A, Wang S, Yamasaki T, Zhrebker L, Sivanand S, Spence P, Kinch L, Hambuch T, Jain S, Lotan Y, Margulis V, Sagalowsky AI, Summerour PB, Kabbani W, Wong SW, Grishin N, Laurent M, Xie XJ, Haudenschild CD, Ross MT, Bentley DR, Kapur P, Brugarolas J. BAP1 loss defines a new class of renal cell carcinoma. Nat Genet 2012;44:751-9.

33. Sato $Y$, Yoshizato $T$, Shiraishi $Y$, Maekawa $S$, Okuno $Y$, Kamura T, Shimamura T, Sato-Otsubo A, Nagae G, Suzuki H, Nagata Y, Yoshida K, Kon A, Suzuki Y, Chiba K, Tanaka H, Niida A, Fujimoto A, Tsunoda T, Morikawa T, Maeda D, Kume H, Sugano S, Fukayama M, Aburatani H, Sanada M, Miyano S, Homma $Y$, Ogawa S. Integrated molecular analysis of clear-cell renal cell carcinoma. Nat Genet 2013;45:860-7.

34. Cancer Genome Atlas Research Network, Comprehensive molecular characterization of clear cell renal cell carcinoma. Nature 2013;499:43-9.

35. Ogino S, Stampfer M. Lifestyle factors and microsatellite instability in colorectal cancer: the evolving field of molecular pathological epidemiology. J Natl Cancer Inst 2010;102:365-7. 
Summary 
Several risk factors have been established to increase the risk of renal cell cancer (RCC). However, the effects that these factors have on RCC risk are rather modest and, in general, the etiology of RCC is still poorly understood. In order to advance in the field of RCC and gain insight into its etiology and prognosis, it is important to search beyond current perspectives and generate new hypothesis for future research. Therefore, the overall aim of this thesis is to unravel novel risk factors and disease pathways implicated in renal (patho)physiology in the etiology and prognosis of RCC.

In part 1 (chapter 2) of this thesis, we investigated the role of sodium intake, potassium intake and fluid intake in relation to RCC risk using a traditional epidemiological approach. We identified that sodium intake is a novel risk factor for RCC, particularly if fluid consumption is low. This interaction between sodium and fluid intake supports our hypothesis that, given the link between sodium and fluid homeostasis in renal physiology, the balance between sodium and fluid intake is important in RCC etiology. We found no indications for modifying or mediating effects of hypertension. This suggests that sodium intake may increase RCC risk independently of hypertension. In addition, we observed that fluid and potassium intake were not associated with RCC risk.

In part two (chapters 3 and 4) of this thesis, we investigated the role of single nucleotide polymorphisms (SNPs) in candidate genes and their potential interplay with the environment in RCC etiology using a molecular-epidemiological approach. Chapter 3 focused on the renin-angiotensin-aldosterone system (RAAS) as potential disease mechanism. We showed that two candidate SNPs in AGTR1 were associated with RCC risk; the homozygote rare genotype of AGTR1_rs1492078 decreased RCC risk, whereas the homozygote rare genotype of AGTR1_rs5186 increased RCC risk. Hypertension modified the association between $A G T$ rs3889728 and RCC risk. Interactions between dietary intakes (sodium, potassium and fluid) were not significant. However, sodium intake was differentially associated with RCC risk defined by genotypes of several SNPs in genes involved in the RAAS. These results indicate a biologic interaction instead of a statistical interaction. In chapter 4 we investigated the role of gene-environment interactions in ion transport mechanisms (ITMs) as potential disease mechanism. We tested main effects of 13 candidate SNPs in ITM genes and gene-environment interactions between these SNPs and associated environmental factors, including dietary intakes of sodium, potassium and fluid, hypertension and diuretic medication. Only ADD1_rs4961 was significantly associated with RCC risk in the main effects analyses. Additionally, three out of four significant gene-environment interactions clustered in SLC9A3_rs4957061, which indicates involvement of SLC9A3_rs4957061 in RCC etiology. Nevertheless, the body of evidence is too weak to support the hypothesis that the mechanism of ion transport is a disease mechanism in RCC etiology. 
In part 3 (chapters 5-7) of this thesis, we classified the clear-cell RCC tumor according to promoter CpG island hypermethylation of a subset of genes to study molecular subtype-specific etiology (chapters 5 and 6) and prognosis (chapter 7) using the approach of molecular pathological epidemiology (MPE). In chapter $\mathbf{5}$ we classified the clear-cell RCC tumor according to a promoter methylation index of genes specifically selected for their involvement in the mechanism of ion transport. We investigated dietary intakes that are linked to ITMs, i.e. sodium, potassium and fluid intake, as potential risk factors for clear-cell RCC using these molecular subtypes. We found that the intake of potassium, but not sodium or fluid, was differentially associated with the molecular subtypes of clear-cell RCC. High versus low potassium intake was associated with a lower clear-cell RCC risk for unmethylated tumors and a higher clear-cell RCC risk for tumors with a high promoter methylation index. Thus, this study illustrates that risk factors may differ according to molecular subtypes of the tumor. In addition, we showed the first evidence for a potential role of ITMs in RCC etiology. In chapter 6, we determined promoter CpG island hypermethylation status for a larger, more general panel of genes and classified the clear-cell RCC tumor accordingly. We investigated dietary intakes that may be linked to the general mechanism of methylation, i.e. alcohol and folate intake, in relation to these molecular subtypes. We did not observe differential associations between alcohol and folate intake and molecular subgroups of the clear-cell RCC tumor defined by promoter CpG island hypermethylation. Therefore, this study does not support the hypothesis that promoter $\mathrm{CPG}$ island hypermethylation of this gene panel may be the disease mechanism linking alcohol and folate intake to clear-cell RCC risk. In chapter 7, we classified the clear-cell RCC tumor by the presence of promoter CpG island hypermethylation of the cysteine dioxygenase type 1 (CDO1) gene and evaluated these molecular subgroups in a prognostic setting. Results demonstrated that patients with promoter $\mathrm{CpG}$ island hypermethylation of $C D O 1$ have a significantly poorer clearcell RCC-specific 10-year survival than those without. Differences in survival were independent of common prognostic makers, including age at diagnosis, sex, TNM stage, tumor size and Fuhrman grade. Thus, promoter CpG island hypermethylation of CDO1 offers additional, relevant, prognostic information, but may not substitute common prognostic makers to predict clear-cell RCC-specific 10 -year survival. Results were validated in clear-cell RCC cases from The Cancer Genome Atlas (TCGA).

Finally, this thesis concludes with a summary and interpretation of main findings, a general discussion and implications for future RCC research (Chapter 8). After extensive considerations of the most important methodological issues, we concluded that this thesis provides the first evidence that dietary sodium intake and renal (patho)physiological mechanisms (i.e. the RAAS and ITMs) were implicated in RCC etiology. Thus, this thesis shows that (molecular) epidemiological research in RCC may benefit from a more renal (patho)physiologic perspective. Moreover, we illustrated 
that molecular (pathological) epidemiology is a promising new field of research which can be used to provide insight into underlying biologic pathways of disease. 
Samenvatting 
Jaarlijks wordt er in Nederland bij ongeveer 10 per 100,000 mensen nierkanker gediagnostiseerd. Daarmee staat nierkanker op de $7^{\mathrm{e}}$ plaats van meest voorkomende vormen van kanker. Nierkanker komt vaker voor bij mannen dan bij vrouwen en naar mate men ouder wordt. Het is bekend dat ook andere factoren naast geslacht en leeftijd het risico op nierkanker kunnen verhogen; zoals overgewicht, roken, hoge bloeddruk en familiaire aanleg. Tegelijkertijd zouden een gematigde inname van alcohol en het eten van voldoende groentes en fruit het risico op nierkanker juist verlagen. Toch is het tot op heden niet precies bekend hoe nierkanker ontstaat.

In dit proefschrift maken we gebruiken van een nieuwe invalshoek om het ontstaan van nierkanker te onderzoeken om op deze manier tot nieuwe inzichten te komen ten aanzien van de ontwikkeling van deze kanker. Het doel van dit proefschrift is het ontdekken van nieuwe risicofactoren en biologische mechanismen, welke enerzijds gerelateerd zijn aan de nierfysiologie en anderzijds het ontstaan van nierkanker of de overleving van patiënten met nierkanker kunnen beïnvloeden.

We hebben deze vraagstelling onderzocht in een groot, prospectief, cohort onderzoek onder gezonde mensen uit de algemene Nederlandse bevolking, namelijk in de Nederlandse Cohort Studie naar voeding en kanker (NLCS). In 1986 retourneerden 120,852 deelnemers een vragenlijst over hun voedingsinname en verschillende andere leefstijlfactoren. Ook verzamelden we teennagels die we later hebben kunnen gebruiken voor het bepalen van de genetische variatie tussen de deelnemers. We volgden deze deelnemers tot 2006, dus meer dan 20 jaar. In totaal kregen 608 van de deelnemers tijdens deze 20 jaar een vorm van nierkanker. In de analyses hebben we de deelnemers met nierkanker vergeleken met een willekeurige subgroep van 5.000 deelnemers uit het totale cohort.

In het eerste deel van dit proefschrift (hoofdstuk 2) stond de relatie tussen de inname van zout, kalium en vocht, en het risico op nierkanker centraal. Met een traditioneel epidemiologische benadering konden we aantonen dat er een verband is tussen een hoge inname van zout en nierkanker. Dit verband leek sterker wanneer er tegelijkertijd ook sprake was van een lage inname van vocht. Deze bevinding suggereert dat de balans tussen zout- en vochtinname mogelijk belangrijk is bij het ontstaan van nierkanker. We konden in dit hoofdstuk geen verband aantonen tussen een hoge inname van kalium en het risico op nierkanker. Het is bekend dat zout het risico op hoge bloeddruk vergroot, terwijl hoge bloeddruk weer een risicofactor is van nierkanker. Echter, het verband dat wij vonden voor hoge zoutinname en nierkanker werd niet verklaard door hoge bloeddruk.

In het tweede deel van dit proefschrift (hoofdstuk 3 en 4) hebben we genetische variatie onderzocht in twee fysiologische systemen die in de nier een belangrijke rol spelen bij het reguleren van de bloeddruk en de zout- en vochtbalans van ons lichaam, 
namelijk het renine-angiotensine-aldosteron systeem (RAAS) en ion-transport mechanismen (ITM). Genetische variaties in deze fysiologische systemen zouden een potentiële verklaring kunnen zijn voor het verband tussen een hoge zoutinname en het risico op nierkanker dat we eerder al hadden gevonden. Om hiervoor aanwijzingen te vinden hebben we zogenaamde gen-omgeving interacties in het risico op nierkanker onderzocht tussen 26 verschillende genetische varianten aan de ene kant en het dieet (bijvoorbeeld zoutinname) aan de andere kant. Hiervoor gebruikten we een moleculair-epidemiologische benadering. Door middel van deze zogenaamde gen-omgeving interacties konden we bewijzen dat RAAS wellicht een rol speelt bij het ontstaan van nierkanker. We vonden namelijk voor meerdere genetische varianten dat het risico op nierkanker bij een hoge zoutinname voor deelnemers met de genetische variant anders was dan voor deelnemers zonder de genetische variant. Daarnaast vonden we dat een bepaalde genetische variant het risico op nierkanker bij aanwezigheid van een hoge bloeddruk veranderde. In tegenstelling tot deze resultaten in het RAAS, konden we niet aantonen dat ook ITM een mogelijke rol spelen bij het ontstaan van nierkanker.

In het derde deel van dit proefschrift (hoofdstuk 5-7) onderzochten we tumorheterogeniteit zowel in relatie tot de ontwikkeling van nierkanker, als in relatie tot de overleving van patiënten met nierkanker. Het vermogen om genen aan- en uit te zetten, onderdeel van de epi-genetica, kan een kenmerk zijn van hoe een tumor is ontstaan, maar ook van hoe een tumor zich zou kunnen ontwikkelen. In twee studies hebben we onderzocht of we met behulp van een bepaalde vorm van deze epigenetica, namelijk DNA methylering, groepen van niertumoren met verschillen in risicofactoren zouden kunnen onderscheiden. In de ene studie onderzochten we DNA methylering in genen die gerelateerd zijn aan ITM en in de andere studie gebruikten we een groep genen met verschillende functies. De eerste studie liet zien dat een hoge kaliuminname verband houdt met een verlaagd risico op nierkanker in de groep zonder DNA methylering in de ITM genen (wanneer deze genen dus 'aan' staan) en een verhoogd risico op nierkanker in de groep met veel DNA methylering in de ITM genen (wanneer deze genen dus 'uit' staan). Deze bevinding is niet in lijn met de bevindingen van hoofdstuk 2, waarin we juist geen verband konden aantonen tussen een kaliuminname en het risico op nierkanker. Hiermee bewijzen we dus dat risicofactoren kunnen verschillen op basis van de tumorheterogeniteit tussen niertumoren. Bovendien vonden we, in tegenstelling tot ons eerder onderzoek in hoofdstuk 4, dat ook ITM een mogelijke rol spelen bij het ontstaan van nierkanker. In de tweede studie over tumorheterogeniteit op basis van de groep genen met verschillende functies konden we geen groepen van niertumoren onderscheiden met verschillen in risicofactoren (alcohol- en folaatinname). Tenslotte, hebben we in de laatste studie onderzocht of we met behulp van DNA methylering in een specifiek gen, het cysteine dioxygenase type 1 (CDO1) gen, nierkankerpatiënten met verschillen in overleving kunnen onderscheiden. In de literatuur staat al beschreven dat DNA 
methylering van het $C D O 1$ gen borstkankerpatiënten met verschillen in overleving kan onderscheiden. Onze studie laat nu zien dat ook nierkankerpatiënten met DNA methylering van het $C D O 1$ gen na 10 jaar een lagere overlevingskans hebben dan nierkankerpatiënten zonder DNA methylering in het $C D O 1$ gen.

We kunnen dus concluderen dat we met dit proefschrift een hoge zoutinname, in het bijzonder in combinatie met een lage vochtinname, als nieuwe risicofactor voor het ontstaan van nierkanker hebben geïdentificeerd. Daarnaast hebben we aanwijzingen gevonden voor de rol van twee fysiologische systemen in de nier, namelijk RAAS en ITM, bij het ontstaan van nierkanker. Daarmee hebben we laten zien dat toekomstig onderzoek naar het ontstaan van nierkanker inderdaad zou kunnen profiteren van onze nieuwe fysiologische invalshoek. Bovendien hebben we aangetoond dat het noodzakelijk is de tumorheterogeniteit tussen niertumoren te includeren in onderzoek naar de risicofactoren en de overleving deze kanker. 
Valorisation addendum 
In addition to the scientific value of this thesis described in Chapters 2-7, the results of the research presented also have societal and economic value. In this addendum we try to put the results of this thesis into a broader perspective and highlight its potential for clinicians and policymakers and in a public health setting.

\section{DIETARY SODIUM INTAKE INTO PERSPECTIVE}

Average sodium intakes around the world are much higher than the 0.2 to 0.5 grams sodium per day that people physiologically need [1]. In fact, most populations around the world are consuming between 3.0 and 6.0 grams sodium per day [7.5 to 15.0 grams of salt (sodium-chloride) per day] [2,3]. In 2012, men and women in the Netherlands consumed 4.0 and 3.0 grams of sodium per day, respectively [4]. Moreover, sodium intakes ranged between 3.0 and 4.0 grams per day in neighbouring countries, including Belgium, Denmark, Germany and the UK [5]. In our study population, the mean sodium intake was measured in 1986 and estimated to be 3.5 grams per day.

It has been established that a chronic excess of sodium may be related to multiple diseases, including hypertension, heart failure and kidney failure. In this thesis, we provide the first evidence that a high sodium intake, particularly in combination with low fluid intake, may also increase the risk of renal cell cancer. Before this finding has any additional value in a public health setting, confirmation of this association in more and other populations is crucial. In addition, lowering of the sodium intake will help to prevent hypertension, heart failure and kidney failure at the population level. Reduction of sodium intake is for example the most used strategy to prevent hypertension. It has been shown in a number of systematic reviews on randomized controlled trials that decreased sodium intake relative to usual or higher intake results in lowered blood pressure in adults with or without hypertension [6-8]. Now, the reduction of sodium intake is a highly prioritized recommendation to prevent all kinds of non-communicable diseases such as cardiovascular diseases, but also diabetes mellitus type 2 [9]. Recently, the World Health Organization (WHO) adjusted the recommendation on sodium consumption for adults, which is now $2.0 \mathrm{~g}$ sodium per day [10].

The question remains how much reduction of the sodium intake at the individual level is desirable. The optimal exposure level of sodium is currently under debate. Firstly, WHO recommendations are based on cardiovascular disease risk and not cancer risk. Moreover, the type of relationship between sodium intake and these disease risks is still unclear, as increasing evidence suggests that the association between sodium intake and cardiovascular events might be J-shaped instead of linear [11-16]. This suggests that high sodium intake is associated with morbidity and mortality, while a 
very low sodium intake (less than 2.3 grams per day) is not associated with health benefits or, alternatively, may be related to a higher cardiovascular risk [17]. This thesis supports, in part, the concerns on too low sodium intake levels, given the observed J-shaped association between added salt intake and renal cell cancer risk. However, it remains unclear whether this higher risk in the lowest sodium consumers is a real physiological risk or perhaps may reflect one's ability to reduce added salt intakes to prevent or control hypertension. Before any further recommendations on lowering sodium intake can be adopted, it is essential to clarify and exclude potential risks of a too low sodium intake for the individual.

Given the particularly high intakes of sodium in many populations to date, the subsequent higher risks of diseases and the positive effects of reducing sodium intake on reducing these disease risks, we feel that the quest to reduce the sodium content of food products and thereby the sodium intake on the population level is still justified, at least as long as the uncertainty on the effects of a very low sodium consumption on the individual level remains.

A number of strategies can potentially be used to decrease the average sodium intake of a population. The simplest and safest strategy to reduce sodium intake is to consume less foods that have high sodium content. Sodium is naturally present in a variety of foods and food groups, which are consumed depending on culture and population [10]. The highest sodium content is found in soups and soy sauce, but fair amounts are also found in for example cheese, milk and shellfish. Moreover, sodium is often found in high amounts in processed foods such as breads, crackers, processed meats and snack foods. To a large extent, people are unaware of the sodium content in particular food items, although recent efforts seemed to increase the awareness of the high sodium content in processed foods. However, awareness interventions on the content of sodium that is naturally present in unprocessed foods, may also increase an individual's ability to consciously choose which type of foods to consume and enables them to better monitor their overall sodium intake.

In addition to foods and food groups, common table salt, including the chemical components sodium and chloride, is often used for seasoning during and after cooking. Because, these habits are particularly influenced by attitudes and beliefs, a systematic review concerning advice to reduce sodium consumption concluded that intensive behavior change interventions targeting decreasing sodium intake are necessary to successfully reduce blood pressure in adults with or without hypertension [18]. However, the authors also concluded that environmental changes (e.g. reduction of sodium in processed foods) would facilitate a greater reduction in sodium consumption and, therefore, have a greater impact. Lobby groups have made multiple efforts to convince policymakers, governments and food industries to reduce 
the amount of sodium in food products. To some extent, small successes to reduce the sodium content in foods have been booked already [19].

\section{THE ROLE OF HYPERTENSION}

In the thesis we found evidence both in favor of and against the role of hypertension in the association between sodium intake and renal cell cancer. Therefore, we concluded that it is worthwhile to further investigate its exact role. From a public health perspective it is crucial to elucidate the potential influence of hypertension. If hypertension would be the driving force of the higher risk of renal cell cancer, preventive strategies to reduce hypertension, other than reduction of sodium intake may be opted for by health promoters and policymakers. One such potential strategy is to normalize the sodium-to-potassium ratio in the body by promoting the intake of potassium rich foods and so increasing the average amount of potassium intake of a population instead of decreasing the amount of sodium intake [1]. Potassium is naturally present in fruits and vegetables, potatoes and nuts, and is recognized to lower the blood pressure [20]. Food manufactures are investigating the opportunities to use potassium chloride instead of sodium chloride for preservation purposes. However, if hypertension does not influence the association between sodium intake and renal cell cancer, reduction of sodium intake would be the best strategy for renal cell cancer prevention after all.

\section{GENE-ENVIRONMENT INTERACTIONS}

In the second part of this thesis (chapters 3 and 4) we studied gene-environment interactions in relation to two biological systems influencing blood pressure and sodium handling, i.e. the renin-angiotensin-aldosterone system (RAAS) and iontransport mechanisms (ITMs) and the risk of renal cell cancer. In gene-environment interaction research there are no direct opportunities to use any findings in a clinical, economical or societal setting at this point. However, these gene-environment interaction studies may help to identify individuals at high disease risk based on their genetic profile and their dietary consumption pattern. We observed, for example, that sodium intake was differentially associated with renal cell cancer risk defined by several genetic variations in genes involved in the RAAS. For the future, this type of information may be used to tailor interventions in so-called precision medicine. For example, salt-sensitive individuals may benefit more from low salt interventions to reduce disease risk than individuals who do not have this sensitivity. However, before we can use information on genetic profiles in a public health setting for prevention, the ethical, scientific and economic issues need to be solved first. 


\section{TUMOR HETEROGENEITY}

In the third part of this thesis (chapters 5-7) we investigated the influence of tumor heterogeneity within the renal tumor. In the clinical setting, a better understanding of inter-tumor heterogeneity and the identification of renal cell cancer subtypes can be used to better classify a renal cell cancer patients' need in terms of disease management and to move closer towards personalized cancer medicine and personalized cancer prevention. For example, a better understanding of tumor heterogeneity and associated subtype-specific risk factors or subtype-specific prognosis is crucial to eventually develop tools that may be used for early detection and to guide clinical decisions on treatment. Currently, patients with advanced cancer experience complex physical, psychological and social consequences not only from the disease itself but also from the treatment. For the majority of advanced cancers, the standard of care still consists of 'trial and error' therapy. This means that a significant subset of patients will not benefit from the therapy but needlessly suffer from the side effects of the drug. Tools to select the most effective anti-cancer therapy and sparing patients the toxicity associated with the treatment are urgently needed to avoid unnecessary reduction of the quality of life. Particularly for renal cell cancer, molecular-targeted agents have successfully been developed and targeted therapies, such as sunitinib, sorafenib, everolimus and bevacuzimab, are currently being used for the treatment of renal cell cancer patients. However, tools to personalize these treatments and guide clinical decision-making are not yet available. Integrating the tumor heterogeneity into (molecular) epidemiological research is a step forward, although it should be recognized that such tools are still far away. However, it is inevitable that guided decision-making instead of 'trial and error' therapy will have a major impact on the quality of life of renal cell cancer patients and may also be attractive from a health economical perspective as it will lead to less useless treatment and ill-spent costs.

In conclusion, this chapter illustrates how the scientific findings described throughout this thesis can potentially be used by clinicians, policymakers and in a public health setting, to create societal and economic value. 


\section{REFERENCES}

1. Holbrook JT, Patterson KY, Bodner JE, Douglas LW, Veillon C, Kelsay JL, Mertz W, Smith JC Jr. Sodium and potassium intake and balance in adults consuming self-selected diets. Am J Clin Nutr 1984;40:786-93.

2. Powles J, Fahimi S, Micha R, Khatibzadeh S, Shi P, Ezzati M, Engell RE, Lim SS, Danaei G, Mozaffarian D; Global Burden of Diseases Nutrition and Chronic Diseases Expert Group (NutriCoDE). Global, regional and national sodium intakes in 1990 and 2010: a systematic analysis of $24 \mathrm{~h}$ urinary sodium excretion and dietary surveys worldwide. BMJ Open 2013;3:e003733.

3. Brown IJ, Tzoulaki I, Candeias V, Elliott P. Salt intakes around the world: implications for public health. Int J Epidemiol 2009; 38:791-813.

4. Rijksinstituut voor Volksgezondheid en Milieu (RIVM), Zoutconsumptie van kinderen en volwassenen in Nederland; Resultaten uit de Voedselconsumptiepeiling 2007-2010. 2012.

5. Intersalt Cooperative Research Group, Intersalt: an international study of electrolyte excretion and blood pressure. Results for 24 hour urinary sodium and potassium excretion. BMJ 1988;297:319-28.

6. He FJ, MacGregor GA. Effect of longer-term modest salt reduction on blood pressure. Cochrane Database Syst Rev 2004(3):CD004937.

7. Dickinson HO, Mason JM, Nicolson DJ, Campbell F, Beyer FR, Cook JV, Williams B, Ford GA. Lifestyle interventions to reduce raised blood pressure: a systematic review of randomized controlled trials. $J$ Hypertens 2006;24:215-33.

8. Dickinson HO, Mason JM, Nicolson DJ, Campbell F, Beyer FR, Cook JV, Williams B, Ford GA. Effects of low-sodium diet vs. high-sodium diet on blood pressure, renin, aldosterone, catecholamines, cholesterol, and triglyceride (Cochrane Review). Am J Hypertens 2012;25:1-15.

9. Bonita R, Magnusson R, Bovet P, Zhao D, Malta DC, Geneau R, Suh I, Thankappan KR, McKee M, Hospedales J, de Courten M, Capewell S, Beaglehole R; Lancet NCD Action Group. Country actions to meet UN commitments on non-communicable diseases: a stepwise approach. Lancet 2013;381: 575-84.

10. World Health Organization (WHO), Guideline: Salt intake for adults and children. 2012; Geneva.

11. O'Donnell M, Mente A, Rangarajan S, McQueen MJ, Wang X, Liu L, Yan H, Lee SF, Mony P, Devanath A, Rosengren A, Lopez-Jaramillo P, Diaz R, Avezum A, Lanas F, Yusoff K, Iqbal R, llow R, Mohammadifard N, Gulec S, Yusufali AH, Kruger L, Yusuf R, Chifamba J, Kabali C, Dagenais G, Lear SA, Teo K, Yusuf S; PURE Investigators. Urinary sodium and potassium excretion, mortality, and cardiovascular events. $N$ Engl J Med 2014;371:612-23.

12. Graudal N, Jürgens G, Baslund B, Alderman MH. Compared with usual sodium intake, low- and excessive-sodium diets are associated with increased mortality: a meta-analysis. Am J Hypertens 2014;27:1129-37.

13. Pfister R, Michels G, Sharp SJ, Luben R, Wareham NJ, Khaw KT. Estimated urinary sodium excretion and risk of heart failure in men and women in the EPIC-Norfolk study. Eur J Heart Fail 2014;16:394402.

14. Stolarz-Skrzypek K, Kuznetsova T, Thijs L, Tikhonoff V, Seidlerová J, Richart T, Jin Y, Olszanecka A, Malyutina S, Casiglia E, Filipovský J, Kawecka-Jaszcz K, Nikitin Y, Staessen JA; European Project on Genes in Hypertension (EPOGH) Investigators. Fatal and nonfatal outcomes, incidence of hypertension, and blood pressure changes in relation to urinary sodium excretion. JAMA 2011. 305(17): p. 1777-85.

15. Thomas MC, Moran J, Forsblom C, Harjutsalo V, Thorn L, Ahola A, Wadén J, Tolonen N, Saraheimo M, Gordin D, Groop PH; FinnDiane Study Group. The association between dietary sodium intake, ESRD, and all-cause mortality in patients with type 1 diabetes. Diabetes Care 2011;34:861-6.

16. Ekinci El, Clarke S, Thomas MC, Moran JL, Cheong K, Maclsaac RJ, Jerums G. Dietary salt intake and mortality in patients with type 2 diabetes. Diabetes Care 2011;34:703-9.

17. Cohen HW, Alderman MH. Sodium, blood pressure, and cardiovascular disease. Curr Opin Cardiol 2007;22:306-10.

18. Hooper L, Bartlett C, Davey SG, Ebrahim S. Advice to reduce dietary salt for prevention of cardiovascular disease. Cochrane Database Syst Rev 2004(1):CD003656. 
19. Rijksinstituut voor Volksgezondheid en Milieu (RIVM). Sodium, saturated fat and sugar content of foods: Food Composition in the Netherlands from 2011 until July 2014 [Monitor Productsamenstelling voor zout, verzadigd vet en suiker: RIVM Herformulerings-monitor 2014]. 2014.

20. Holbrook JT, Cottrell SL, Smith JC Jr. Correlations of changes in dietary potassium and sodium with blood pressure during a one-year study. Am J Clin Nutr 1984;40(6 Suppl):1390-2. 
Dankwoord 
Het spreekt voor zich dat ik dit proefschrift nooit had kunnen schrijven zonder de steun en inspiratie van velen. Daarom wil ik iedereen die heeft bijgedragen aan dit proefschrift hartelijk danken. Ik ben de afgelopen (ruim) 4 jaar een wijzer mens geworden op alle vlakken en dat komt mede door jullie!

Allereerst mijn promotieteam: prof. dr. P.A. van den Brandt, prof. dr. M. van England en dr. L.J. Schouten: Piet, ik wil je bedanken dat ik binnen de NLCS mijn promotieonderzoek heb kunnen doen. Jouw zakelijkheid en no-nonsens redeneringen hebben mij gedurende het hele project enorm geholpen. Leo, als dagelijkse begeleider zal je het vast niet altijd makkelijk hebben gehad met zo'n direct en eigenwijs persoon als ik. Naast je inhoudelijke bijdrage aan dit proefschrift en de leuke discussies die we vaker hadden, heb ik ook het vertrouwen en de vrijheid die je me tijdens mijn promotieonderzoek hebt gegeven om mijzelf te ontwikkelen echt heel erg gewaardeerd. Bedankt! Wie weet zullen onze wegen elkaar in de toekomst nog eens kruisen. Manon, ik ben zeker niet de eerste die benoemd hoe heerlijk jouw enthousiasme is. Jij ziet mogelijkheden en kansen en daar hou ik van! Bovendien heb ik heel veel van je geleerd, inhoudelijk en over mezelf. Ik hoop dat ik in de toekomst nog ooit de kans krijg om meer van je te leren.

Dit proefschrift is voor een belangrijk deel tot stand gekomen met behulp van de vakgroepen Pathologie, Toxicologie en Medische Oncologie:

Marcella, uren hebben we besteed aan het bekijken van blokjes en coupes van de GENRE-serie. Jouw expertise en inzet hebben mede geresulteerd in een prachtig GENRE-II! Daarnaast heb ik ook persoonlijk heel veel van je geleerd over de pathologie. Bedankt voor de prettige samenwerking. Kim en Kim, jullie hebben fantastisch labwerk geleverd! Ik heb altijd het volste vertrouwen in jullie kunde gehad. Bedankt! Leander, wat voor mij ingewikkelde materie was, was voor jou dagelijkse kost. Je hebt een belangrijke bijdrage geleverd aan verschillende artikelen in dit proefschrift. Dank daarvoor!

Frederik-Jan en Roger, bedankt voor het meedenken over de genotypering en de interpretatie van de moleculaire data in dit project. Het zijn juist die ogenschijnlijk kleine opmerkingen die het verschil maken. Leonie en Joy, ik vond het erg leuk een kijkje te nemen in 'jullie' lab en heb erg veel respect voor de grote hoeveelheid werk die jullie voor mij (en andere NLCS-Aio's) hebben verzet.

Patricia, vanuit medisch-oncologisch perspectief had jij altijd goede aanvullingen op het onderzoek. Daarnaast vind ik je ook nog eens een fantastisch mens! Ik wens je veel beterschap. 
Tijdens dit promotieonderzoek was ik werkzaam bij de vakgroep Epidemiologie. Graag wil ik al mijn collega's bedanken voor hun collegialiteit en de geweldige ondersteuning en betrokkenheid die ik heb ervaren.

Jolanda, als ik nu zout over de aardappels strooi moet ik nog wel eens aan de uitspraak denken die je maakte tijdens het controleren van de additionele zout-vragen uit de NLCS vragenlijst: "Oeh, dat is een zouterik!". Met humor wordt het werk veel leuker!

Christel, Martien en Monique, jullie stonden aan de wieg van mijn (nog maar korte) wetenschappelijke carrière die begon als student bij de Health Sciences Research Master (HSRM). Bedankt voor jullie steun en begeleiding! In die tijd heb ik in tegenstelling tot veel andere HSRM studenten nooit gebruik gemaakt, Christel, van jouw beroemde tissue-uurtje, maar gelukkig heb ik dat later wel ingehaald ;)!

Aio's en oud-aio's. Er zijn al veel Aio's 'van mijn tijd' vertrokken, maar gelukkig gaat dat altijd gepaard met een afscheidsetentje, dat tegenwoordig ook wel een beetje een reünie is geworden. Ik heb heel lang gedacht dat het de lunch en de koffie waren die me de dag door hielpen, maar inmiddels ben ik erachter; het waren jullie! Een promotieonderzoek staat of valt bij leuke Aio collega's en wat dat betreft had ik het niet beter kunnen treffen!

Janneke, mijn roomie! Tragisch hoe wij uiteindelijk toch nog uit elkaar moesten gaan, snik... We hebben vaak samen onze gedachten laten gaan over ingewikkelde zaken (zoals pannenkoeken) maar ook alledaagse dingen (bijvoorbeeld genotypering en Cox regressie analyses). Ik heb daardoor veel met je kunnen lachen en heel veel van je geleerd. Ik ben ervan overtuigd dat ik deze kennis in de toekomst nog vaker zal gebruiken... Veel succes bij je nieuwe baan!

Anne en Nadine. Wat was het heerlijk om met gelijkgestemden zoveel te kunnen delen, en dat terwijl er uiteindelijk altijd een taart of maaltijd op tafel stond, of je wekelijkse hardlooprondje er weer op zat. Dat is nog eens efficiënt! Ik denk met heel veel plezier terug aan die tijd!

Een speciaal bedankje gaat uit naar mijn paranimfen, Noreen en Rachel. Ik voel me vereerd dat jullie op deze speciale dag naast me willen staan. Donkerblauw is prima $:$.

Ik wil mijn collega's van PALGA bedanken voor de nieuwe uitdaging en de 'andere bril'. Jullie zijn een fantastische groep mensen die, heb ik geleerd, ook nog eens heel belangrijk werk doen. Annette, Bea, Bert, Caro, Chantal, Esther, Hannelore, Jolanda, 
Lucy en Paul, ik ben heel blij dat ik jullie heb leren kennen en ieder uur in de trein daarvoor is het dubbel waard!

Vriend(inn)en. Jullie zorgen voor essentiële afwisseling in mijn week(end). Wat een dolle boel is het als het lukt om met alle meiden van thuis weer een activiteit te plannen! Spelletjes, verrassingsdagjes, Gentse feesten en Ibiza. Als ik bij jullie ben, ben ik even helemaal weg van het werk! Daarnaast is het kijken van 'WIDM' en 'Boer zoekt vrouw' toch het allerleukst met de vakkundige commentaren van de Rowzeetjes erbij, ofwel bij iemand op de bank met een kopje thee ofwel in de groepsapp. Binnenkort is het alweer ons tienjarig jubileum; dat vraagt om een jubileum weekend! Ook heb ik vele leuke avonden te danken aan de vriendengroep uit Asten; in het bijzonder de kookavonden (met 'TBTH'), de wintersport en de sushi-avonden met de meiden als de mannen op weekend zijn $(-)$. Ik kan er echt van genieten!

Maud, als studie-, stap-, feest- en commissiegenoot hebben we tijdens onze studententijd Maastricht onveilig gemaakt, zodat we ons daarna konden storten op serieuze zaken. De perfecte voorbereiding op het 'grote-mensen-leven', waar ik nog vaak met veel plezier aan terug denk! Ik hoop dat we elkaar ondanks alle veranderingen nog regelmatig blijven zien, ook al zijn de afspraakjes dan wat burgerlijker.

Inge, tegelijk zijn we aan de HSRM begonnen. Regelmatig hebben we vanaf toen samen gegeten en geluncht en iedere keer kwamen we tot de conclusie dat het helemaal niet uit maakt waar, met wie of waarop je promoveert. ledereen loopt tegen dezelfde dingen aan en de oplossing is bijna altijd hetzelfde. Ik heb tijdens mijn hele promotieonderzoek heel veel aan je gehad en het was altijd gezellig. Inge, de aanhouder wint!

Familie. Pap en mam, jullie hebben een groot aandeel gehad in dit proefschrift, ook al zullen jullie dat zelf misschien ontkennen. Ik voel dat jullie mij steunen en trots op mij zijn en dat geeft mij kracht om door te gaan, ook als het soms niet meezit. Ik ben klaar voor de volgende uitdaging; jullie ook $:$ ? ? Etienne en Evelyne, en Jordi, thuis komen is toch veel leuker wanneer jullie er ook zijn! Als 'grote' zus ben ik trots op wat jullie al allemaal hebben bereikt en hoe jullie je weg hebben gevonden, ook al betekent dat dat ik nu niet meer altijd van jullie kan winnen.

Frans en Tilly, er wordt wel eens gegrapt dat we bij jullie komen om 'bij te komen'. Maar het klopt als een bus; bij jullie is het altijd ontspannen en relaxt en genieten we van elkaar onder het genot van een hapje en een drankje. Heerlijk! Frank en Hanke, en Mark, als we straks alle vijf (inclusief Bas en mezelf) gepromoveerd zijn moeten we toch binnen een paar minuten uit die verdraaide escaperooms kunnen komen... Ik 
wens jullie veel succes bij jullie promotie. Hanke, bedankt dat ik regelmatig in Utrecht bij je mag blijven slapen, nu ik in Houten werk. Daarmee help je me enorm!

Oma, met jouw 97 jaar heb jij alles eigenlijk al wel meegemaakt. Je hebt zelf helaas nooit de kans gekregen om te studeren, maar ik weet zeker dat het je gelukt zou zijn. Je bent een doorzetter. Jouw wijsheid inspireert me en daarom draag ik dit proefschrift op aan jou!

Bas, vanaf onze eerste ontmoeting zijn we onafscheidelijk. Je haalt het beste in mij naar boven en je maakt mijn wereld altijd net even leuker en mooier. Zonder jou ben ik niet compleet. Ik hou heel veel van je... 
About the author 
Ivette Antoinette Gerarda Deckers was born on January $22^{\text {nd }}, 1987$ in Nijmegen, the Netherlands. After completing secondary school (Athenaeum) at St Ursula in Horn, the Netherlands in 2005, she studied Health Sciences at Maastricht University, in Maastricht, the Netherlands. Three years later in 2008, Ivette obtained het BSc. degree and enrolled in a two year, English-taught Health Sciences Research Masters' program with specialization in clinical epidemiology at Maastricht University. She obtained her MSc. degree in 2010. During her one-year the Masters' internship at the Department of Epidemiology, Maastricht University, she spend a five month period abroad at the Center for Population Health Sciences in Edinburgh, United Kingdom and first-authored a systematic review of epidemiological studies in the field of allergy, which was published in PLOS ONE. After graduating, Ivette started a PhD project at the Department of Epidemiology and GROW, School for Oncology and Developmental Biology of Maastricht University under supervision of promotores prof. dr. Piet A van den Brandt and prof. dr. Manon van Engeland and copromotor dr. Leo J Schouten. The research, as described in this thesis, was conducted within the framework of the Netherlands Cohort Study. From October 2014 onwards, Ivette works as research consultant and data analyst at the Dutch Pathology Registry (PALGA). 
List of publications 
1. Deckers IAG, Schouten LJ, Van Neste L, van Vlodrop I, Soetekouw PMMB, Baldewijns MMLL, Jeschke J, Ahuja N, Herman JG, van den Brandt PA and van Engeland M. Promoter methylation of $C D O 1$ identifies clear-cell renal cell cancer patients with poor survival outcome. Clin Cancer Res 2015 Apr (Epub ahead of print)

2. Deckers IAG, van den Brandt PA, van Engeland M, van Schooten FJ, Godschalk RWL, Keszei AP and Schouten LJ. Polymorphisms in genes of the reninangiotensin-aldosterone system and renal cell cancer risk: interplay with hypertension and dietary intakes of sodium, potassium and fluid. Int J Cancer 2015, 136(5):1104-1116

3. Deckers IAG, van den Brandt PA, van Engeland M, Soetekouw PMMB, Baldewijns MMLL, Goldbohm RA and Schouten LJ. Long-term dietary sodium, potassium and fluid intake; exploring potential novel risk factors for renal cell cancer in the Netherlands Cohort Study on diet and cancer. Br J Cancer 2014, 110(3):797-801

4. Deckers IAG, McLean S, Linssen S, Mommers M, van Schayck CP and Sheikh A. Investigating International Time Trends in the Incidence and Prevalence of Atopic Eczema 1990-2010: A Systematic Review of Epidemiological Studies. PLoS ONE 2012, Jul;7(7)

\section{Submitted}

1. Deckers IAG, van den Brandt PA, van Engeland M, van Schooten FJ, Godschalk RWL, Keszei AP and Schouten LJ. Gene-diet interactions in ion transport mechanisms in relation to renal cell cancer risk.

2. Deckers IAG, van Engeland $M$, van den Brandt PA, Van Neste $L$, Soetekouw PMMB, Aarts MJB, Baldewijns MMLL, Keszei AP and Schouten L. Promoter CpG island methylation in ion transport mechanisms and associated dietary intake jointly influence the risk of clear-cell renal cell cancer.

3. Schouten LJ, Deckers IAG, van den Brandt PA, Soetekouw PMMB, Baldewijns MMLL and van Engeland $M$. Alcohol and dietary folate intake and gene promoter methylation in clear-cell renal cell cancer. 
